\title{
The Business of Resilience: Philanthropy, Partnerships, and Politics
}

By

Phillip André Primeau

A thesis submitted to the Faculty of Graduate and Postdoctoral Affairs in partial fulfillment of the requirements for the degree of

Doctor of Philosophy

in

Sociology

Carleton University

Ottawa, Ontario

(C) 2020, Phillip André Primeau 


\section{Abstract}

The concept of resilience has entered into the lexicon of the everyday while enjoying an ever-expanding range of applications and associations within the public, private, and philanthropic sectors. This dissertation critically engages resilience discourses and practices by tracing a network of relations composed of both people and things. Taking cues from Actor-Network Theory, I bring into focus a latticework of actants that has enabled the concept of resilience to function, be mobile, expand and stabilize into what I call 'philanthropic resilience' and 'financialized resilience'. I offer a novel reading of the career of resilience by shedding light on how the concept has been deployed across a diverse set of fields and assemblages. To illustrate key features of the philanthropic form of resilience I turn to the Rockefeller Foundation's 100 Resilient Cities initiative (100RC), to date the most expansive experiment in incubating city resilience interventions. I show how the 100RC successfully grew a resilience network through philanthropic partnerships, how it created the Chief Resilience Officer position as an embedded municipal actor, and how it enrolled a selective set of actants tasked with solving the problem of resilience valuation theoretically and practically. I argue that the idea of 'resilience dividends', once confined to the philanthropic sector, has been incorporated into the financialized resilience form through speculative investment products such as bonds. I contend that resilience bonds, along with the issuance of profitgenerating climate resilience bonds, show that the concept of resilience has materialized in powerful social practices beyond metaphorical and metonymical applications. This dissertation offers theoretical and empirical lenses to better parse the political and social ramifications of the business of resilience. 


\section{Acknowledgements}

I've become familiar with concrete. I know, not typically how you would start a section that basically says 'so long, and thanks for all the fish'. But it's true. The foundation of this dissertation was poured while I spent my evenings in a concrete basement in Lowertown. There were computers and video games in one room; a pingpong table and an uneven billiards table in another. An occasional pasta meal or some microwaved popcorn broke the lingering dampness. It was more than a youth drop-in centre, though — it was a community. So, when I started to spend all my time in Loebanother stale concrete building - I felt fortunate to join a welcoming community. I've been part of the Sociology \& Anthropology Department at Carleton for nearly a decade. During this time, I have crossed paths with and have learned from far too many people to list here. I wish to highlight and thank a few, beginning with departmental staff. Paula Whissell, Kim Mitchell, Darlene Moss, Patricia Lacroix, Marlene Brancato, Kimberly Séguin, Karen Tucker, Stephanie LeBlanc: the mortar that holds everything together. Thank you for your generosity, compassion, and dedication. I'm also indebted to my supervisory team. Their comments and insights helped me to assemble disparate thoughts into something coherent. Bruce Curtis has inspired my theoretical and analytical thinking since I began my MA. That his patience, guidance, and support were integral to this project are just some of the myriad ways he has helped me to become a better academic and a more enlightened person. Bruce has been a constant source of inspiration, a seemingly bottomless reservoir of knowledge, and a close ally during dark times. Aaron Doyle and Carlos Novas acted officially as committee members, but their involvement, influence, and support in my pursuits runs much deeper. My desire to be a better educator 
comes directly from Aaron's passion, and my drive to see things differently ontologically stems from Carlos. I cherish the time we have spent together, whether on a softball field off campus or crammed into a taxi in Buenos Aires. I truly wouldn't have been able to finish my writing without Alexis Shotwell's encouragement and kindness. Mike Mopas has been a source of assurance and creativity, lending an ear at critical junctures throughout this project. Xioabei Chen stepped in at the right moment to get me moving again. I would like to extend a very special note of gratitude and admiration to William Flynn. I have not only enormously benefited personally and professionally from his ongoing friendship and mentorship; he has also shown me the generative potential of collaborative work. I'm fortunate and privileged to have been part of many projects with Billy as a $\mathrm{PhD}$ student and am constantly amazed at what this kind-hearted and sympathetic podcast co-host accomplishes. To my close friends, confidantes, and comrades, Aaron Henry, Matt Sanderson, Mark Ramsay, Katie Boudreau Morris, Greg Brown, Matt Hawkins, Alex Bing, Zoey Jones (et al., you know who you are): thank you!

My family's support cemented this project. Richard \& Susan, you were always just a phone call away. Valerie, you've cared for me like a son. Melanie, my spouse, partner, and best friend: without the support, encouragement, and not-so-subtle shoves back to the computer, none of this would have happened. I'm fortunate to have had the opportunity to be intellectually inquisitive with the person I love. Thank you, Mel. And to our cat, Ainsley, for keeping me company during all those late nights.

Brigitte, Antoine, and Éric showed me real-life examples of what it's like to be resilient. Jake, Tyler, Sam, and Rory were always willing to grant me refuge and to refocus my attention. Stace, Eva, and Aleah provided encouragement, levity, and dinners; 
Charlie is wholly responsible for my interest in vintage speakers. I saw Pier-Luc, Alexy, and Brithanny grow up to become remarkable young people whom I admire. I remember a trip to NYC with Jean-François and André. It was meant to be for fun, but I made sure we studied the city's post-Hurricane Sandy resilience projects. We stood by the Rockefeller Centre. We visited memorials. We toured Yankee Stadium. We walked the Brooklyn Bridge. We shared laughs. For days, I explained how resilience had utterly transformed the city, that I had something to say about it, and, that I wanted to abandon the $\mathrm{PhD}$. They told me how I had their uttermost respect for having embarked on this scholarly way of life - the first $\mathrm{PhD}$ in the family. We all missed our grandparents very much; we shared tears. I can remember the concrete building and the basement pub we were in when I decided that I owe it our father to finish. Dad would be very proud. My Uncle Marc and Aunt Deb housed, fed, and consoled me during difficult times at the end of this project: I was geared up to submit when my mum fell very ill. As a family, we all scrambled. Amidst a pandemic and halfway across another province, I found myself in yet another gloomy concrete building. Sometimes, there is no bouncing back. In a yellow hospital room, I sat with the woman who taught me perseverance. I did the talking for us both that last day. It was the closest we'd ever been. And then: stillness. It is to the honour and memory of my parents that I dedicate this work. They embodied resilience every day of their lives and showed me how to be strong. They are the concrete pillars upon which I stand.

What's next? 


\section{Table of Contents}

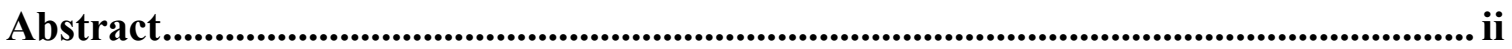

Acknowledgements ...................................................................................................... iii

Table of Contents .............................................................................................................. vi

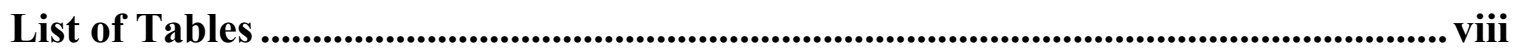

List of Illustrations............................................................................................................. ix

Chapter 1: Introduction ............................................................................................. 10

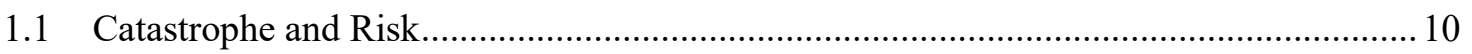

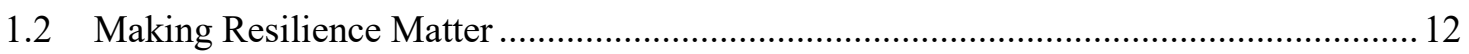

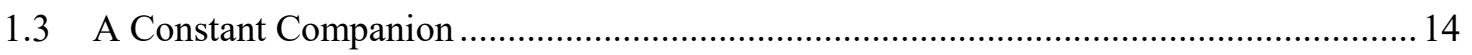

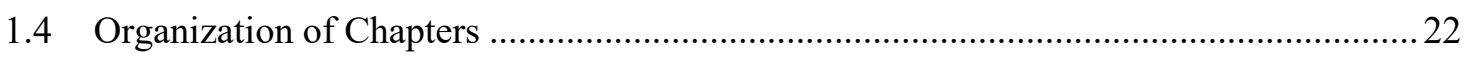

Chapter 2: Reflections from the Field................................................................................ 26

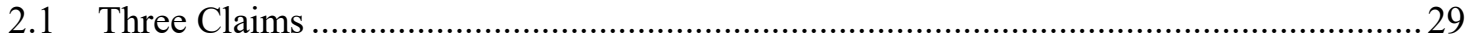

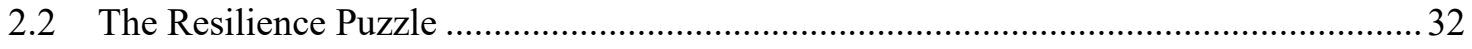

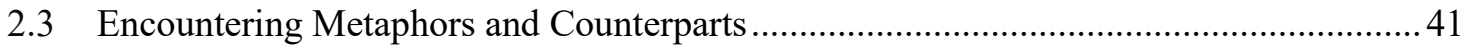

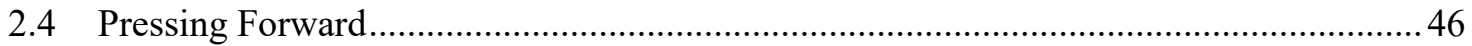

Chapter 3: The Resilience-Network as Actor-Network .......................................... 48

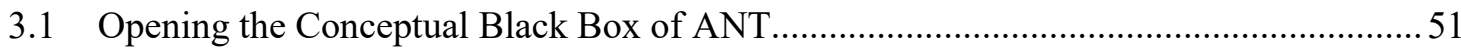

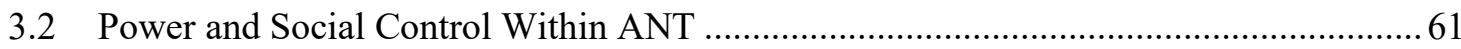

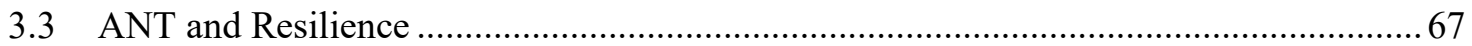

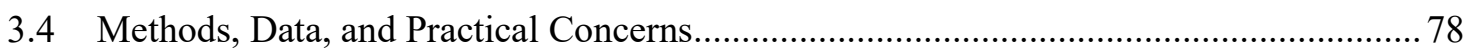

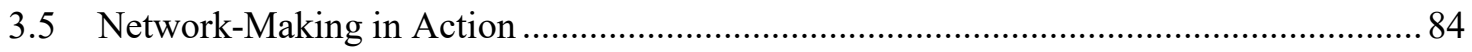

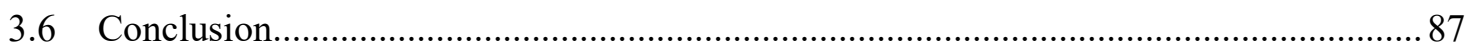

Chapter 4: Chasing the Career of Resilience ............................................................... 92

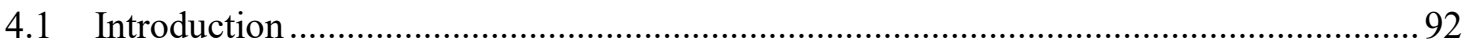

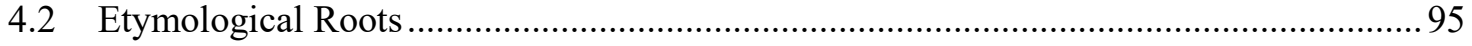

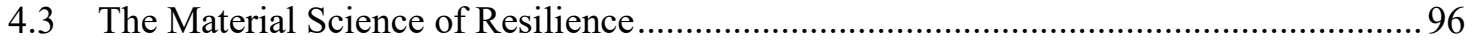

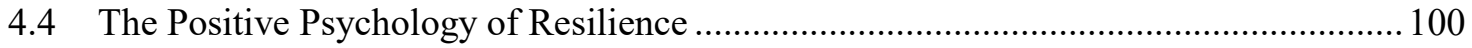

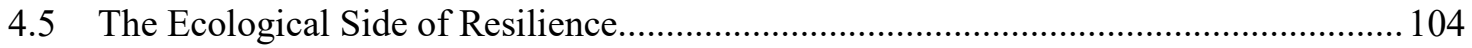

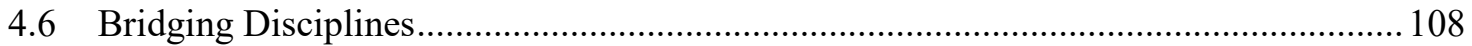




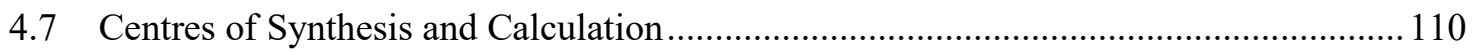

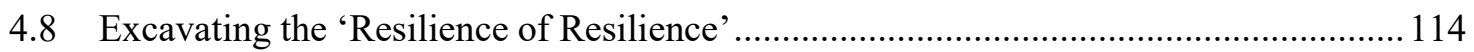

Chapter 5: Philanthropic Resilience ................................................................................. 119

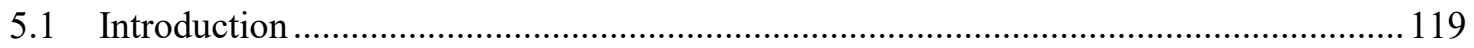

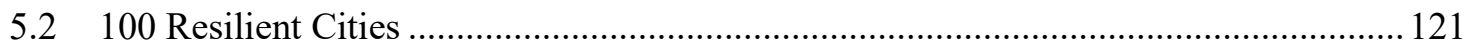

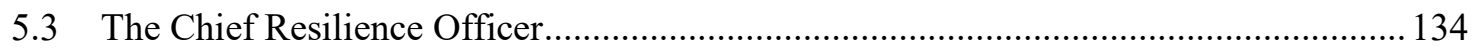

5.4 Policy Standardization: The Case of Toronto's Climate Change Orientation................. 143

5.5 The 'Mayor Minus One' Problem: Disputes in Network-Making .................................. 146

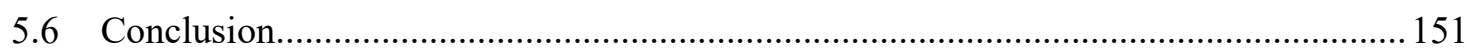

Chapter 6: Financialized Resilience .................................................................................... 156

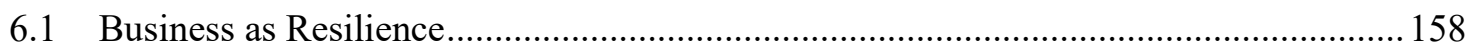

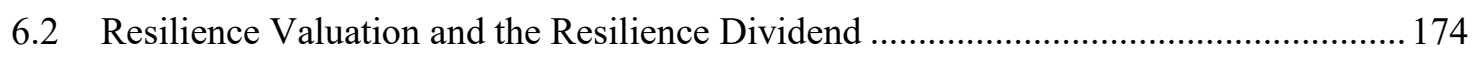

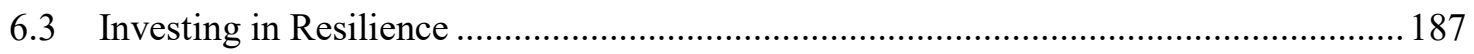

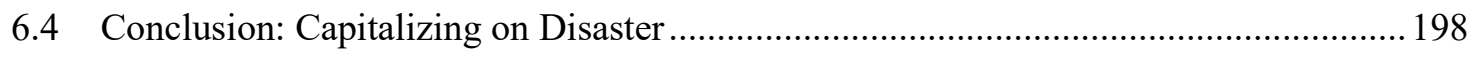

Chapter 7: Conclusion: Bouncing Back, Bouncing Forward .................................... 201

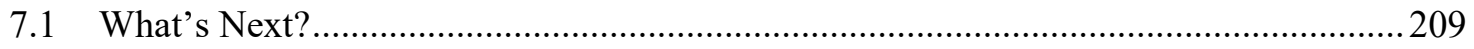

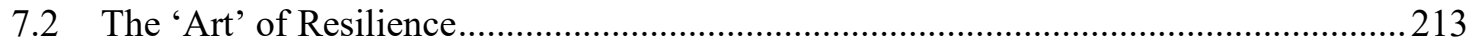

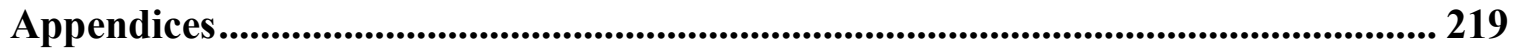

Appendix A Key Resilience Discourses found in Social Science Publications .....................220 Appendix B Selection of Academic Journals Having Published Resilience Related Articles in

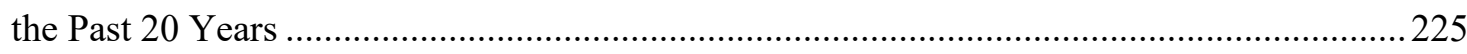
Appendix C Extract From 100 Resilient Cities Member Guide: Understanding Of Mutual Commitment 227

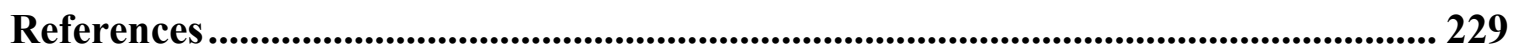




\section{List of Tables}

Table 1 Sample of common definitions of resilience within psychology.................. 101 


\section{List of Illustrations}

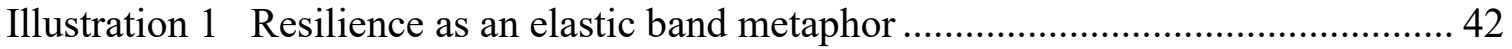

Illustration 2 Counterweight metaphor of resilience ............................................ 44

Illustration 3 Depiction of the adaptive cycle of resilience ................................... 77

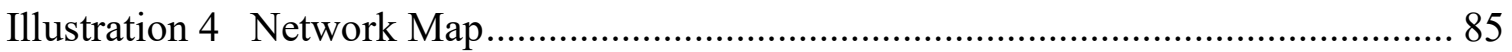

Illustration 5 Ball and cup heuristic of system stability...................................... 106

Illustration 6 What can 100RC do for a city? Michael Berkowitz in 2014. ................ 129

Illustration 7 Arup and The Rockefeller Foundation's city resilience index............... 134

Illustration 8 First Chief Resilience Officers Summit: Capacity \& Skill Building ...... 140

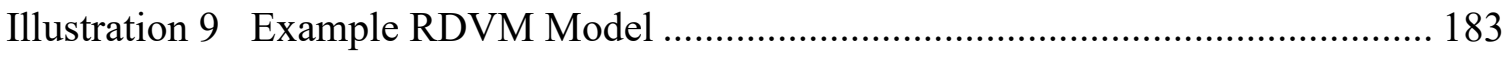

Illustration 10 Re.Bound Resilience Bond Model .................................................. 192

Illustration 11 Climate Resilience Principles............................................................... 195

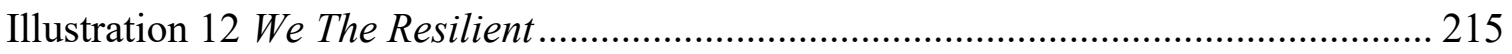

Illustration 13 F Grass installation in Vancouver, B.C ............................................ 216

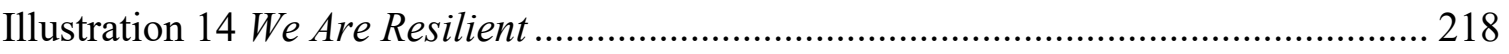




\section{Chapter 1: Introduction}

I do not mean to be alarmist about the state of the world - but I am alarmed. The threats we face to our personal health, to the health and stability of our communities and cities, to our natural systems, and even to our species, are formidable and growing in numbers and severity, affecting larger and more densely settled populations...I have no doubt that with resilience building through innovation and collaboration, we can find solutions to prevent the problems of the world from accelerating toward planetary disaster - and take us instead toward a resilience dividend.

Rodin 2014, 90

\subsection{Catastrophe and Risk}

Cities are faced with a plethora of complex challenges. From natural disasters caused by changes in the climate and the natural environment to the aging and crumbling infrastructure that underpins the devastating potential of human-made catastrophe, the urban environment has come to be synonymous with risk, danger and hazard. Contemporary city administrators are faced with attempting simultaneously to address floods, hurricanes, acts of violence, abject poverty and racism, just some of the 'wicked problems' (Rittel \& Webber 1973) of our times. Furthermore, disruptions caused by critical events have revealed weaknesses in key municipal government processes and services. Public transportation system failures following heavy rain, massive electrical outages caused by high winds and loss of life due to lax building codes, such as the case of the Grenfell Tower fire that killed 72 people in West London, reveal some of the vulnerabilities that metropolitan dwellers face. Urban centres around the world are confronted with the potential consequences of being ill-prepared. Faced with widespread susceptibility to catastrophic events, however dire and dreadful it is, we must be reminded that, "the arrangements of society become most visible when challenged by crisis" (Wolf 2002, 231). Within this context, the concept of resilience has emerged as a 
way that public institutions can diligently manage calamity, overcome failure and, ultimately, become more robust. Put simply: be better.

In the process of 'becoming resilient', cities optimistically envisage taming uncertainty and avoiding misfortune. While this dissertation touches on the multiple forms that resilience has taken, my main focus in this work is the type of resilience, and an accompanying set of tools and techniques, that allows for the preservation of life and the extension of public goods. I am critical of resilience responses. However, it would be hard to argue against the desire to thwart misery and injury. On the one hand, the allure of resilience manifests itself in some of the basic necessities of life. On the other hand, much like other sets of tactics intended to increase happiness and social well-being, we may ask: are resilience strategies indeed built to extend the public good, as the hype purports, or is the foundation of resilience building to be found in other inclinations? This dissertation critically engages resilience discourses and practices by tracing a network of relations composed of both people and things. My argument is that responses to calamity and catastrophe that follow resilience thinking are, as the cases that I highlight reveal, structured and informed by the demands of private capital. In particular, this has led to the development of philanthropic and financialized forms of resilience. If I am correct that philanthropic and financialized resilience are being positioned as the de facto means through which individuals, institutions and, indeed, whole societies may come to persevere through misfortune and adversity, then we must ask: who stands to gain most from 'becoming resilient'?

To begin to address these questions, I propose that we treat resilience literature as a pseudo-archive, or at least as a more or less defined field (champ). Rather than focusing 
our gaze on the definitions, or lack thereof, of resilience, by treating resilience as a field, accompanying scholarship, discourses and articulations can become something manipulable and a target of analysis. I adopt an abstracted stance in relation to resilience, concerned with dynamics and relationships as well as the rules or boundaries that characterize the field. I propose no new definition nor do I aim to advance what should be done in order for resilience to function more effectively. I propose, instead, to garner reflexive knowledge, rather than instrumental knowledge of resilience. It is from this stance that my critical treatment of resilience enters into focus. By adopting an ontological position that does not essentialize the concept of resilience, I do not seek to reduce the concept of resilience to a list of attributes or essential qualities. I am in fact declaring that resilience is made and unmade. As such, I propose a sociological and relational treatment of resilience network making, not a political economy critique. This dissertation sheds light on some of the configurations and assemblages surrounding resilience, ultimately pointing to a series of choices that we are faced with. My main argument is that we must pay attention to how resilience has been mobilized and put to use alongside financialized logics, including how resilience is valued and traded as an asset. In short, we must attend to the business of resilience.

\subsection{Making Resilience Matter}

How can we make resilience matter? To understand how resilience fits into our lives: to make sense of how people come to make sense, in times of uncertainty, in times of chaos? It means asking questions. It is questioning deeply. In attempting to make resilience matter, I am reminded of Bent Flyvbjerg's invitation to ask: "who gains, and 
who loses and through what kinds of power relations" $(2001,131)$ ? Who stands to gain is not a typical question to ask of resilience. Everyone gains according to the standard logic: if we embrace resilience, no one can lose or fail ${ }^{1}$. Failure is just part of the resilience curve, a learning moment in the journey of our complicated lives-as resilience psychologists would like us to believe. If a community comes together to build resilience by talking about local issues, everyone is better off than they were before-so the resilience intervention workers would tell us. And when a city builds a new floodwall, everyone can sleep more soundly - so the resilience engineers boast. Architects of resilience have no shortage of ways to proclaim widened public gains from their efforts. But this is not always the case. If everyone gains through resilience, the business of resilience means that some gain more than others. In the ecological literature, the question of who gains or loses is a mute one. The thinking often goes that "there are in nature no rewards or punishments, just consequences" (Westley et al. 2001, 103). However, bluntly put: "in society there are always rewards and punishments: some people gain while others lose in the process of resilience-building" (Davoudi 2012, 306). By asking who stands to gain and what conditions allow for some to gain more than others, this dissertation refocuses the critique of resilience away from definitional squabbles. In particular, I offer a sketch of how resilience has come to be reconfigured into new political assemblages. The first, what I call 'Philanthropic Resilience' is predicated on the intervention of, and investment from, the philanthropic sector backed by private capital sponsors. This form of resilience, as I will argue, has also led to another mutation, what I call 'Financialized Resilience'. I argue that these forms of resilience

\footnotetext{
${ }^{1}$ A New York Times crossword reminds us that to 'lose resilience' is, ultimately, to sag.
} 
depend on the technical ability and philosophical desire to calculate and successfully extract a value from resilience interventions, what has been called a 'resilience dividend'. The valuation process allows further mutations and translations to occur, including the deployment of resilience within the financial sector in the form of investment bonds. Taken together, this work adds to a growing set of literature concerned with investigating how resilience contributes to new and ongoing forms of governmental assemblages. By turning to Actor-Network Theory to trace the network-building work that actors (human and non-human alike) engage in, I am able to offer a novel rendition of how resilience is made, unmade, put to use and circulated. In short, I shed light on the business of resilience.

\subsection{A Constant Companion}

This project started as an investigation into the vague notion of resilience. I had initially set out to investigate the evolution of the meaning, application and understanding of the concept of resilience, probing the conceptual disparities surrounding resilience while shedding light on how the term has been used across time and space. My intention was to show various ways by which the idea of resilience had been conceptualized and deployed, locating how attempts to condense and extend the concept have meant that resilience is politics by other means. In some ways, I have done that. But, not exactly. The puzzle I had wanted to piece together revolved around the discourse of resilience, the term itself and the practices linked to shifts in the concept. This seemed like a viable and vital project for our contemporary condition. As I was trying to be a focused historical sociologist, I, at some point, turned to the data. My archive of sources was the product of 
almost eight years of collection work. By nature or force of habit, I am a bricoleur. LéviStrauss offers one reading of this, saying:

In its old sense the verb 'bricoler'...was always used with reference to some extraneous movement: a ball rebounding, a dog straying or a horse swerving from its direct course to avoid an obstacle. And in our own time the 'bricoleur' is still someone who works with his hands and uses devious means compared to those of a craftsman $(1974,16-17)^{2}$.

Tinkering is another word that comes to mind. Putting the unfamiliar to use. Walter Benjamin has referred to my affliction as that of a collector. To tinker, one must collect: I like to collect articles, snippets of newspapers, fragments; scraps (Henry 2017). Then, I attempt to reassemble the clippings into something that has voice. It's a good start to understanding what questions are important, which actors to focus on. What matters.

For this project my collecting began with anything that deployed the concept of resilience. News articles, radio segments, government reports, banking predictions, preschool curriculum recommendations, 'how to' guides to happiness, conference summaries, peer-reviewed research, websites, movies and so on. It was a never-ending stream of data. In September of 2017, I reported some 47 million webpages used the term resilience in some capacity. In January 2019, that number touched 167 million. That's an addition of 10 million webpages a month! I have locally stored just over 800,000 textual items that use the term resilience. I was able to parse this down to a few hundred reports, targeting the most vocal webpages in the process. Diligently and honestly, I began to listen to what the fragments were saying. I soon realized that I had a problem. The scraps I had assembled revealed a fundamental reality of resilience that was at odds with what I was asking. I had been approaching the puzzle of resilience as if the concept existed on a

${ }^{2}$ The presence of a common resilience metaphor in this passage does not go unnoticed. 
shelf, ready to be taken up and deployed by actors as they saw fit. In reality, the story the data was telling me was that resilience was not prepackaged; resilience was being made, and unmade, continuously. There were, in fact, multiple resiliences and the concept was being coupled in sectors I had not previously anticipated, such as in speculative finance. Furthermore, resilience was not off in the distance. The work being done to make and remake what resilience is and how it is deployed happens all around us. It was a pivotal moment for me, as well as for the project. The revelation forced me to narrow the scope of the project, now I was asking: how does resilience crystallize around one particular case? And: what does this particular resilience network look like? It also permitted me to look ardently at how resilience was being 'done' right in front of me, concretely and on the ground, and not in hypothetical terms. Hidden in plain sight, the network-forming activities that I was interested in were within my grasp.

At the start of this section, I said that I had envisioned a project that investigated the historical trajectory of the concept of resilience. That wasn't where my focus on resilience started, though. It really started when I stumbled across the concept while looking into community-based programs. These programs all sought to 'make a difference'. At the time, I was working with youth (I was told I was a counselor) and I was trying to make a difference in my own way. The young people I was working with (who I was told were 'at risk') didn't care what we called what we did; most just wanted a safe place to hang out after school, free internet access, a snack and maybe a can of pop for the walk home or wherever they were headed. It's not that resilience is inherently a bad term. It's just that it doesn't mean a whole lot to people's everyday experiences. The young people I spent time with didn't parade around admiring their community's 
resilience in the face of adversity. No, they were just trying to get to school, or to work, or to the drop-in centre that was also my home every weekday after school until 9:00 p.m., sometimes later if someone needed us to be open. The thing about low-income neighbourhoods is that the people who live there know they are in a low-income neighbourhood. The drugs, the gangs, the crappy apartments, the constant police presence, the dark alleyways, the way some people who work there call themselves: counselors, support workers, intervention teams. All are constant reminders of the social and economic conditions that are, well, pretty shitty to live in. So it was a little confusing to realize that some cities were adopting a resilience approach to low-income communities. On the surface it sounds good, but once the resilience process is underway what does it actually mean? What is the result of fostering, building or otherwise shoringup resilience? And who is involved along the way? In one-way or another, my own variegated career trajectory has had a constant presence of resilience. At each turn, these questions seemed to spring back up.

Following my stint as a youth worker, I found myself working as an Assistant Director at a not-for-profit community organization. I did some outreach and tried to build relationships with other community organizations. Resilience tagged along. What I came to understand was that resilience building — whether imminent or immediate—did not translate into new roads, better apartments or 'safer' streets. Police seemed not to be much involved in the process. So, what was really going on? Well, the squad of counselors, support workers and intervention teams — of which I was now a part—would gather a bunch of local community members and organizations together to talk it out. Together they (we) would identify what was good and what was not so good about the 
neighbourhoods we all worked and lived in. Starting with a focus on what was working, at some point there would be a strategy to devise some sort of plan to address what wasn't. Cool. Now that everyone was on the same page, these resilience-building exercises lent credibility to certain demands. One of the iterations I have seen is that lowincome neighbourhoods ask for more reliable and more accessible public transit. Now armed with the results of a resilience-building exercise, a demand to the city can be made to improve public transit. More affordable transportation can lead to more employment which, in turn, can help low-income households. So we are told and so I believed.

I left the community sector to continue my educational career. This is where resilience and I met on a theoretical plane. The theory fuelling the sorts of resilience exercises I had been a part of is loosely grouped around what has been called 'community economic development' (CED). CED starts with several principles: first, a belief that various actors and sectors of communities are all interdependent. Second, "CED encourages self-reliance, sustainability, and independence as a way of dealing with the stresses of global social and economic change" (Colussi 2000, 7). And, third, that a CED approach can strengthen communities by bolstering their economies. Community, independence, economy. The contours of CED are drawn close to classical neoliberal thinking.

As an undergraduate staring down graduation with only a methods course left to complete, I stumbled on a resilience-building project that sparked my interest for a course paper. I was minoring in Public Administration and had experience in the not-for-profit community sector; I wanted to do a project that combined at least those two elements. A move that I could not predict would structure the next decade of my life. The first 
substantive definition of resilience that I engaged with academically was from The Centre for Community Enterprise (now the Canadian Centre for Community Renewal). It was in a publication aptly called The Community Resilience Manual (Colussi 2000). In this manual, we find: "a resilient community is one that takes intentional action to enhance the personal and collective capacity of its citizens and institutions to respond to, and influence the course of social and economic change" (5). During the 1980s and 1990s, market pressures prompted government authorities to rethink service delivery models (Lindquist 2000), devolving what were once hallmark services of the welfare state to lower levels of government and community organizations (Furlong 2016). Doing more with less seemed to be the way forward, but how to do so was a growing problem to be solved. Community resilience training became an attractive option. "The state of community resilience," we are told by Colussi, lead author of the Manual, "plays a large part in determining the future of the places we live in: whether they survive or merely cope with a declining quality of life, or successfully adapt and prosper" $(2000,5)$. The options we are presented with seem somewhat bleak: tread apparently endless stormy waters or fundamentally change in order to move on. In chapter 6 , I return to this dynamic found within administration and business literature. Meanwhile, as an aspiring graduate student wary of ultimatums and silver bullets, resilience and CED within this context raised all sorts of red flags. I wrote the paper, passed, and moved on. My relationship with resilience did not.

Seemingly unshakeable, I continued to encounter resilience at almost every twist and turn: as a policy analyst for the Canadian Federal Government working on new resilient records management infrastructure, in proposed municipal environmental plans that I 
received in the mail at our new house, on the bookshelves where I side-gigged taking inventory, even in an off-the-cuff comment by the officiant at our wedding (yes, yes, love is resilient—get on with it!) It came about almost naturally that, now as a graduate student, I had to continue my relationship with resilience. This time around, however, resilience presented itself in a more sophisticated, nuanced articulation.

Back to this project. Sifting through the mountain of data that I had collected, the pieces of the resilience puzzle that I was seeing formed an intricately woven fabric. Multiple contours. The surface smooth in spots, jagged in others: seemingly random. An emergent pattern is traceable, however. In the quest to develop better definitions of resilience and the desire to model intervention strategies on the idea of resilience, private capital had made its move. Seizing its opportunity, financialized capital has begun to creep into bed with municipal resilience planning. The world of public administration and the realm of speculative, high-risk finance now dance to the hypnotizing tune of resilience. The relationships that have been forged between municipalities and private investment firms are more than a simple fling. Through multi-year contracts that have unknown and unrealized repercussions (Could big finance run cities? Does big finance run cities!?), it is ever more difficult to map a world where resilience is not coupled with financialized capital. The financialized version of resilience involves much more than simply rekindling a hyper-romanticized version of community spirit: new relations of capital are being built. These new relations of capital are maintained through intricate networks of actors, institutions and digital data hubs that coalesce into a global, seemingly charitable iteration. This is what I call 'philanthropic resilience'. 
Philanthropic resilience resembles the benevolent community interventions that I spoke of earlier, but on a much larger scale (the tireless efforts of the Catholic Church to mould the souls of its flock also had humble beginnings). If we follow the trail from a community drop-in centre to a city's programs to address low-income housing, all the way up the chain to creditors, land developers, insurance brokers and investors, we discover a burgeoning world longing for the business of resilience. The Rockefeller Foundation's 100 Resilient Cities (100RC) initiative started with a pledge of $\$ 100 \mathrm{M}$ to help 100 cities. Since 2013, 100RC has amassed \$3.35B from private and philanthropic sources. The World Bank has secured $\$ 4.5 \mathrm{~B}$ in resilience funding through guaranteed loans for 150 cities. The catastrophe bond market reached an impressive \$30B in 2018 . More than $\$ 8 \mathrm{~B}$ worth of resilience bonds have appeared on the world stage, many (if not all) purchased by municipal authorities to round out their resilience strategies. I know what $\$ 10$ is, even $\$ 100,000$ or $\$ 1 \mathrm{M}$ mean something to me. Counting it out is possible. $\$ 4.5 \mathrm{~B}$ is a number that doesn't carry much real-world interaction. So, when Impact Forecasting reported that 2017 was economically the costliest year on record for losses caused by natural and 'man-made' catastrophes, totalling more than $\$ 353 \mathrm{~B}$, my mind tries to find an equivalency. Three hundred and fifty-three billion. That's about three times more than there are stars in the Milky Way galaxy or about the GDP of Israel. In the catastrophe market, the stakes are high and the bets have been placed on resilience.

Sifting through and engaging with debates about resilience was stimulating. Academically. A part of me knew that these squabbles didn't contain the sort of ardour that the project needed. That I wanted the project to have. No, that the topic deserved. So I wrestled with a set of questions over and over: Who is right? Who is wrong? How does 
resilience matter? Had radical scholars made the quintessential Marxist faux pas by claiming that they knew more about the lives of the people they wrote about than the people themselves? Was I too waddling into the same Marxist false consciousness waters as those radical scholars? I knew that practitioners who engaged with the concept of resilience were not being duped by some invisible power ${ }^{3}$. At the same time, however, I found myself searching for shadowy figures lurking about. I wanted to know if an invisible power was behind the resilience turn; and, if some mystical, magical or megalomaniacal force was at work, of course, I needed to know. As a general rule, I don't subscribe to conspiracy theories. Dubious claims cannot be substantiated by empirical selectivity. But what happens when the empirical evidence does point to a rather bleak conclusion?

\subsection{Organization of Chapters}

The dissertation is organized as follows. In chapter 2, I outline how I approach the study of resilience. I offer three claims about resilience and advance an avenue for a productive critical study of it. Next, I argue that metaphors and analogies are central components in the study of resilience. Paying attention to these rhetorical and storytelling devices helps us to more accurately trace the work that resilience deployments are doing. I end the chapter by signalling that I am concerned with the socio-historic processes of resilience, attending to the idea that resilience is politics by other means. As such, this work is an attempt to add to the ongoing dialogue about resilience, helping us understand what goes into resilience network-making as well as what is at stake.

\footnotetext{
${ }^{3}$ I am not making reference to what some call 'Resilience Trutherism'. For an overview of climate resilience conspiracy theories, see Brentin Mock (2018).
} 
Chapter 3 provides an overview of the theoretical and methodological underpinnings of the dissertation. Following an overview of how I engage with Actor-Network Theory (ANT), the chapter argues for the inclusion of non-humans in the analysis: that we ought to pay close attention to the role that both people and things play in resilience networkmaking activities. If we are informed by an ANT lens, we may ask: what is the materiality of resilience? Or: what kinds of 'things' go into making resilience possible? In this sense, we may also ask: how is resilience made/unmade? Sociologically it is not habitual to speak of a concept as being made/unmade; this chapter offers a particular argument that in the case of resilience we should do so and that a broader argument that all sociological concepts could benefit from a materiality-based ontology. The chapter advances the argument that while the world of resilience is indeed made-up of all kinds of things - academic papers, websites, grants, questionnaires, indices, data, metal, bouncing balls, debt, stocks, hurricanes, flood water and so forth-we need a way to understand how they are structured. To do so, I excavate a sociological understanding of power and social control from ANT that allows me to grasp how struggles over definitions, financing arrangements and even visual representations serve to configure the field of resilience.

Chapter 4 offers a select reading of some of the ways that the concept of resilience has been deployed. In this chapter I treat the concept of resilience as having a career. Much like one's employment history, I show how resilience has had a trajectory. I trace a few of its origins and point to how the concept of resilience was introduced into a variety of academic and practical fields of knowledge. The range of definitions of the concept that I present indicates not only a sustained interested in the term over time, but also a 
series of truth claims concerning what the concept can and cannot (or should not) address. I point to the development of both resilience centres of synthesis and resilience centres of calculation. Both types of institutional assemblages are concerned with creating and expanding a resilience network. I conclude with a broad survey of how resilience has entered into the lexicon of the everyday. My argument throughout this chapter is that the trajectory, and how the concept has been deployed, did not have to be the way it is: alternative trajectories and avenues could exist. Things could be different for resilience.

In chapter 5, I undertake an investigation of the Rockefeller Foundation's 100 Resilient Cities initiative (100RC). I position the initiative as a program that was informed initially by academic articulations of the concept of resilience, then, as the program grew, adapted those articulations to render the concept more mobile and suited to their particular needs. The target of the 100RC's work was to integrate its definitions of resilience into municipal policy. The work involved enrolling corporate partners who developed resilience models and tools, then selecting cities across the globe to participate in the program. The initiative also gave birth to a new category of municipal actor on whom I shed light: the Chief Resilience Officer. The Rockefeller Foundation brought a distant concept into proximity of its immediate philanthropic work, and then expected others to follow. In many ways, the dovetailing of municipal policies and local community concerns fostered the conditions of possibility for the encroachment of the philanthropic sector in catastrophe and disaster planning and mitigation. The chapter traces how the 100RC initiative is one way in which we can come to understand the ebb and flow of what I call 'philanthropic resilience'. Philanthropic resilience starts with the 
philanthropic sector's involvement in, and desire to influence, municipal programs and projects. One of the form's key characteristics is its drive to link private capital with public institutions/goods. As I illustrate, the Rockefeller Foundation placed key personnel within municipal administrative bodies to serve in an oversight capacity and influence resilience programs directly. This is in contrast to traditional philanthropic arrangements that offer grants to finance prospective projects without direct oversight or involvement. A second key characteristic of philanthropic resilience resides in its ultimate goals: business continuity, return on investment and standardization.

Extending the analysis of the relationship between private capital and resilience, chapter 6 critically examines the ways in which the discourse and practices of resilience have been informed by financial logics. This financialization process is rendered most evident through the development of a resilience valuation model by the RAND Corporation, funded by the Rockefeller Foundation and promoted by the 100RC initiative. I also shed light on the resilience bond framework proposed by Re.Bound. Both of these developments have led to what I term 'financialized resilience'. Financialized resilience has roots in the Rockefeller Foundation and seeks to incentivize municipal authorities through capital investments in resilience projects. Financialized resilience has been bolstered by philanthropic resilience: the two go hand-in-hand. 


\section{Chapter 2: Reflections from the Field}

The deepest problems of modern life flow from the attempt of the individual to maintain the independence and individuality of his existence against the sovereign powers of society, against the weight of the historical heritage and the external culture and technique of life.

Simmel 1971[1903], 324

Since I began this project, many others have also taken notice of 'the resilience turn'. The accounts range from scans of the literature, tracing bibliometric trends and laying bare the forms of academic networks that are being forged around the concept of resilience, to targeting new forms of sociability and the politics of resilience within the 'anthropocene' ${ }^{4}$. This chapter serves to position my work within a literature that critically examines resilience. I argue that we must come to view resilience as an analytical category that can be approached through a reflexive lens. What does studying resilience reflexively look like?

Critical readings have pointed to the potentially politically demotivating repercussions that are found in certain articulations of resilience (Reid 2012). Practitioners, too, have critiqued resilience as being too vague (White \& O'Hare 2014), not providing enough direction actually to effect change on the ground (Garrett 2016), and even futile (Chadburn 2015). However, Scott-Smith (2016) says both sides are wrong, that the critiques levelled at resilience cannot simultaneously be founded. ScottSmith argues that the essence of the scholarly argument is that resilience shifts attention from the state to the individual and encourages us to embrace precarity. The essence of

\footnotetext{
${ }^{4}$ See for example the collection of essays found in the 2017 two-part special issue of the journal Resilience: International Policies, Practices and Discourses, edited by Kevin Grove and David Chandler.
} 
the practitioner argument, however, is that resilience shifts attention from the individual to the state. Both cannot be true; indeed, it is "the paradox of resilience" (663).

Where does that leave us? A paradox sounds rather ominous. Faced with conflicting and contrary understandings of resilience, Scott-Smith suggests that, "our task is not to shove this diversity into a single box or melt it all into a murky soup of resilience" (2016, 674). Rather, he suggests, "Our task is to understand these differences, articulate them more clearly, and learn what they can achieve in different contexts" (674). This sort of context-dependent thinking leads us away from generalizations, steers us towards the case study as methodological choice, and provides us with a platform for value-rational questions (Flyvbjerg, 2001). I will return to the idea of value-rational questions later. For now, I want to foreshadow my intention to approach the study of resilience from what I think is a third way: another way to dance with resilience that is not outright resistance, or a sole focus on context-dependent cases. In critically positioning ecological resilience within the social world of planning, Davoudi hints at what I am advocating by stating that "resilience has as much to do with shaping the challenges we face as responding to them" (2012, 306). Positioning resilience as holding the ability to shape how we view the world moves us closer to treating the concept of resilience reflexively and as an analytical category instead of a stagnant object ${ }^{5}$.

Within the literature, one stream of critical orientation posits that the conceptual vagueness that characterizes resilience is precisely what makes the concept appealing. "Much like the concept of globalization that rose to popularity in the 1980s and 1990s," Brassett, Croft and Vaughan-Williams (2013) tell us, "Resilience seems to carry a

\footnotetext{
${ }^{5}$ This is similar to how Beck and Knecht argue that the concept of 'crisis' can be used as a heuristic, prompting us to ask, "how crises can be transformed into objects of knowledge" $(2016,104)$.
} 
productive ambiguity that both resists exact definition and allows for a spectrum of interactions and engagements between policy and the everyday which are as (seemingly) effective as they are (apparently) apolitical" (221). Of course, resilience discourse is not without politics. That much everyone seems to agree on (Joseph 2013). The ability to mould and shape what resilience means entails that one is able to wedge the buzzword into a broad range of activities (Boin, Comfort \& Demchak 2010). By paying attention to the network-building activities that constitute how resilience is made, unmade, and deployed is how I begin to approach this study reflexively.

This chapter continues with the following claims. First, that resilience is characterized by intersections, as well as by the formalized version of intersections: partnerships. Second, that we must adopt an analytical lens sensitive to historical developments to understand the career of the concept of resilience. And, third, that doing resilience, what I call 'resilience-building', is a political process. Taken together, these three claims serve to signal how I approach the study of resilience. Next, I sketch the relationships between metaphors, analogies and resilience. The deployment of resilience metaphors serves to translate an abstract concept into associations that are more easily knowable. Paying attention to the language used to talk about the world around us offers an opportunity to gleam insights into how the things we describe are shaped by the way we describe them. As such, I contend that the work that the concept of resilience does is shaped and reshaped through the ways about which resilience is spoken and written. 


\subsection{Three Claims}

My first claim is that resilience is characterized by intersections. One form of intersection interrogated in this dissertation is the partnership. Resilience partnerships are found across academic disciplines, research programs, and policy, carrying an array of ontological, epistemological, theoretical, and methodological orientations. Resilience intersects, transcends and, in a sense, expands traditionally understood disciplinary boundaries. This claim differs from the observation of increased inter- and multidisciplinary, approaching something close to what has been framed as transdisciplinarity. The intersections and partnerships I am interested in, however, traverse the confines of academia, emerging in territories as diverse as economic policy, structural engineering, transportation, child development, infectious disease control, and professional sports. I take the ubiquity of resilience as a signal that the ways in which it is currently deployed is informed by past successful and unsuccessful deployments and attempts at networkbuilding. Tracing the intersections and partnerships that result because of, and alongside, resilience network-making is a way to understand how the concept circulated between and across actors. Without this work, the extension of resilience into everyday life is not possible. In this sense, resilience is relational.

My second claim is that, in order to sketch the career of resilience, we must adopt a historical perspective that allows us to grasp its evolution and the various trajectories the concept has taken. My critique of the analyses found in recent literature, which have claimed to adopt a historical ontology, is that they cast their gaze no further than where a neat and tidy definition of resilience resides. In other words, most ontological work on resilience begins after much of the formative work on the concept has been done. The 
critiques are, in the main, pointed at undoing and redoing resilience's forms, rather than detailing the processes and actors involved in the crystallization and hardening of particular understandings of the concept. Seeking to find something akin to the birth of resilience is not my intention. I am much more interested in understanding how the concept has evolved within certain parameters. It is a historical stance about contemporary currents.

Relatedly, my use of Actor-Network Theory (ANT) is concerned with tracing the connections, tactics, strategies, and effects of actors as they, too, navigate and form the complex terrains of our social and material world. My account of resilience does not presuppose essences or foreshadow discrete entities as starting points for an analysis. Instead, my project takes seriously Bourdieu's emphasis that "it is the very categories with which the historic object is constructed that should be the object of a historical analysis. The same pertains in relation to the terms with which we speak about reality" (Bourdieu \& Chartier 2015, 11). Resilience, from this perspective, operates as more than a simple word or concept: it can be viewed as a historical category through which other categorizations are made possible. For instance, the process through which communities come to be labelled as resilient is an example of how the category of resilience is deployed leading to a new category: resilient cities. The opposite also holds; a lack of resilience leads to the category of vulnerability or at-risk.

My third claim is that resilience is profoundly political. That is different from saying that there are 'resilient politics', or that there are resilient states/nations/sovereigns (not to mention the Israel Resilience Party). My claim does not concern whether a supposed flourishing democratic political sphere exists and has reinvented itself over time or if 
there has been a political debasement in the face of neoliberal economic programs. What I am claiming is that in order to understand resilience, we must explore its political dimensions and its political repercussions beyond dichotomous categorizations of 'good' or 'bad'. Mapping how actors engage in network-forming activities, enlist allies, appoint spokespersons to diffuse a certain articulation of resilience, and exercise control at a distance, reveals more than simple configurations of discourses: it opens up an avenue to identify relations of power. This approach builds on work that identifies how and in what ways resilience has permeated and politicized all aspects of life, including the taken-forgranted.

Identifying and naming people, places and things as resilient (or conversely, as not resilient) creates a plane of intelligibility upon which action may be taken ${ }^{6}$. The naming of activities undertaken by resilience is tied into practices of governing the self and others, and serves to fuel ethical conceptions. It is from this perspective that I argue that resilience is political: it involves finding solutions to particular (social, technical, governmental) problems at particular points in time. I am interested in how resilience has been picked up and put to work; such as, in the ways by which an entire industry of selling services to municipalities has formed around the abstract idea of resilience. The formation of intellectual and practical fields, the process of forming an avenue to understand and deploy resilience, has also been characterized by politics. As such, this project sheds light on ethical and political implications and their effects. To do so, I question taken-for-granted assumptions that have hitherto framed critical analyses of

\footnotetext{
${ }^{6}$ Resisting the categorization of resilience is also an important aspect of the politics of resilience, unfortunately not taken up in this work. For examples of how this has been approached, see: Ryan 2015; Hempel and Lorenz 2014.
} 
resilience. As a result, I distinguish category slippages and draw attention to moments when articulations of resilience exceed their definitional confinement and coalesce into new formations.

\subsection{The Resilience Puzzle}

I propose that, in order to make sense of the career of resilience, the interplay between philanthropic resilience, resilience's financialized form, and the effects of the adoption of the concept, we must map the resilience network that has been enacted. This entails distinguishing between two main types of resilience discourse. The first centres on the normative definitions and applications of resilience. The normative program has sought to explain resilience as something individually and socially beneficial, offering the concept as a benchmark against which measurable actions can be taken. Analysts exploring resilience normatively have concerned themselves principally with the ontology of resilience: what it is, how best to articulate its component parts, and to what degree indicators of resilience are observable in particular cases. These discourses are most often concentrated in areas of academic research. However, I have observed that attempts to extend normative definitions into practices focused on measuring resilience are appearing alongside resilience policies. The development of resilience scales and resilience metrics has been an area where scholarly work and policy development have found common ground. My choice to focus on the 100RC initiative is a direct response to this expansion of normative concerns into metrical concerns. How and in what ways has the project of attempting to measure resilience expanded? Who are the actors involved? And, what work has gone into making measuring resilience possible? What effect does 
extracting value from resilience carry?

The second set of resilience discourse has been concerned with its epistemology. While not entirely refuting normative approaches, analysts have advanced that resilience must be understood from particular disciplinary stances; that the embrace of resilience as a concept occurs from various vantage points. Certain positions, such as comparative methodologies and systems analytics, have been privileged over others, creating conditions ripe for claims of authority, legitimacy, and expertise. Both lines of inquiry have their separate positivist, constructivist, structuralist, interactionist, and critical positions, which has contributed to the 'fuzziness' of the concept in general. Furthermore, attempts to historicize the concept have been more a question of strategic moves to build credibility and legitimacy for a particular program of study rather than exercises in developing a historiography of resilience. By focusing on the concurrent development of these two programs, I will make clear some of the contours of a field that is, I argue, central to how resilience is rendered mobile and useful.

If I am correct in identifying political practice as a structurational element of resilience, a series of problematizations then emerges. I frame these as questions: under what circumstances is resilience proposed as a solution to understanding specific individual, social, environmental, or ecological observations? How and why were the definitional and measurability aspects of resilience stressed? And, perhaps most importantly for my project, what were the conditions of possibility that allowed for the identification of people, things, and processes as possessing resilient properties? I argue that the development and adoption of specific articulations of resilience is contingentcontingency understood as a relational quality. What I mean is that particular 
circumstances and social relations have fostered the development of resilience as a heuristic solution to certain problems. It does not need to be the way it is; alternative definitions and applications are possible. As I show, we can understand this development stemming from three broad fields of practice: first, during the 17th and early 18th centuries, particularly in the fields of proto-engineering, architecture, and attempts to classify scientific discovery; second, during the late 19th and early 20th centuries, in the fields of material sciences and scientific commercialization activities; and lastly, since the 1970s and 1980s under the rubrics of 'engineering resilience' and 'systems resilience'. I am less concerned with the development of resilience along causal-temporal lines and more interested in tracing the evolution of the forms which resilience has taken. Where do these articulations go? What happens to them, and what effect do they have? My decision to concentrate attention on the 100RC initiative's deployment of resilience is spurred by these questions and attempts at relationship mapping.

Resilience does not benefit from a ready-made and tidy definition. The conceptual 'fuzziness' (Pickett, Cadenasso \& Grove 2004, 381) surrounding resilience offers practitioners opportunities to mobilize and mutate the term within projects as they see fit. It is precisely the vagueness of this concept that has allowed municipalities to deploy resilience within forward thinking strategic plans, as well as within narratives of understanding and moving beyond past catastrophic events such as floods or earthquakes. Similarly, conceptual investigations of resilience have had to grapple with a multitude of renderings of resilience.

Analysts attempting to reconcile definitions of resilience have relied upon more or less the same sources, proposing slight variations of focus and of emphasis. The resulting 
expansion of the quantity and content of definitions of resilience has not, however, been accompanied by a corresponding refinement in the historiography or the career of the concept. Shaikh and Kauppi (2010), for example, discuss the relative coherence of definitions of resilience found within psychology and sociology. Walklate, Mythen and McGarry (2012) argue that what is interesting is the "extent to which concepts such as risk, fear and now resilience emerge, gain credence, and become enshrined in policy, often without either accord about their meaning or prior examination of their utility" (186). Indeed, the process of conceptual diffusion is messy and often unfinished. Walklate, Mythen and McGarry go on, however, not to trace the processes involved in this acceptance, but rather attempt to "bottom out the etymology of resilience and to track the nascent narratives that have developed around it," surmising that "establishing and understanding the historical (dis)connections between the utilization of resilience in academic and policy narratives is a precursor to establishing an informed debate regarding the multiple applications, potential uses, and pitfalls of deploying resilience" (186-187). They are correct, nonetheless, in claiming that the multiplicity of applications and definitions of resilience "reflect[s] a concern with overcoming and/or learning from adversity/disturbance in such a way that ensures the viability and/or integrity of the 'individual' or 'system"' which is targeted by a resilience discourse (189). Seeking to address this concern has resulted in the pluralization of the concept.

The addition of an ' $\mathrm{s}$ ' to resilience is intended to draw attention to its multiple definitions and applications. While the plural form of resilience has been in existence at least since 2012 in the work of Walklate, Mythen and McGarry (2012), it is in a 2016 special issue of Dialogues in Human Geography, particularly with Simon and Randalls' 
turn towards Mol's (2002) 'the body multiple', that the stylization took hold in an important way. I take seriously the proposal to treat resilience as multiple. However, simply showing the existence of multiple realities constituted by or through resilience does not tell us much about how these multiplicities came to be. Consequently, I seek to extend the line of analysis of the resilience multiple through a close examination of the work undertaken by 100RC, Chief Resilience Officers, attempts to calculate resilience's 'value', and the ways in which the circulation of capital has intersected with the circulation of resilience discourses: the business of resilience. This coincides with an attentiveness to the truth claims made on behalf of resilience across fields.

Within the field of psychology, Luthar, Cicchetti and Becker (2000) offer a sweeping review of resilience literature from the 1970s to the late 1990s. Their assessment focuses on definitional and methodological disparities in studies that relied on resilience scales, vulnerability assessments, and risk/protective factors. Their work draws parallels between the controversies surrounding resilience to those that emerged in the early 1990s around the concept of 'empowerment'. Luthar, Cicchetti and Becker are wary of researchers looking to capitalize on resilience's popularity, cautioning "greater attentiveness to the bidirectional nature of links between the pursuit of knowledge on protective processes in resilience and intervention efforts" (17). Extending beyond the field of psychology, my project pays attention to the links between what is said to be known about resilience and how these forms of truths about resilience are enacted. This work also provides a temporal extension to Luthar, Cicchetti and Becker (2000), offering an analysis of 18 years of developments since their publication.

Bibliometric methods of investigating resilience have also been popular. Downs et al. 
(2013), for example, used a sample of social and natural science texts to understand how knowledge about resilience is formed. They found key methodological and epistemological differences between these two broad fields of study that suggested fundamental differences in how the concept of resilience was understood and subsequently put to use. Their study revealed a catalogue of 12 core iterations of resilience stemming from the social sciences which informed natural science research. The study involved the use of Web of Science (ISI) boolean search parameters, which produced 3,759 social science texts and 2,789 texts from natural science fields. The authors went on to randomly select 337 papers for closer inspection. While the methodological choices made could be critiqued, it was in fact quite well suited to the design of their study. As such, I pay attention to the link between the social and natural sciences' treatment of resilience. For example, I have identified roughly 38 core definitions of resilience used across the social and natural sciences (see Appendix A). These sources of definitions are commonly appealed to in texts and have a relatively broad circulation. My project thus extends the bibliometric forms of analysis that have been done by widening the scope for inclusion in two significant ways. First, by tracing how actors engage with resilience, instead of simply the appearance of a term in a word search, I am able to qualitatively document how definitions of resilience have changed over time. This is the case, for example, for an important player within the resilience network: the Resilience Alliance. Noticing shifts in definition from absorbing, to tolerating, to withstanding disturbances is an important insight into the career of the concept that my project proposes ${ }^{7}$.

\footnotetext{
${ }^{7}$ I am also attuned to publications from Resilience Alliance sponsored works that attempt to link ANT and
} 
The second way in which my project proposes to extend bibliometric informed accounts is by adhering to ANT's insistence of ontological symmetry by treating actors equally for the purposes of mapping their work. My approach is thus in contrast to that adopted by Olsson et al. (2015) who turned to 'top-ranked' journals to explore the quantitative and qualitative characteristics of academic usage of resilience (9). In this example, high-ranking journals were determined by using ISI Web of Science/Knowledge, which is standard practice when gauging usage among the more popular academic journals. There are, however, some methodological problems that come with using 'top-ranked' and popular journals. Most obviously, journals that are not highly ranked are correspondingly not considered worthy objects of analysis. This privileges certain usages within particular disciplinary traditions that may in fact not be representative of how other fields have taken to the idea of resilience. For example, Resilience: International Policies, Practices and Discourses, which published its first volume in March 2013, merited only a slight reference in the analysis presented by Olsson et al. (2015). Yet, David Chandler, Resilience's editor/founder, is aggressively defining the field of resilience scholarship accompanied by several other security/securitization scholars such as Brad Evans, Julian Reid, and Mark Neocleous. If we approach the systemic study of publications critically, it becomes less a question of how many times an article has been cited, or its 'influence' as determined by algorithms, and more about the details of how debates, that are central to the formation of concepts, circulate and form networks of truth claims. The gatekeeping role in struggles for

social-ecological resilience. Stone-Jovicih's (2015) argument that ANT already contains elements of socialecological resilience thinking is one of the recent attempts to argue ANT can help refine normative definitions and applications of resilience in the field of ecology. 
definitional dominance must not be overlooked. Paying attention to formative debates, even if we disagree with the findings, is an important step in tracing truth claims within the field of resilience network-making.

One such formative debate can be found between two types of critical theories of resilience. The first, promoted by Evans, Reid and Neocleous, argues that resilience thinking homogenizes social experience, casts life as fundamentally vulnerable, leads to political debasement/ennui, and signals the collapse of subjectivity and the contemporary rise of a post-political environment. These accounts inevitably lead us to a critique of governing strategies that rely on neoliberal forms of power. While those critiques are valuable, my project rejects that particular form of analysis, which unfolds by way of resemblance: neoliberalism supposedly individualizes, resilience was individualized, hence resilience must be neoliberalism. This is, of course, not exactly the line advanced by critical scholars, but pretty close. Nonetheless, my aim in is to demonstrate that neoliberalism is a node within the resilience network, not a terminal point. As such, I follow where actors go and what they do with the concept of resilience. Some, for example, within sustainability journals or biodiversity texts, do not make mention of neoliberal pressures. These texts connect and translate the concept of resilience in unique ways, turning to analogous terms that may be foreign to the social sciences while revealing that resilience has many faces. In a similar way, Lisa Hill and Wendy Larner (2017) show the benefit of moving beyond treating neoliberalism as a monolith that imbues all social relations in the same way. While investigating the emergence of 'resilient subjectivities' within neoliberal governance, Hill and Larner (2017) argue that these subjectivities are actually dynamic. At different times, individuals and groups can 
be more or less resilient. It's an important characteristic of how resilience is deployed. In actuality, paying attention to the ways in which resilience is rendered mutable within and across fields allows us to grasp the multiplicity of ways that governing occurs as well as the productive potential found by employing the concept of resilience.

The second critical theory of resilience, adopted principally by Simon and Randalls (2016), advances that there exist multiple resiliences within an array of definitional and ontological nuances. While Simon and Randalls are not arguing to rescue resilience for a progressive political project, they do argue that the concept is in fact productive and that we must interrogate the conditions of possibility surrounding deployments of the concept. These types of treatments have since focused on the concept of multiplicity to make sense of resilience. The suggestion that there are multiple resiliences opens further grounds to investigate the concept through the lens of ANT. These accounts have listened to the suggestion that if "realities are about relational patterns of association and dissociation in practice, then it follows that there will be lots of realities not just over time, but alongside one another at the same time that there is ontological multiplicity" (Law \& Singleton 2014, 384). Recognizing that there can be ontological multiplicity with regards to resilience begs several relevant ANT inspired questions: How do resilience actornetworks operate? How do actors variously translate the concept of resilience into terms that can be grasped and differentiated by other actors? And, what are the effects of those translations? In addition to multiplicity, I argue that capturing those questions methodologically requires paying attention to metaphors and analogous terms used to speak of resilience. 


\subsection{Encountering Metaphors and Counterparts}

Metaphors allow us to experience the social world we inhabit. Metaphors are much more than romanticized linguistic devices; metaphors are certainly not limited to poetic or artistic expression. As Lakoff and Johnson have shown, metaphors are essential components of everyday thought and "our ordinary conceptual system, in terms of which we both think and act, is fundamentally metaphorical in nature" (1980, 3). Moreover, metaphors direct our attention to how concepts operate. If resilience is the vehicle through which we are expected to bounce back from unexpected and catastrophic events, then metaphors are our roadmap. Following this line of thought, several analysts have explored the metaphorical dimensions of resilience. Brand and Jax (2007), for example, argue that the metaphorical usage of resilience serves as a 'boundary object', ultimately fostering interdisciplinary discussions. Coaffee, Wood and Rogers $(2009,111)$ have called resilience a 'floating signifier', arguing that the versatility of the term as a metaphor has fostered its usage across multiple domains. Pickett, Cadenasso and Grove state that this type of usage "proves useful, as metaphors are intended to offer novel ways of thinking about and understanding complex phenomena and, particularly to reveal new connections and insights across seemingly disparate conceptual paradigms" $(2004,381)$. In short, metaphorical understandings allow us to productively trace where and how resilience is deployed; my project takes seriously the metaphorical dimension of resilience. In Chapter 5, we will see how metaphors are essential to the performance of conceptual work undertaken by Chief Resilience Officers.

By extending the implication of these metaphors, I am taking a lead from Olsson et al. (2015) who point out that "the choice of metaphors is not only epistemological but 
also ethical and performative, resulting in actions and real social consequences" (6). They also argue that, "when resilience as a metaphor becomes widespread, this has implications for social science and society" (6). Indeed, some of these implications include how analysts have chosen to pursue inquiry into how resilience could be made productive. While paying close attention to the ways in which a Foucauldian genealogical method can reify the concept of resilience, Michelsen (2017) argues that the resilience metaphor be adopted to better understand revolutionary strategies, carrying a radical political potential that is untapped by following Foucault's treatment of practices. Bijker (2008) suggests that, from an STS perspective, a sensibility to the vulnerability component found within resilience thinking helps us understand processes of coproduction and negotiation that are emblematic of the science/technology and culture relationship. This paves the way for an appreciation of the counterparts, or analogous terms, that run parallel to resilience metaphors.

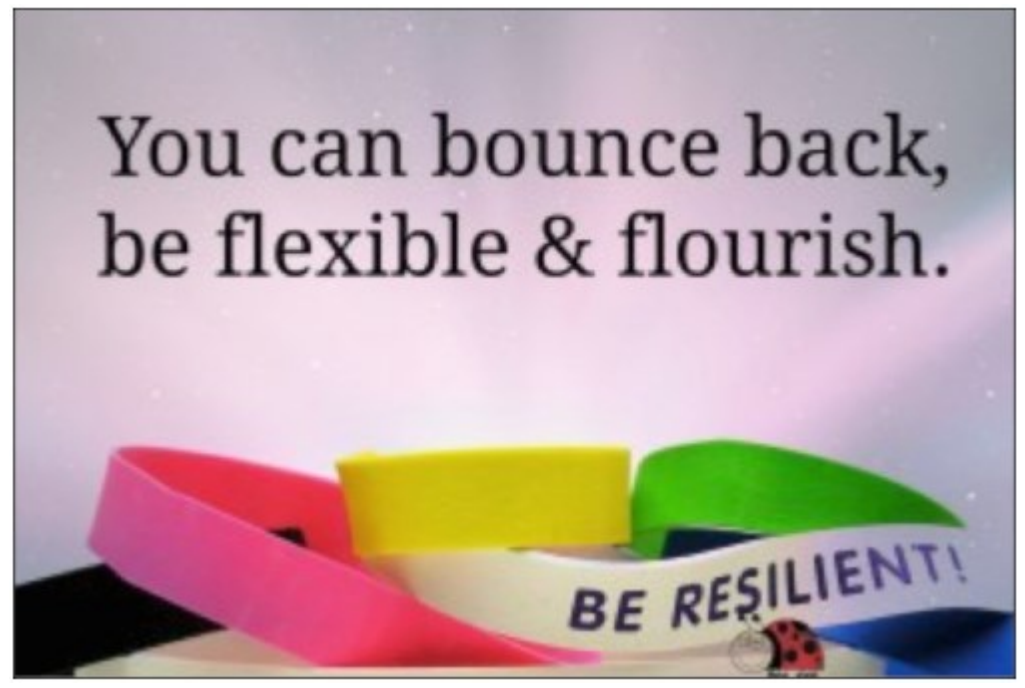

Illustration 1 Resilience as an elastic band metaphor Image source: https://solutionsforresilience.com/resilience-is/ 
Relatedly, resilience literature has drawn links between other concepts, such as: redundancy, diversity, efficiency, autonomy, strength, interdependence, adaptability, collaboration, recovery, connectivity, robustness, transformability, feedbacks, vulnerability, coping, uncertainty, risk, crisis, and foresight (Tasan-Kok, Stead \& Lu 2013). On the one hand, these conceptual links have occurred as attempts to better understand resilience. On the other, as Endress (2015) points out, resilience is increasingly linked to concepts that are a reflection of "recent self-descriptions", which "predominantly respond to the individual, subjective side of the modernity-specific hallmarks of the contemporary era" (537). These conceptual links include terms such as: activation, empowerment, flexibility, creativity, and (lifelong) learning. While this list is not exhaustive, it shows the expansiveness of what resilience can be linked to as well as its embeddedness in forms of sociality (Chandler 2013b; Diprose 2015). Endress (2015) tentatively advances that resilience literature has thus far been cast either along descriptive-analytical lines, or as a reflection of normative-interventionist understandings. To be able to make sense of resilience, Endress argues, we must investigate "the social fields, professional contexts and institutions in which concepts of resilience are enforced and various programs of action are propagated and implemented" $(2015,541)$. I respond to this invitation particularly in Chapter 4 , when discussing centres of calculation and centres of synthesis, and in Chapter 5, when discussing the 100RC program ${ }^{8}$.

\footnotetext{
${ }^{8}$ I am also able to extend Dwiartama and Rosin's (2014) work on the intersections of resilience and ANT in a critical fashion. I do not consider Dwiartama and Rosin's work to be an accurate representation of the potential of ANT. In fact, the work funded by the Resilience Alliance uses the principle of agency found in ANT to argue on behalf of a renewed normative understanding of resilience in social-ecology systems (SES). It seems rather counter-intuitive from an ANT analyst perspective to want to aggressively close a controversy by offering an alternative definition based on ANT ontology.
} 


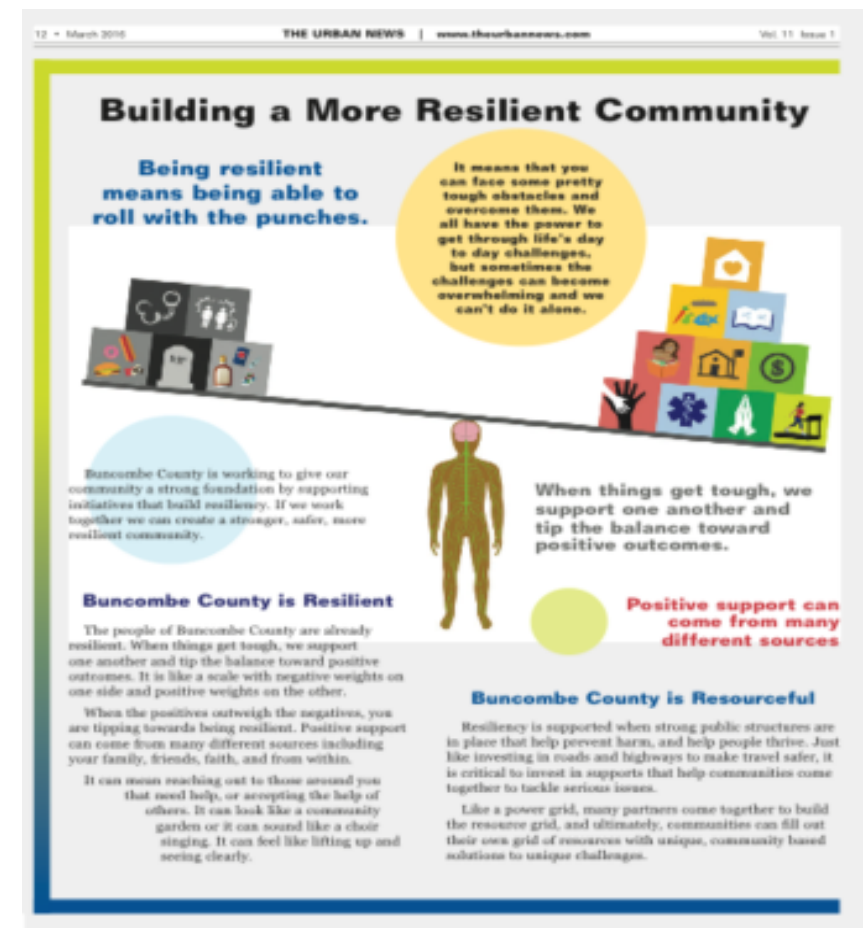

Illustration 2 Counterweight metaphor of resilience

Image source: http://theurbannews.com/business/2016/building-a-moreresilient-community/

My work follows another one of Endress' recommendations, namely, that sociological studies of resilience ought to "study the genealogy (the 'career') of the concept from a sociology-of-knowledge and sociology-of-science perspectives" (541). By doing so, I investigate the people, places and things that uphold, enforce and extend the concept of resilience as well as "those groups of agents who make it their business to (re)code resilience and to flag up their interests under the banner of resilience" (541). I distance myself slightly from Endress in terms of his insistence that resilience can be productively mobilized as an analytical lens through which we may understand how something comes to be regarded as 'threatened', 'vulnerable' or 'at-risk' (537). While the analytical usage of resilience may provide insights into how actors can become enlisted/enrolled within particular processes, or how categories can be made through the 
deployment of resilience, Endress' proposal runs the risk of masking certain displays of force between actors. One example of this masking, I argue, is found in Curtis's (2014) attempt to overlay a resilience-vulnerability lens/scale onto historical trajectories of European states from the Middle Ages to around the period of industrialization.

The long durée, Curtis (2014) purports, allows the opportunity to trace how resilient or vulnerable certain regions were when faced with stressors. Certainly, his analysis reveals that some regions were able to withstand perturbations, such as drought or famine, while others experienced mass immigration, loss of life, and were not able to recover. However, attention to the relations of domination that underpin certain perturbations is lost when focusing on reactive strategies. Rather than call a particular society resilient, as Curtis does, we may say that it simply coped or learnt to put up with its domination (by either an external sovereign power such as a king or by the natural elements such as floodwater). The more salient part of this critique is that attempts to trace resilience in the manner Curtis has shown negate processes of subjectivation that occur alongside/within processes of articulating resilience.

In paying close attention to the links between the articulation and the application of resilience, my work also responds to Endress's call for sociological research on resilience "which is aware of the normative neutrality, the temporality, the constitutive perspectivity, as well as the unavoidable power relatedness of the concept of resilience, [and] will manage to conceptualize the phenomena in question as an open socio-historical process" $(2015,541)$. Metaphors and analogous terms for resilience are more than just language; they are ways through which we come to understand the world around us and act as a signifier for the people, things, and histories making up that world. 


\subsection{Pressing Forward}

My focus on the socio-historic processes of resilience can be found throughout this work. From tracing the evolution of how the concept of resilience has been deployed across and within particular disciplines, to acknowledging the original motives underpinning the Rockefeller Foundation's mandate, I try to convey that continuities and ruptures characterize resilience. The most pronounced portion of this work where I do so is found in chapter 6, where I detail a trajectory of resilience discourses from the field of organizational studies and from business literature. I show how, over time, the resilient firm is ascribed similar characteristics as the resilient worker. This coalescing results in a form of objectivation/subjectivation that intersects with desires to assess and extract value. In the final analysis, value extraction in the pursuit of profit is an integral aspect of the business of resilience. Resilience, tuned to the rhythm of extractive processes, allows for new, creative forms of sociality, including new ways of 'doing capitalism.' For example, resilience bonds reimagine key relationships among people, emotions, infrastructure, catastrophic events, and the powerful forces of speculative and financialized capital. The invention and diffusion of capital in the form of resilience bonds include a rethinking of how risk is warded off, absorbed, or spread around: a question of who wins and who loses in the new cap and trade of disaster loss.

In claiming that resilience is politics by other means, characterized by power relations, I offer to the literature on resilience a critical perspective, informed by ANT orientations, that hinges on the idea that resilience actor-networks are contingent and fragile: things do not need to be the way they are. The following chapter details further 
how ANT, and other key methodological considerations, have been incorporated into this work. 


\section{Chapter 3: The Resilience-Network as Actor-Network}

For ANT there is no 'society' as such, in the sense of a domain consisting exclusively of relations between human subjects, as these relations are always mediated and transformed and even enabled by nonhumans of diverse kinds, whether objects, materials, technologies, animals or ecosystems. Instead of a dualist conception of 'society' and 'nature', or 'subjects' and nonhumans, ANT posits hybrids of 'societies-natures', heterogeneous assemblages in which humans and nonhumans are inextricably mixed up together.

Nimmo 2011, 109

This chapter presents how this dissertation engages with Actor-Network theory (ANT). I contend that ANT offers us an ontological perspective as well as a variety of concepts that help reveal and then make sense of the complexities of the sociotechnical world of resilience. ANT is simultaneously exciting and vexing. Exciting because it offers us potentially new ways to think about relationships, new vocabularies to communicate the messiness of life, and alternative frameworks that have the potential to be ontologically inclusive. Vexing because ANT cannot be generalized or ultimately reduced to a common theoretical tradition, methodological practice, or epistemological standpoint. In other words, “one person's use, or reading, of ANT may differ considerably from others" (Cressman 2009, 2). In engaging with ANT rather than offering a distillation of it, I am also making the claim that it exists outside any one application. As such, I draw on Law's $(2004,7)$ insistence that "ANT was never supposed to be a programmatic theory, but a loose intellectual 'toolkit' or 'sensibility'” (in Nimmo 2011, 109).

Approached as a toolkit, or sensibility, the necessity to attempt a comprehensive overview is rendered rather asinine. I find it much more productive to speak in terms of ANT preoccupations or perspectives. This chapter does not seek to offer a historical 
overview of how ANT came to be, although I do hint at some of those trajectories. Nor do I seek to propose a comprehensive treatment of all the elements that could be found in an ANT informed account. I use the word could here because I wish to emphasize that turning to ANT relinquishes almost all requirements of the analyst to confine their observations along strict theoretical boundaries. If an overarching argument is to be followed, it is that ANT is a viable approach for qualitative sociology, including historiographical approaches that rely on documentary sources. Relatedly, I wish to convey that ANT is an apt perspective to turn towards to trace the careers of concepts as well as the networks that result from engaging with concepts. It is thus a fitting approach for the study of resilience. Advocating on behalf of a framework that is characterized by a thick vocabulary to understand concepts, which are themselves laden with twists and turns in vocabulary, also seems rather fitting (if not ironically ambitious).

ANT scholars have developed a dense set of terms to describe the actions and behaviours of humans and non-humans. This vocabulary is intended to treat all actors as equals. Perhaps seen as somewhat off-putting to new students of ANT, this language has been derived from case studies that have attempted to find ways to "systematically avoid replacing [actors'] sociology, their metaphysics and their ontology with those of the social scientists who were connecting with them through some research protocol" (Latour 1999, 20). Latour further qualifies ANT as being "a theory that says that by following circulations we can get more than by defining entities, essence or province" $(1999,20)$. ANT is not about pulling the curtain aside to reveal puppeteers, evil forces or hidden programs of control. ANT is about tracing the connections, tactics, strategies and effects of actors as they, too, navigate and form the complex terrains of our social and material 
world. A good ANT account, according to Passoth \& Roland (2010), is one focused on "relations rather than on related entities" (828). In this way, ANT is grounded on a pragmatic relational account that does not presuppose essences or foreshadow discrete entities as starting points for an analysis (see Kivinen \& Piiroinen 2006; Passoth \& Roland 2010). I rely on this aspect of ANT to begin to make sense of how resilience networks materialize.

Since ANT is described as something that is performed rather than something that is summarized (Law 1997; Law \& Singleton 2000), this chapter serves to provide a sketch of some of the characteristic ways I perform ANT. I shed light on the possibilities that emerge for the understanding of resilience when an ANT lens and associated tools are adopted. I also focus on the questions of power, pointing to how ANT's main tenets help make sense of how resilience is delineated, equally by people and things. Finally, this chapter provides a foundational account of how ANT can be deployed to better understand the network-forming activities that are essential to the existence of the concept of resilience. It would be much too lofty a goal to attempt to provide a 'true' account of what ANT is or is not. Instead, I have approached this chapter as a useful roadmap for my own engagement with ANT's focus on "tracing the complex relationships that exist between governments, technologies, knowledge, texts, money and people" (Cressman 2009, 3). I took this as my starting point. As a result, my choice of this theoretical and methodological model cannot be neatly separated from the very objects of study it takes as its focus. To help unpack this work of co-creation, I begin with a survey of some of the main concepts that can be found in ANT-inspired accounts, introducing some of the concepts that will be deployed in later chapters. 


\subsection{Opening the Conceptual Black Box of ANT}

I will start by saying that there are four things that do not work with actornetwork theory; the word actor, the word network, the word theory and the hyphen! Four nails in the coffin.

Latour 1999, 15

While Latour's now (in?)famous denunciation of ANT can be found in almost any survey of the field, and has served as a spring board for an 'after ANT' movement, it contains a series of signposts pointing to several foundational elements which are deserving of attention. To start: actors. The word actor seems rather harmless at first. However, as Mol (2010) has shown, this is far from the case. By playing on the idea that an actor can be passive or active, ANT allows us to shift focus on whom (or, as we shall see, what) is considered an actor, as well as refocus attention by not asking "where the activities of actors come from, but rather where they go" (255). Mol elaborates upon this line of thought: "effects are crucial. Not goals, not ends, but all kinds of effects, surprising ones included" (255). We are immediately confronted with a different kind of way of seeing actors. An actor may choose not to act at all, but this does not mean that they are deprived of the role. Not acting is not non-acting. Mol captures this ANT filament by stating that "a strategist may be inventive, but nobody acts alone" (256). Strategically, an actor may choose to let go and terminate whatever it was they initially were doing. This passivity does not mean that they have ceased acting. An ANT lens allows us to see that attempts to give up require quite a bit of work and that even inaction carries multiple effects. The idea that actors do not act alone is thus carried through even in their inaction. As I've illustrated, an ANT lens questions the once taken for granted concept of actors as being 
agents of acting: proposing shifts in the way we come to understand actors. A major shift in this understanding concerns the ontological composition of an actor.

Perhaps one of ANT's most contentious proposals is to treat non-humans as ontologically similar to humans, both retaining the title of actor or actant $^{9}$. Doors (Latour, 1988a), electric cars (Callon 1986), paper, DNA, professors, students, examinations, texts, and so on are all to be treated as capable actants. For Latour, this means that an ANT account will treat all "on exactly the same ontological footing" (Harman 2009, 14). Through an ANT lens, the world is made up of a plethora of material things, and these things occupy a central place in our ontology. The ANT hardline to this stance is that "nothing exists but actants, and all of them are utterly concrete" (Harman 2009, 16). Relatedly, for Latour, actants are seen as events. These events happen "only once, at one time, in one place" (Harman 2009, 17). An actant, then, is an event with no essence that is constituted by a series of relations and is always specific to and encrusted in one moment. The point of this metaphysical posturing is to arrive at an ontological and epistemological position that rejects a view of the naturally occurring durability of materials, objects, or actants. If everything is an actant as well as an event that is only ever occurring at one place, at one time, then the seemingly enduring nature of an object is not the result of its essence but is rather the result of a series of translations, negotiations, and the resulting coordination across an entire network of actors. Law (1986) summarizes, by saying: "Durability is better seen as a function of the interrelation of translated objects rather than as something that naturally inheres in objects

\footnotetext{
${ }^{9}$ I have adopted the terms actant and actor. I do so because they are terms of art in the field. My intention is not to add confusion with a toilsome vernacular or jabberwocky. In most cases, replacing actant for actor will not significantly change the meaning being conveyed.
} 
themselves" (20). The durability of something, then, is the result of extensive work: when we witness the durability of an actant, it is the effect of prior successful campaigns to make and remake stable relations. Resilience, as I will show, comes to be as a result of the work that actants undertake. From the myriad of definitions to the policy papers that promote resilience interventions, ANT allows us the opportunity to pay attention to the actions and non-actions of actants as constitutively forming how resilience is imagined and done: effects. As such, we can envision the resilience field as being filled with actants, all of whom are entering into relations with other actants and producing effects through their work. Grasping the work that actants are doing is one of the most crucial aspects for an ANT-inspired account.

Leaving the hyphen in ANT alone for a moment, the word network requires some attention. In ANT, the idea of a network differs from that found in other social theories and especially from technical accounts. For a city-planning engineer, for example, a network is envisaged as an entity composed of inputs and outputs. This is not exactly the type of network found in ANT. Latour (1996) draws attention to this by arguing that it would be wrong to imagine an ANT network in technical or infrastructural terms ${ }^{10}$. Sewage, train or telephone networks can carry similar characteristics of an actor-network. They may be composed of an "exclusively related yet very distant element with the circulation between nodes being made compulsory through a set of rigorous paths giving to a few nodes a strategic character" (Latour 1996, 2). A computer network may well be

10 I differ from Latour on the treatment of infrastructure. It may well be the case that infrastructural networks carry strong actor-network characteristics. I do not subscribe to the type of absolute inclusion/exclusion that is sometimes found in Latour's work. In the final analysis, an infrastructural network, for me, may be an actor-network and can thus be mapped out and observed as such. 
the prototype of this sort of technical network ${ }^{11}$. The sort of technical networks that are imagined by engineers are "only one of the possible final and stabilized state of an actornetwork" (Latour 1996, 2). From an ANT perspective, networks may be highly localized, contain no obligatory paths, and have no strategically placed nodes. Resilience echoes this form of decentralized network, prompting us to question how it remains stable. For ANT analysts, a stabilized network such as a power grid, and the resilience network, as I will show, is not the end point of analysis, nor is it even the beginning of one. The stabilized networks that come into existence are some of many possible outcomes of a series of relations, all predicated on the actants involved.

The second way in which an actor-network differs from other accounts of networks is its distancing from social networks. ANT attempts neither to recreate nor to explain social networks. Social network studies takes its target of investigation to be the social relations between human actors. This approach accounts for a network's composition and particularities. As such, the focus is on individual entities entering into relations and the subsequent social/natural and structure/agency ${ }^{12}$ characteristics of those relations. ANT, on the other hand, extends the focus of relations to include non-human and non-

\footnotetext{
${ }^{11}$ Latour often refers to 'double click' information. The metaphor of the computer mouse implies a parallel to computer networks, at least initially. Essentially, double click information, for Latour, is the type of supposedly honest, transparent, and faithful communication that is the result of hiding all the work that goes into something. Science was Latour's referent, but we can imagine a series of realms in which the rendering of blood, sweat, and tears is communicated as something sleek and complete without complexity or risk (see Latour 2003).

12 I am not suggesting that ANT escapes the structure/agency debate. Rather, I find that most ANT accounts attempt to more or less bracket the debate than to 'solve' it in any serious form. In any case, ANT scholars have developed a vocabulary that is focused on actors' ability to act, rather than their inability to. There is some sleight of hand with regards to the structure/agency debate, but it is a strategic move that is worth mentioning. Mol hints at this, with a discussion of the term 'fluid' found in some ANT accounts: "alongside the term network another term, fluid, was brought into play. Actors may be enacted in networks that have a stable syntax, but it is also possible that their ability to act is afforded to them by a context that is adaptable and varied and behaves in a more fluid way" (Mol 2010, 259).
} 
individual entities. It is a background/foreground reversal. "Instead of starting from universal laws—social or natural—and to take local contingencies as so many queer particularities that should be either eliminated or protected," an ANT account of networks for Latour "starts from irreducible, incommensurable, unconnected localities, which then, at a great price, sometimes end into provisionally commensurable connections $(1996,3)$. Patterned relations are not the rule; they are the exception. An ANT-informed account does not focus on why networks take the forms they do. Nor do ANT accounts fall back on 'standard' sociological tropes to make sense of why actors do what they do (i.e., neoliberalism's logic forces actors to behave in certain pre-planned patterned fashions). Rather, ANT's focus is to describe and detail empirically how networks take shape, how they are made to hold those configurations, and how they sometimes fail. For Mol, this means there "is no attempt to hunt for causes: the aim is rather to trace effects" (2010, 261). In tracing the effects of relations, I approach the study of resilience not by finding solace in "a few predetermined categories" (Law 1986, 6), but by becoming an explorer seeking to find how connections are formed. By flipping the standard sociological explanatory trope of 'interests' on its head, for example, Mol illustrates that "instead, the term 'interests' deserves to be read as a verb: to interest $(2010,359)^{13}$. As such, my ANT account of how the resilience network is formed is predicated on the idea that "associations have to be made" (Mol 2010, 359). Those associations and the critical, yet

\footnotetext{
13 This sort of reversal becomes all the more important when tracing networks that contain certain amounts of secrecy (the "it must be a backroom deal" type of response). It is likewise all too easy for an analyst to explain away certain complex connections with the reductionist economic view of rational choice decisionmaking ("someone must be getting something out of it-money, power, prestige, etc."). In fact, we may find that some connections hold in the absence of a traditionally 'rational' reason (how is it that sticky notes remain in frequent circulation within highly digitized office environments that have much more efficient instant messaging and sophisticated digital reminder systems?).
} 
delicate, work of linking actants always require something else: translations (Harman $2009,18)$.

Translations are how actants come into contact with one another and how networks can begin to take shape. Translations are also what we, as ANT analysts, are to attend to. Simply put, translations are active attempts at doing something on the part of actants. For Callon, "Translation leads to the identification and shaping of allies and to seeking their support" $(1995,52)$. Law echoes this position, urging us to view translation as "a verb which implies transformation and the possibility of equivalence, the possibility that one thing (for example an actor) may stand for another (for instance a network)" (Law 1992, 386). The relationality found in Law's account is also found in how Callon (1995) has articulated the role and effect of translations within actor-networks, stating that:

translations are always tentative and in certain cases postulate completely new actors, which are then brought into existence. The translations might be inscribed in texts stating explicitly the contribution of the projected work, in material substances, or in skills and instruments. These translations might require huge investments. They link closely the definition of very technical problems with the constitution of a space for the knowledge that is produced (52).

From linkages between entities to textual inscriptions, translations operate on the level of actants; translations serve to connect actants together, helping to communicate intentions. Actants engaged in work in one field can attempt to translate their results to recruit another set of actants working within another distant field. This type of translation work involves long-distance communication and the effect, if successful in their recruitment campaign, would be an enlargement of the actor-network. Translations, however, come at a cost. There can never really be a totally truthful translation between actants: "Divergence between translations and the proliferation of entities is the rule, not the 
exception" (Callon 1995, 55). So, while actants may attempt to impose their own forms of equivalences, trying at all cost to restrain and restrict the proliferation of multiple accounts and understandings, it is ultimately futile: "the universe of translation is polytheist" (Callon 1995, 55). So, too, is the world of resilience.

For Latour, the work of translation is accomplished by a mediator who is "not some sycophantic eunuch fanning its masters with palm leaves, but always does new work of its own to shape the translation of forces from one point of reality to the next" (Harman, 2009, 15). Translations, then, are also always about the negotiation, control, and resistance to certain forms of reality (Callon 1984). Within the resilience network, these types of translations are undertaken by Chief Resilience Officers who experiment with ways of understanding and communicating what resilience means in the context of 100RC municipal programs. Furthermore, the valuation of resilience required another set of translations in order to steer resilience into the financial sector. Taken together, the translation chains surrounding resilience are composed of statements, technical devices, and sets of skills. To help further understand how these elements of translation work converge, a related ANT concept is useful: inscriptions.

The notion of an inscription includes "graphic displays, laboratory notebooks, tables of data, brief reports, lengthier and more public articles and books" (Callon 1995, 50; Latour \& Woolgar 1979). Such an empirical focus runs parallel to Foucault's exposition that institutions such as hospitals, prisons, the army, and so forth, function, at least in part, by placing the individual within a "network of writing" (Callon 1995, 189). Inscriptions, then, are in constant interaction with other inscriptions and inscription devices. These inscription devices can be seen as "any item of apparatus or particular 
configuration of such items which can transform a material substance into a figure or diagram which is directly usable" (Latour \& Woolgar 1979, 51). Some inscriptions are more useful than others, but their common characteristic is their capacity to render something previously immobile mobile. A set of skills is required to translate even the most basic forms into something suitably useful locally, and we can imagine an extended set of skills to render something useful at further distances ${ }^{14}$. This process, referred to by Law (1986) as heterogeneous engineering, produces sets of statements that can then travel across time and space more easily than mere inscriptions. Spectronomy, X-rays, cost overrun tables, word counters, scribes: these can all be considered inscription devices, some more sophisticated than others. The translation of events into twodimensional representations capable of travelling great distances away from their originating locations need not be restrained to materials, however. Words and, I argue concepts, including resilience, can undergo these mutations. The actions of contracting, elongating, punctuating, or severing texts serve as mechanisms to facilitate their travelling. Scanning, digitizing, copying, or coding extends the reach of texts. It follows, then, that when we metaphorize, personify, or euphemize concepts, the effect is to translate a word into something transportable, mobile, and actionable. The rhetorical spins that are placed on words and concepts can be seen as attempts to exercise some control over them. As such, some attempts succeed while others fail; some attempts include the enrolment of additional actants who are requested — and expected—-to do rhetorical work.

\footnotetext{
${ }^{14}$ For an account of precisely this sort of long-range control, see Law 1984.
} 
In ANT parlance, actants are both the human and non-human entities that surround us and the formation of networks is the effect of the work accomplished by these actors. Sometimes (oftentimes), these attempts fail. As analysts, we need to pay attention to the work that is being done by actants, trace objects in action and provide thick descriptive accounts of what we can see (Harman 2009, 14). In a somewhat overlooked chapter in the Pasteurization of France (1988b), Latour proposes the principle of irreduction. By this, Latour's argument is essentially that no object is inherently reducible to any other. As Harman points out: "It is always possible to explain anything in terms of anything else-as long as we do the work of showing how one can be transformed into the other, through a chain of equivalences that always has a price and always risks failure" (2009, 15). In Chapter 5, I show how the Rockefeller Foundation initially failed to extend the resilience network by not recruiting Alameda as a member city, pointing to a rupture in the chain of equivalencies that the organization was attempting to make. As we have seen, actants can accomplish these linking activities through chains of translationswhen successful. What matters in my deployment of an ANT account is the tracing of heterogeneous associations and networks, while also paying attention to how the work of associating and networking is accomplished.

For this task, ANT offers us the ontological and epistemological lenses to make unique contributions. It is then less about describing the 'inputs' and 'outputs' of networks and more about describing the various ways in which actants contribute (or not) to the processes of network formation as well as the effects of those contributions. It is a question of form and process. Law (1992) summarizes this position by stating that at the core of ANT is: 
a concern with how actors and organizations mobilize, juxtapose and hold together the bits and pieces out of which they are composed; how they are sometimes able to prevent those bits and pieces from following their own inclinations and making off; and how they manage, as a result, to conceal for a time the process of translation itself and so turn a network from a heterogeneous set of bits and pieces each with its own inclinations, into something that passes as a punctualized actor (386).

The end results may always change and, indeed, can be envisioned in a multitude of ways. Things do not need to be the way they are.

By drawing attention to the ways in which ANT approaches actants, networks, translations, inscription devices and the irreducibility of entities, we can begin to appreciate the nuances of how bits and pieces are held together. On the one hand, relationality, multiplicity, and framing enter into our ontological gaze (Law \& Singleton 2014). On the other hand, we are left with the very real observation that some bits and pieces, and, indeed, some actants, appear more capable than others. Some actants can assemble and translate far better than others. And some actants enjoy a longer reach than others. These are important questions to consider that I will turn to in Chapters 5 and 6 while mapping the resilience network that includes the work of an international philanthropic conglomerate like the Rockefeller Foundation as well as theoretical models like the Resilience Dividend Valuation Model. How, then, can we speak of influence and order within a world punctuated by heterogeneous entities? To begin to address these questions, the next section explores ANT's treatment of power sociologically. 


\subsection{Power and Social Control Within ANT}

I don't know how things stand. I know neither who I am nor what I want, but others say they know on my behalf, others who define me, link me up, make me speak, interpret what I say, and enroll me. Whether I am a storm, a rat, a rock, a lake, a lion, a child, a worker, a gene, a slave, the unconscious, or a virus, they whisper to me, they suggest, they impose an interpretation of what I am and what I could be.

Latour 1988b, 192

The ANT world is composed of heterogeneous entities: objects, people, technologies, as well as human and non-human actants. These entities engage in networking building work through translations, relying at times upon inscription devices and mediators for success. If their work succeeds, translations are hidden: black boxed, so to speak. At first reading, the articulation of the world of ANT resembles that of a battleground, calling attention to strategies, displays of force, moves, and countermoves. The analogy of war, however, only goes so far to capture the particularities of how ANT approaches questions of power and social control. In this section, I focus on the ways in which entities enter into relations, emphasizing a relational account of power found within ANT sensibilities. It is this emphasis on relationalities that informs how I come to understand key processes contained in resilience network-building activities.

From an ANT perspective, actants are not presumed to enjoy inherently superior or inferior features than other actants. In fact, as Harman (2009) reminds us, actants, "are not stronger or weaker by virtue of some inherent strength or weakness harboured all along in their private essence. Instead, [actants] gain in strength only through their alliances" (15). Strength, capability, range of influence, and so on can all be obtained and enhanced through relationships. Extending one's influence across time and space is thus 
seen as being an effect of a series of linkages and enrolments. There are no naturally occurring entities that are predestined to succeed or fail; everything is dependent on the ability to recruit allies and band together in chains capable of influencing others. As such, ANT positions power as an inherently relational effect. Law (1986) articulates this position by drawing attention to how power makes an appearance in the methods that actants employ to collapse both the large scale and the small scale, thereby creating obligatory passage point "for the high and the mighty and thereby exerting distant social control" (9). Simply put, an obligatory passage point is a sole avenue or path that leads to where actors want to go. Obligatory passage points allow actors to achieve their goals, while offering a particularly high level of control and oversight over how those goals are met. Obligatory passage points force all translations through a singular point of contact, much like a funnel guides the flow of liquid towards a singular point of exit.

The ability to force translations through one point allows actors the opportunity to control both the quality and quantity of future translations. We must not forget that this is accomplished by the prior work of assembling and enlisting many heterogeneous elements (human and non-human alike). Law suggests that we pay close attention to the ways in which actants go about translating with the aim of enhancing the capacity of materials' social control potential. Law's argument is that "the form of materiality is altered in a process of translation during which the less mobile is converted into the more mobile" $(1986,12)$. The method of rendering an entity more mobile can be read as an attempt to create the conditions of possibility for some form of control, not necessarily an obligatory passage point. Law adds that "the processes of schematizing, simplifying and juxtaposing" are "elementary forms of translation" that when applied to mobile entities or 
materials make it "possible to think in terms of long-distance social control. Until this happens, only local control is feasible" $(1986,16)$. Here, within ANT we can see an appreciation for social, material, geographic, and symbolic forms of distance. Power, again, is seen as an effect when actants attempt to shape thoughts and actions through translations. For Latour, objects are "neither a substance nor an essence, but an actor trying to adjust or inflict its forces, not unlike Nietzsche's cosmic vision of the will to power" (Harman 2009, 15). The question of willingness thus enters into the equation: are all entities as willing as the next to be enrolled or translated? In our case we may ask if certain domains or entities are willing to be described as resilient. It is an important question, as those entities that are less willing will require more work on the part of actants to be enrolled into the resilience network. As I will show in chapter 6 , the quest to formulate a resilience dividend was not made easy. The idea of making things mobile and docile through alliances found in ANT allows us to appreciate the philosophical and technical leaps that the Rockefeller Foundation undertook in order to arrive at an operationalized account of a 'resilience dividend'. As such, I will show how the Rockefeller Foundation exercised a level of control, from a distance and with the help of a network of willing actants, over the articulation and deployment of the concept of resilience.

Another way to speak of how power operates within the world of ANT is to speak of 'winners' and 'losers'. As actants negotiate translations and enter into displays of force, they rely on alliances to accomplish their goals. This involves strategies for the recruitment of other actors, capitalizing on their forces through newly forged relations and joint alliances - partnerships. However closely this may resemble a militaristic view 
of relations of force, it does not mean that the capabilities of actants can be determined in advance. Harman (2009) reminds us, "winners and losers are inherently equal and must be treated symmetrically. The loser is the one who failed to assemble enough human, natural, artificial, logical, and inanimate allies to stake a claim to victory" (19). This notion is extended even further by Harman (2009) to capture the multiple realities of actants, "the more connected an actant is, the more real; the less connected, the less real" (14). The result of seeing relations of force in this way is that, as in Foucault's (1977) account, power is not drawn from some central place. Rather, actors amass power by assembling a network of allies. Accumulating power in this fashion carries risks. The force of actants is always in doubt, and can never be predicted. As elements come together in the formation of a network of translations, "Every actor has a choice: to extend further, risking dissidence and dissociation, or to reinforce consistency and durability, but not go 'too far"” (Latour 1988, 198). It is worth quoting Latour (1988) further on these processes of ally formation and the spreading of relations, as it gets to the heart of the question of willingness to be enrolled by others:

an [actor] needs faithful allies who accept what they are told, identify itself with its cause, carry out all the functions that are defined for them, and come to its aid without hesitation when they are summoned. The search for these ideal allies occupies the space and time of those who wish to be stronger than others. As soon as an actor has found a somewhat more faithful ally, it can force another ally to become more faithful in its turn (199).

Some allies are thus better suited than others. The quest for willing and capable allies requires not only skill in identifying and enrolling others, but also in preserving relationships between and among allied actants. Harman (2009) recapitulates this position by stating that "it is never the actant in naked purity that possesses force but only the actant involved in its ramshackle associations with others, which collapse if these 
associations are not lovingly or brutally maintained" (20). The balance of power between actants needs to be seen as the result of a series of negotiations. While some actants may be physically stronger than others, and their fates seemingly sealed, their relative strength or weakness is the result of much past work. As such, we must come to see power too as a result, not a predetermined essence. Power is the result of many successful negotiations and translations; social control is thus the result of an accumulation of actants who are able and willing to use their position of superiority in numbers to have some influence. We must not forget, however, that actants are also resisting and can resist being enrolled or turn their backs on others. Thus, there are always gaps and loopholes: everything is always fragile. All networks and associations may fail, and many may succumb due to the resistance of actants. In a world composed solely of heterogeneous entities pushing and pulling their influence around, the mutated virus that kills the king can be seen to have resisted the commands of antibiotics, physicians, laboratory results, and immunization programs. The king may have enjoyed the power and social control that went along with collecting taxes through carefully organized alliances, but he was no match for the virus that cared little about overbearing fiscal policies.

ANT scholars, informed by Foucauldian preoccupations, have been interested in the ways in which decentralized sets of laws, rules, norms, and regulations have been linked to social order. ANT accounts differ, however, from those of governmentality inspired accounts in that the focus is less on the forms of governing and more concerned with the work that goes into ordering. Mol (2010) makes the point that ANT accounts have articulated, "when norms have been set, 'normalization' does not automatically follow (263). Network making requires work, trust in the actors involved, and entails some level 
of risk. It is an active and highly relational process. As such, thinking about how networks come to be and how they are held together through the terms modes of ordering and co-ordination seems more appropriate, as it invokes the active work involved in the process of network making and remaking. Co-ordination has the benefit of calling attention to the continual work involved, for sure, but also the tensions that exist between and among actants throughout networks. Law (1986), writing before Mol's articulation, hints at this essential focusing on co-ordination work, saying:

power may be seen as an effect of the creation of a network of mobile, durable yet tractable agents that have been sent out in one another's company. A text by itself will be ignored. A person will be snubbed. A device will rust. But if the three are put together it may become, as the case of Pasteur suggests, more difficult to ignore them. Under the right circumstances, the effect is that of power (34).

The task for analysts operating within the frameworks of STS broadly, and ANT in particular, must then centre on "the methods by which actors seek to open up certain possibilities whilst denying others to those round about them" (Law 1986, 8). At the heart of coordination work is the opening up or closing of avenues for action. This is how, in ANT terms, actants extend their power and have influence that leads to some sort of social control. I add to this vocabulary the idea of 'incubation' and 'partnership'. As I will show in chapters 5 and 6 , the partnerships that were forged in order to extent the resilience network served to incubate possibilities, offering a bailiwick wherein actants could fertilize and grow resilience proposals and strategies with less interference. The act of incubation, promoted by the Rockefeller Foundation, takes the form of a working session or a community consultation. The risks are lessened by the choice of venue and audience. The work performed during the incubation process can be highly guarded by 
the incubator or its close allies. As I show in chapter 5, the Chief Resilience Officer served this dual role of spokesperson as well as bailiff in the development and deployment of municipal resilience interventions.

\subsection{ANT and Resilience}

Resilience is much more than simply a metaphor. It is an organizing principle and a mode of harnessing and maintaining social order and control.

$$
\text { Walklate, Mythen \& McGarry 2012, } 197
$$

So far, I have offered a selective exposition of ANT. I have focused on key terms, how these relate to ANT's ontological proposals, and have pointed to how ANT can help us understand the question of how power flows within the resilience network under study. This focus has been, for the most part, on how to go about the business of working with ANT. What, then, are the objects of investigation? Where are we to find these actants, translations, enrolments, displays of force and so on?

Methodologically, the story of resilience is just that: a story. If science and technology studies and works in the field of historical epistemology have shown us anything, it is that ideas travel through place and time in sometimes-oftentimesunpredictable and contingent ways. These scientific diffusions are imbued with narrative and rely on storytelling techniques and literary devices. Go to any academic conference and witness the fifteen-minute performance before a small gathering. It is a form of storytelling. The story may be dull and mind blazingly boring, as is sometimes the case. Or it can be seriously stimulating. Nonetheless, the presenters are relaying a story, using a variety of narrative techniques to do so. The same is true for scientific texts, including 
those from the natural sciences ${ }^{15}$. The use of metaphors and analogies as narrative technique, for example, is a case in point. Gingras and Guay (2011) document the use of analogies and analogous thinking following the Industrial Revolution by text mining the Philosophical Transactions of the Royal Society of London. As they uncover, analogies were useful in attempting to explain a complex novel idea or discovery and their use gained in frequency and popularity. Analogies allowed, and continue to allow, authors an avenue to connect to their readers: finding common ground through shared experiences across time and space. Metaphors function in a similar way. Bauman, for example, turned to metaphors repeatedly (Jacobsen \& Marshman 2008). It would be difficult to find a graduate student who cannot at least gesture to the idea that modernity is something liquid: a somewhat hardened metaphor by now (within the social sciences at least). The analogy, and similarly the metaphor, however, can only take us so far. Neither analogies nor metaphors are exact replications of the object under scrutiny. That is the point. This complex thing referred to as modernity can be explained through a simpler concept of liquidity. What we immediately encounter is a set of characteristics that allow us to begin to conceptualize another object's characteristics. It is a link between something known, or more easily grasped, and something more complex or fleeting. It is a successful translation because it allows us to come closer to a shared understanding. The successive translations that have occurred in the story of resilience are the ontological backbone of what I consider to be a valuable ANT-inspired account.

A second literary device that I want to draw provisional attention to is the aphorism. Simmel was one of the masters of aphorisms, having learnt the form from his

15 A focus on the psychology of analogies and metaphors is found in Dreistadt (1968). 
engagement with the works of Kant (Swedberg \& Reich 2010). Two of my personal favourites are: 'thinking hurts' and 'the artist is capable of doing what the logician is not: to extend a concept without it losing content'. Aphorisms function differently than analogies and metaphors. They accomplish a different task and make us think (which can end up hurting!). An aphorism is not necessarily comparative in the same way as a metaphor, but it remains a literary device designed to stimulate the reader/audience. 'Bounce back' is a common aphorism within the resilience literature. It does not come close to Simmel's quality; nonetheless, it is used over and over again to speak of the concept of resilience. If the stories I want to tell, the stories that make up a narrative of resilience, are composed of literary devices then my story should be too. From an ANT perspective, the translation that I attempt needs to draw on the vocabulary of the actors that I am observing. Simmel's compacted articulation of the capacity of artists to extend concepts without a resulting loss in content is an apt way of thinking through roles that various actants take or are given. The ability to translate with minimal loss of coherence is a skill that actants would certainly need to command if they wished to enlist others through their work. Here I am thinking of the Chief Resilience Officer, which we will encounter in chapter 5 , as a prime example. This, of course, begs the question if concepts, such as resilience, can be treated as actants in this scenario.

The answer to the question of whether concepts can be considered actants from an ANT perspective lies partially with how Latour positions actants within his proposed object-oriented ontology ${ }^{16}$. Since all things are granted equal weight and are all

\footnotetext{
${ }^{16}$ It would be inappropriate to say that all ANT analysts treat actors in the same way and that there is a definitive answer to the question of whether concepts can be considered to constitute actors. In fact, much emphasis should be placed on how ANT-informed accounts approach case studies without a preconceived
} 
considered as concrete as the next, "All natural and artificial things must count as actants as long as they have some sort of effect on other things" (Harman 2009, 16). The relational aspect of the effects that actants may have must not be overlooked. Alone, objects, things and people are not configured as actor-networks. As such, if we wish to determine if the concept of resilience is an actant, we must turn to its relations with other actants within what ANT scholars have termed hybrid collectives.

Much like resilience, ANT has relied on a variety of vocabularies as well as a variety of definitions at various times. To add to this confusion, ANT has gone by different names: The Sociology of Translation (Callon 1984), Co-Word Analysis (Callon, Law \& Rip 1986) and Actant-Rhizome Ontology (Latour 1999), for example. Each morphology has brought new analytic tools to the foreground. Callon and Law (1997) add to this expansive set of terms by drawing our attention to hybrid collectives, which are the result of four core STS principles (which I read as also ANT principles):

a. the social is heterogeneous in character;

b. that all entities are networks of heterogeneous elements;

c. that these networks are both variable in geometry and in principle unpredictable; and,

d. that every stable social arrangement is simultaneously a point (an individual) and a network (a collective).

The first argument is that the social is materially heterogeneous. People, texts, chickens, tables, and atoms are all a part of the world we inhabit. This is not a difficult extension of the imagination after having absorbed that non-humans are also actants. The twist, as we have seen, is to consider how these heterogeneous "Elements and materials participate in social ordering" (Callon \& Law 1997, 168). Their second argument is that there is no 
difference between individuals and the "network of entities which acts through the person. Network and person: they are coextensive" (Callon \& Law 1997, 169). This argument requires a little bit more imagination. I interpret it as an extension of the concept of irreduction initially proposed by Latour (1988b). By placing actants and networks along the same ontological line, none can be reduced to another. As such, it is not quite correct to state that actants are positioned outside/inside a network. Networks do not have an insider/outsider dynamic, per se with regards to actants. The more salient point for my purposes is that Callon and Law extend this principle to include texts, saying "Texts also reflect, are produced by, and help to create, a teeming world of entities" (1997, 170). This world, as we have seen, is punctuated by translations, but also "objects—-for instance people and texts — are processes of transformation, compromise or negotiation" (Callon \& Law 1997, 171). This third argument can be seen as conveying the idea that entities are always fragile, unpredictable, malleable and subject to change. This is true with regards to human relationships as well as textual relationship-networks consisting of actors that are texts. The fourth principle addresses what happens when an actor-network passes from something malleable to something more durable. For Callon and Law, "that a network which is relatively stabilized also tends to become an entity, a black box, a black box that...translates the various materials that make it up. It translates them by co-ordinating them, by fronting them and by standing for them in a simple and coherent way $(1997,174)$. These black boxes have the effect of hiding the multiple translations as well as the work that is going into making the entity appear durable and defined. As long as something is working, there is little will to open it up to observe its inner functioning. 
Resilience then, from this perspective, can (sometimes) be seen as a black box. For example, the multiple metaphors that have been variously relied on to promote the idea of resilience have been taken up by some actors as readily understandable/communicable, which then increases the chances that more actors will become enrolled in promoting the concept themselves. The metaphors become black boxed: disappearing from perspective to be no longer questioned. Similarly, attempts to translate the concept of resilience have at times relied on inscription devices such as graphs, charts, tables, and flow diagrams. Once these translations begin to work, a tangible form of resilience takes hold through textual representations of resilience.

For Callon and Law, the task of sociologists, then, is to "find ways of characterizing the patterns in the relations of influence - the patterns that make up hybrid collectives" (1997, 179). Similarly, for Latour, when characterizing patterns, language need not be privileged and the supposed variance between literal and metaphorical uses of words becomes irrelevant. For Latour (1988b),

because there is no literal or figurative meaning, no single use of a metaphor can dominate the other uses. Without propriety there is no impropriety. Each word is accurate and designates exactly the networks that it traces, digs, and travels over. Since no word reigns over the others, we are free to use all metaphors. We do not have to fear that one meaning is 'true' and another 'metaphorical'. There is democracy, too, among words. We need this freedom to defeat potency (189).

This openness to texts and language, however, is not immediately shared among ANT scholars.

The treatment of texts has been a source of contention for those working within ANT frameworks. By exclusively looking at texts, so the criticism goes, we lose the uniqueness that is present in everyday interactions and practices. Texts are seen as too 'flat', and too 'mute' on the messiness that is emblematic of what an ANT informed 
account is trying to trace (Nimmo 2011, 113). Mol focuses on "the knowledge incorporated in daily events and activities rather than knowledge articulated in words and images and printed on paper" $(2002,32)$. This privileging of the ethnographic does not sit well with historiographical methods that not only rely on texts, but also place a heightened level of confidence in the realm of the textual. Can ANT be beneficial and productive in the world of words, or is the limit of ANT's reach within the world of things?

Considering that Latour's work concerning Pasteur relied on historical artefacts, I think it is a rather safe assumption to say that ANT can work with texts. Nonetheless, some important elements should be kept in mind. Nimmo suggests that we view texts as “inscriptions, which is to say, not just 'representations' of a complex reality that always eludes them, nor just as 'sedimentation' of practices, but as technologies of translation and mediation, or "mobilizations of the world"' $(2011,114)$. Texts, then, are to be understood not as mirroring a reality 'out there', but rather as "enactments of reality" (Nimmo 2011, 114). As such, some elements are made visible while others are hidden through the text. Texts are, in this way, hybrid. They consist of materials and require certain technical elements to come into being. Beyond this, a particular text is intricately connected to a series of practices and we could even say that the creation, distribution, storage, preservation, or consumption of texts are practices that are intrinsic to the text itself. Thus for Nimmo, "texts as mobile and material inscriptions that are active agents who assemble, shape and connect practices, and, in doing so, enact objects, constitute subjects, and inscribe relations, ontological boundaries and domains" $(2011,114)$. 
A text can be taken up, read, circulated and considered highly regarded. That text can then be mobilized in a series of translations for a period of time, having great and even far-reaching effects. A while later, a new text may appear, superseding the original. The first is left by the wayside to collect dust, while the other enjoys grand victories at its predecessor's expense. The effect of a text is dependent on its work, and its work can only occur if it is enacted and enrolled in a network of relations that grants it a series of conditions of possibility. This differs from the strategies of reading a text within a context, or reading beyond the text as is common in literary studies (Fuller \& Sedo 2013). The treatment of texts from an ANT perspective requires a sense of situatedness and a sensibility towards reflexively treating the ways in which texts can act ${ }^{17}$.

This attention to the effects of texts requires analysts to be reflexive in two ways. The first form of reflexive work concerns both the conditions that enable the creation and circulation of texts, and also the sources of that textual data. This can be accomplished by paying attention to where and how a text was produced, the actors involved (or not involved) in its production, and the forms of translations that the text underwent. But the more important reflexive work, in my view, is one that is attuned to the ways in which any particular text is performing the actions of condensing, simplifying, elongating, highlighting, relegating, or calculating. It is in these actions that insights into the effects of texts can be made. Paying attention to what does not sit well, what is strange and what is a category slip allows analysts the opportunity to interrogate texts, especially official documentary forms, with renewed insight (Curtis 2014). If we add to this an ontology that treats humans and non-humans symmetrically—-the text itself as well as clues that

\footnotetext{
${ }^{17}$ Law and Singleton (2014) point to this by drawing attention to the constructivist and material-semiotic forms of STS.
} 
are contained in the form the text takes-we can productively combine ANT with documentary methods. Nimmo contends, "the task for the ANT researcher then is to be the 'ethnographer of the text' who follows those processes in all their heterogeneity" $(2011,116)$. Following the text, much like following any other actor, requires attention to moves and countermoves and stratagems, but also moments of failure and abandonment: tracing a text reflexively requires an openness to being surprised. This is what paying attention to texts as being relational entails. This approach is beneficial for tracing the ways in which texts have circulated around the theme of resilience: it allows for an ontology that is accepting of concepts and a methodological grasp that extends ANT into documentary sources. Beyond these aspects, two related empirical and theoretical elements of resilience lend themselves particularly to being explored through an ANT lens: materiality and multiplicity.

Resilience thinking does not only operate within the realm of language and texts. For example, when a suspension bridge is devised to withstand earthquakes or floods, the concept of resilience is structuring design, build, and maintenance activities (Chavel \& Yadlosky 2011). From the type and thickness of anti-corroding paint, to the frequency of drain pipe cleaning following snow melt, everything that is known about a bridge is modelled, evaluated, and optimized in an effort to erect a structure that will withstand stress and recover from shocks. These are all fairly good things if you rely on a bridge to travel. The refinement of large-span, high-weight bearing bridges and associated road arteries facilitated the expansion of urban centres. Seeing the development of urbanization through the lens of resilience requires an attentive eye to the material aspects of the term as well. In fact, it is actually rare to find the type of single file, single 
vehicle wooden covered bridge that I used to cross to get from one farm to another growing up. That particular bridge, the only remaining McCallum inflexible arched truss bridge in North America lasted 148 years before being given a restoration. Not too bad for a bridge that was purposefully designed to lack flexibility/resilience. More to the point, resilience thinking has had significant implications for the way in which organizations conduct their day-to-day business. For instance, the practice of supply chain management, arguably now one of the most talked about elements in the distribution of goods and services, has at its core the idea of resilience (Ponomarov \& Holcomb 2009, 130). The ability to create and refine infrastructural systems that are predicated on the concept of resilience is quite interesting from an ANT lens. It means that we must pay attention to a wide variety of objects, technologies, design theories, and processes that have been enrolled and expected to speak on behalf of resilience.

Recognizing that there can be ontological multiplicity with regards to resilience begs the ANT questions of how do those networks operate? How do actants variously translate the concept of resilience into terms that can be grasped and differentiated by other actants? And what are the effects of those translations? Simon and Randalls propose that "critical assessments of resilience can cut across the generality and evasiveness of the term by nailing it down and forcing the question of specifics when it is summoned, which we maintain is perhaps the only universal moment for politicizing the concept" (2016, 15). Informed by an ANT ontology, my approach to locating the politics of resilience differs slightly. Building on the multiplicity of the concept of resilience, we may indeed locate its circulation among a wide array of actants. Tracing various moments of successful and unsuccessful translations is one point of contact where the politics of 
resilience can be observed. For example, one of the major sources for the 'resilience turn' was Lance Gunderson and C.S. Holling's book Panarchy (2002).

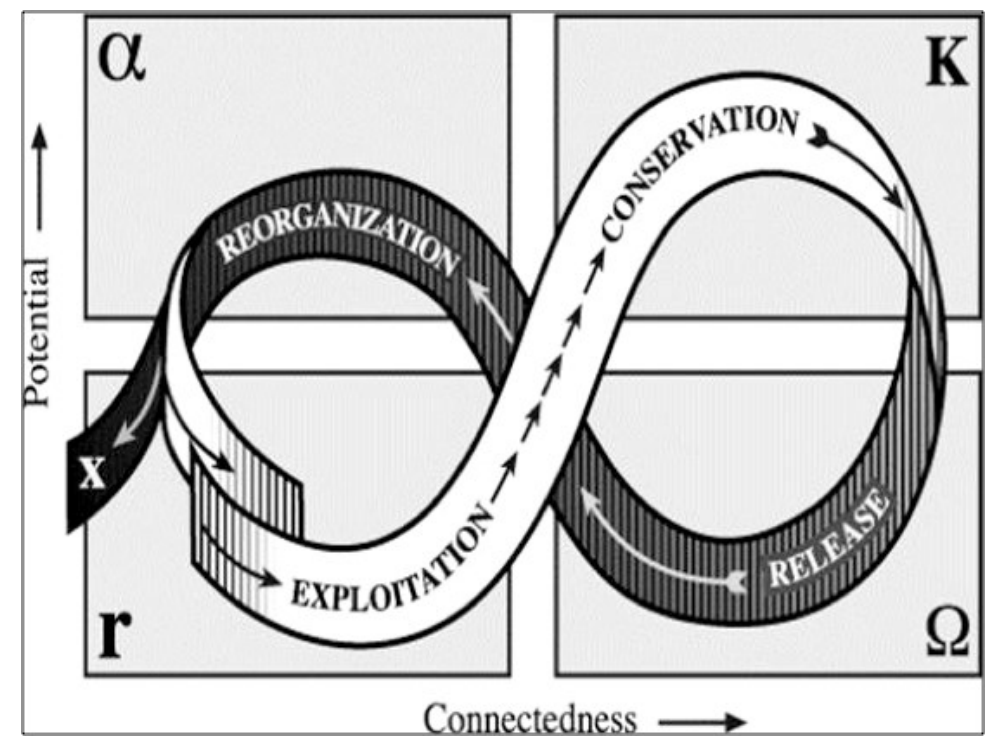

Illustration 3 Depiction of the adaptive cycle of resilience Image source: https://www.resalliance.org/adaptive-cycle

While widely cited as the inspiration and the catalyst for much of the resilience work currently underway, perhaps Panarchy's most important legacy has been an image that appears on its cover. From over 500 plus pages of text, it is the image of an altered infinity sign that has been translated into what resilience is, means, and represents. The point here is that Gunderson and Holling's politics behind turning to the concept of panarchy and resilience have been lost by subsequent actors' translation work. Gone are the mentions that capitalism and inefficient government regulation and oversight in key areas of forest management policy are the root causes of the depletion of available resources. Gone are the links between consumerism and thoughtful, long-term ecological 
sustainability plans ${ }^{18}$. Politics was enacted through translation. It is as important to take note of what is included as well as to what is not when translations occur.

As form, relations of power always define resilience; to treat it otherwise indeed neglects its reciprocal effects. While not an ANT theorist, I subscribe to Simmel's insistence that "the starting point of all social formations can only be the reciprocity of effects between person to person" (Simmel in Pyyhtinen 2010, 7). Building on Simmel's focus on effects between people, ANT allows us to enrich the account by also including things (non-humans). By tracing what devices, technologies, and actors (human and nonhuman) are enrolled in order to form and then sustain a heterogeneous resilience network, we are able to trace how resilience is politics by other means ${ }^{19}$.

\subsection{Methods, Data, and Practical Concerns}

I maintain close associations between theory, method, and data. I approach the design of the project as one that necessitates that these relationships be constantly kept in check. I have found that tracing how the concept of resilience moves requires something stable to assess it against. In my case, analytical categories inspired by ANT have provided the stable footing upon which to follow the travels of a concept, how the concept changes from one place to the next, and the work that actants undertake in order to render resilience mobile. I have made sure that the empirical variables under scrutiny correspond to an analytical category. It has been the case that following resilience reveals a plethora

\footnotetext{
${ }^{18}$ In all fairness, I do not think that Gunderson and Holling advanced progressive political views. They advocated for increased amounts of rationalization in the forest and ecological sustainability sectors, ultimately wanting to close gaps between the predictable and unpredictable. The point I wish to make is that even this aspect has been lost in the translations of their work, more or less reduced to a diagram form that has been mobilized in resilience campaigns.

19 This is a play on Latour's famous phrase 'science is politics by other means'.
} 
of new actors and networks. By relying on analytical categories, my analysis groups actors on a plane upon which they can be assessed and discussed, rather than assessing their work anew each time I encounter a new actor. This is a different methodological approach than creating categories and extrapolating from the behaviours of a few. What I am proposing is neither generalization nor extrapolation. I provide, in the ANT tradition, a rich descriptive account of each actor: focusing on the work that actors do becomes one of my methodological focuses. In this way, I am tracing the circulation of the concept of resilience through time and space, while also paying attention to network forming work that allows this circulation to occur. I focus on the gradual expansion of the network, coalescing into philanthropic and financialized forms of resilience, while metabolizing definitions of resilience to produce new hybrid definitional forms.

Data for this project was collected from a variety of documentary sources. Each source of data for the project corresponds to a different area of the resilience network that I investigate. As such, the data I use aligns with my research questions, probing resilience within particular locales and following a specific set of actors. To be able to trace resilience through time and, in particular, within academic disciplines (Chapter 4), I have identified a list of journals where resilience research has been published in the last 20 years (see Appendix B). The method of initial retrieval was fairly rudimentary: a boolean text search for the keywords 'resilience', 'resiliency' \& 'resilient'. Once an archive of these texts was formed, the second step involved interrogating those texts, going from most recent back through time, with a specific set of questions. I have adapted Bergström, van Winsen, and Henriqson's (2015) model of systematically analyzing resilience texts, producing four guiding thematic questions: 
a) The rationale for resilience: why do we need resilience?

b) The object of resilience: what is it to be resilient?

c) The definition(s) of resilience relied on: how is resilience defined, and which sources are relied on?

d) The subject of resilience: who/what does resilience, who/what is responsible for resilience?

These questions allow me to identify a series of actors (human and non-human) who are being called upon to join resilience actor-networks. The expansiveness will have already become noticeable. Initially, I suspected that I would discover a core set of actors and articulations of resilience, pointing to certain 'epochs' of resilience thinking. The findings of my project certainly point in that general direction. However I have decided not to formally label the network that I trace using temporal markers, such as epochs. The borrowing and mixing is more concerned with how actors actively translate and render the concept of resilience useful. My main focus will be to ascertain if their methods are qualitatively different. This will provide a unique assessment of the career of the concept, supplementing both the historical trajectories traced by Alexander (2013) and the genealogical accounts proposed by Walker \& Cooper (2011), Joseph (2013), and Evans and Reid (2014).

A second set of data for this project comes directly from the Rockefeller Foundation and their 100RC initiative. Documentary data, including reports, briefs, and strategic plans were consulted to map how the Foundation sought to enroll actors in its resilience network-building work. Relying on this textual data, inevitably, revealed the successes of the Foundation. Failure is rarely reported through publicly available means. To get a sense of some of the less-than-successful attempts at network-building, which are as analytically important as successful ones, I turned to municipal documents. Municipalities have been the targets of the 100RC since its inception. Municipalities have 
taken proactive steps to engage with the Foundation; they applied to become 100RC members by way of three competitions from mid-2013 to late 2015. Application processes have been variously documented and catalogued by municipal councils, some even publishing acceptance or refusal letters. Turning to the municipalities themselves, that have a different set of expectations regarding the publication of their official affairs, meant that I was able to supplement the information presented by the Rockefeller Foundation. I have not, however, traced all the municipalities that have engaged with the 100RC. I shed light on municipalities that had a Chief Resilience Officer for more than a year, as these provided more detailed accounts than a municipality that was only in the beginning stages of the initiative. To date there are over 80 active Chief Resilience Officers within the 100RC initiative, approximately 30 of those are employed in predominantly English and/or French administrative environments, and most were hired after 2017, with fewer than 20 working since 2016. While most documents of interest are available online, some required in-person consultation, or were only delivered upon request. Reviewing municipal documents for the selected cities revealed the processes that helped extend the resilience network.

Finally, a third set of data relied upon for this project constitutes first-hand accounts from Chief Resilience Officers who have spoken openly about their work. These empirical elements come in the form of public interviews, published progress reports, publicly available memos, and the like. Included here are also public profiles of Chief Resilience Officers, documenting their previous experience and career trajectories ${ }^{20}$.

\footnotetext{
${ }^{20}$ The main repositories for this data are the Rockefeller Foundation and corporate partners' websites. Since web pages are ever changing, I captured screenshots or downloaded digital copies of the information
} 
While these accounts cannot attest to all of the activities that Chief Resilience Officers undertake, the life stories and backgrounds of Chief Resilience Officers become fused with the trajectories of the concept of resilience. As such, the Chief Resilience Officer acts as an embodiment of the type of resilience that the Rockefeller Foundation is seeking to advance, as well as an important public spokesperson and advocate for resilience. The position of Chief Resilience Officers within the resilience network is also worth noting, as it is relationally one of the main passage points, or connecting nodes, between municipalities, 100RC, the Rockefeller Foundation, initiative platform partners, insurance firms, metrics and indicators, and valuation models. While Chief Resilience Officers occupy a central place in the visualization of the resilience network that I have mapped, we should not think of them as being at the centre of this network. As their accounts show, and the network activity I have mapped confirms, Chief Resilience Officers are more akin to air traffic controllers than pilots. In Chapter 5, I detail the role of the Chief Resilience Officer as a pivot point: an intermediary between actants as well as a point of passage between theory and practice.

A brief note on the project's overall method of presentation is warranted before continuing. For this project, I embarked on a careful cataloguing exercise, particularly in areas concerned with the changes that have taken place in articulations of resilience. I have not ventured to recreate those, at times minimal, changes. That would be excessively tedious to write and I would not wish to brew the sort of acrimony in my readers that a text of the sort would entail. Instead, I have bracketed the analysis, revealing the aspects of most importance and interest while leaving aside the more insipid amassing an archive of web pages has proven to be a useful tool when stored locally. 
parts. It is a series of choices that are informed by the relative proximity I enjoy to the field, as well as a penchant for good storytelling. In this way, it is not so different from the work that results from an in-depth ethnographic field study. My project, however, did not require me to change living conditions (aside from the occasional visit to the archives). This stance also allowed for inquisitiveness, discovery, and surprise.

Leaving open the possibility of being surprised by what actants do and how they accomplish (or fail in) their work allowed me to pay attention to category slippages and notice things that did not quite fit. In some instances, stringing together this narrative account of resilience made visible how actants have sometimes gone to great lengths to reconcile conflicting definitions of resilience. In these instances, it was rather obvious and I could point to a shift or the adoption of a strategy, for example. However, while actants laboured to create resilience practises from metaphors, I too sometimes found myself enthralled by the rhetorical clashes and the tenacious disciplinarianism of the field. On occasion, and early in the project, I found myself cheering on particular ways to explain resilience over others; I have caught myself naively labelling some actants as simply wrong. I have presented my findings in a way that does little to reveal my leanings on that issue. I have tried, as much as possible, to let the actants speak and given them the space to make their appeal. This does not mean that this dissertation is devoid of politics.

The politics of resilience is not solely in the act of naming: it is found in how resilience is done. I have chosen to pay attention to the philanthropic and the financialized versions of resilience, both of which carry significant implications 
regarding the availability, feasibility, distribution, and capitalization of resilience interventions.

\subsection{Network-Making in Action}

This dissertation focuses on the crystallization of a resilience network. The project could have gone in many different directions (and could have easily been three times as long). Indeed, while tracing lines of translation and following the work accomplished by actants I encountered diverging paths, meandering trails, and dead ends. I made conscious decisions as to which trajectories to pay attention, and which intersections to avoid. I chose to focus on the philanthropic resilience network not because it was the most convenient, nor because it is the most visible resilience work being done. The decision to map a part of the philanthropic resilience network was precisely because its extremities are so far apart from each other, almost seemingly too far removed from coexistence to function. But the network does function. At the forefront of the project was a constant search for how the network was formed and how it was kept together. Below is a graphic representation of the network. It is a simplified illustration of the various actants involved. We can imagine that the concept of resilience is the glue that is holding the nodes together-each node being a flattened or compressed representation of an actant's activities. The diagram is a useful heuristic to detail the materials that were used in the current project, as well as to explain the inclusion decisions that were taken. 


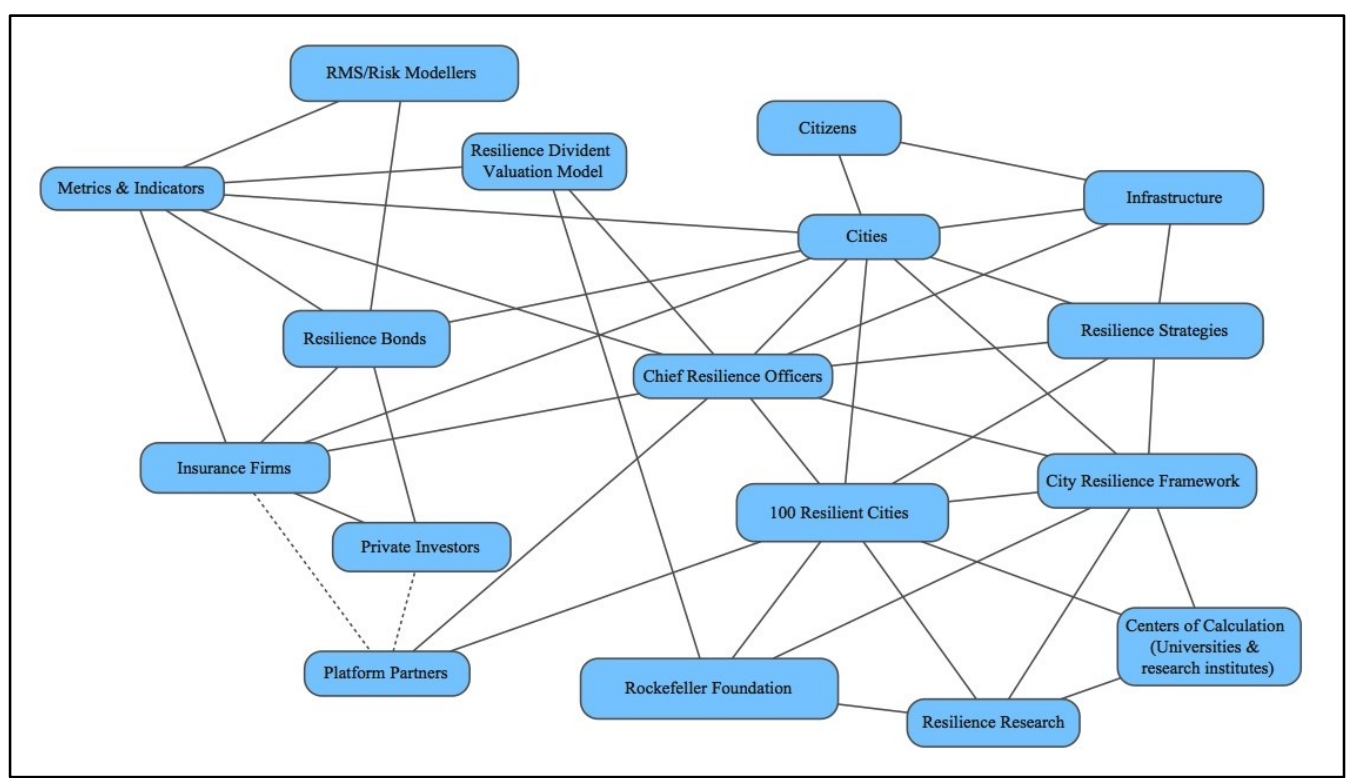

Illustration 4 Network Map

One of the main characteristics of this particular network is that it does not contain a centre. The lines that connect the nodes do not all emanate from a single source. It is a decentralized network in that regard. As a result, the empirical work that went into mapping the relationships was not focused on materials produced by any single source or actant. My first point of contact, and anchor, for tracing the network was an examination of reports and documents produced by the Resilience Alliance. The Resilience Alliance, which I treat as a centre of calculation, also publishes the journal Ecology and Society that is a primary source of peer-reviewed articles on the topic of resilience.

The Resilience Alliance also enters into network forming relations with universities, government and non-government agencies. One of those agencies is the Rockefeller Foundation - and, by extension, the 100RC initiative. From here, I was able to further map the 100RC's activities by selectively collecting documents: sanctioned reports, news releases, media interviews by key personnel, and research briefs are among the types of textual material relied on. This material was both produced by, and in partnership with, 
The Rockefeller Foundation and the 100RC. The Resilience Dividend Valuation Model (RDVM), for example, was produced by the RAND Corporation with financial backing from the Rockefeller Foundation. The City Resilience Index, based on a theoretical model that originated with the Rockefeller Foundation, was produced by UK-based engineering firm Arup. Each of these entities is treated as an actant. Once enrolled in the network, their work translating the concept of resilience results in the creation of texts, guidelines, indexes, illustrations, diagrams: inscription devices. This was the primary form of data that I relied upon to complete this dissertation. It allowed me to follow what actants were saying and doing, and the effects of enrolling, translating and, ultimately, making resilience mobile.

A second quality worth highlighting is that the various nodes are operating at different levels of abstraction and embeddedness. In fact, this is a reflection of a characteristic of the resilience network that is also found within the 100RC initiative. Paying attention to how actants navigate different levels of abstraction, producing different sets of data along the way, offers an opportunity for tracing how concepts at one level come into contact with artifacts produced at another. For example, Chief Resilience Officers working at the municipal level are expected to translate a set of core indicators into actionable line items for city administrators. I am thus able to follow chains of translation from the theoretical concept of resilience found in academic literature through to indicators in a manual and ultimately to a resilience checklist, revealing the work that goes into making resilience actionable and useable for certain actants. The work of contracting, compressing, and cramming entails exerting influence over the potential avenues that are embedded into abstract concepts. Making manageable forms necessitates 
having power over their final configuration. Each successive shift leaves behind traces of data that I have followed in order to reassemble and lay bare the work done to resilience.

Tracing relations and network building activities between cities and the 100RC initiative were also accomplished by examining documents obtained through Freedom of Information frameworks, media outlets and informal channels. By way of these outlets, I was able to obtain emails, such as those between city staff and 100RC personnel. These communications revealed aspects of the relationship-building work that went into forming the 100RC network of cities. Additionally, these documents offered a glimpse at how cities formally applied to the initiative, as well as how municipal staff adapted to the deployment of resilience strategies. Where appropriate I have signalled that these sources of data were consulted with the in-text format: (NAME OF CITY, 'COMMUNICATION', DATE).

\subsection{Conclusion}

ANT does not tell anyone the shape that is to be drawn - circles or cubes or lines - but only how to go about systematically recording the world-building abilities of the sites to be documented and registered. In that sense the potentialities of ANT are still largely untapped, especially the potential implications of a social theory that would not claim to explain the actors' behaviour and reasons, but only to find the procedures which render actors able to negotiate their ways through one another's world-building activity.

Latour 1999, 21

This chapter has laid out the methodological foundations of the current work. By turning to an ANT-inspired methodology and theoretical leaning, I am in a position to trace resilience network activities. I also am in a position to grasp the concept of resilience in its de-essentialized form. ANT has sought to challenge the ways in which both what is termed 'nature' and what is termed 'the social' are understood as pure entities. By 
treating subjects and objects as radically similar, ANT-informed accounts have been able to push back against the essentialism that fuels the nature/social divide. This problematizing has carried various titles: 'the sociology of translation' (Callon, 1986); 'ontological politics' (Mol 1998; Law 2004); 'cosmopolitics' (Stengers 2010). At their core, these accounts seek to bridge the nature/social, human/nonhuman, subject/object distinction by treating both sides equally, hence relying on an ontology of symmetry. Or, as Latour has styled it, a 'generalized symmetry' (1993). The insistence on the ontological symmetry found in ANT offers one avenue of analysis that attempts to escape the anthropocentric metaphysics fuelling some traditional sociological accounts of networks. Latour suggests that in order "To balance our accounts of society, we simply have to turn our exclusive attention away from humans and look at nonhumans" (1992, 227).

The suggestion to cast a gaze towards material actors has been eagerly taken up by analysts working within the loosely defined science and technology studies field. Turning to nonhuman actors forces analysts to pay attention to the role that material objects and systems play in the co-construction of socio-technical assemblages as well as to the ways by which actors are enrolled and enlisted in such networks. For sociologists, it means paying attention to the relationships between material objects and people, giving equal analytical weight to both. Power can thus be analyzed from the vantage point of the effects of relations of force (Latour, 1986), be they human-human interactions or nonhuman - human interactions (including the nonhuman - nonhuman relationships all around us). The focus on 'grand inventors' and 'great discoveries' is displaced in favour of a more nuanced understanding of history, opening an opportunity to embrace and 
include within narrative elements such as contingency, failure and unintended consequences. Furthermore, through such an ontological widening, a renewed focus on the mundane practices, 'messy actualities' (Larner 2000, 14) and 'little tools' (Asdal 2008) of socio-technical/political systems can begin to occur. The benefit of such a framework comes from an attempt to embrace and extend Foucault's (1988a; 2011; 2012) suggestion to take seriously the multiple ways in which governing the self and governing others occurs. By paying attention to human as well as nonhuman actors, we can conceptualize what Foucault (1988b) has termed 'technologies of the self' - one of four social technologies, together with meaning, making, production, and power/domination, that captures practices of self-formation —along a plane of intelligibility that extends to the materiality of governmental schemes. Understanding networks, power relations, and regimes of authority as being formed by both humans and nonhumans challenges the taken-for-granted idea of 'the social'. This also means that the phenomena that we observe, "can be neither simply 'natural' nor (more obviously) only 'social"' (Law \& Singleton 2014, 380).

By taking seriously the roles of both humans and nonhumans as important elements of social action and social organization, and by treating the various heterogeneous elements that constitute 'the social', we are able to engage in "'more than social' history" (Nimmo 2011, 110). I have argued here that ANT is amenable to a variety of empirical traditions, including historiographical-inspired accounts that rely on documentary sources. ANT need not privilege the ethnography or the ethnographic method. It does, however, require of analysts to follow the texts. It is perhaps best, then, not to view ANT as a theory at all. As Mol (2010) states, ANT offers no "consistent method. It rather takes 
the form of a repertoire. If you link up with it, you learn sensitizing terms, ways of asking questions and techniques for turning issues inside out or upside down" (261). ANT is better seen as "something that helps scholars to attune to the world, to see and hear and feel and taste it. Indeed, to appreciate it" (262). By accepting this we may in fact be accepting a larger set of implications regarding the practice of social science found in ANT. For Latour (1999), the potentials have yet to be seen:

ANT does not tell anyone the shape that is to be drawn - circles or cubes or lines - but only how to go about systematically recording the world-building abilities of the sites to be documented and registered. In that sense the potentialities of ANT are still largely untapped, especially the potential implications of a social theory that would not claim to explain the actors' behaviour and reasons, but only to find the procedures which render actors able to negotiate their ways through one another's world-building activity (21).

In a similar vein, Mol (2010) suggests we adopt the perspective that "theory is a repository of terms and modes of engaging with the world, a set of contrary methodological reflexes" (262). This articulation of the connections between theory and method is, I think, quite productive. It allows us as analysts to be reflexive of the world around us: the world we also are a part of and, through our actions or inactions, contribute to making. The benefit of ANT then, "is not that it is solid, but rather it is adaptable" (Mol 2010, 265). This adaptability is precisely what we uncover when we start to peel back the layers around us and observe the multitudes of associations and dissociations (Law \& Singleton 2014) between people, things, translations, networks and the coordination work that somehow and, with much effort, contribute to our social world.

Finally, the appearance of stability in the world around us is the result of numerous forces. The world does not need to be the way it is. Indeed, the way things are is the 
result of ongoing sets of negotiations and translations, enlistments and the work of allies. It would be false to claim that the world around us is a fabrication, the result of exclusively human intervention. As Harman (2009) points out: "The world does resist human fabrication" (22). Nor can we imagine a world made-up solely of human discourse. For Latour (1988b), "anything does not go. Discourses and associations are not equivalent, because allies and arguments are enlisted precisely so that one association will be stronger than another" (168-169). Simply put: truth is not a correspondence between statements and the world that they attempt to define. Linking statements about the world back onto the world involves much more than a simple statement (Harman 2009, 19). Proclamations require allies to have any force. Scientific observations need translations to be rendered mobile. Truth is dependent on networks. "If all discourse appears to be equivalent, if there seem to be 'language games' and nothing more," Latour (1988b) tells us, "Then someone has been unconvincing" (168-169). This has potentially radical implications in the way we understand the practices of politics and policy (Law \& Singleton 2014, 380). Touching on the idea of practices within ANT, Mol (2010) highlights that the term 'network' has been "overused and may have been emptied out, sucked dry", adding that "one way or another, these days most ANT researchers no longer unravel singular networks, but attend to coexisting ones in tension" (260). A negation between the division of practice and discourse can be seen as the culmination of a metaphysics that rejects dualism and a set of ontological principles that extend beyond humans. In this last analysis, ANT allows us to see "practices as relations that are heterogeneously material and semiotic, filled with social and technical tensions and politically performative" (Law \& Singleton 2014, 380). In the chapters that follow, I will 
show how this happens and how we have all, knowingly or not, come to share a place in the world where the business of resilience proliferates.

\section{Chapter 4: Chasing the Career of Resilience}

Catastrophes can make the visceral argument for action on reducing emissions more powerfully than 100 scientists and their climate projections. Until large numbers of people become seriously frightened by climate disasters, it seems we will never achieve enough on emissions reduction. Yet disasters cannot be summoned on command. We are reckless to entrust the fate of the planet to the spontaneous advocacy of catastrophes.

Muir-Wood 2016, 248

\subsection{Introduction}

The concept of resilience has become increasingly fashionable across domains: from natural disaster preparedness and athletic performance to infrastructure design and youth psychology. As well, the term resilience is no longer isolated to specialized fields, such as ecosystem conservation or national counterterrorism. Yet, there is a lack of consensus as to what the term actually means and, conversely, if a narrow definition could be useful at all. As Fisher warns, "One could easily become confused about what resilience is and how it is done because of the different ways in which it is articulated and given meaning" $(2016,33)$. This lack of common agreement is all the more pronounced as the sum of people, places, things and processes that can be imagined to be, or aspire to become, 'resilient' steadily increases. Moreover, there is a decisive lack of unanimity as to where the term originated-carrying confusion as to the term's politics and political standpoint — or what the effects of relying on the term could be. Brand and Jax (2007) have described resilience as a 'boundary object', one that "facilitates communication across disciplinary borders by creating shared vocabulary although the understanding of the parties would differ regarding the precise meaning of the term" (23). They mobilize 
Star and Griesemer's (1989) idea of a boundary object, originating from the STS field, to make sense of the simultaneous expansion in the use of the concept of resilience without a resulting hardening of a definition. As a boundary object, resilience has different meanings for various users while allowing for communication between various disciplines. Strunz (2012) offers a similar perspective when calling resilience 'polysemous', meaning the concept has many closely related meanings, which allow it to be fluid and - potentially—useful in contexts dealing with societal stakeholders. Pickett, Cadenasso and Grove (2004) show the metaphorical value of the 'fuzziness' of the concept, while Thorén and Persson (2015) show how resilience is both defined ostensively (identifying something in the world) as well as stiputively (highlighting a distinction).

These accounts highlight the fluidity found in the use and application of resilience. This fluidity offers scholars and practitioners opportunities to mobilize and mutate the term within projects as they see fit. The problem, then, is how do actors do that? Accounts that point to definitional and applicative fluidness of resilience fail to show the work that has gone into the successive mutations of the concept. Brand and Jax (2007), for instance, take the end result of a series of negotiations performed by actants as their clue that the term effectually operates as a boundary object. What is missing is an account of the strategies, tactics, moves, and countermoves that render resilience as a concept mobile and, as such, productive. Likewise, the social context from which articulations of resilience have emerged is often lacking. This chapter offers a rich descriptive account of how actors have interacted with the concept of resilience, revealing the career of the concept and the various effects produced by series of translations and negotiations. 
From the philosophy of science perspective, Thorén (2014) notes a distinction between the concept of resilience and what has been termed 'resilience thinking' or 'resilience theory' (308). These concepts are presented as being related to "a resource management approach and a view of the world that is not necessarily tied to scientific discourse and academic institutions" (Strunz 2012, 113). The search for definitional clarity of resilience has, at times, shown that distinguishing between articulations is beneficial to the term's application. Brand and Jax (2007), for example, did list thirteen distinct definitions of resilience to illustrate the concept's general applicability despite its ambiguity. Throughout this work, my treatment of resilience's associative concepts differs. I include articulations of resilience thinking and resilience theory in the career of the concept of resilience, a move that forces us to think through how resilience has been deployed as a fluid category rather than as a descriptor of a particular end result or terminal state. For example, as we will see, resilience theory has become tied to academic institutions in the form of 'centres of resilience calculation' where attempts are well underway to develop resilience metrics. These centres act as nodes in the resilience network, serving to expand and create new relationships in the field of resilience, regardless of which definitions particular actants are using.

This chapter also provides a historical overview of the concept of resilience. I focus on sites and developing networks of actants - both human and nonhuman. I focus on various definitions and engagements of the concept of resilience across and within key disciplinary fields. Through these engagements, key actants become enrolled in the creation of a network of truth related to the concept of resilience. The following is not meant to be a comprehensive genealogical portrait of resilience. Rather, I show the 
multiple ways that the concept of resilience has emerged, has been applied or has been left to the wayside. The overall impression I aim to convey is that, parallel to resilience's long and debated history, its network of allies and spokespersons has steadily grown. Understanding what has informed the narratives associated with resilience will help us make sense of its subsequent applications.

I will begin by briefly tracing resilience's etymological roots, after which I offer a reading of resilience within the fields of material sciences, psychology, ecology and what have become known as 'bridging' disciplines. I then apply the conceptual notions of 'centres of synthesis' and 'centres of calculation' to help make sense of how resilience has proliferated institutionally, attracting lucrative research funding packages in the process. I conclude by acknowledging the expansiveness of the resilience metaphor, including in the lexicon of the everyday.

\subsection{Etymological Roots}

The term resilience stems from several post-classical Latin roots, the most prominent being that of resilientia, which is closely associated with avoidance and can be identified as early as 1540 in texts (Rogers 2012,142). Later in its emergence this root became associated with the action of rebounding or recoiling, stemming from the Latin intransitive verb resilire, to resile: "recoil, rebound, resume shape and size after stretching or compression; have or show elasticity or buoyancy or recuperative power" (Almedon \& Glandon 2007, 129). Klein, Nicholls \& Thomalla (2003) have traced the term to resilio, and the Latin root of the French verb has been associated with resiliere (Paton \& Johnston 2006). 
In 1625, Francis Bacon published his writings on natural history in Sylva Sylvarum. The text contains what is considered to be the first scientific use of resilience. Bacon used the concept to translate his observations on echoes, leaning on the term's imagery of 'bouncing' or 'rebounding'. This imagery was extended in one of the first known dictionary entries for resilience that can be found in Thomas Blount's 1618 Glossographia. Here, the term carried a double meaning: to rebound and to go back on one's word. Blount's 1656 edition went through several iterations and was "imitated by eighteenth-century authors (whose works also included the term resilience) on both sides

of the Atlantic, but the Glossographia faded into obscurity with the publication of more authoritative lexicons" (Alexander 2013, 2709). These modernized lexicons, for the most part, left the imaginative concept of resilience aside in favour of more practical ways of defining movements.

\subsection{The Material Science of Resilience}

The imaginative and metaphorical deployments of the concept of resilience that appeared in the 17th century paved the way for the concept's re-emergence among proto-physicists and engineers during the 19th century. In 1818, for example, Thomas Tredgold used the term to describe the properties of certain species of wood in On The Transverse Strength and Resilience of Timber. In this essay, Tredgold identifies a problem with the availability of oak wood for the construction of military vessels. Demand far exceeded the availability of the hardened wood for the British. As such, Tredgold identifies larch wood, known in Canada as Tamarack or Juniper, as the most acceptable substitute to oak. The wood's "strength, toughness, or elasticity" (215) was not inferior, at least according 
to Tredgold. In fact, larch trees planted in the worst soils and the most exposed environments "have thriven the best" (214) according to Tredgold. He knew all too well that his audience required proof of such claims. He conducted a series of experiments on a variety of types of wood, demonstrating that larch "is best adapted to resist the force of a body in motion" (215). By producing a series of tables claiming properties of wood, Tredgold advanced that "larch is superior to oak in stiffness, in strength, and in the power of resisting a body in motion (called resilience)" (216). The elastic but durable material would be fitting for military vessels.

Three years later in The Philosophical Magazine and Journal, the same journal in which Tredgold's essay appears, a report of the "elasticity of the lungs, and mechanism of respiration" was published (Murray 1821, 279). Between 1817 and 1819 James Carson conducted a series of experiments aimed at determining the properties of lungs. "Breathing," the author contends, "is an "interminable combat between the resilience of the lungs and the irritability of the muscular fibre of the diaphragm" (279). Breathing is equated to the movement of pistons, metaphorically recalling the power of the steam engine: breathing is construed as a series of oppositional movements, the body acting and reacting in an exchange of force. "The continual attacks of the exhaustless," the article concludes, "though weaker, assailant rouse the more gigantic, but intermittent, repellent energies of its opponent. It is a war offensive and defensive. Thus does the contest continue for life with equal success, and at its close remain a drawn battle" (280). In this imaginative anatomical representation, the piece extols a double sense of resilience: as physical characteristic, on the one hand, and as essential for survival on the other. Carson did not want to show that lungs were simply elastic, he wanted to show how "nature had 
contrived to render it subservient to the purposes of life": how resilience is rendered useful (Carson 1820, 29). Anatomically and materially, there emerged a conceptual divide between resistance and resilience. Use of the term resilience, meanwhile, was obdurately associated with these two spheres.

During the early 1900s, the use of the term resilience became most pronounced within the fields of mechanical and civil engineering. Almost all materials could be associated with, or at least measured for, their inherent resilient properties. Cast iron, wrought iron, steel, rubbers, brick, stone and so forth, all became objects worthy of study. In 1907, for example, the study of the resilient properties of materials earned an entire chapter in a textbook marketed to manual training schools (Merriman 1907). The 'I' and ' $\mathrm{T}$ ' beam, commonly used when joisting buildings, became a fundamental component of material resilience investigation. The maximum pressures that such designs could withstand under particular conditions needed to be known; the resilience measure differed from that of strength and stiffness, which could also be calculated mathematically. Heat, too, became a fundamental element against which resilient materials would be measured, especially rubber compounds. "A resilient piece of rubber," the Vanderbilt chemical company tells us, "is said to have 'snap' or a 'fast' comeback" (Rogers 1948, 66). Expressing resilience was not practically straightforward, however. The company suggested the use of a Goodrich Flexometer to measure and, perhaps more importantly, express resilience in standardize units of energy. Expressing the resilience of certain rubber compounds to various amounts of heat meant that industries could select appropriate materials for particular applications. Tires, belts, hoses, insulation for wires and tubes, footwear, and even latex were measured and given 
more or less standardized resilience scores. Soon, the term resilience started to gain fervour outside of the engineering domain.

In 1919, Napier Shaw and Elaine Austin, in a multi-volume treatise on meteorology, used the term resilience to refer to the interaction of air and water, as well as to interactions within the atmosphere and the resulting conditions. For Shaw and Austin, "water-vapour is the agent which nature uses to attack the resilience of an entropic layer, and weather is the result of the interminable play between the resilience which depends on entropy and the penetrating force which comes from the condensation of water" $(1919,302)$. Here, the effects of forces acting upon each other within the atmosphere hinge upon the resilience of one component. Already, Shaw and Austin showed that "we can no longer look upon it [the atmosphere] as a single homogenous mass" (302). Recognition of the heterogeneousness of natural elements that interact, play, negotiate and simultaneously coexist are found in this rather banal 1919 publication. Crawford S. Holling and others further advanced this idea of resilience, particularly within an engineering resilience framework.

Throughout the mid-twentieth century, the concept of resilience continued to be applied to the fields of material science; in particular, to textile manufacturing. It "was so frequently used that it prompted specific conceptual discussion and disambiguation" (Thorén \& Persson 2015, 68). In 1948, R.M. Hoffman proposed a generalized concept of resilience to rectify the multiple meanings of the concept floating around. He stated that the many meanings of resilience created a paradox "because they are all at least partially true but, at the same time, inconsistent" (141). Hoffman advanced that resilience should be defined "as the capacity of a substance to return to its original state at some later time 
after the removal of a deforming stress" (141). Hoffman's observations about the truth claims regarding resilience resonated throughout the twentieth century as the concept moved through the niche research wings of fields such as positive psychology and ecology (see, for example: Rutter 1985; Bonanno et al. 2007; Herrman et al. 2011; Holling 1973, Gunderson \& Holling 2002).

\subsection{The Positive Psychology of Resilience}

Resilience within psychology owes its beginnings to child development studies, particularly in research exploring how some youth 'bounced back' to overcome adversity while others did not. Werner and Smith (1982) neatly capture this dynamic with a study titled Vulnerable but Invincible. Historically, within the field of psychology, the concept of resilience came to replace the concept of 'invulnerability'. Psychologists have tended to use the term around three sets of articulations: meeting developmental goals in spite of adversity; sustained competence under stress; and, the ability to recover following trauma. Successive deployments of resilience have tended to focus on individual attributes and capacities, showcasing psychology's dominant trope of feedback loops. The following examples illustrate this:

\begin{tabular}{|l|l|}
\hline \multicolumn{1}{|c|}{ Definition } & \multicolumn{1}{|c|}{ Reference } \\
\hline $\begin{array}{l}\text { The capacity for successful adaptation, positive functioning, } \\
\text { or competence despite high-risk status, chronic stress, or } \\
\text { following prolonged or severe trauma. }\end{array}$ & $\begin{array}{l}\text { Egeland, Carlson } \\
\text { \& Sroufe, 1993 }\end{array}$ \\
\hline $\begin{array}{l}\text { Good adaptation under extenuating circumstances; a recovery } \\
\text { trajectory that returns to the baseline functioning following a } \\
\text { challenge. }\end{array}$ & $\begin{array}{l}\text { Butler, Moreland } \\
\text { \& Leskin, 2007 }\end{array}$ \\
\hline $\begin{array}{l}\text { Adult capacity to maintain healthy, symptom-free } \\
\text { functioning following potentially traumatic events. }\end{array}$ & $\begin{array}{l}\text { Bonanno et al., } \\
2007\end{array}$ \\
\hline Capacity for successful coping. & $\begin{array}{l}\text { Cederblad et al., } \\
1994\end{array}$ \\
\hline $\begin{array}{l}\text { Possession of selective strengths or assets to help an } \\
\text { individual survive adversity. }\end{array}$ & $\begin{array}{l}\text { Connor, Davidson } \\
\& \text { Lee, 2003 }\end{array}$ \\
\hline
\end{tabular}




\begin{tabular}{|l|l|}
\hline $\begin{array}{l}\text { Ability to sustain normal development despite long-term } \\
\text { stress, adversity, or maltreatment. }\end{array}$ & $\begin{array}{l}\text { Friborg et al., } \\
2003\end{array}$ \\
\hline $\begin{array}{l}\text { Emotional stamina, a characteristic of people who display } \\
\text { courage and adaptability in the wake of life's misfortunes. }\end{array}$ & Wagnild \& \\
Young, 1993 \\
\hline $\begin{array}{l}\text { The process of, capacity for, or outcome of successful } \\
\text { adaptation despite challenging or threatening circumstances. }\end{array}$ & $\begin{array}{l}\text { Masten, Best \& } \\
\text { Garmezy, 1990 }\end{array}$ \\
\hline
\end{tabular}

Table 1 Sample of common definitions of resilience within psychology

The goal within psychological literature has often been to locate 'protective' factors, or protective mechanisms (Rutter 1987). In switching focus to how individuals thrive, by asking 'what works' rather than by adopting a disease model of human behaviour, positive psychology has further expanded the vocabulary and understanding of resilience. Indeed, Martin Seligman, considered to be one of positive psychology's 'founding fathers', promotes resilience as a behavioural adaptation tool that can be learned (2011, $\mathrm{n}$. p.).

The fervour generated by positive psychology has led to a number of popular books on resilience that are typically found on the self-help shelves of bookstores. Titles like The Resilience Factor (Reivich \& Shatté 2002), Resilience: Why Things Bounce Back (Zolli 2013), The Power of Resilience (Brooks \& Goldstein, 2004) or 21 Days to Resilience: How to Transcend the Daily Grind, Deal with the Tough Stuff, and Discover Your Strongest Self (Montminy 2015) point to resilience as a viable, transformative way to live better lives. After winning several prizes for Bouncing Back: Rewiring Your Brain for Maximum Resilience and Well-Being (2013), Linda Graham published a follow-up book titled Resilience: Powerful Practices For Bouncing Back From Disappointment, Difficulty, And Even Disaster (2018). Overcoming personal hardships through introspection and solitary daily exercises has indeed led to a cottage industry of self-help gurus and purported 'resiliency experts'. The topic of resilience has also captivated the editors, and, presumably, the readers, of the Harvard Business Review. An entire issue 
devoted to resilience appeared in 2011, including a contribution and a guest appearance on the magazine's podcast by Martin Seligman. The concept was also central in a series on emotional intelligence in 2017. In these deployments, resilience is summoned as a viable way to "immunize people against learned helplessness, against depression and anxiety, and against giving up after failure": in short, teaching us, "to think like optimists" (Saligman 2011, n.p.). Positive psychology's focus on bouncing back and not giving up should not be read as a philosophy of resistance, however. The conditions of possibility offered by positive psychology's resilience-building efforts are more focused on one's ability to navigate circumstances rather than to attempt to effect social or structural change. This signals positive psychology's stance on practice.

One narrative that is often reproduced and appealed to within popular positive psychology works is one of fostering resilience over time and through systematic practice. For example, in 2014, Time published an article entitled How to Be Resilient: 8 Steps to Success When Life Gets Hard (Barker 2014). Of note is the third recommendation: "be a quitter". The article touted the advice that "you quit baseball when you were 10 and quit playing the piano after just 2 lessons. Nobody sticks with everything. You can't." The article pivots from childhood learning to political economy, stating, "When the company starts laying people off, there's always one guy smart enough to immediately jump ship and pre-emptively get a new job." As once stalwart sectors of national economies crumble, the advice may resonate those who face increasingly precarious employment terms. Relatedly, the Time article suggests: "Some people are smart enough to realize, 'I am never going to be a great Tango dancer and should double my efforts at playing poker"'. The bet is actually that resilience can 
increase happiness, reduce stress, and better our overall health.

Two years later, Time continued to extol the self-help form of the resilience narrative in a digital piece entitled How to Develop a Psychology of Resilience (Meier 2016). Once again, one of the piece's main recommendations was to adopt an attitude of disengagement, this time through, "a mindless activity like coloring or watching TV" (Meier 2016). The author makes the point that disengagement is not for relaxation or as a pastime, but rather as a means to repress potentially negative emotional disturbances. Maria Konnikova (2016), writing for The New Yorker, traces resilience within positive psychology by showing readers that the idea of the link between resilience and happiness has strong empirical support from the discipline of psychology. In example after example, resilience is linked to how we can better ourselves. This version of resilience is plugged into the happiness industry, offering techniques and strategies to increase our wellness through "silent relationships to the self, rather than vocal relationships to each other" (Davies 2015, 273). Be it through meditation or colouring, the goal of this kind of 'resilience thinking' is to "become more flexible and able to deal with [adversity], move on, learn from it, and grow" (Konnikova 2016, n.p.).

Within these narratives, resilience is summoned as an analogy or metaphor for resourcefulness, the ability to 'bounce back' following traumatic events, certain 'buffer capacities' of organisms, the ability to overcome adversity and an ability to 'absorb perturbations' (Adger 2000, 349; Folk 2006; Hart, Blincow \& Thomas, 2007). Literature on resilience distinguishes between resistance and bouncing back, the former conceptualized as blocking disruptions, while the latter is seen as the capacity to recover from shocks or perturbations (MacKinnon \& Derickson 2012). The latter is favoured by 
proponents of the term and takes on an aura of adaptability. Resilience thinking presupposes that resistance does not foster recovery in that the prior position, orientation, or disposition of things and people remains unchanged. Adaptability, for resilience thinking, means changing positions so as to embrace stressors and foster flexibility. The question of social change is thus circumvented, prioritizing personal growth and malleability.

\subsection{The Ecological Side of Resilience}

Within the field of ecology, during the 1950s and 1960s, resilience can be found alongside other terms: 'resistance', 'persistence', 'constancy', 'hysteresis', 'elasticity', etc. In more recent ecological work, Volker Grimm and Christian Wissel (1997), for example, list 70 different 'stability' related terms, and 163 associated definitions. As Thorén notes, "The semantic diversity here is considerable" (2014, 305). Nevertheless, the uptake of the concept of resilience led to two common usages. First, there is the 'return to a reference state after disturbance'. This usage was advanced by Stuart Pimm (1984) and the notion underpinning this articulation was sometimes appealed to alongside other key terms of the era. Kristin Shrader-Frechette and Earl McCoy $(1993,33)$ call it ‘dynamic balance', Holling (1973) called it 'stability', and later 'engineering resilience' and 'ecological resilience' (Holling 1996; Holling \& Gunderson 2002). It is the latter concepts that were embraced within ecological literature and indeed defined ecological thinking for most of the $20^{\text {th }}$ century. This way of understanding resilience focused on stability. Resilience from this view engages global equilibria of systems. Here, authors have focused on the time needed for a system to return to a steady state after a shock or 
perturbation (Ives 1995; Mittelback et al. 1995; Pimm 1991). Holling's engineering resilience reflects the motivation, also found the field of engineering, to design systems with, "single operating objectives" (Gunderson 2000, 426). From this perspective, there is only ever one steady state of a system. If other states exist, "They should be avoided by applying safeguards" (Gunderson 2000, 426). According to Gunderson, this definition of resilience extended beyond ecology into fields such as physics, material engineering and control system design (2000).

The second way that resilience has been approached within ecological frameworks is by acknowledging the existence of multiple states of equilibrium. Here, shocks, perturbations and instability can actually force systems into another steady state entirely. From this perspective, "Resilience is measured by the magnitude of disturbance that can be absorbed before the system redefines its structure by changing the variables and processes that control behavior" (Gunderson 2000, 426). This perspective has been called 'ecological resilience' (Holling 1973; Walker 1981). The key difference between the two models lies in how they view multiple stable states. As Thorén notes, "The language of 'resilience' in ecology should be understood in the context of the debate over the stability-diversity thesis, i.e., the idea that diversity and stability are positively covariant" $(2014,305)$. While the field of ecology was not always concerned with the ways in which things bounce back, the concept of resilience within the field can be directly attributed to Holling's work. More importantly, the enduring notion of ecological resilience is attributed to Holling.

While engineering resilience focuses on a system's core operating variables and the time required to regain these conditions after a disturbance, ecological resilience takes 
stock of how a system can adapt, change and actually create new conditions and parameters. The metaphor of balls and cups is often used to express how resilience is measured within the ecological resilience framework. The ball represents the system, the valleys of the cups represent stability domains or system states and the slopes represent the stability landscapes, what keeps things stable: resilience. When a shock or disturbance shakes the ball, the measure of resilience is expressed as the length of slope that keeps the ball from bouncing to a new valley. The possibility of multiple valleys, or, new system states, is the key difference between engineering resilience and ecological resilience.

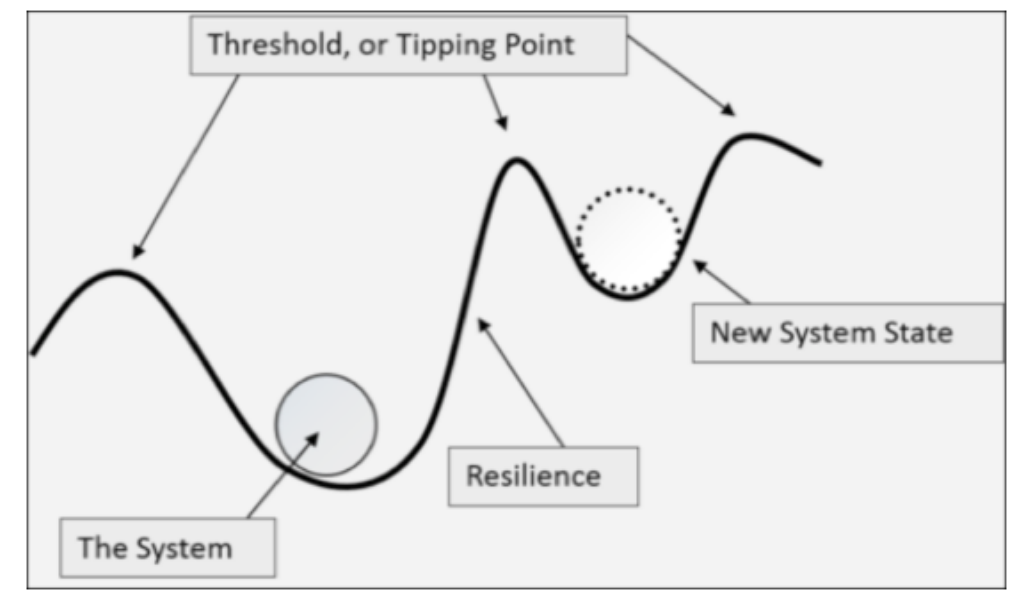

\section{Illustration 5 Ball and cup heuristic of system stability}

Image source: http://www.conservationofchange.org/resilience/

Resilience research from an ecological heritage is rooted in post-positivist epistemology and seeks to render systems thinking/theory applicable to complex interactions. "Concepts of resilience are used to describe the relationship between the system under observation and externally induced disruption, stress, disturbance or crisis," Lang $(2010,16)$ tells us. In a more general sense, Lang continues, "Resilience is about the stability of a system against interference." The vast majority of this literature adopts 
the understanding that resilience implies more than simply shaking-off perturbations, however. It requires an awareness of being which is highly relational. Holling captured this aspect of resilience as early as 1978 , stating:

however much we may be sure of the stability landscape of a physical system, rarely will we know the societal or ecological stability landscape in great detail. Policies often attempt to reduce variability within these partially understood systems, either as a goal in itself or as an effort to meet standards of safety, health, or environment. That changed variability in turn may itself shift the balance of natural, cultural, or psychological selection so that stability regions will contract. Paradoxically, success in maximizing the distance from a dangerous stability boundary may cause collapse because the boundary may evolve to meet the variables. That is, if surprise, change, and the unexpected are reduced, systems of organisms, of people, and of institutions can 'forget' the existence of limits until it is too late" (Holling 1978, 104).

As Evans and Reid (2013) point out, resilience ontologically hinges on vulnerability in that "to become resilient, one must first accept that one is fundamentally vulnerable" (84). Such vulnerabilities are expansive: our bodies, our minds, our built environments, our socio-technical systems. The list is endless and is grounded within an ethic of care, carried by a set of valuations. What becomes vulnerable are elements that have a certain emotional proximity and attain a level of value which, if altered, would result in a corresponding sense of loss. Zebrowski (2012) echoes this sentiment, interpreting resilience as a value within contemporary liberal security arrangements such as civil contingency planning.

In summarizing the key differences between engineering resilience and ecological resilience, Gunderson ${ }^{21}$ reminds us that, "no single mechanism can guarantee maintenance of resilience" $(2000,436)$. For Gunderson, social resilience is attained by

\footnotetext{
${ }^{21}$ It is worth signaling that Gunderson's paper from which I take these excerpts was supported by a grant from the John D. and Catherine T. MacArthur Foundation and was a contribution to the Resilience Network. Gunderson's comments on social learning and a focus on capital and skills must be read against the backdrop of this connection to the philanthropic sector.
} 
focusing on learning and understanding cross-scale interactions (2000). In other words, resilience needs to be social and relational. Furthermore, Gunderson positions learning, trust and engagement as key aspects that need to be integrated into any serious attempt to build resilience. "Social learning," Gunderson's thinking goes, "is facilitated by a recognition of uncertainties, monitoring and evaluation by stakeholders" $(2000,436)$. As such, resilience is attainable by "focusing on keystone structuring processes that cross scales, on sources of renewal and reformation, and on multiple sources of capital and skills" $(2000,436)$. As we will see, these remain the hallmarks of how resilience is being done and are the foundation of what I have called philanthropic resilience.

\subsection{Bridging Disciplines}

The resilience discourse has entered a phase characterized by discipline bridging, as well as inter/intra-disciplinary. While these are relatively new developments in the way in which the resilience form has circulated, it was a key component to the resilience framework proposed by the likes of Lance H. Gunderson, Crawford S. Holling, and others during the 1970s and 1980s. In their attempts to craft a general theory of change, Holling and Gunderson wished to fill disciplinary gaps, chiefly within sustainability studies, with theories of resilience. They advocate that theories that ignore the concept of resilience were too "simple" and lacked "an integrative framework that bridges disciplines and scales" (Holling, Gunderson \& Ludwig 2002, 8). Others have gone further, emphasizing that resilience carries a broad appeal that cuts across the social and natural sciences. Charles Perrings, for example, notes that: while the notion of system resilience has its roots in ecology, it is concerned with something that is common to any 
stochastic evolutionary system - the effect of the stability domain structure on the system's dynamics. These matters are currently attracting attention in a variety of different fields within economics, and in a variety of different disciplines (Perring 1998, 511 in Thorén 2014, 304).

From the cross-disciplinary work being done, two overarching resilient forms-we may call these meta-forms - are identifiable: one cognitive and emotive, the other structural and "a kind of systemic property" (Lang 2010, 16). In Chapter 5, we will see that both of these forms are present in the work carried out by Chief Resilience Officers, at, for example, the municipal level. Both forms of resilience are appealed to when negotiating the preservation of local infrastructure or when seeking capital to rebuild following a catastrophic event. It is in this way that the contours of resilience are rendered smooth and has led to its omni-situatedness. The work of making the boundaries and contours of the resilience discourse disappear has resulted in the ability to apply the term across and within a variety of settings, fields, and people.

Building on this dual characteristic of the resilience form, Lentzos and Rose (2009) note the concept's suppleness and enveloping use: "Resilience implies a systemic, widespread, organizational, structural and personal strengthening of subjective and material arrangements so as to be better able to anticipate and tolerate disturbances in complex worlds without collapse, to withstand shocks, and to rebuild as necessary" (243). The deployment of the concept without recognition of its formative value has been somewhat problematic, however. Within the field of rural sociology and within the context of community capacity building, for example, investigations of resilience have been primarily informed by functionalist and static institutional accounts, generally 
lacking political, social and historical specificity (Cote \& Nightingale 2011; Davidson 2010; Keck \& Sakdapolrak 2013). This has led some to question the place of agency, structure, culture and power within community resilience thinking and programs (Berkes \& Ross 2013; Davidson 2010, 2013; Ross \& Berkes 2013). These dissident voices are equally part of the network that has formed around and is extending the concept of resilience into new fields and new applications.

As we have seen, resilience carries multiple definitions for a variety of actors. This characteristic has led some analysts to call resilience a 'unifying concept' (see, for example Gunderson \& Pritchard 2002, xxi). Thorén (2014), in particular, has advanced that while the resilience discourse cuts across disciplinary fields, the unification work done by the concept of resilience is attributable to its abstract application. The context insensitivity that accompanies abstract deployments of resilience "comes at a price, since the unification that ensues is often relatively weak" (304). This critique of the empirical applicability of resilience has not, however, stopped empirical research that bridges disciplines. I contend that it is precisely context insensitivity and abstraction that have enabled large research programs, premised on the concept of resilience, to flourish.

\subsection{Centres of Synthesis and Calculation}

Parallel to analytical and practical developments, we have witnessed the growth of resilience 'synthesis centres' (Hackett \& Parker 2016) and 'centres of calculation' (Latour 1987). In the discipline of ecology, the Stockholm Resilience Centre is a transdisciplinary research institute that operates as a hub for conferences, publications and data sharing. Launched in 2007, the Centre is a joint initiative between Stockholm 
University and the Beijer Institute of Ecological Economics at the Royal Swedish Academy of Sciences. Carl Folke is the co-founder of the Centre, as well as, at the time of writing, its chair. In 2016, according to Clarivate Analytics (a division of Thomson Reuters), Folke is among the most highly cited researchers in the world, having published more than 200 peer-reviewed articles, many books and book chapters, and he sits on the editorial boards of more than 10 peer-reviewed journals. Most of Folke's work deals with ecological resilience. The Centre is in fact a spin-off of the Resilience Alliance. The Institute of Social Innovation at Waterloo University, headed by Frances Westley, is another Resilience Alliance derivative. The link between Folke, the Stockholm Resilience Centre and The Institute of Social Innovation lies with Crawford Stanley (Buzz) Holling.

As we previously saw, Holling is considered a pioneer in the field of ecological resilience. His notoriety in the field was not accomplished solely on account of his publications. Holling was a key figure involved in establishing and expanding the resilience field through centres of synthesis. During the 1990s, Holling and several others formed the Resilience Project. Backed by private funding from, among others, the MacArthur Foundation, and working independently, a small group of ecologists (5 at most, including Holling) all sought to "answer the question: 'were there common rules or a common language that guided a few dozen different ecosystem examples?'” (Holling 2017, 71). After having published over 100 articles and four books, the Resilience Project was deemed to be a successful synthesis, leading Holling to jump-start the Resilience Alliance. In 1997, its six founders ran the Resilience Alliance: Brian Walker, Carl Folke, Lance Gunderson, Steve Carpenter, Phil Taylor and Holling. Many of these names appear again and again within the resilience literature. Built on private capital grants from the 
McArthur Foundation, the Ford Foundation, the Rockefeller Foundation and others, the Resilience Alliance eventually acquired a peer-reviewed journal—the Journal of Ecology and Society — and benefited from a paying membership base of around 20 institutions. The Resilience Alliance formed a network and acted as a centre of synthesis around questions of resilience and ecology with over 100 researchers across 9 countries. In his 2017 memoir, Holling describes the process of forming the Resilience Project and the initial work that went into creating the Resilience Alliance. A key focus of Holling's reflections is financing. How does one find money to start an international network? It's a good question. Holling offers some advice, based on lessons learned, that include things like make sure membership dues are as low as possible, use the internet but also have face-to-face meetings in fun places, build a fun culture, don't own anything, and so forth. One piece of advice does stand out more than the others: Holling advises on the need to "get flexible money...but never from government sources, which I found to be too fearful, or too jealous of innovation and gambles, or too stretched by competition for limited funds" (2017, 76). From at least the 1990s, resilience and philanthropy shared mutual interests. In Chapter 5, I will investigate this relationship further. For now, I want to highlight two other centres of calculation that have benefited, at least in part, from government as well as private sector sources of funding.

In Canada, the Resilience Research Centre housed at Dalhousie University promotes a socio-ecological conception of resilience in its documenting and dissemination work that is partly funded through the Social Science and Humanities Research Council. From 2003 to 2005, the centre operated 'The International Resilience Project', headed by Michael Ungar (see Ungar 2003; 2004; 2005; 2007; 2012). The project produced a 
resilience assessment tool, the Child and Youth Resilience Measure (CYRM), essentially a questionnaire that could assess one's level of resilience (Liebenberg, Ungar \& LeBlanc 2013). In addition to its metrological contribution to resilience thinking (Ungar 2003), the project attempts to expand and combine suitable methodologies for resilience research such as using visuals during interviews (Liebenberg 2009), video and photo elicitation (Liebenberg, Ungar \& Theron 2014), grounded theory and narrative inquiry (Lal, Suto \& Ungar 2012), and visual data and grounded theory (Liebenberg, Didkowsky \& Ungar, 2012). The Centre went so far as to suggest that social workers rewrite narratives in the form of a novel, advancing the benefits of a fictionalization of resilience (Ungar 2011).

Conglomerate centres have also begun to develop in the field of civil engineering. For example, in 2014, the US Department of Commerce's National Institute of Standards and Technology (NIST) announced a \$20 million award to Colorado State University to establish the Community Resilience Center of Excellence. The Center is a partnership between 10 research universities and seeks to "accelerate the development of systemlevel models and associated databases to support tools that will help local governments decide how to best invest resources intended to lessen the impact of extreme weather and other hazards on buildings and infrastructure systems and to recover rapidly in their aftermath" (NIST 2014). Tulane's University Disaster Resilience Leadership Academy (DRLA) is another example of a multidisciplinary centre of resilience calculation that combines elements of psychosocial and behaviour sciences and disaster studies. Benefiting from a US\$5M grant from the Bill and Melinda Gates Foundation in 2012 to develop curriculum and a common resilience building training program, the DRLA created a network of twenty universities across eighteen countries to "foster knowledge 
creation, exchange, collaboration and resource sharing" in the field of leadership resilience (DRLA n.d.).

Within these centres of calculation, we witness the coalescing of philosophical explorations and practical applications of the concept of resilience. The legitimacy that these centres have enjoyed as a result of reputational prestige has aided the diffusion of their versions of resilience. Narratives of resilience stemming from Ungar's work, for example, are prominently cited within and outside the fields of psychology; Ungar himself is habitually referred to as a pioneer in the field of resilience research across the social sciences and humanities. Similarly, DRLA's executive director, Ky Luu, is credited with crafting a model of resilience building leadership training that other institutions ought to replicate, within the United States and worldwide (see for example, Rodin 2014, 130). Before joining the DRLA, Luu held prominent positions within the Office of US Foreign Disaster Assistance, USAID and the Centre for Disaster Philanthropy, as well as being the principal investigator on grants related to resilience building tallying more than US\$38.7M. Holling, Folke, Westley, Ungar, Luu, and others have capitalized on associational prestige and professional expertise to further expand the influence of centres of resilience synthesis and calculation. As such, these centres play an important role in expanding the resilience network.

\subsection{Excavating the 'Resilience of Resilience'}

In the twenty-first century, resilience has entered the lexicon of the everyday. It would be difficult to read print news and not encounter the word; it is near impossible to avoid the almost daily usage of the concept on media outlets. Resilience resonates with politicians, 
bureaucrats, academics, and even cultural products. Resilience was the chosen title of a 2002 Law and Order: Special Victims Unit episode that followed the trail of a suspicious youth suicide that was linked to the stressors of sexual assault. Barack Obama, subsequent to the Boston Marathon explosions, proclaimed that the city "is a tough and resilient town" (Time 2013). Boston, unlike the fictional departed youth, could recover. "Resilience" is also the title of several films, including one that apparently depicts a man "caught between resilience and ruthlessness" (IMDB 2014a), and another offering a mother-son story of reunion after spending 30 years living in different countries. Emotional ruptures run parallel to spatial ruptures and, presumably, capture an audience. I have seen neither.

It is difficult to find a contemporary policy document that does not refer to resilience in some fashion. Public Safety Canada proclaimed in a deliberately titled report that the department is Building Resilience Against Terrorism (Public Safety Canada 2013). Within the context of climate change, the World Bank is Building Urban Resilience in East Asia by offering "practical tools for risk assessment that can be used for city-level investment decisions" (2013, xiii). The Scottish government has created a Resilience Division intended to "support the front line agencies that deliver emergency planning and response" (Scottish Government 2015). The U.S. Army has deployed a resilience-training component as part of their Comprehensive Soldier and Family Fitness program. In 2012, USAID published Building Resilience to Recurrent Crisis a policy and program guidance document for building resilience; and, in 2018 the United Nations Office for Disaster Risk Reduction produced a Words Into Action guideline document intended "to advise local governments (authorities, planners and managers at city or other subnational levels) 
on developing and implementing a holistic and integrated [disaster risk reduction] (DRR) strategy that contributes to building resilience at the local level" (UNDRR 2018, 8). The list could go on.

The historical expansiveness of the concept of resilience is also one of its hallmarks. Thorén (2014) notes that, according to the Web of Science, the number of published works containing resilience in the titles has exponentially increased since the 1980s. In 1993, for example, 60 published papers contained the term resilience, compared to close to 800 by 2013. Thorén's (2014) conclusion that this uptake is due, in part, to an uptake of its usage across many fields including sociology, anthropology, economics, history, urology, urban studies, materials sciences and so forth. This is further confirmed when extending a search for the term's use. Using Scopus, a search for published academic material between 1990 and 2016 yielded 166,298 results. Approximately $25 \%$ of these publications were produced from within the social sciences. Google Scholar returned over 667,000 results for the same period, of which more than 51,200 were published between 2015 and 2016 alone. According to the database PsycINFO, between 1997 and 2017 10,927 peer-reviewed articles were published with the term resilience in either the title or abstract. This number can be compared to Steven Ward's (1996) analysis for the concept self-esteem between 1967 and 1994, which yielded 7,479 articles. Finally, if Google is any indicator, there are over 47 million websites using the term. The word 'sociology' produces almost 84 million, while the word 'god' is found on almost 1.4 billion websites. Of course, these are not exact representations of the usage of the concept of resilience. It would be almost impossible to capture its frequent usage colloquially or in texts that circulate outside of searchable databases. These figures, however, do indicate 
the magnitude of its usage.

As analogy, metaphor, organizing principle or governmental aim the concept of resilience has become something of an 'immutable mobile' (Latour 1986b): its translatability to diverse contexts without a corresponding loss of the concept's inherent characteristic has been quite remarkable. Perhaps we should come to speak of resilience itself as a 'resilient mobile'? Of course, someone beat me to that punch. Simon and Randalls (2016) declared, "The resilience concept has demonstrated its own extraordinary resilience". Fisher's stylization is more poignant, "the resilience of resilience" $(2016,32)$. However, as Zebrowski (2016) reminds us that "in practice, the meaning(s) of resilience continue to escape the categorical structures developed by academics. But if resilience cannot be defined, this does not mean it does not make sense" (6). The lack of consensus surrounding definitions of the concept of resilience has not prevented its application, mutation and travel. In fact, urban resilience policy has relied precisely on the concept's elasticity and mobility to garner legitimacy; by being able to compress and extend how resilience is understood, municipalities have been able to adapt the concept to fit local issues.

We must be careful not to grant the narrative of resilience exclusive agency over its mutability. It is, after all, a series of actors who adopt, play with, deploy and adapt the resilience narrative and metaphors as they see fit. The question then, for a critical exploration of resilience, becomes: How can we bring actors back into the resilience paradigm, while retaining a focus on the metaphors and narratives that make resilience the concept it is? In what ways are policies then informed by and informing shifting resilience narratives? And, methodologically, how can analysts grasp and hold steady 
resilience narratives long enough to identify key traits and effects? How can we chase the 'resilience of resilience'? I tackle these problems in the next chapter by focusing on the policies and strategic frameworks that are produced by key actors at the working level through the Rockefeller Foundation's 100RC. I have chosen to focus on the work being done by Chief Resilience Officers as a case study of how actors have been recruited and enrolled to act as spokespersons for resilience. By closely following these actors, we can make sense of the movements of the concept on the ground, as well as the subjects it envisions creating. Furthermore, the result of this particular configuration has resulted in the growth of a novel resilience form: philanthropic resilience. As we will see in the following chapters, tracing the ways in which actants call upon, put resilience to use, and attempt to extract value from resilience has also led to the bourgeoning fields of philanthropic resilience and financialized resilience; the career path of resilience continues to broaden. 


\section{Chapter 5: Philanthropic Resilience}

The idea that we really could invest in building an infrastructure that would allow private investors to create double bottom line outcomes-positive social and environmental returns and positive financial returns-was percolating, but it was a disorganized field, a lot of small flowers blooming. What we did was bring the infrastructure, the platforms, the metrics, the networks, the policy changes. Last year there was $\$ 60$ billion under investment in impact investing funds. We helped to create the structure of social impact bonds, but we've been working on other kinds of bonds, infrastructure bonds, resilience bonds, and that's really getting a lot of traction and new investment. [Impact investing] was one thing I wanted to make sure was so far along with good metrics, the other was resilience. When we began the work, it was a concept that was pretty academic, and now it has become a global practice. We have 50 cities in Asia building resilience through the Asian Cities Climate Change Resilience Network, we have 100 cities globally doing 100 Resilient Cities with chief resilience officers, but now 72 private sector actors on a platform that are delivering resilience goods and services to our cities, Palantir, Swiss Re, Veolia, Microsoft, Cisco. There's a marketplace for resilience goods and services. A lot of private capital is getting unleashed into it.

Judith Rodin in Dill 2016

\subsection{Introduction}

This chapter undertakes an investigation of the Rockefeller Foundation's 100 Resilient Cities (100RC) initiative. I position the initiative as a program that was informed initially by academic articulations of the concept of resilience, then, as the program grew, adapted those articulations to render the concept more mobile and suited to its particular needs. The target of the 100RC's work was to integrate its definitions of resilience into municipal policy. The work involved enrolling corporate partners who developed resilience tools, then selecting cities across the globe to participate in the program. I investigate this work: focusing on the administrative contours that the Rockefeller Foundation enacted to structure the $100 \mathrm{RC}$, program requirements and expectations that the 100RC placed on municipalities. I include key communications that the Rockefeller 
Foundation and 100RC spokespersons undertook and identify the process to which municipalities adhered in order to qualify for a $\$ 1 \mathrm{M}$ grant from the Rockefeller Foundation.

Second, this chapter explores the 100RC's development of a new category of municipal actor: the Chief Resilience Officer. I ask: Who are Chief Resilience Officers? What does a Chief Resilience Officer do? Which definitions of resilience do they rely on? What are some of the observable effects of Chief Resilience Officers' work thus far? In what ways do Chief Resilience Officers serve as another contact point for rendering resilience mobile?

This section starts by documenting the trajectory of the appearance of Chief Resilience Officers, then dives into the various strategies and tactics that Chief Resilience Officers have turned to in the performance of their duties. This section also brings my tracing of the career of the concept into close analytical and empirical proximity to how the concept of resilience has been deployed and variously adopted or refuted by Chief Resilience Officers whilst carrying out their work. In the data driven economies that underpin contemporary urban centres, Chief Resilience Officers are positioned to direct and ensure the continued flow of data from municipal administrations to global financiers and risk modellers. They act as bridges between the theoretical and the practical fields of resilience. In this way, Chief Resilience Officers are akin to a pivot point or an interchange (échangeur (Ewald 1986)): a junction that plays an important role for the onboarding and continued operation of resilience within 100RC member cities. Building on these observations, I argue that these new municipal actors play an essential role in the development of what I call 'philanthropic resilience'. 
Philanthropic resilience starts with the philanthropic sector's involvement in and desire to influence municipal programs and projects. A key characteristic of the form is its drive to link private capital with public goods. Whereas traditional philanthropic arrangements offer grants to finance prospective projects without direct oversight or involvement, in the Rockefeller Foundation's case, key personnel paid for by the Foundation were placed within municipal administrative bodies to serve in an oversight capacity and influence programs directly. A second key characteristic of philanthropic resilience resides in its ultimate goals: business continuity, return on investment, and standardization.

The Rockefeller Foundation brought a distant concept into proximity of its immediate philanthropic work, and then expected others to follow them. In many ways, the dovetailing of municipal policies and local community concerns fostered the conditions of possibility for the encroachment of the philanthropic sector onto catastrophe and disaster planning and mitigation. It is no longer a question of if private capital has informed resilience programs. The question is now: in what ways is private capital informing resilience programs?

\section{$5.2 \quad 100$ Resilient Cities}

On April 29, 2013, the Rockefeller Foundation's board of trustees ratified "a global challenge to identify 100 cities...to build greater resilience, particularly at the city level, as natural and man-made shocks and stresses grow in frequency, impact, and scale" (Martin et al. 2018, 1). It was the beginning of the 100RC program. A few weeks later, on May 14, 2013, 'Rockefeller Foundation Day' was proclaimed by then mayor of New 
York City Michael Bloomberg. As a member of the billionaire business elite and philanthropist, Bloomberg, by making this proclamation, was nodding to the centennial of the Rockefeller Foundation. Officially founded in 1913, the Foundation has become one of largest philanthropic organizations in the United States, with annual grants hovering around US\$170M and total assets worth over US\$4B. The Foundation has a long and variegated history - which includes funding research into eugenics and invasive psychiatry - that has intertwined business with philanthropic ideals, expanding on Andrew Carnegie's influential The Gospel of Wealth, published in 1889. Carnegie's vision "called for the wealthy to channel their fortunes to the societal good by supporting systematic social investments rather than haphazard forms of charity" (Birn 2014, 2). Today, this practice of philanthropy by the ultra-rich has expanded into what is popularly referred to as 'philantrocapitalism' (see, for example: Bishop \& Green 2008). ${ }^{22}$ The term was intended to describe the way charitable giving had become synonymous with tax havens, corporate influence and, most importantly, capitalism's way of (re)structuring the social. However, Bishop and Green's term was eagerly endorsed by Bloomberg, backed by philanthropic giant Bill Gates, and generally admired by the very people targeted in the book. Wealthy and influential philanthropists absorbed the critique and essentially reaffirmed the position: capitalism can do charity better; philanthropy modelled on business practices 'can save the world'. The vision of philanthropy saving the world provided a backdrop for the Rockefeller Foundation's plan to offer resilience grants to one hundred cities around the globe.

\footnotetext{
${ }^{22}$ The original 2008 subtitle of Bishop and Green's Philanthrocapitalism reads: 'How the Rich Can Save the World'. In 2009, that was adapted to read: 'How Giving Can Save the World'. One of the effects of the 2008 global financial crisis was to lay bare that the rich were not, in fact, saving the world.
} 
Between August and September 2013, McKinsey and Company conducted an analysis for the Foundation to gauge exactly how to move forward administratively. The goal of their analysis was to determine "the best operating structure" for the 100RC program (Martin et al. 2018, 91). The decision eventually was made to splinter off 100RC from the rest of the Rockefeller Foundation's activities. The new entity would "staff up with subject matter experts and work with chosen cities" (Martin et al. 2018, 91). This new entity could operate with fewer overhead costs, while still benefiting from the Foundation's brand. Moreover, the new separate entity could hire staff and become a 'centre of excellence' in urban resilience (Martin et al. 2018). The new entity was incorporated in early September 2013.

That the Rockefeller Foundation made the decision to establish 100RC as a separate entity is important to highlight, as it is a reflection of the logic driving the program: organizational nimbleness for efficiency, risk aversion through financial insulation, and project focused talent acquisition. This administrative and structural distinction did not, however, carry over into a functional division between the two entities. Judith Rodin, the Rockefeller Foundation's president from March 2005 to February 2017, was heavily invested in the 100RC program. Rodin routinely made public announcements on behalf of the program, gave interviews on how 100RC was progressing, played a role in core operations, and even stepped in directly when mayors expressed reservations (Alameda communication, March 10, 2014). Rodin's stake and implication in translating and enrolling spokespersons for the concept of resilience will become clear in this chapter. For now, it is important to note that the 100RC initiative was not the first time that the Rockefeller Foundation was involved with resilience network-building. 
In 2008, the Rockefeller Foundation launched the Asian Cities Climate Change Resilience Network (ACCCRN). The program sought to build urban climate change resilience across 10 cities in Vietnam, India, Indonesia and Thailand by mainstreaming local efforts, creating a network of local practitioners, and financing city resilience strategies. The network benefited from strategic, technical, and practical assistance from a wide range of partners including the International Council for Local Environmental Initiatives (ICLEI), the Asian Disaster Preparedness Center (ADPC) and the Institute for Social and Environmental Transition (ISET). The ACCCRN also profited from a network of private firms acting as partners on the project. These partners included APCO, a global media and communications consulting agency, and Arup, the same UK-based engineering and design firm that would play an important role in designing the resilience index that 100RC member cities ultimately relied upon to develop resilience strategies. The Rockefeller Foundation was directly implicated in ACCCRN from 2008 until 2016, while leaving the project's governance to an independent group and the project as financially self-sustaining. Through ACCCRN, the Rockefeller Foundation approved and funded a total of 42 city projects in 10 cities carrying a price tag of US $\$ 16 \mathrm{M}$. The projects initiated through ACCCRN were focused exclusively on building urban climate change resilience. However, for the Rockefeller Foundation, and for Rodin in particular, translating the concept of resilience into policy and action always entailed a broader lens than climate change alone could offer.

In 2014, Rodin published The Resilience Dividend: Being Strong in a World Where Things Go Wrong. In the book, Rodin makes the claim that the 100RC initiative was a response to Hurricane Sandy, which struck New York City in 2012. The storm, and one 
could argue the proximity of the effects of the storm felt personally by Rodin, was a motivator to extend resilience beyond weather and into the very fabric that cities are built upon. In a sense, it was the damage caused by the storm that led to the creation of the urban resilience network. In the book, Rodin makes the claim that resilience is composed of five key characteristics. "To be resilient," Rodin argues, "is to be aware, adaptive, diverse, integrated, and self-regulating" (2014, 13). A year earlier, Rodin (2013a) articulated an expanded set of characteristics that resilient systems have in common with one another:

1. The capacity for robust feedback loops that sense and allow new options to be introduced quickly as conditions change.

2. The flexibility to change, and evolve, in the face of disaster.

3. Options for limited or 'safe' failure, which prevents stressors from rippling across systems - requiring islanding or de-networking at times.

4. Spare capacity, which ensures that there is a back-up or alternative available when a vital component of a system fails.

5. The ability for rapid rebound, to re-establish function quickly, and avoid long-term disruptions.

This leads us to ask: by having these five characteristics, resilient systems are resilient to what (Carpenter et al. 2001)? Or, for whom is this resilience (Cretney 2014)? In The Resilience Dividend, Rodin reminds us that the twenty-first century has brought with it many complex, wicked problems - from climate catastrophe to oil spills, and from chemical plant disasters to racial violence, we come to realize that life is complicated and that there is no easy solution to profound systemic issues. Nonetheless, Rodin summarizes the challenges we face as being composed of three foundational factors: urbanization, climate change, and globalization $(2014,68)$. This condensing epitomizes the Rockefeller Foundation's frame of reference for the 100RC initiative; Rodin's 
articulation was a signal for what pressing issues were positioned at the forefront of the $100 \mathrm{RC}$ 's theory of change as well who the primary agent of change was to be-cities.

Still from The Resilience Dividend, Rodin enumerates several ways that cities can "go about addressing vulnerabilities" (2014, 143). Chief among the suggestions are strengthening infrastructure, improving transportation, transferring risk through insurance, and practising preparedness (143-160). Rodin is a proponent of parametric insurance, going so far as to say that "the purchase of parametric insurance could be a driving force in the resilience-building activities of many communities" $(2014,157)$. Indeed, according to Rodin, insurance coverage and the supposed associated economic trickle-down effects that insurance brings are an important component to how cities are to practise resilience. Rodin speaks of this process in economic terms, writing:

Becoming more resilient in a turbulent and unpredictable world will require that, when disruption inevitably strikes, insurance coverages have been secured, so that our cities, communities and the people that inhabit them can recover more rapidly and to lessen the public expenditure in the aftermath of disaster that may be better applied to activities and initiatives that help us build resilience before disruption strikes" $(2014,154)$.

Funnelling funds through insurantial technologies, so the story goes, can help tame unpredictability and actually open up funds to prepare for the unpredictable. The story Rodin is trying to sell is that since disruptions are inevitable and unavoidable; best, then, to be equipped with insurance coverage to rebound after calamity strikes. Tautological, maybe. Profitable, certainly.

The 100RC initiative was originally backed by a $\$ 164 \mathrm{M}$ commitment by the Rockefeller Foundation and $\$ 230 \mathrm{M}$ in pledged support from partners. As of January 2019 , the initiative swelled to $\$ 3.35 \mathrm{~B}$, driven by private and philanthropic capital. To join, cities had to apply to a contest and commit to hiring a CRO, either from within their 
ranks or from an external staffing process. Cities also had to commit to following a series of steps, which were in some case specific, while other series applied to all cities. Taken from a template contract agreement between 100RC and member cities, a selection of the list of general commitments for all cities reads as follows (see Appendix C: 100RC Understanding of Mutual Commitment for complete list):

1. Participate in the full $100 \mathrm{RC}$ program, including committing to inclusive and broad-based engagement that seeks input and participation from diverse stakeholders both inside and outside of government.

2. Ensure substantial involvement from the City Leader, municipal government, and senior officials in key milestones throughout the Resilience Strategy process.

3. Commit to hiring a CRO at a senior level within municipal government, and collaborate with 100RC around the selection of a candidate, placement within the government, and reporting structures.

4. Engage in and contribute to the 100RC Network, focused on building a professional field of resilience practitioners, sharing lessons and practices, and wherever possible acting as an advocate and liaison to non-100RC members in your region and around the globe who are interested in learning how to create Resilience Strategies.

5. Leverage applicable tools, services, and partners from the 100RC Platform as your city develops and implements its Resilience Strategy.

6. Encourage cooperation across municipal functions and authorities for the purpose of developing a comprehensive resilience strategy.

7. Provide timely reports, evaluations, and grant monitoring to 100RC.

8. Engage in a transparent and collaborative partnership with 100RC based on principles of building holistic city resilience and work with 100RC to understand and navigate changing local circumstances as they arise.

In December 2013, a first group of 33 cities was selected ${ }^{23}$. In 2014, a second group of 35 cities became members. By May 2016, the Foundation boasted that it had reached its goal of 100 members following a third round of selection. Some of the member cities

\footnotetext{
${ }^{23}$ Literature produced by the Rockefeller Foundation is scrubbed of any mention of cities that were selected and then subsequently abandoned the initiative. I have been able to trace that the following cities were among those selected, then were no longer active in the initiative as of at least June 2018: Alameda, California; Arusha, Tanzania; Ashkelon, Israel; Bengaluru, India; Enugu, Nigeria; Jacksonville, Florida; and, Phnom Penh, Cambodia. The omission leaves us wondering if other cities have been removed, or if the very design of three competitions was a foreshadowing of members dropping out of the initiative.
} 
include Atlanta, Belfast, Boston, Boulder, Buenos Aires, Calgary, Jakarta, London, Montréal, New York, Singapore, Toronto, Tulsa and Vancouver. According to the Foundation, the selected member cities represent one fifth of the world's urban population. In total, more than one thousand cities applied to become part of the network. Exactly why the cities were selected is not specified. During the competition phases, there were extensive discussions between potential applicants and 100RC staff. Finding a good fit seemed to be the most pressing concern (Vancouver communication, March 1, 2016; Vancouver communication, March 9, 2016), as was a city's ability to position someone close to the mayor to act as CRO (Alameda Communication March 11, 2014; see Appendix C: 100RC Understanding of Mutual Commitment).

According to Michael Berkowitz, president of 100RC, a good application was one that had four key characteristics. First, 100RC administrators were looking for an innovative, engaged, and committed executive at the municipal level, including some level of political stability within the elected body. Second, 100RC wished to fund cities that had a recent or pressing "catalyst for change," like a flood or rising sea levels. What those 'catalysts' were differed from case to case, as applicants were encouraged to find several key issues that 100RC money could, in theory, help fix. Third, applicants needed to show their ability to work alongside a variety of types of stakeholders, from "business leaders, to advocates for the homeless, to academic water experts." Last, following from the 100RC's desire to have flexible and nimble cities join their ranks, applicants were advised to show a willingness to engage in partnerships and demonstrate an openmindedness regarding how to go about the process of resilience-making (Berkowitz 
2014). This emphasis on collaboration and partnerships was a common theme across all 100RC activities.

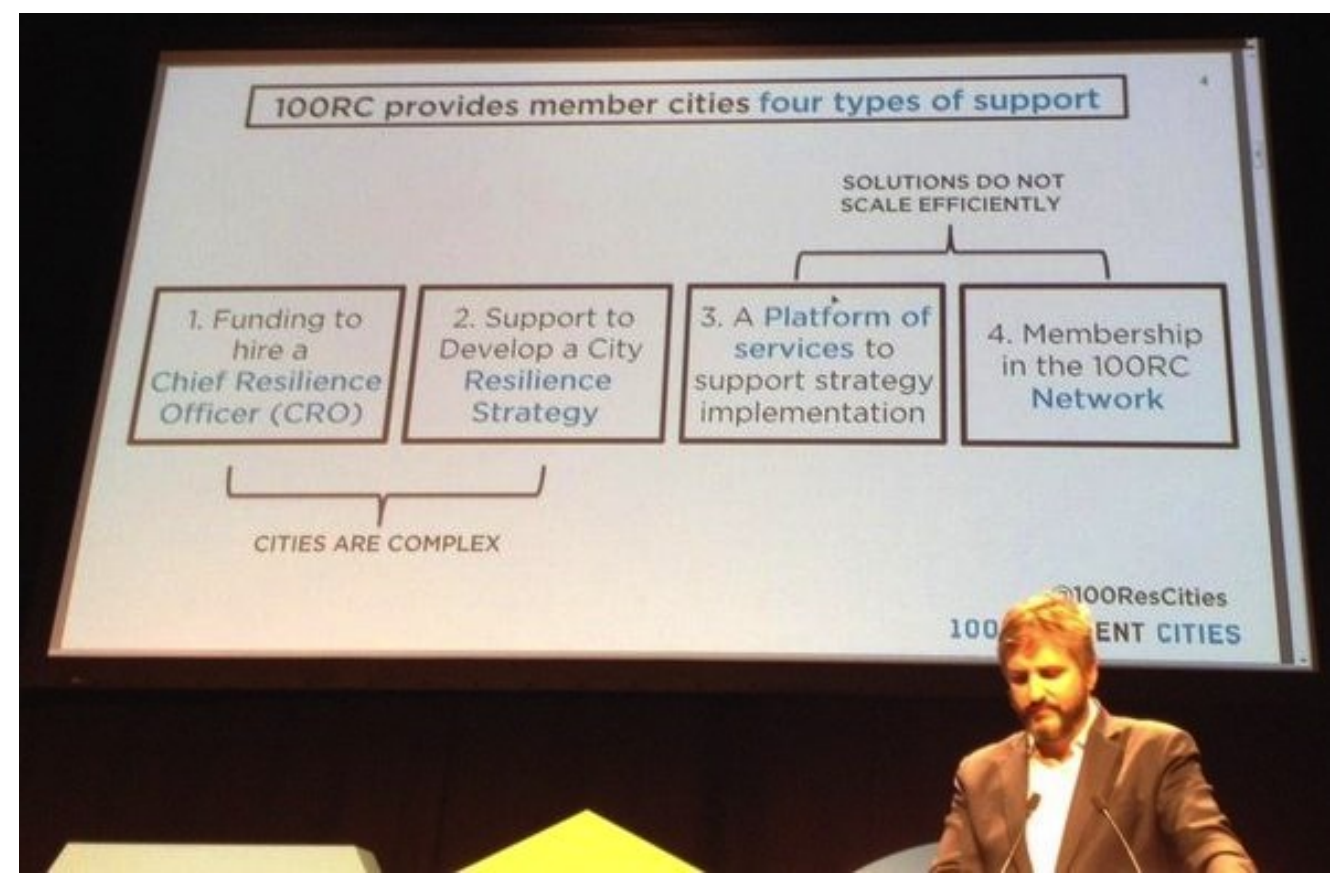

Illustration 6 What can 100RC do for a city? Michael Berkowitz in 2014. Image Source: 100 Resilient Cities (@100ResCities).2014. “MT@parra_esther@Berkmic Providing guidance \& a knowledge sharing network \#SmartCityExpo." Twitter, November 20, 12:10 PM.

A core component of the $100 \mathrm{RC}$ initiative was the financial incentives offered to city administrators for the purposes of hiring someone to act as Chief Resilience Officer. The 100RC initiative offered up to $\$ 1 \mathrm{M}$ to each city, covering the salary of a Chief Resilience Officer for two to three years and providing access to technical and logistical knowledge through 'platform' partners. From the executive level to the program planning level, municipalities that wished to benefit from the Rockefeller Foundation's money and access needed to begin to think and act in terms of partnerships. As such, member cities were encouraged to liaise with the initiative's partners: Swiss Re, a Switzerland-based reinsurance company that offers member cities access to their proprietary risk and hazard 
modelling tool (CatNet); Palantir, a US-based software firm that offers member cities big data analytic software; and, the American Institute of Architects, which offers design and model-building code development assistance to municipal administrators. Other partners include UK-based engineering firm Arup, energy and smart infrastructure firm SIEMENS, communications and networking conglomerate CISCO, Microsoft, the Virginia Tech Advanced Research Institute, UC Berkeley Centre for Catastrophic Risk Management, and international design and architecture firm Perkins Eastman. As this condensed list of partners shows, it is clear that no single city could possess these resources. Thus, these partners are envisioned as being a core component of the Chief Resilience Officer's resource toolkit.

Communicating the benefits of the 100RC initiative was an important activity within the network. The Rockefeller Foundation, as well as 100RC, used several channels and avenues during different phases of the program. Initially, external communications were mostly executive-level information sharing, detailing what the 100RC initiative was, the initiative's goals, and how cities could join. These activities occurred primarily on the Rockefeller Foundation's websites, social media channels, and through media engagements by key personnel. Aimed at advertising the 100RC program to city managers and mayors, the messaging contained in these communications was focused on what the program could do for cities and the application process details. Alongside this 'programmatic' information, a second form of messaging, emanating still from the Rockefeller Foundation, appeared and began to circulate. This form of messaging was different, containing a moralistic thread and a call to action. To use Judith Rodin's language, these communications were trying to make the "business case for improving 
the resilience of cities" (Rodin 2013b, n.p.). A 2013 Guardian op-ed penned by Rodin is a good example of the 100RC 'pitch'. In this article (which reads as a long infomercial), Rodin warns that, "with a changing climate, rising populations and resource scarcity, cities need to be able to bounce back from crisis." Rodin walks us through the perils that cities face, and lands on resilience as the ultimate solution. Of course, Rodin plugs her own five key characteristics of resilience to make her case, but up to this point the article is virtually identical to hundreds of others circulating at the time. Then Rodin switches gears and reveals a side of the 100RC program that usually remained hidden, writing:

as governments around the world become increasingly cash-strapped, the public sector cannot foot the bill alone, and nor can philanthropy. Private capital must be part of the equation, and not just as a moral imperative, but for the continuity of business operations...indeed, businesses are only as resilient as the cities and communities in which they operate, and factors seemingly beyond their jurisdiction-like land usage and planning for transit lines - are inextricably bound to their long-term competitiveness and success (Rodin 2013b, n.p.).

Private capital to the rescue. That Rodin appeals to business continuity is not all that surprising. Resilience, after all, is about continuity. Linking businesses to cities and communities, again, is not all that revolutionary within the context of the rise of socially responsible business practices. What is different about Rodin's message is actually bound-up in one word: seemingly.

On one side, the things that are, and have been, firmly within the purview of cities, elected officials, planning committees and oversight mechanisms; while on the other side, business competitiveness and success. If cities fail, it is up to private capital to pick up the slack, moralistically and for continuity's sake, according to Rodin. Historically, the private sector had two responses in such a scenario: either build its own internal resilience to withstand downturns; or, provide products and services to help others- 
including public-private partnership arrangements. Essentially, Rodin proposes a third way: a bridge between two sides that are 'seemingly' divergent. This third way is the 100RC program and philanthropic avenues into cities. In this form of messaging, the $100 \mathrm{RC}$ is to "provide the risk capital that will allow cities to begin planning and acting on resilience strategies" as well as "funding to hire a chief resilience officer, support to develop a resilience plan, and access a suite of innovative services, including technical support for big data analytics and leveraging private financing" (Rodin 2013b, n.p.). The 'seemingly' becomes more apparent: through the 100RC initiative private capital and businesses can have influence on key strategic areas normally guarded by city administrators. All they have to do is provide financing. In Chapter 6, I describe resilience bonds as one financing vehicle through which this can be accomplished long after the 100RC's direct involvement in municipal affairs ends.

A third form of messaging aimed at citizens, advocacy groups and non-profit organizations also occupied much of the 100RC external communications activities. While these communications occurred principally on social media channels, they should not be taken lightly simply because of the medium. The Rockefeller Foundation's Twitter account (@RockefellerFdn), for example, benefits from over 210,000 followers and the 100 Resilient Cities account (@100ResCities) reached around 100,000 followers in 2019.

Following each selection round, cities that had signed on to the initiative were tasked with acting as spokespersons for the 100RC. Official media launch events were mandatory for each new city selected (100RC Member Guide 2014; 2016). Joint communication events, especially when coordinated across multiple cities, carry risks to network relations. Ensuring that a specific language and standardized messaging was 
being delivered to media outlets was a significant aspect of the 100RC (Vancouver communication, March, 2016). As a result, 100RC produced a template press release, ready-to-use social media messaging complete with graphics, a fill-in-the-blank op-ed, and even talking points for an interview or a press conference question and answer period (100RC Member Guide 2014; 2016).

The initiative tasks each member city's Chief Resilience Officer with devising a resilience strategy ${ }^{24}$. Strategies are tailored to each city's particular circumstances by addressing 'risks' and 'stressors' and are intended to feed into a 'roadmap to resilience' that is actionable in the short term. The process for identifying what a city should focus on is guided by a 'City Resilience Index'. The Index is a creation of UK-based firm Arup, financed by the Rockefeller Foundation, and leans on Rodin's five key characteristics of resilience (see Illustration 7 below). The process is expected to take from six to nine months, according to the Rockefeller Foundation, and then fine-tuned as programs become implemented. The stated objective is to "trigger action, investment and support within city government and from outside groups" (100 Resilient Cities 2017). The strategy uses the language of capacity building and is expected to lead to long-term resilience thinking. The duties of the Chief Resilience Officer that I have been pointing to, if it is not obvious by this point, are vital to the 100RC. In fact, the position of the Chief Resilience Officer is the hinge upon which the entire initiative runs.

\footnotetext{
${ }^{24}$ After hiring Elliot Cappel as the city's CRO, Toronto's virtual staff directory offered a brief-and somewhat vague — overview of what the new position entailed: "The Chief Resilience Officer will accomplish the following: Lead a resilience assessment process with stakeholders around the city, to understand what we are doing well and how we can get better. Develop an action plan for implementing new resilience initiatives citywide. Support stakeholders and the City to ensure we apply a 'resilience-lens' to all of our investments and services. Engage with the 100 Resilience Cities network to draw in resources and lessons which can be applied in Toronto" (Toronto November 29, 2017).
} 


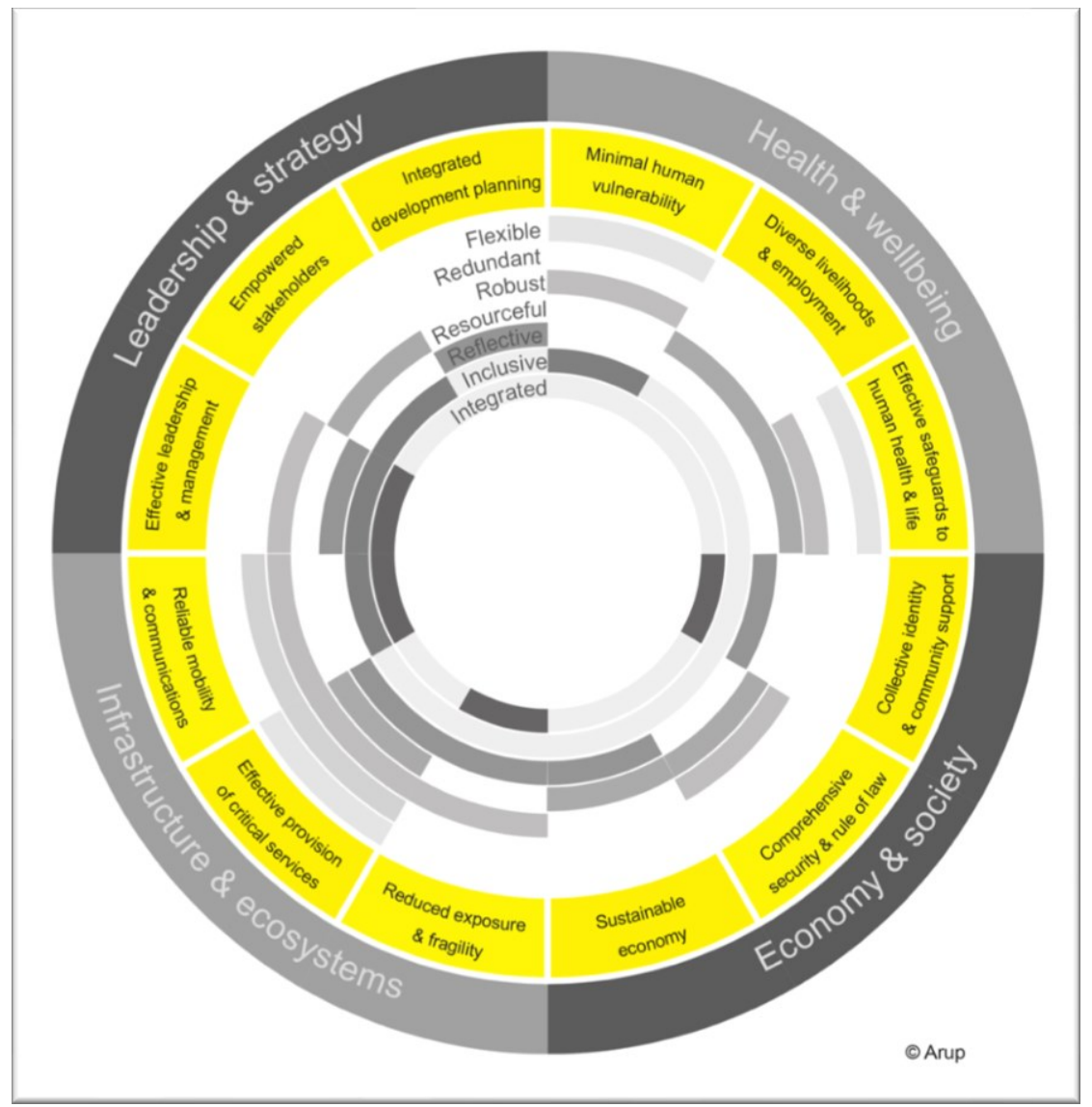

Illustration 7 Arup and The Rockefeller Foundation's city resilience index The resilience index was first used in the 100 Resilience Cities initiative (2013). Image source: https://join.cityresilienceindex.org/\#/

\subsection{The Chief Resilience Officer}

With cities exploring new tactics to increase resilience-from building infrastructure, to financing climate-adaptable projects - who takes ownership of making sure the water board, transit agency and public works department are all connecting on these vital issues? Enter the chief resilience officer.

Owens 2014

Chief resilience officers are charged with protecting their cities. Each acts as part emergency management coordinator and part politician, part consensus builder and part risk officer. They essentially safeguard everything from budgets to buildings and people to ports.

Jeff Hebert, CRO, New Orleans in Roberts 2017a, 61 
During its inaugural years, the 100RC initiative appeared to be a convenient way to market financial, technological and infrastructural services to cities by acting as what was essentially a giant billboard for the Rockefeller Foundation and its partners. Then, in October 2016, 100RC published a report entitled Resilience in Action: Early Insights Into How Cities Are Institutionalizing Resilience. It was the initiative's first substantial public report detailing some of the impacts that were made in member cities. It was also the first report to document the activities of Chief Resilience Officers. Prior to that point, the title was little more than a moniker for the 100RC initiative. The report detailed an expanded goal of the initiative, moving from a focus on external partnerships to institutionalization:

Our hope is that through this seed funding, global network, and technical and strategic support, cities will assume the mantle of resilience building and advance the field by institutionalizing resilience into their core operations and plans for the future. This institutionalization is key to catalyzing action for the long term, and to ensuring that the concept of urban resilience is adopted and embedded in such a way that cities are in fact better able to prepare for and recover from a range of shocks and stresses, and in particular that their poor and vulnerable populations are better off as a result (100 Resilient Cities 2016, 5).

It is through this institutionalization of resilience that, the report tells us, the initiative had begun to witness impacts and that cities had already started to "restructure their governments to think differently about risk and plan holistically for an uncertain future" (100 Resilient Cities 2016, 5). The position of Chief Resilience Officer had begun to be formalized, "making the CRO's role equally as essential as the head of civil defence or director of city planning" (100 Resilient Cities 2016, 5). It is the combination of these two processes, one that $100 \mathrm{RC}$ aptly calls 'institutionalizing resilience', that is "both permanently establishing the function of [CRO], as well as integrating and mainstreaming the concept of resilience into city services, plans and initiatives" (100 Resilient Cities 
2016, 5). Some examples of mainstreaming work that the report points to include: integrated multimodal transit, new recreational amenities, and enhanced design standards for streets in New Orleans that incorporate storm water management; a professorial chair in Resilient Cities at the University of Melbourne ${ }^{25}$; and, the development of the Bus Rapid Transit (BRT) system in Semarang, Indonesia. While these projects required varying levels of partnership agreements and stakeholder engagement, they all point to a more profound claim: resilience is not some wishy-washy buzzword. Resilience is serious business. The report makes clear that institutionalizing resilience extends across economic, social, and infrastructural domains and, in doing so, reproduced a key aspect of the Rockefeller Foundation's goal: "to articulate urban resilience in a measurable, evidence-based and accessible way that can inform urban planning, practice, and investment patterns which better enable urban communities...to survive and thrive multiple shocks and stresses" (Arup 2015, 3). How, then, is resilience articulated in the work Chief Resilience Officers do?

The first Chief Resilience Officer appointed through the 100RC initiative was Patrick Otellini, hired by the city and county of San Francisco. Days after taking office, when asked what he thought the term resilience meant, Otellini told a reporter, "resiliency is such a buzzword. You can say anything is resiliency. If I could talk creatively enough about a pothole replacement program, I could say that's an effort in resiliency26." $\mathrm{He}$ added that he felt that one of his and other Chief Resilience Officer's biggest challenges was that "if you don't develop a narrow focus and try to whittle down the giant scope that

\footnotetext{
${ }^{25}$ Lars Coenen was appointed as inaugural chair in August 2016. He assumed the post in early 2017.

${ }^{26}$ Using almost the same language, Kevin Bush, upon being named Washington D.C.'s Chief Resilience Officer, said: "Resilience is a bit of a buzzword these days-I'll admit that. [...] But to me, resilience is about the immune system of a city" (Chason July 27, 2017).
} 
is the big picture of resiliency into some real action items, a lot of CROs are going to be paralyzed" (Owens 2014, n.p.). Otellini's focus on actionable, 'on-the-ground' work is common among Chief Resilience Officers. For Pittsburgh's Chief Resilience Officer, Grant Ervin: "the activities of resilience aren't anything new...the cities are talking in that same type of language. The difference is the approach." (Schwab 2017, n.p.). Describing what this approach is, however, is proving difficult. In Semarang, Indonesia, for example, Chief Resilience Officer Purnomo Dwi Sasongko says one of the challenges he faces is explaining what the concept means to a non-Western audience: "Resilience is something new in Indonesia-it has a different meaning," (Schwab 2017, n.p.). Schwab (2017) reports that communicating resilience in Semarang has meant turning to a strategy of finding metaphors that resonate with different communities: in order to convince citizens of resilience's value, [Sasongko] has to explain it in different ways to different groups. For the younger generation, resilience resonates when he explains it in terms of communication - that the city is sufficiently connected in order to stimulate growth and react to new challenges. For the older generation, he explains resilience in terms of quality of life, describing how it can make the city better in the future. In artistic communities, he focuses on how resilience can help traditional culture and local wisdom survive.

Sasongko also uses metaphors to describe how Semarang's resilience strategy fits within existing governance structures, saying his office is "like bridges between what the government wants and what the community needs." Sasongko also articulates most poignantly the dependencies within the resilience network, stating that "Semarang can be resilient if the cities surrounding the city are doing the resilient work...there is 
interdependency between them" (Schwab 2017, n.p.). The apparent focus of Chief Resilience Officers on interdependencies can be seen as facilitating a city's internal work, on the one hand, as well as coordinating with external partners on the other.

Oakland's Chief Resilience Officer Kiran Jain sees her job as focused on the city's economy and governance structures, saying, "Our governance structure over the last 50 years isn't built to withstand the challenges of the next 50 or 100 years" (Schwab 2017, n.p.). She adds that "government needs to learn to be more agile in its service delivery." Jain's comments further reveal the interplay between unknown future events and the potential role a city can play, "When you're looking at a rapidly changing economy and planet, what services do we need to think about today to minimize the impact of what these changes are going to bring?" (Schwab 2017, n.p.). One example of the changes the city has undertaken is the transferring of the city's Rent Adjustment Program from a paper-based service outlet delivery model to a digital management system and web portal for claims. Schwab (2017) makes the case that these shifts are "part of increasing financial and economic resilience in a rapidly growing city, while showing how effective a more agile government can be." Chief Resilience Officers speak of making connections between municipal departments; in essence, they are acting as 'interchanges' or 'conduits'. Similarly, San Francisco's Chief Resilience Officer reflects that “it's not my job as a CRO to be a subject matter expert on everything that resiliency touches, but it is my job to be a conduit to make sure we're connecting the experts from both public and private sector to get them talking, and also within our city family to break down these silos" (Owens 2014, n.p.). Attempts to break municipal silos have meant that private sector actors are seen as important avenues through which the success of resilience 
frameworks can be achieved. If Chief Resilience Officers are the conduits, private capital—and, as we shall see in chapter 6 , specifically, financialized capital-is the imagined golden honey that needs to start flowing.

Given the challenging experiences created by the destruction of Hurricane Katrina in 2005, New Orleans eagerly joined the 100RC initiative. While recounting the work city officials did following the disaster, Jeff Hebert ${ }^{27}$, the city's Chief Resilience Officer, said "a lot of the things that we did very early on, legislatively, were about transforming our building codes and other different types of laws that we had to put in place to make sure insurers feel comfortable coming back into the market after the devastation" (Roberts 2017a, 62). Hebert further underscored the relationship between the insurance industry and relief efforts by stating: "We really understood that being able to have a place be insurable was directly connected to the viability of us being able to come back" (Roberts 2017a, 62). The view is extended to the preservation of life when Hebert adds that Chief Resilience Officers "seek to save lives, protect vital infrastructure and limit economic interruption" (Roberts 2017a, 60).

These sentiments get to the heart of the economics-risk interplay at work within resilience policies crafted by Chief Resilience Officers. According to Hebert, while public investment remains a priority, he and his team are also looking "at risk transfer products and other things that [they are] modelling with the insurance industry that can help [them] financially prepare for those things that are coming our way in the future"

\footnotetext{
${ }^{27}$ At the time of writing, Hebert is no longer acting Chief Resilience Officer. He is a partner at HR\&A, a private consulting firm offering real estate, economic development, and program assistance to an array of clients. One of those clients was the City of Toronto. The firm provided consulting services on the Toronto Waterfront Revitalization project, the Lower Don Lands naturalization project, the Gardiner Expressway project, and the Canada Square project, to name only a few. The firm was also a 100RC platform partner, helping craft several resilience strategies for cities.
} 
(Roberts 2017a, 63). The logics that inform private sector strategies also help to explain how Chief Resilience Officers move within networks of cities. For example, Rotterdam has been receiving on average 80 delegations of city administrators a year looking to learn what they have accomplished in resilient water management designs. The city's Chief Resilience Officer says that they are "working on the city but it's also businesswe can export this knowledge to a lot of cities" (Schwab 2017, n.p.). From breaking down silos to exporting resilience knowledge as a commodity, Chief Resilience Officers are trying to justify their policy proposals. Here, the legitimation process is underscored by data models.

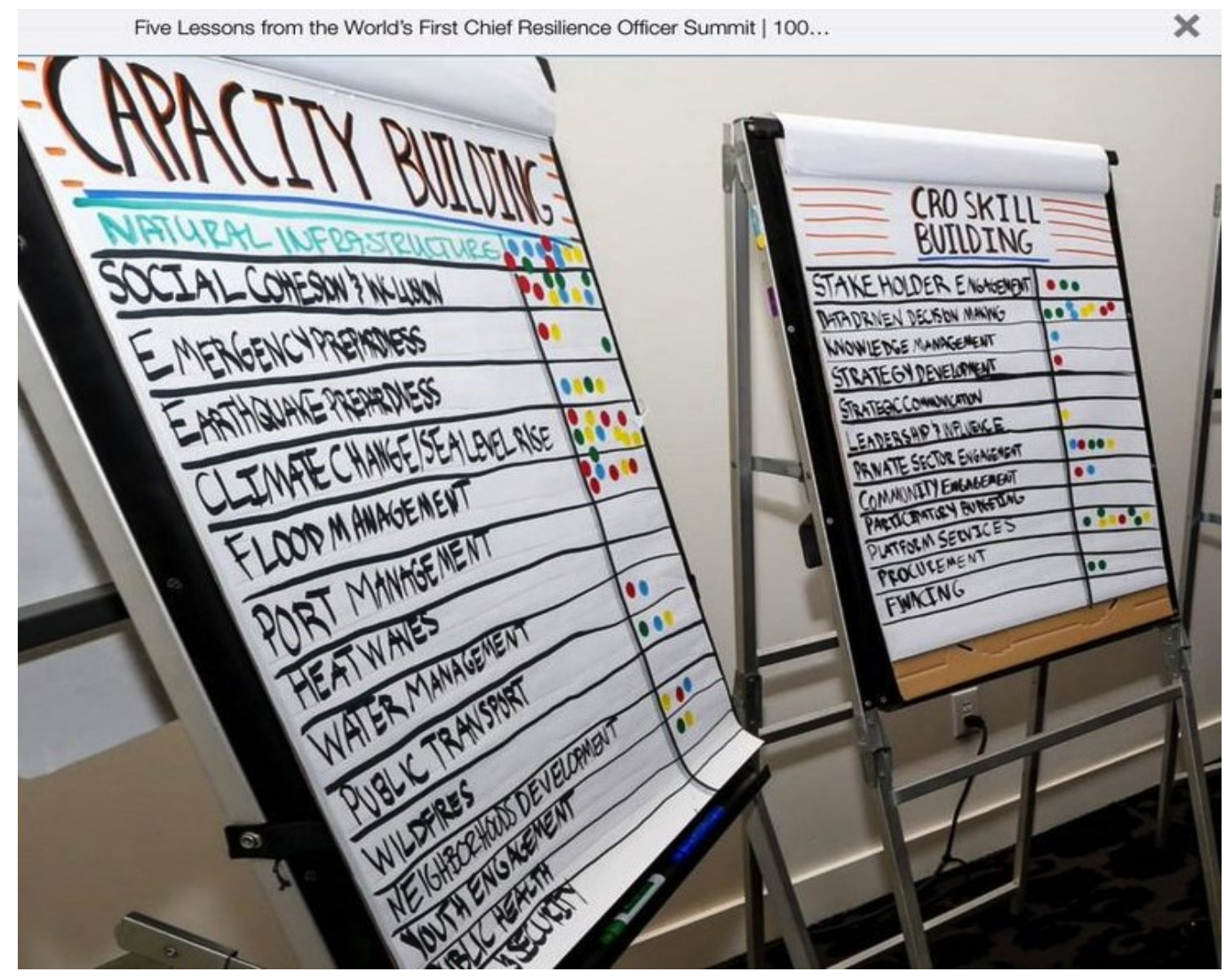

Illustration 8 First Chief Resilience Officers Summit: Capacity \& Skill Building

Image source: Marco Albani (@albanimrc).2014. “@100ResCities love all the dots on natural infrastructure. Say more! @JustinCMAdams @G_Boccaletti.” Twitter, November 26, 4:40 PM. 
Chief Resilience Officers are also building datasets in an effort to better equip themselves with metrics that can then be applied to evaluate resilience strategies. Oakland's Chief Resilience Officer, Victoria Salinas is, for example, spearheading an open government project to map the city's infrastructure. One arm of the project allows users to check if they live in what is considered a weaker wood-framed building. According to Salinas: "it's easier to have a map of every parcel and what buildings are there. It's much harder to then get to the stage of knowing precisely what risks the buildings are exposed to, how they're going to be affected and then, of course, the people in them" (Owens 2014, n.p.). These maps are startlingly similar to nineteenth-century fire maps that catalogued risks at the level of individual units. For Christine Morris, Norfolk's Chief Resilience Officer, there's a similar fixation on datasets: "cross-sectionalizing" what could be useful data. Morris says that “maybe we haven't used [real estate records] as effectively as we might in the future-combining it with economic development data and understanding where opportunities lie at the neighbourhood level to help those collaborations we need to have happen across business, university, city and other stakeholders" (Owens 2014, n.p.). Senior vice president of 100RC, Andrew Salkin, sums up the legitimacy-making function of resilience data analytics by saying that "data is a critical piece of information that you need to make good policy and management decisions, and it is also crucial when sharing with your citizens why you are taking certain decisions" (Daubach 2018, n.p.). The forms of data that become prioritized within resilience strategies are indicative of the type of knowledge that is meaningful for resilience architects. At the first Chief Resilience Officer summit, attendees expressed a strong desire to learn more about data driven decision-making, private sector integration, 
and 100RC platform services above all other potential skills that a Chief Resilience Officer could possess (see Illustration 4 above). The way that data is being positioned is key here; it is not a war between qualitative and quantitative forms of data, but a war between the actionable and the unserviceable.

In this empirical pragmatist scenario, an array of data becomes enrolled into resilience frameworks. Chief Resilience Officers are translating new or already existing datasets to the field of resilience, making data speak the language of resilience that can then be understood by other stakeholders. Envisioning their role as a combination of coordinator, data scientist, and political liaison, they approach the problem of resilience as one that unifies them. Chief Resilience Officers tend to gravitate towards the practical and the empirical: How can resilience be defined and communicated? How can it be made measurable? And, how do we know if a particular resilience approach is working? Conceptually, all data could be applicable to the concept of resilience through a common framework and set of definitions. From international economics to local issues, Chief Resilience Officers are constantly pivoting between scales. These scales provide the potential to integrate different arrays of data to the more common municipal ones already known. The 'discovery' of new extra-local datasets that inform local resilience strategies is the cornerstone of how Chief Resilience Officers market their success. Meanwhile, it is the all-encompassing form of the resilience narrative that is taken up and deployed in the work performed by Chief Resilience Officers. It is in this way that the translation work Chief Resilience Officers are performing is an aspect of resilience standardization. In chapter 6, I extend the analysis of standardization work to the field of resilience metrics, exploring the feedback loops that are created when attempting to measure resilience for 
practical purposes as well as the extended networks of financial capital that result from resilience valuation.

Has this sort of alignment also occurred at the policy level? In the next section, I explore the process of policy standardization at the municipal working level. I sketch how the City of Toronto came to be a 100RC member and eventually appointed a Chief Resilience Officer. The case of Toronto shows us the moves taken at the policy level and how the City gravitated towards resilience programming over other potential options. Resilience programs are just one of an array of options: it didn't have to turn out the way it did. In Chapter 6, I will further build on this standardization component by outlining attempts to build valuation models of resilience through the use of metrics and key indicators.

\subsection{Policy Standardization: The Case of Toronto's Climate Change Orientation}

The process by which the City of Toronto came to appoint a Chief Resilience Officer is indicative of the insistence by the Rockefeller Foundation that urban resilience policy focus on certain key areas and of its reliance on a particular definition of resilience. An overview of the reports received by the Toronto City Council shows a trajectory that has increasingly aligned with the goals of the 100RC initiative. In July 2007, City Council unanimously adopted the proposals found in a report titled Climate Change and Clean Air Action Plan. Included in this Plan was language that spoke of "unavoidable changes to climate." In February 2013, City Council received a report entitled Toronto's Future Climate: Study Outcomes, which summarized research conducted to forecast likely climate conditions for the City. Then, in December 2013, City Council asked for, and 
received, an updated report on climate research entitled Resilient City: Preparing for Extreme Weather that outlined existing policies, programs, and initiatives. That report put an emphasis on interdependencies within and outside City and external service providers and key operations, suggesting that these interdependencies require further investigation and attention. In June 2014, City Council then received the report Resilient City: Preparing for Climate Change. This report outlined an approach for integrating climate change resilience into decision-making and coordination of key city operations and services. That approach was endorsed by the subsequent adoption of a policy framework entitled Climate Change Risk Management, which outlines the responsibilities of executive management in identifying and mitigating climate risks. City Council further required that periodic updates on the policy framework be brought before executive management and the council. The framework led to the creation of a pan-departmental working group named Resilient City Work Group, which acts as a governance structure for the City's resilience policies.

In 2015 the City of Toronto formally applied to the 100RC initiative and, in May 2016, the City was accepted into the initiative's network of cities. According to documents from the City Manager's officer: "Staff were advised that Toronto's selection was informed by its existing and demonstrated leadership toward incorporating resiliency across the organization" (Toronto November 14, 2016, Report: EX20.9). Indeed, Toronto had begun to use the language of resilience that was aligned with that of the 100RC initiative. The city had even included the Rockefeller Foundation's definition of resilience in a memo to the city council before it applied for funding. Once Toronto became a 100RC member, it launched, in 2016, a search for a Chief Resilience Officer, 
ultimately appointing Elliott Cappel1 ${ }^{28}$ on June 15,2017 . The City's view of the position of the Chief Resilience Officer is concisely summarized (while remaining remarkably vague) in a press release:

The role of the CRO is to break down existing barriers in government, lead a process of uncovering a city's major challenges, support the design of initiatives that address many of those challenges simultaneously and help the city become better in both good times and bad. The CRO does this by accessing tools and services provided by 100RC — including access to millions of dollars of free services provided by platform partners - and bringing in people from all sectors of society. The CRO accounts for preexisting resilience plans and creates partnerships, alliances and financing mechanisms that will address the vulnerabilities of all city residents, with a particular focus on low-income and vulnerable populations. The position is fully funded by 100RC (Toronto 2017, June 15).

Toronto's experience with the Rockefeller Foundation and the 100RC initiative is an example of a successful attempt at standardization and expanding the resilience network. Indeed, the combined effect of the translation and enrollment work meant that the city of Toronto hired a Chief Resilience Officer and, ultimately, in 2019 created a resilience strategy based on the 100RC formula (Toronto 2019). It went more or less according to plan. This isn't always the case. The next section offers a brief overview of what went wrong (or, what is publicly known to have gone wrong) in one particular case: Alameda, California. The ordeal could be called the 'Mayor Minus One' problem. As I will show,

\footnotetext{
28 According to the press release announcing his appointment, "Cappell, a Toronto native, is an international climate resilience strategy specialist with experience in over 20 countries. He has more than 12 years of strategic policy experience, most recently at Adam Smith International (ASI), a policy development and project management firm, where he served as head of climate change strategy. Cappell possesses detailed understanding of resilience principles and their application to policy, and has consulted for such organizations as the World Bank and the United Nations. He has also served as a senior advisor on strategic policy to the Government of Ontario and has worked with more than 25 Ontario municipalities on urban development action plans" (Toronto June 15, 2017).
} 
the failed networking-making attempt reveals the fragile nature of relationships and the difficulties encountered when attempting to enroll spokespersons and align interests.

\subsection{The 'Mayor Minus One' Problem: Disputes in Network-Making}

Alameda, California is located south of Oakland and east of San Francisco. Nicknamed 'The Island City', Alameda occupies two islands and a portion of mainland. The city was founded in 1853, later incorporated in 1872 and enacted a charter in 1937. Between 1860 and 1890 the population grew from a mere 460 residents to over 11,000 . This trend has continued, more or less, until the present day. Now, close to 80,000 people call Alameda their home. Mark Twain once called the city "the Garden of California" (2010, 254). Fast-forward to 2013, when the effects of climate change and ageing infrastructure on an island city serve to stoke real anxieties around rising sea levels and crumbling bridges. The Rockefeller Foundation's idea to help build resilience was particularly appealing to cities like Alameda that had relatively small tax bases, high flood risk, reliance on key infrastructure, and an elected council motivated to do good (not to mention both geographic and social proximity to San Francisco and Oakland, the poster children of 100RC resilience programming). So when Alameda made a bid to join the 100RC initiative, it wasn't a surprise that it was selected. What was a surprise was that the bid was ultimately unsuccessful. How could a small city win, and subsequently lose, \$1M?

Newspapers and reports at the time were split between two (mostly speculative) accounts of why the city lost the 100RC deal (Cohen 2014, April 4; Ellson 2014, April 3; Ellson 2014, May 12). On one, side there were those who could not resist the opportunity to claim incompetence: Alameda's City Council was so incompetent; they lost what was, 
essentially, free money for the city. The second narrative to surface was that the 100RC and, by extension, the Rockefeller Foundation were simply asking for too much. City Council was not going to hand over the keys of the city just to play along. What actually happened is somewhere in between: incompetence on both sides and everyone asking for too much from one another. 100RC's insistence that the position of the Chief Resilience Officer be within the mayor's office caused some problems for municipal councils. Enrolling spokespersons for resilience too close to the main source of municipal authority was particularly risky if the idea of resilience was a new one. Asking too much of actants can cause them to back off, jeopardizing network-making efforts. In the case of Alameda, 100RC felt pretty confident that its decision to enroll a Chief Resilience Officer at that level would be justified by the fact that the City already had some experience in the field of resilience planning. What threw the negotiations off was a move on Alameda's part to close ranks and protect the old guard.

Alameda's administrators determined they wanted someone with ample experience to act as Chief Resilience Officer. Ricci Zombeck was their choice. A long-time firefighter with seven years of experience in disaster preparedness, Zombeck would move into the Chief Resilience Officer position for at least two years. Of course, Fire Chief Michael D'Orazi was of the view that it was time to give Zombeck his dues, especially if he was to act as spokesperson in the Mayor's Office. Big salaries are not what the 100RC pays for. First problem: compensation. If Zombeck could not fill his pockets, he could do the same work for less pay but not in the Mayor's Office. Alameda's compromise would have worked. Same function and same duties as all the other Chief Resilience Officers being hired, but working out of the Department of Fire Protection. "We weren't really 
looking for a flag waver or policy person who would stand next to the Mayor," D'Orazi said in an interview after the affair went public.

D’Orazi said that the city saw the role of the Chief Resilience Officer as, "more of a grassroots level organizer and conductor. That was how I looked at it" (Ellson 2014, May 12). Second problem: embeddedness. Indeed, communications between Alameda City staff reveal that the proximity of the Chief Resilience Officer to the mayor's office was a point of contention, especially between Fire Chief D'Orazi and 100RC administrators. Writing to Alameda's Assistant City Manager, D’Orazi says that the 100RC had described the Chief Resilience Officer position "as a 'Mayor minus one', high-level person within the organization" (Alameda Communication March 11, 2014). That sort of promotion summoned heightened wage costs that the $100 \mathrm{RC}$ was unwilling to pay. D’Orazi's protestations go beyond salary, however. In the same communication, D'Orazi reminds the City's Assistant City Manager that they have already assured 100RC that, "there is no dotted line from the CRO to the Mayor's Office and our commitment to sustaining the program, I don't see where they should try to dictate our organizational needs or question our veracity" (Alameda Communication March 11, 2014). From D'Orazi's perspective, the success of the program did not hinge on where the Chief Resilience Officer was located organizationally. Nonetheless, how the relationship between the Chief Resilience Officer and the Mayor was to be formally structured was paramount to the deal for the 100RC.

Presumably after some internal negotiating, the City Manager was in a position to write to 100RC staff that, "Alameda's CRO would report directly to the Mayor, be the driver of the City's resiliency policy, coordinate with the residents and business 
community as well as neighbouring jurisdictions, and that the City intends to support the position post Rockefeller funding" (Alameda Communication March 11, 2014, 15h21). For the 100RC Initiative, the relationship between the Chief Resilience Officer and the mayor, the proximity of those two entities in the resilience-building blueprint, needed to be more than a 'direct report'. Too little, too late in an already fraught relationship; so move on without Alameda they did. Michael Berkowitz wrote to D'Orazi: "after our many discussions over the past weeks, including talking with Mayor Gilmore and meeting with Chief Zombeck in person last week, it is clear to us that Alameda's strategy is incompatible with 100RC's vision for our network of Cities" (Alameda Communications March 28, 2014). The deal was off.

What led to Alameda losing the funding package offered by 100RC? Incompatibility of vision, perhaps. Soured relations between city staff and 100RC administrators from the start probably didn't help either. In the end, however, the proximity of the Chief Resilience Officer to the Mayor's Office proved to be too much of a barrier to the network-making that the $100 \mathrm{RC}$ was trying to accomplish. We must not forget that extensive work went into enrolling spokespersons into the programs and strategies that $100 \mathrm{RC}$ ultimately created. Alameda proved to be too unruly to manage or steer in the direction that was needed to form a cohesive partnership. This proved to push the limits of philanthropic resilience—-but did not extinguish it.

In March 2019, Alameda's City Council declared a climate emergency, then in September City Council released a strategy document entitled Climate Action and Resiliency Plan (CARP) (Alameda 2019). The opening pages of the strategy read:

While the City Council is responsible for adopting this plan and the City Manager will ensure we achieve its goals, the Assistant City Manager will 
ultimately be responsible for ensuring implementation stays on track among the various City departments involved in the process. A new, full-time Sustainability Coordinator will report to the Assistant City Manager and liaise with various climate change and resiliency groups, as well as City staff and community members (Alameda 2019, xvi).

The role of the new 'Sustainability Coordinator' sounds very much like 100RC's envisioned role for the Chief Resilience Officer-minus the Mayor. The Alameda strategy attempts to depoliticize and normalize resilience-building efforts into the machinery of municipal services and new partnership agreements, such as with local and regional utility providers. One way through which the strategy document suggests resilience building be funded is precisely via these new partnership agreements. Specifically, the strategy proposes one method by which residents can increase their energy efficiency, stating:

To avoid the need for upfront funding of energy retrofits, building owners can enter into arrangements with energy service companies (ESCOs), whereby the ESCO provides an energy savings guarantee and the building owner secures a loan from a lender based on the guaranteed savings provided. From the owner's perspective, the savings from the retrofits will offset the loan payments. From a lender's perspective, the savings guarantee provided by the ESCO gives the lender confidence that the project will generate a positive cash flow (Alameda 2019, 130).

The new Alameda resilience plan is remarkably similar to those created under the supervision of the 100RC initiative: partnerships, politics and business.

In closing, Alameda found a way to recreate the sort of resilience-building strategy that the Rockefeller Foundation was promoting without direct involvement of the 100RC initiative. That the Alameda strategy closely resembles a 100RC-led plan is instructive. Even though the City pushed back against the philanthropic resilience that 100RC was offering, it joined the resilience network through its own means and on its own terms. The Alameda case reveals how actors can be enrolled into the resilience network through 
interests and, relatedly, how philanthropic resilience interests actors to action. It also shows us that continued resilience building is happening based on the models generated by the Rockefeller Foundation and 100RC. Once the idea and outline of a resilience strategy is put into motion, with all of its accompanying documents, templates, guidelines, and examples, momentum and emulation propels circulation.

\subsection{Conclusion}

When cities and populations are overburdened, chronic stressors grow and can reach a tipping or crisis point. In addition, they are more vulnerable when shocks occur. It is harder to escape a fire or earthquake from an overcrowded building. An overburdened sanitation system is more likely to back up into water supplies and spread disease. These systems do not 'fail safely'. When they are disrupted, they often take other systems down with them.

Rodin 2014, 72

This chapter has shed light on the Rockefeller Foundation's 100RC initiative. I have sketched how the program came to be as well as how it recruited members and wedged its resilience priorities into those of municipalities. I have also shown how the position of the Chief Resilience Officer is imagined to function within and alongside municipal decision makers. I have argued that the 100RC acts as a quasi-obligatory passage point in an expanding technocratic web of Chief Resilience Officers, municipal authorities, insurers, private investors and program partners. The latter are an amalgamation of private, not-for-profit, academic and philanthropic organizations that provide services to cities. They act as problem solvers for those who come to realize that resilience articulates problems that are not easily solved. Resilience narratives become hardened and crystallize within city reports and frameworks. The work that goes into preparing, 
presenting and approving a municipal report should not be passed off as intangible. As shown by the example of the City of Toronto, this process has occurred over time and with the involvement of the 100RC initiative; and, as the Alameda case reveals, can fail. The alignment with an external foundation grants legitimacy to proposals at the operational level and serves as a convenient source of language and strategic policy direction at the communications, managerial, and governance levels. Policy instruments relied upon at the city council level quickly begin to resemble those relied upon by comparable city councils. The level of standardization in various cities' resilience policies remains to be seen, and is not something currently found in the resilience literature. Moreover, as Martin et al. state: "Though supported in scholarship and practice, the 100RC efforts at city transformation is still, ultimately, an experiment" $(2018,14)$. Investigating how members of the 100RC initiative have fashioned their policies on the models promoted by the Rockefeller Foundation, and the outcomes of those strategies, would further our understanding of the ways in which this network operates. I hope this dissertation can spark that work to fruition.

In April 2019, the Rockefeller Foundation unexpectedly announced that it was terminating the 100RC (Bliss 2019). The announcement was made via a rather rambling press release penned by the 100RC President, Michael Berkowitz (2019) — sunken into the eighth paragraph, nonetheless. The communication contained no details of the fate of the employees working on the 100RC initiative, or exactly how platform partners would continue to be available for member cities. In place of 100RC, the Rockefeller Foundation transitioned to a 'resilience office', fulfilling existing funding agreements. The Foundation also pledged to "include resilience activities in its domestic economic 
mobility programs" (Igoe 2019) and to fund a resilience-focused program at the Atlantic Council. Support to the Atlantic Council included a US\$30M grant to the Adrienne Arsht Center for Resilience, which "helps build and scale solutions for individuals, communities, and institutions to navigate global shocks and stressors" (Atlantic Council 2019). All rather vague.

Amidst the announcement, the Rockefeller Foundation had already begun using the language of 'incubation', acting as an imagined 'incubator' for resilience-building among other activities. This language was leaned on by the Foundation in a press release to make sense of the development: "The Rockefeller Foundation has a long history of incubating projects and entities that have matured to become independent organizations in their own right" (Rockefeller Foundation 2019). The press release lists several projects or initiatives in which the Foundation claims to have played an incubator role: the Global Impact Investment Network (GIIN); the Alliance for a Green Revolution in Africa (AGRA); the Acumen Fund; and, the International AIDS Vaccine Initiative - to name only a few. We have already seen this style of philanthropic resilience with the ACCRN. The Foundation kick-started the initiative, expanded a network of resilience spokespersons, offered cash grants, then handed over the project to another entity. The process is not dissimilar from the 100RC. Philanthropic resilience done in this manner is short-term, network-building focused, and intended as a way to jump-start projects. The effects, however, are much longer-lasting than the philanthropic sector's direct involvement.

So, the king and queen have fled the castle; the throne is empty. Moved on. Found something more exciting, maybe something more worth their energy. But moving on does not mean that their previous work does too. The Rockefeller Foundation may have 
taken a step in another direction, away from its direct involvement in city resilience programming, but the effect of their previous work carries forward. City resilience strategies remain in play, policy decisions will still be acted upon, and resilience as a concept has entered into the common municipal lexicon. For example, Gatineau's mayor relied on the idea of resilience to express the city's flood readiness after a series of tornadoes touched down within the city limits (see, for example, Union des municipalités du Québec 2019). If we must talk of legacies, the 100RC's legacy is not that it introduced municipalities to resilience as a new idea, but that it codified how resilience is to be done. 100RC established that urban resilience is best done through partnerships involving the private sector in the front lines of the policy-making process (for example in Rodin 2014, 136).

The solution to the problem that the Rockefeller Foundation sought to solve reveals one of the hallmarks of philanthropic resilience. The problem was both technical and philosophical. On the one hand, the technical desire (need?) to secure capital flows from increasingly cash-strapped cities was a major hurdle to overcome. On the other hand, there was a philosophical problem of extending private interests in the realm of public policy. Bureaucratic processes already limit how and under what circumstances a municipality can enter into relationships with private firms and it is rare that private interests can adapt and influence policy directly. The solution involved an engagement with the philanthropic sector. Under the guise of a philanthropic grant, municipalities were able to gain access to resources they may not have otherwise accessed. At the same time, through an elaborate partnership network, private firms were able to insert their 
interests in the heart of municipalities' policy regimes. It's a novel take on the philanthropic sector's raison d'être: to pivot private capital towards the public good.

The formal end of the 100RC, just as I finish writing-up this work, is a fitting apogee to rest on for a moment. It allows me to think about my own engagement with the concept of resilience. In the introduction, I signalled how the concept was slippery, evading attempts to firmly grasp hold of it long enough to make some sort of observation. I had not taken time to imagine what this project would look like if 100RC wrapped up its work, never mind think about when the initiative would terminate: terminal points were not my primary concern. In this case, we can ask: What's the end plan? Greg Guibert, Boulder, Colorado,'s Chief Resilience Officer offers us one suggestion. Guibert succinctly connects philanthropic resilience to the enduring vision of social change that uniquely defined Rockefeller's 100RC program, by stating that: "while each of these (resilience) projects has value in their own way, each of the projects is enculturating either the community or the organization to resilience and building the pathways for an enduring culture change" (Roberts 2017d, 74). This cultural change, I argue, involved becoming accustomed to the idea that resilience is business by other means. As my next chapter traces, I argue that philanthropic resilience's game plan rests on connecting private capital to public institutions. One way that this is accomplished is through the valuation of resilience dividends and the bond market. 


\section{Chapter 6: Financialized Resilience}

Organizations are still essentially human enterprises and as such, the concept of resilience seems to be an appropriate standpoint from which to view the complexities of organizational change. The challenge to organizations is to recognize that many of the resiliency factors are currently embedded in their people and processes awaiting a supportive push to surface them. Openly beginning the dialogue is the first step in diverting the separate trickles into a large mainstream of resiliency in facing the unpredictable, the unexpected, and the unimaginable shifts of the future.

Horne \& Orr 1998, 39

So far, I have primarily shed light on two ways that resilience has been deployed. The first is from a philosophical or theoretical paradigm: resilience to make sense of the world. It is an epistemological position. Through metaphors, analogies, and descriptive models, resilience from this domain is a suitable way to express the relationship between two or more objects or subjects. This is where definitional struggles occur and where the concept of resilience is called upon to represent abstractly an increasing number of people and things. Resilience takes on a metonymical meaning; becoming shorthand for a set of attributes and indicators that are presumably desired - the resilient young people of the downtown core; the resilience of the banking system; the resiliency of the cod population. I have also shown how resilience has been deployed in a practical sense. Municipal policies and the 100RC initiative are illustrations of resilience in action more specifically; the practices associated with resilience building or engineering resilience more broadly.

Practising and enacting resilience has involved the recruitment of key actants - in the context of municipal strategies, Chief Resilience Officers - to be spokespersons on behalf of resilience. Championing resilience by converging the abstract and the practical is the next step. It is a process that takes work. One way that this can be understood is similar to 
how an intangible good becomes monetized as an asset in the capitalist marketplacewhat is sometimes referred to as 'assetization' (Birch 2016). The process can be conceptualized in a linear fashion: an intangible good, like intellectual property rights (the abstract concept of resilience), is made into/reified as a 'thing' (a resilience practice or tool of resilience-building activity), which then takes the form of an asset that can be valued (the extraction of capital gains from a resilience project). In a tautological fashion, Birch conceptualizes assetization as "a process in which value is constituted by the management of value and valuation" (2016, 470). For Birch (2016) and others (for example, Tutton 2011; Martin 2015, Styhre 2015), the significant aspect of assetization is how "assets are governed and managed within organizational entities, rather than how it is constituted or represented by biological matter, liveliness, surplus life, and so on" (Birch 2016, 470). Conceptualizing resilience as an asset is helpful in the current context of exploring the interplay between forms of abstract resilience and practices of resilience on the ground. It allows us to take stock of how organizations mutate, manage, and monetize resilience.

In this chapter, I start by teasing out key aspects of organizational resilience. I focus on two distinctions made by proponents: the need to adapt rapidly to changing environments seen as a series of organizational characteristics; and, a series of capacity building traits individuals should foster in order to overcome vulnerability and risk within business cycles $^{29}$. In this way, I disaggregate the organizational resilience literature to show, first, a general outline of the emergence of the resilient organization, and, second, attempts at populating those institutions with a particular form of resilient subjects. If we

\footnotetext{
${ }^{29}$ For a more exhaustive overview of the development of resilience within business and management literature specifically, see Linnenluecke 2015.
} 
pay close attention to how classic models have envisioned organizational resilience, we are able to catch glimpses of how resilience emerged as a measurable asset and how resilience enters into contact with neoliberal concerns for profitability and surplus extraction: core elements of the resilience dividend envisioned by Judith Rodin. This is the business of resilience. Now, I turn to Horne's (1997) proposed model of resilience as a starting point to explore a series of intersections between organizational studies, value extraction, the resilience dividend, and the financialized form of resilience.

\subsection{Business as Resilience}

As we saw in Chapter 4, the concept of resilience has been circulating across disciplines for quite some time, mutating along an expansive trajectory. The field of organizational studies is no different. Horne (1997) provides the context for the resilience turn within organizational and business theories: the prevailing mode of organizational functioning was premised on mechanistic models of operations-prioritizing efficiency, predictability, and output. From Adam Smith's division of labour to Frederick Taylor's scientific management to more recent machine-focused metaphors, the shop floor was to be 'reengineered', 'redesigned', and 'resized' to increase production and profit. Incremental change meant that organizations could structure their activities around maximum production levels at near zero cost, finding a formula that worked and sticking with it for the long run. Horne observes: "the time-consuming, efficiency-refining processes that have been the mainstay organizational focus for so long no longer have the competitive breathing room to work their magic" $(1997,25)$. What changed? New emerging markets, new disruptive technologies, demographic shifts, a global economy, 
and the vanishing of traditional dominant economic, political and military forces that also structured the rules of the game. Capitalism could be screwed. Well, maybe capitalism as it was once imagined and done.

Horne offers a way out: organizations have turned their back on the traditional idea of 'products', embracing the concept of 'transactions' - touch points, or points of contact, between the purveyors of goods and services, and swaths of eager consumers. "The dynamic, interactive nature of transactions calls for business organizations to adopt a totally different viewpoint," Horne tells us $(1997,25)$. Furthermore, "This new and different organizing imperative...will need to elevate the concept of effectiveness as the prime driver to successfully accommodate the speed and ambiguity of changes to come" (1997, 25). Managers need to relinquish control, an "illusory" doctrine says Horne (1997 26). Instead, organizations need to embrace fluidity, change, creativity, and unpredictability. What's next? In Horne's words: "what is the proper metaphor-model to use as the visioning springboard for creating the new organisation?" $(1997,26)$. The answer is a rejection, a counterintuitive turn away from technological solutions towards "a model framework even older than the machine-the ecosystem" (Horne 1997, 26). As we will see, the adoption of the ecosystem as a driving mode of operations offers to organizations an opportunity to embrace resilience.

Horne's articulation of the organizational ecosystem was built upon a philosophy of natural ordering. According to Horne "productive capacity will continue to be important to organizations, but it must now take its place in a much more balanced order of things" (1997, 26). This ordering, according to Horne, was happening within the context of "chaotic times" and offered "the perfect environment in which to explore the self- 
renewing qualities of resilience within an organization" (Horne 1997, 26). When the environment surrounding an organization becomes unstable and unforeseeable, it is the innate capacities of organizations that must be drawn upon. "One of the hallmark qualities of ecosystems in general," Horne continues, "is their capacity for naturally occurring resilience when faced with major change. They return to a level of balance among the elements" (Horne 1997, 26). This realist elemental epistemology precludes a mystical depiction of resilience: resilience is natural, it is real, it is found in the ecosystem, and, as such, was always there. Resilience is, and always has been, the bedrock of capitalist production; we just needed to come to terms with the ecosystem where it is forged. The task, then, is to locate it and tap into it, like a miner excavating resilience from the grip of gangue. In organizational language, Horne (1997) relies on the notion of learning: "Becoming a 'learning organization' has much to do about learning about your own system's resilience" (26). Much like the 100RC definition of resilience, Horne's articulation ultimately combines mechanistic and environmental metaphors with the sense that resilience is fundamentally part of an entity. Horne, however, goes one step further than 100RC in signalling that a lack of resilience, or an unawareness of its potential, results in 'regressive' behaviour:

Organizational resilience is the ability of a system to withstand the stresses of environmental 'loading' based on the combination/composition of the system pieces, their structural interlinkages, and the way environmental change is transmitted and spread throughout the entire system. To varying degrees, resilience is a fundamental quality found in individuals, groups, organizations, and systems as a whole. It allows a positive response to significant change that disrupts the expected pattern of events without resulting in regressive/non-productive behaviour $(1997,27)$.

According to Horne, "the coming age of organizational resilience-and all it embodies - is upon us" $(1997,28)$. Moreover, "Only those who recognize the need to 
embrace and operationalize the notion of resilience will achieve true corporate stardom in the $21^{\text {st }}$ century" (Horne 1997, 28). Resilience or perish. This 'coming of age', for Horne, is the information age. Horne's anxieties about regressive and non-productive behaviours are a sign of both technological forewarnings and hi-tech allurements that remain common fodder within business-minded literature. However, Horne's orientation is decidedly not technological: it is relational and it is entrepreneurial. Horne maintains that "the main outcome of this era (the information age) for successful organizations will be a hallmark of 'resilience' that reflects their ability to combine information with a range of other factors to flex, mould, adapt, and redefine themselves to face ever-changing conditions" (Horne 1997, 28). Central to this version of resilience is the relationship between organizations and their changing environments: creativity and finding novel ways of trudging onward underscore how resilience is done. These key characteristics get carried over and persist throughout organizational theories of resilience, especially in later work by Horne.

In collaboration with John E. Orr, Horne refined his epistemology of ecosystem resilience into a substantive theory of organizational resilience. As we will see, Horne and Orr also articulated an ontological repertoire of organizational resilience that would later serve as a basis to assess the activities of organizations and, more concretely, how to assess value from organizational activities. At the outset, it is worth noting the context from which Horne and Orr's turn to resilience arises.

For Horne and Orr (1998), resilience is not simply a world punctuated by technology that makes resilience appealing; it is the pace at which change occurs. "It is no wonder that the shift from a framework of evolutionary, predictable, planned change to one of 
rapid, discontinuous shifts has left us feeling blindsided on a daily basis" Horne \& Orr (29) tell us. Coupled with an imperative to understand our environment (so as not to be blindsided), and to tame the unpredictable forces beyond control, organizations should be spurred to adopt resilience practises as, "we literally are able to see and interpret more information faster" (Horne \& Orr 1998, 29). Within this perceived climate of rapid change, the concept of organizational resilience is presented as a viable practical paradigm (Horne \& Orr 1998, 30). Resilience, according to Horne and Orr "is based on the premise that the world in general and the organizational environment in particular will continue to change in new, wondrous, and unexpected ways" (30). The wager, then (presented unparadoxically), is on resilience's ability to retain the 'new, wondrous and unexpected' while overcoming uncertainty and frantic change. "The new imperative for organisations," Horne and Orr (1998) insist, "is to develop their resilient ability to absorb change with a minimum of disruption, instead of continuing to uphold the increase of productive capacity as the prime objective" (30). If organizations do not adopt the kind of absorptive capacity that resilience offers, "It will not matter what the productive capacity was or could have become" (Horne \& Orr 1998, 30). In Horne and Orr's view, the battlefield is set: the standard capitalist model of maximum exploitation and profit generation is no longer sustainable - a more agile and flexible model for business needs to be adopted. The proposal is that organizational change not be connected solely to heightened productivity but should also include end goals that supposedly allow for the continuation of operations amidst an unpredictable future. Business as usual is no longer an option. 
Organizational resilience, then, promises "a practical response to change and provides a new way of viewing the attributes that contribute to the creation of a resilient organisation" (Horne \& Orr 1998, 29). Horne and Orr's organizational resilience model has a strong focus on application. It is not presented only as a theory of change, but also as a series of practical steps that any organization could take to ensure its long-term performance. The drivers of their approach are found from within two fields that we have previously explored: the material sciences side of engineering and the dynamics of ecosystems from ecology. The result is a theory of resilience that hinges on the idea of internal, elastic properties of any organism. Flexing, bending, and moulding around changing environments, the resilient entity can withstand shocks and pressures imposed on it by external or internal forces. The elastic characteristic is envisioned as more than a simple metaphor: it is a structuring quality that enables, "systems to dynamically reshape themselves" (Horne \& Orr 1998, 31). Such is "a central premise of organisational resilience" Horne and Orr tell us $(1998,31)$. Furthermore, the authors state that "resilience is a fundamental quality of individuals, groups, organizations, and systems as a whole to respond productively to significant change that disrupts the expected pattern of events without engaging in an extended period of regressive behaviour" (Horne \& Orr 1998, 31). The question then becomes how: How are organizations meant to build or tap into their resilient potentials?

Horne and Orr tell us that there are seven major 'streams of resilient behaviour'. These streams include: community, competence, connections, commitment, communication, coordination, and consideration. Seven Cs. Horne and Orr's organizational resilience model was not meant only to be a theory; it needed to have 
applicative power. In 1995, they cofounded the Center for Organizational Resilience Studies. One of the early products from the Center was an assessment tool called the Organizational Resilience Inventory-1996. The inventory was a series of 74 items meant to assess the behaviours of an organization and identify those that were most resilient and those that were most regressive. The inventory measured organizations across all seven streams of resilience qualitatively and quantitatively, resulting in a high-level assessment of how resilient an organization is, as well as where an organization deploys efforts to foster resilience.

Horne and Orr's aspiration was that organizations use the model to spur organizational dialogue. However, using the assessment tool was not the only way organizations could become more resilient. Organizations were inspired to "initiate an internal examination of systems resilience by discussing the concept at various management levels within the company" $(1998,35)$. The authors even went so far as to provide a series of guiding questions that management teams could use to spur resiliencefocused dialogue. "We have found that the concept of resilience," Horne and Orr state, "is very accessible to most people, and use of the term conjures up images of specific factors and behaviors in short order" $(1998,35)$. Much like their claim that, "resilience is an old and much honoured quality recognized throughout human history" (1998, 39), Horne and Orr appear to understate not only the fuzziness of the concept, but also its historical specificity to the modern climate. Even if they overplay their hand rhetorically, the work that such statements do need to be recognized. By appealing to resilience's deep historical roots, and a general adeptness at grasping its meaning, Horne and Orr are normalizing the concept principally for a business-minded group. The move dilutes the 
concept, removing theoretical ambiguity, and hardens the concept of resilience against a select few images. In ANT terms, this work enables resilience to be practical (sensible), practicable (possible), and actionable (useful). This type of work is important for the concept conceptually and a necessary stride towards the financialization of resilience. Treating resilience as an independent asset, one possessing extractable value, can be found embedded within what Horne and Orr refer to as 'units'.

For Horne and Orr, one goal of assessing resilience is to foster organisational change. Their inventory and index of resilient attributes accomplish this. Ultimately, however, the process of assessing resilience in organizations "is to develop a whole-systems response" $(1998,36)$. Where Horne and Orr's model resembles the Rockefeller 100RC model the most is in what they call 'units'. Units can be departments or entire divisions within organizations. The size of a unit seems not to be a factor, so long as there is a clear division between the unit and the whole. The necessity for delineations between units is born from a desire to identify and leverage the system's most advantageous actants. Horne and Orr advocate that "organizations can identify units with high levels of resilience within their borders in order to examine specific practices/processes/performance aspects that appear to support and nurture resilience" (1998, 37). Furthermore, "High-resilience units can serve as 'mentors' or models for units with lower ranges of resilience, to assist them to absorb significant changes more effectively" (37).

Horne and Orr's model of units resembles the 100RC's network of connected cities. In the latter, we find a model that places some municipalities in partnership with others on a mentor-mentee relationship, as well as the encouragement to create relationships 
between adjoining cities to better prepare for natural disasters, for example (some call this 'lateral relations', for example, van der Spek, Kruizinga \& Kleijsen 2009; van der Meer-Kooistra \& Scapens 2008). The end goal in both is to foster change, modifying behaviours and ways of being and doing. Even if "under the stress of significant change, there is always a tendency to hang on to the 'old ways"' (Horne \& Orr 1998, 35-36), organizations and, perhaps more importantly, the individuals constituting organizations need to adapt and move toward resilience. Horne and Orr conclude by prognosticating that 'today's often described 'chaotic times' would seem to offer the perfect environment to explore the self-renewing qualities of resilience" $(1998,39)$. That was 1998.

Following September 11, 2001, the field of business and organizational management met the concept of resilience head-on. Diane L. Coutu, writing for the Harvard Business Review, offered one of the first distillations of the concept of resilience for the businessminded community within the context of "terrorism, war, and recession" $(2002,46)$. In her piece, Coutu positions the puzzle of resilience to be solved as one that hinges on the question of "why do some people suffer real hardships and not falter? What exactly is that quality of resilience that carries people through?" $(2002,46)$. Before offering a tentative answer, Coutu concedes, "Resilience is one of the great puzzles of human nature, like creativity or the religious instinct" $(2002,46)$. Nonetheless, Coutu calls on academic researchers from fields such as psychology and organizational studies, as well as entrepreneurs and some of corporate America's top CEOs and COOs of the time, to arrive at three 'truths' of resilience. First, "resilient people...possess three characteristics," Coutu tells us, "a staunch acceptance of reality; a deep belief, often buttressed by strongly held values, that life is meaningful; and an uncanny ability to 
improvise" $(2002,48)$. Second, that any individual can "bounce back from hardship with just one or two of these qualities, but you will only be truly resilient with all three" (2002, 48). And, third, the main characteristics of resilient people "hold true for resilient organizations as well" $(2002,48)$. These characteristics culminate in a pragmatic theory of organizational resilience. Coutu tells us, "being lucky is not the same as being resilient" $(2002,55)$. Resilience, then, is purposeful, planned, and, more importantly, a competitive advantage that not everyone can have:

resilience is a reflex, a way of facing and understanding the world, that is deeply etched into a person's mind and soul. Resilient people and companies face reality with staunchness, make meaning of hardship instead of crying out in despair, and improvise solutions from thin air. Others do not. This is the nature of resilience, and we will never completely understand it (Coutu 2002, $55)$.

If I had to find an undercurrent to popular criticisms of the millennial generation, this account of resilience would fit the bill. The context from which Coutu is writing must not be overlooked. Terrorism, war and recession. With existential anxieties of terrorism and a series of fiscal retrenchment programs (somewhat forecasting an economic collapse) already at work, we can imagine why the need to adopt the sort of stiff upper lip Coutu is advocating would gain popularity.

Sixteen months after Coutu's article was published, Gary Hamel and Liisa Vålikangas (2003) reaffirmed to the readers of the Harvard Business Review that resilience is, indeed, the proper path forward. In "The Quest for Resilience," Hamel and Vålikangas try (in much the same way as Horne \& Orr) to uncouple efficiency from resilience - what they describe as a paradox. Doing more with less and producing more at a lower cost are already engrained business mantras. Changing how organizations operate, however, is not straightforward. Resilience, for Hamel and Vålikangas, is not 
just the ability to adapt quickly but it is also the built-in sets of processes that allow for change without trauma. Here, trauma can be understood as catastrophic failure: a company shuttering; people going bankrupt; loss of money; economic downturns. The cyclical nature of business means that at some point, ready or not, an organization will be faced with some sort of potentially catastrophic scenario. Organizations would do better to do something about it before it is too late. Prevent trauma rather than treat it-so to speak.

Just getting by, muddling through, or the old adage of 'picking oneself up by the bootstraps' is no longer enough in this version of resilience-building. According to Hamel and Vålikangas, "continued success no longer hinges on momentum. Rather, it rides on resilience - on the ability to dynamically reinvent business models and strategies as circumstances change" $(2003,53)$. Hamel and Vålikangas continue, telling us that we must come to accept "strategic resilience" as: not about responding to a one-time crisis. It's not about rebounding from a setback. It's about continuously anticipating and adjusting to deep, secular trends that can permanently impair the earning power of a core business. It's about having the capacity to change before the case for change becomes desperately obvious (2003, 53-54).

In other words, "to thrive in turbulent times," organizations must focus their gaze on 'renewal': "the natural consequence of an organization's innate resilience" $(2003,54)$. Hamel and Vålikangas (2003) see resilience as being capable of profound transformational change, arguing that:

the goal is a strategy that is forever morphing, forever conforming itself to emerging opportunities and incipient trends. The goal is an organization that is constantly making its future rather than defending its past. The goal is a company where revolutionary change happens in lightning-quick, evolutionary steps-with no calamitous surprises, no convulsive reorganizations, no colossal write-offs, and no indiscriminate, across-theboard layoffs. In a truly resilient organization, there is plenty of excitement, but there is no trauma $(2003,54)$.

Facing the inevitable - once we realize what that inevitable actually is - is an important step in the direction of resilience engineering. Hamel and Vålikangas' 
rendering of resilience culminates in the need for an epistemological shift: "to be resilient," they write, "an organization must dramatically reduce the time it takes to go from 'that can't be true' to 'we must face the world as it is"' $(2003,54)$. How is denial of 'the real world' to be broken? Similar to Rodin's insistence that situational awareness be developed by "going out into the field and taking a look" (Rodin 2014, 15), Hamel and Vålikangas propose that walking around, on the ground can help realign knowledge and offer an acceptance of reality. After all, they proclaim that "as the rate of change increases, so must the personal energy you devote to understanding change" $(2003,57)$. We must remember, however, that Hamel and Vålikangas, much like other commentators from within the business and organizational world, want to position resilience as an innate quality of institutions as well as individuals. In so doing, they expose the subjectivity forming potential within the resilience narrative.

Hamel and Vålikangas offer an array of analogies between biology, ecology, and business. Organizations, according to this logic, can and do operate under some of the same principles found in ecosystems and in our bodies. The quest for resilience culminates at the intersection of rational process and spontaneous, automatic responses. This is illustrated best in the following passage:

When you run to catch a cab, your heart rate accelerates-automatically. When you stand up in front of an audience to speak, your adrenal glands start pumping-spontaneously. When you catch a sight of someone alluring, your pupils dilate-reflexively. Automatic, spontaneous, reflexive. These words describe the way your body's automatic systems respond to changes in your circumstances. They do not describe the way large organizations respond to changes in their circumstances. Resilience will become something like an automatic process only when companies dedicate as much energy to laying the groundwork for perpetual renewal as they have to build the foundations for operational efficiency $(2003,63)$. 
The discussions found in Horne (1997), Horne and Orr (1998) and Hamel and Vålikangas (2003) are focused principally on the organization. It is the shop floor, the warehouse, the accounting division and, ultimately, the firm that are the targets and in need of resilience. At another scale, we find Coutu (2002) and Mallak (1998), who promote models of resilience that focus on an organization's personnel. According to Mallak (1998), the assembly line worker, the forklift driver, the tax accountant and the salesperson all "need to learn how to be resilient - that is, how to design and implement positive adaptive behaviors quickly that are matched to the immediate situation — while enduring minimal stress all the while" (8). The trope of preventing trauma comes back full circle to positive psychology, but this version seeks to "avert catastrophes by acting quickly and effectively in crisis situations" (Mallak 1998, 8). The focus of this form of organizational resilience is personal, situated at the juncture between worker and individual agent:

Self-efficacy means a person has confidence in his or her ability to perform a specific task in a particular situation. This is the cognitive side of resilience; in resilience we are concerned not only with a person's confidence and belief in his or her abilities, but with their actual execution of those abilities directed toward a specific problem (Mallak 1998, 9).

The notion of 'self-efficacy' offers a clue that this conception of resilience relies on, more or less, positive psychology's individualizing inclinations. For Mallak, "most events that employees respond to are not crises, but these events often require similar forms of response. Resilience encompasses many of the day-to-day coping strategies" (Mallak 1998, 9). For Mallek, coping, remaining positive and averting catastrophe are all aspects of the form of resilience that will ultimately enable organizations to prosper.

Mallak presents a series of claims of what a resilient person is, and how a resilient person acts. One of these claims is that members of an organization aspiring to become 
resilient ought to perceive their experiences constructively: even if it hurts, focus on the positive and move on. Mallek says that "by forming a positive and constructive perception of the problem, the individual is more likely to be able to solve the problem. Complaining, escaping, and other similar responses work against the resolution of the problem and are considered negative coping strategies" (Mallak 1998, 10). The goal is to move beyond mere coping strategies (water-cooler protesting, taking personal days off, or simply quitting come to mind) to transition to a state of resilience that "seeks to produce eustress (positive stress) in situations" (Mallak 1998, 9). Retention is best. Relatedly, as workers, we are to perform positive adaptive behaviours: change is good: adaptation is paramount. Mallek grounds this in the view that "the ability to respond in a positive and adaptive fashion to a wide range of events is a defining characteristic of the resilient individual" (10). This gets translated into the notion that "a resilient individual takes an active approach toward solving problems in the workplace. A resilient individual needs to perform positive adaptive behaviors" (Mallak 1998, 10). Being proactive, the socalled 'thinking outside the box', and not engaging in 'programmed responses'-the habitual, business-as-usual style responses to problems - are what makes a member of an organization positive, adaptive, and, by consequence, resilient. Resilient individuals are considered to be "opportunity-driven rather than danger-driven" (8), and "resilient employees expend less effort in assimilating organizational changes and therefore have greater potential to improve productivity and quality" (Mallak 1998, 9). To be able to become an adaptive superstar, however, organizations need to grant their members access to the resources they may need, as well as promote their ability to make decisions on their own. This is where Mallak builds on Weick's (1993) influential theory of sense making 
in organizations. The proposal is that members of organizations practise bricolage, or "develop the ability to create solutions on the spot using materials on hand" (Mallak 1998, 13). Nonetheless, even if we are granted resources and expanded decision-making authority, making 'good' decisions is not a natural outcome. To make good decisions, Mallak says, we must come to embrace uncertainty. A fixed amount of information available about our choices, and presumably a limited amounted of time to make a decision, means that building a 'tolerance for uncertainty' will help keep things moving; the elasticity that has become synonymous with resilience rests, in the final analysis, on tolerances: of uncertainty, of material resources available, of levels of positive thinking, and, perhaps, of catastrophic loss itself. As we will see later in this chapter, decisionmaking — that is, making 'good' decisions — is a central component in attempts to derive the value of resilience.

These articles offer but a small glimpse into the sort of discussions that were happening within the business community and more broadly within organizational studies literature. They are important contextual accounts that we should not easily dismiss as circumstantial. Proposals to take resilience seriously, as personal quality and organizational characteristic, are part of the same network that is informed by and informs the Rockefeller Foundation's thinking around resilience. Recall, for example, Judith Rodin's five key characteristics of resilience that are uncannily similar to Coutu's as well as Hamel and Vålikangas' articulations. It is in this way that we can conceptualize a resilience network that extends from organizational studies, through individual psychosocial characteristics to disaster management paradigms. 
In 2016, Kopans refreshed the key qualities of a resilient individual-again for the Harvard Business Review. This time, in addition to fostering a positive outlook on life, being risk tolerant, and choosing to be around other people who are generally also happy, ambitious and positive, we are to create 'positivity currency'. "We can't just print resilience the way countries print money," Kopans reminds us (2016, 3). We must make (print) our own positivity currency "because maintaining a positive outlook and regularly expressing gratitude are the bullion bars that have real value in backstopping and building resilience" (3). The analogies with the financial world don't stop there. Kopans proposes that we create a 'bull market' for our own resilience: “financial markets boom when increasing numbers of investors want it...likewise, our own resilience grows when we encourage positivity buyers to enter the market" (3). Combine currency and investments, and we land on another of Kopans' notions: that "resilient individuals diversify their positivity currency" with a portfolio approach (3). Resilient people, the thinking goes, want to "increase their overall resilience by evaluating what it is that provides the highest returns across their entire 'life portfolio' and then investing more in those areas" (3). Highest return for resilience investment is key. Once all that positivity currency is invested and stockpiled and the rewards are coming in, Kopans suggests that one "find a regular time to celebrate and reflect on your positivity currency" (4). Moreover, "Building individual resilience requires regular reviews of positivity data" (4). Kopans confesses: "I do it while I wait for my morning coffee" (4). The pivot towards the language of value, currency and resilience data is not random. It is part of a broader shift to know and to access resilience. To be sure, this move isn't exactly new; we can find calls for resilience information and metrics from the 1990s. Wheatley, for example, said: 
"If we are seeking resilient organizations, a property prized in self-organizing systems, information needs to be our key ally" $(1994,108)$. Information about organizations, accounts of how individuals are faring amidst economic uncertainty, data on performance, and even levels of happiness. It is one thing to account or count something; it is another to attempt to extract value from what is being tallied. The financialized form of resilience begins with the desire to capture a surplus: financialized resilience depends on the ability to measure how much resilience profit is being generated - a dividend. The business of resilience trades in resilience dividends.

\subsection{Resilience Valuation and the Resilience Dividend}

From a business perspective this may seem to make sense, as it can be difficult to quantify what the return on an investment in resilience might be. But we know there are returns-in the form of reduced cost of relief, fewer work days lost, and less money spent on health care and reconstruction, as well as in building stronger communities and workforces that will be more capable of sustaining long-term economic growth through ups and downs.

Judith Rodin 2014, 141

There has been a progression and refinement concerning the resilience of organizations and individuals. This is especially clear within organizational literature and business practice. The terminal point in the accounts reviewed above has been that of surplus, or of profit. The resilient organization is thus imagined to be able to continue to generate surpluses amidst crisis, for example. Resilient individuals are capable of continually (and predictably) carrying on with their labour. It follows, then, that the next quest is to identify just how much surplus resilience is really capable of generating. How much "economic growth through ups and downs" can be realized, to use the words of Rodin $(2014,141)$. Three models have appeared that attempt to quantify and extract value from 
the concept of resilience: RAND Corporation's Resilience Dividend Valuation Model (RDVM); Overseas Development Institute's (ODI) triple dividend of resilience; and, Global Infrastructure Basel Foundation's (GIB) valuation model. All three frameworks are functionally linked to the Rockefeller Foundation and they seek to build on Rodin's concept of the resilience dividend in their own ways ${ }^{30}$. It is the RDVM that has ultimately garnered the most attention and publicity. In this section, I review key aspects of the RDVM, focusing on the model's theoretical foundation located in inclusive wealth economic analysis, as well as by exploring the RDVM's assumptions concerning knowledge. Taken together, I am able to provide a sketch of how the RDVM attempts to solve the problem of resilience valuation both theoretically and practically.

Brian Strong, San Francisco's Chief Resilience Officer, links the benefits of a resilience approach to emergency response and disaster recovery prevention to the ability to extract value from resilience in this way:

It's in all of our best interests to be more resilient. It's in the best interests of the city, the insurance companies, the businesses, private property owners. So how do we work better to capture some of the value that we would be gaining and to be able to use some of that value to fund this critical infrastructure (Roberts 2017c, 66).

Similarly, Boulder, Colorado's Chief Resilience Officer, Greg Guibert, is a proponent of modelling and measuring resilience, saying that "you can use a catastrophe model to model your risk to a certain range of hazards, and then you model it with the intervention that you're proposing, then that delta is the resilience value of that project" (Roberts

\footnotetext{
${ }^{30}$ The ODI study does not carry an explicit mention of having received funding from the Rockefeller Foundation. However, the Rockefeller Foundation financed other resilience related work completed by ODI during the same time period. As such, ODI's triple dividend of resilience proposal is at least tangentially linked to the Rockefeller Foundation and is directly linked to Rodin's fashioning of the concept.
} 
2017d, 74). Knowingly or not, Guibert is speaking of Rodin's 'Resilience Dividend'. While the idea of measuring a return, or a dividend, on resilience projects (or investments) is prized, the actual practical way to do so remains somewhat of an enigma. "The longest road to go right now is actually the quantifiable value of any particular investment," Guibert remarks, "the avoiding loss thing is really an interesting piece. The idea of metrics and valuation around resilience is really the frontier of the space right now" (Roberts 2017d, 74). Entering this new frontier is RAND Corporation's proposal.

In 2017, financed by a partnership with the Rockefeller Foundation, RAND released the Resilience Dividend Valuation Model (RDVM). According to a report released by RAND, the RDVM is "a modelling framework that can be used to support decisionmaking about resilience investments by quantifying a resilience dividend" (Bond et al. 2017a, 1). As we saw above, the idea of a 'resilient dividend' was pioneered by then President of the Rockefeller Foundation, Judith Rodin (2014). Put simply, the 'resilient dividend' is "the difference in net benefits to society between a resilience project and business as usual" (Bond et al. 2017a, 1). The RDVM is "designed to provide a systematic, 'structural' framework for assessing resilience interventions that ultimately create benefits and costs within a system such as a community or city" (Bond et al., 2017b, xi). Moreover, the model is "a means to systematically account for the returns to resilience investments across a variety of contexts" (Bond et al. 2017a, xi). The model combines elements of project planning and economic valuation to forecast an economic return on investment. This valuation exercise finds its roots in the theory of inclusive wealth. 
Two streams of wealth accounting have come to dominate contemporary discussions: comprehensive wealth, which seems to be the World Bank's preferred model (World Bank 2006, 2011); and, inclusive wealth, which sometimes goes by the name of "genuine wealth" (Arrow et al. 2004), and seems to be favoured by the United Nations (UNUIHDP, UNEP 2012; 2014; 2018) ${ }^{31}$. Inclusive wealth is defined as "the aggregate value of all capital assets, where the value of a unit of a capital asset is measured by the contribution it makes to increasing current and future human well-being (Polasky et al. 2015, 446; see also Arrow et al. 2004).

Inclusive wealth theory "values the capital stocks within a system, taking into account the manner in which goods and services are produced from the capital stocks and how society values those goods and services" (Bond et al. 2017a, 2). In other words, the RDVM "represents the (net present) value of a system derived from the contributions of capital assets to society's well-being" (Bond et al. 2017a, xi). The "underlying intuition and conceptual structure" found within inclusive wealth theory and built into the RDVM assumes "that capital stocks (human labor or man-made capital) combine with technology (methods and tools) to produce flows of goods and services" (Bond et al. 2017b, xi). Well-being is thought to be derived from the consumption of goods and services and the creation of income (or profit) for producers, thus "satisfying consumer demand, and improving quality of life, among other benefits" (Bond et al. 2017a, xi).

\footnotetext{
${ }^{31}$ The terms inclusive wealth and comprehensive wealth are sometimes confusingly used interchangeably, or actually used to denoted key differences. For the purposes here, these differences do not matter. As Engelbrecht (2016) says: "the basic idea behind both the World Bank's and the Inclusive Wealth Reports' approaches to 'wealth accounting' is the same. Economic sustainability is assumed to require a nondeclining level of total assets (i.e. capital or wealth) per capita over time, not a non-declining level of output as conventionally measured by GDP per capita (GDPpc), and ecological sustainability is more likely to occur if the value of nature (i.e. all forms of natural capital) is properly measured and incorporated into the wealth accounts" (13).
} 
Changes in how people respond to their circumstances are taken into account by what is called an 'allocation mechanism'. However, macroeconomic models can rarely capture the particularities and subtleties of life.

To be 'inclusive', the value from all forms of capital must be included into the wealth accounting framework. According to Polasky et al., "ignoring some forms of capital risks sending the wrong signal" $(2015,446)$. Five forms of capital are dominant within the literature: financial capital, human capital, manufactured capital, natural capital, and social capital. Some authors also add knowledge capital (see, for example, Hamilton \& Hartwick 2014) and treat human health capital as distinct from human capital (see, for example, UNU-IHDP \& UNEP 2012). Each type of capital is quantified and a monetary value is assigned to it. Some forms of capital are easier to quantify than others. Quantities of manufactured capital can be fairly well estimated based on available data, whereas other forms of capital, such as social capital, requires using 'shadow prices'. Shadow prices are estimates, non-market substitutions. Guesses. Moreover, some forms of capital are really tricky to quantify. Access to fresh air or the provision of potable water, for example. These things add to social well-being, but are not easily quantified by market prices (although we can imagine that the market value for an ounce of fresh air has been computed somewhere). "Empirical measures of inclusive wealth to date have not really been inclusive," declare Polasky et al. $(2015,456)$.

In theory, the value of any capital asset "is equal to the present value of rents generated by the asset, so that in principle the value of capital captures expectations about the flow of current and future benefits" (Polasky et al. 2015, 447). Even the United Nations, which publishes its Inclusive Wealth Report biannually, admits that wealth 
accounting cannot currently capture the fine details of how capital stocks are consumed and valued. For example, as long as some capital stocks, like forests, are depleted at the same rate as other capital stocks grow, well-being is presumed not to be affected. Life tells us that our well-being is actually much better from access to a quiet meadow in a forest than a dining room table and a bookcase. While inclusive wealth theory has come a long way since the United Nations' started using the terms in its 2012 Report, it remains unclear if the theory can support the finely tuned scales that we expect from a tool that assesses our collective well-being. Nonetheless, the RDVM rests on the assumption that valuation can be done on all forms of capital: financial, human, ecological, or otherwise.

The RDVM offers a "framework for valuing and monetizing the impacts of a resilience project (or potential resilience project) compared to a business as usual (BAU) scenario in which the project does not take place" (2017b, xii). The difference between the two is the resilience dividend" (2017a, xii). From a 'systems-of-systems' approach, the framework "provides a production-oriented structure that can be used to represent complex systems in a dynamic context" (Bond et al. 2017a, 23). The envisioned system is broken into capital stocks and their progress (growth or decline), the array of human responses to shifts in capital stocks, the output of the stocks (such as goods or services), and the "well-being that these flows create" (Bond et al. 2017a, 23). Each of these primary components is understood as being functionally connected, and "affected either directly or indirectly by resilience interventions" (Bond et al. 2017a, 23). The model seeks to account for the overall impact that resilience projects may incur: naming a surplus a dividend. Essentially profiting from resilience. How 'resilience interventions' 
are defined and the way in which RAND envisions resilience, as a concept, are important to the way the RDVM model works to do the business of resilience.

In its report on the model, RAND summons Arup's City Resilience Index and the Rockefeller Foundation's articulation of resilience, the latter of which includes five 'key characteristics'-aware, diverse, self-regulating, integrated, and adaptive (Bond et al. 2017a, 149); recall my discussion of the partnership between Arup and the Rockefeller Foundation in Chapter 5. The roster of characteristics is identical to Rodin's articulation (2014); and, the list has foundations in Horne and Orr's (1998) 'seven C's' inventory of resilient organizations. A brief look at how these characteristics are translated into resilient dividends is instructive to its performance.

Changes to awareness, diversity, integration, or adaptability are theoretically understood to mean changes in the allocation mechanism, "either through changes in individual behaviour or changes in the institutional structures that govern that behaviour" (Bond et al. 2017a, 149). The approach is dynamic since resilience, envisioned as a thing, is also thought to be dynamic. An increase in awareness, for example, is presented as individuals or firms acquiring more accurate information about "stocks, probabilities, and/or potential behavioural mechanisms to mitigate against negative shocks or stressors (or, alternatively, the ability to exploit opportunities more efficiently) (Bond et al. 2017a, 149). If this information is positive, the authors of the report tell us, presumably "overall welfare could be expected to increase" (Bond et al. 2017a, 149). On top of being dynamic, RAND's presumption is that resilience is also relational. This notion is carried forward to other resilience characteristics that are important for the valuation process. 
An increase in diversity, a third characteristic to pay attention to according to RAND, is understood to represent an increase in "substitutability in the production functions," ultimately resulting in "relatively less impact on the human systems when faced with a shock or stressor" (Bond et al. 2017a, 149). A change in integration is similarly inferred, where exposure to "differing ideas or strategies may result in private or public actions that are different than that which would have been taken otherwise" (Bond et al. 2017a, 149). Another way that 'diversity' could impact resilience returns is found in changes to the institutional structure of systems through policy changes that "alter the incentives and opportunities of individuals and firms" (Bond et al. 2017a, 149). Although RAND does not use this particular language, wedged somewhere between agency and structure lies resilience: the RDVM, then, becomes a tool to tease out optimal conditions for action/restraint. Resilience is thus dynamic, relational, and caught between fields of opportunity and walls of constraint. This rendering of resilience-in-action culminates in the idea of adaptability. For RAND, adaptability means "the ability of individuals and firms to change their behaviors in response to changes in capital stocks, the aforementioned characteristics, or other perceived changes in system elements" (Bond et al. 2017a, 149). This may be the most significant element of the RDVM model, as it asserts that there is no guarantee that an increase of a particular characteristic will result in changed behaviour. For example, acquiring more information does not necessarily translate into better or more informed decisions. Actors may, indeed, not act at all. In RAND's words, “The provision of outputs does not necessarily lead to changes in outcomes, nor it is certain that the same information provided to heterogeneous agents will result in the adoption of the same behaviors, and thus the outcomes may differ" 
(Bond et al. 2017a, 150). RAND stresses this aspect throughout the report, stating that, "changes in the flows of private goods and services to stakeholders depend on the actions of key players" $(2017 \mathrm{a}, 141)$. Later, the authors state that:

in cases where an institutional change is the primary intervention to deal with a shock or stressor, predicting behaviour with and without the intervention is the key to the analysis. It is this behaviour, and the aggregate patterns of system development that result, that ultimately drive the resilience dividend (Bond et al. 2017a, 143).

While the model stops short of offering an explanation as to why agents may choose not to act, we are to be satisfied with the view that many of the Rockefeller Foundation's resilience projects aim to change allocation mechanisms as "a primary project output objective, with the hopes that these outputs will translate into improved societal outcomes (Bond et al. 2017a, 149). Hoping, then, is the best that we can expect; agents are unpredictable, even for advanced economic models of social behaviour (not to mention all the unruly nonhumans that may spring up and refuse commands). This ambiguity aside, the RDVM nonetheless presents practitioners with a step-by-step guide to assess the resilience dividend: all those benefits that could accrue if actants behaved.

Assessing the resilience dividend, according to RAND, can be accomplished through a six-step process. The guide makes it clear that this process is not "a 'toolkit' in which predefined tools can be extracted and applied to a given intervention" (Bond et al. 2017a, 19). Rather, the process they outline is to be used flexibly to support decision-making through estimating a potential resilience dividend. The six major steps RAND proposes are expressed as follows:

1. Define the intervention and BAU [business as usual] scenarios;

2. Map the system;

3. Define the shocks and/or stressors;

4. Map out the changes to the system in the intervention and BAU scenarios;

5. Estimate the intervention and BAU paths; and, 
6. Aggregate the estimates of well-being.

The process can be done pre-project, or post-project, but RAND places an emphasis on performing such evaluations during the planning stage of project development. Quantitative data is preferred over qualitative and, since resilience is considered to be dynamic, some data are only available after a shock or stressor occurs. In such cases, RAND suggests to adopt 'dynamic data collection strategies', essentially introducing ongoing data collection into resilience-focused projects. In other words, sometimes we need a catastrophe to be able to collect sufficient data to calculate our resilience dividend.

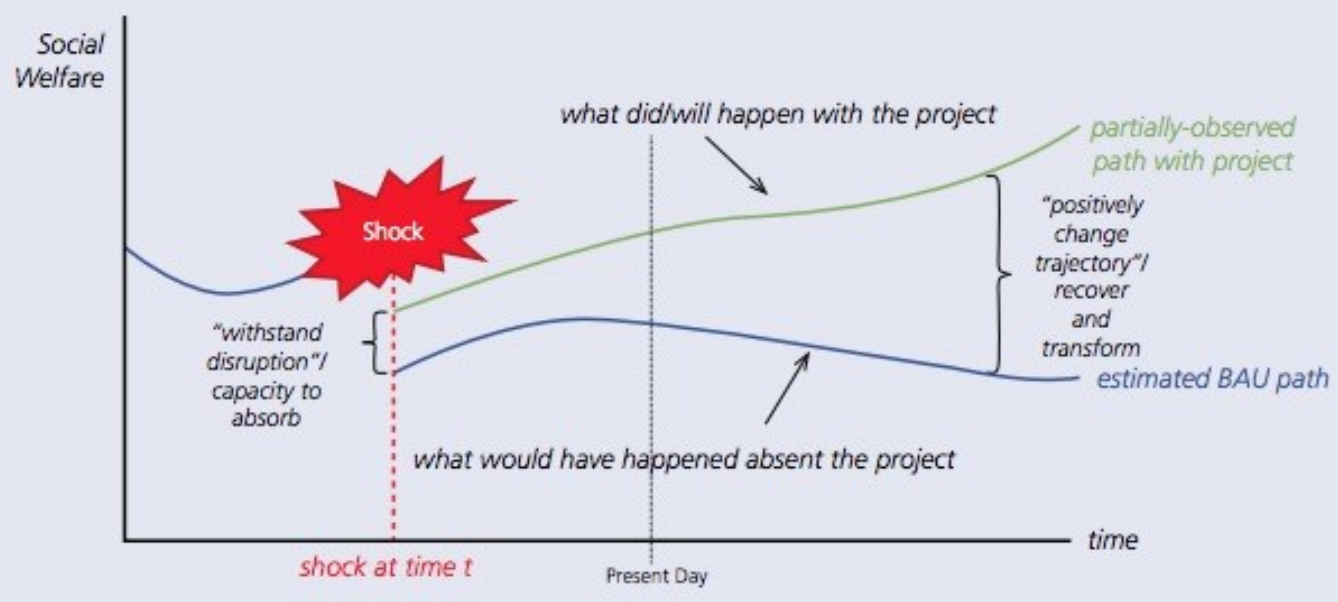

\section{Illustration 9 Example RDVM Model}

Representation of how a project with no co-benefits and a single shock could be valued. Image source: Bond et al. 2017b, 14.

RAND's report lists several key advantages and disadvantages of the RDVM model. Chief among the advantages is an explicit link to project-related benefits. Presumably, the RDVM is better at distinguishing between thoughtful and planned changes compared to serendipitous ones. Relatedly, the report stresses that another of the RDVM's advantages is its focus on identifying and measuring behaviours. While it is true that the inclusive 
wealth theory that the model is predicated on offers a particular vantage point from which human behaviour can be assessed, it remains rather crude and it cannot foresee the depth of changed behaviour that results from significant systemic changes. The report also boasts that the RDVM offers a key advantage "in terms of modelling, data collection, and estimation" (2017b, xii). The report includes three disadvantages of the RDVM as well.

First, the model is more complex than possible alternatives. The suggested remedy is that if practitioners turn to homebrew versions of resilience assessment, an estimate of a partial resilience dividend could be derived. Second, extensive data is needed to quantify the resilience dividend, which could be off-putting. Again, the remedy is for practitioners to trade complexity for a simplified modelling approach. Finally, the report states: "Some stakeholders may be uncomfortable with the underlying assumptions of the model" (2017b, xii). It is unclear which assumptions the authors are thinking of directly, or which stakeholders they are anticipating will be offended. Presumably, mining the resilience dividend is a delicate practice, practically and politically.

The RDVM rests on several key assumptions. First, that decision-making—good decision-making - is inherently economic. In fact, as the RAND report highlights, finding feasible resilience policy and programming involves prioritizing those projects that will yield maximum total net benefits. Failure to access the net value of a project's potential resilience dividend properly will, inevitably, lead to undervaluing certain projects and potentially to suboptimal decision-making. According to the authors of the RDVM, "the provision of information has the ability to change how people respond and how they choose which goods and services to produce and how to produce them (Bond et al. 2017b, 23). While RAND acknowledges that the data needed for such a resilience 
valuation exercise can be incomplete, compiling a robust data set will advance how decisions are made. The decisions that RAND is referring to include, not inconsequentially, the provision of municipal services and the future of public infrastructure, such as storm protection systems (Bond et al., 2017b, 12). Here, decisionmaking is a process of balancing costs and returns on investment; and, in this logic of decision-making, benefit-cost analysis along monetary lines dominates how a resilience project is valued.

A second assumption found in the RDVM concerns knowledge, particularly the production and accumulation of quantitative knowledge. This prioritization of the quantitative, however, comes at a cost. Due to the need to extract value from forms of capital that are not so willing to be appraised, practitioners have to be resourceful and imaginative. With a focus on benefits, RAND advances that:

valuing these additional benefits from a resilience project requires that we understand how resilience policy and program interventions change the valuable elements of any given system over time - through providing resources, relaxing constraints, or increasing opportunities to stakeholdersand apply the means of monetizing these changes. Of particular importance is the consideration of the linkages between elements of a system and how the system structure can be leveraged to create additional co-benefits (Bond et al. 2017b, 1).

In a companion guide intended for practitioners, RAND enumerates a series of specialized skills that would be needed to apply the valuation model, since "the RDVM is a complex approach based in economic and systems theory and requires high-level skills" (Bond et al. 2017b, 27). On RAND's list of attributes viewed as desirable and useful, we find: "experience with formal program/project evaluation, experience with causal statistical inference, experience with simulation modelling, experience with benefit-cost analysis and other economic techniques, experience working with imperfect data" (Bond 
et al. 2017b, 1). This desired experience is coupled with the requisite knowledge of "monetizing vs. not monetizing changes in the flow of goods and services" and "treatment of distribution of future shocks" (Bond et al. 2017b, 1). What is curiously missing from the list, and from how the RDVM positions knowledge more broadly, is the ability to imagine unintended consequences. Within the RDVM, all resilience-building activities have some level of positive effect on relations. The possibility of carrying through with interventions that lead to negative outcomes is simply not an option: this is bad economic decision-making in the first place. The business of resilience privileges sound economics.

RAND's model is certainly not the first, or only, experiment in measuring resilience. For example, Sharifi (2016) lists 36 different community resilience assessment tools, while Jones (2019) explores 17 approaches to climate change resilience measurement and Saja, Goonetilleke, Teo and Ziyath (2019) identify 31 resilience measurement frameworks related to disaster management. Pursuits of the metrication of resilience are not lacking. Assessing a resilience dividend, as coined by Rodin (2014), however, is distinctive in the field of resilience measurement. As I mentioned at the start of this section, prior to funding RAND's effort, the Rockefeller Foundation had commissioned the Global Infrastructure Basel Foundation (GIB) to derive a model capable of assessing the value of resilience. In the end, the RDVM was favoured and promoted over GIB's valuation model. Why that happened is opaque. One possibility is that GIB's model produced a resilience value that was too complex, too messy actually to be practical. In a lengthy account of their work, GIB reports that:

resilience is a multidimensional issue. It contains, among others, many different financial, social and environmental aspects. By taking account of 
resilience in all its dimensions, it is not possible for such a study to provide a final result in the form of a single monetary value. Measurement results remain multidimensional just like the real world we live in. Given that our suggested approach simplifies, quantifies and allows for comparability, we defend its multidimensional character. It may not be the simplest approach, but it is likely to be the only way to get a true and deep idea of resilience (Oberholzer, Knep \& Vögeli 2017, 71).

Reproducing and accounting for the intricacies of resilience, and by extension social life

itself, was not the purpose or the pursuit of the valuation exercise as envisioned by the Rockefeller Foundation. A valuation model, at its core, was a means to render the complex simple while isolating 'a single monetary value' from resilience interventions. This single value, expressed as a resilience dividend, is one of the fundamental characteristics of philanthropic resilience. The network that is formed by an amalgamation of the relationships that sustain philanthropic resilience is tethered to the very idea of a resilience dividend. These newly generated dividends can be stockpiled, traded, invested, or used as collateral against other pursuits. If philanthropic resilience provides an entrance for resilience in its financialized form, resilience dividends are the key needed to unlock the gates.

\subsection{Investing in Resilience}

In 2015, the Rockefeller Foundation financed an initiative led by Re.Focus, a design and finance firm that brokers public-private partnerships in the areas of sustainability and resilience engineering. The initiative, dubbed Re.Bound, initially leaned on a group of high-profile insurance organizations such as Goldman Sachs, Swiss Re and RMS to validate the conceptual foundation of what Re.Bound calls 'resilience bonds'. These new insurance instruments are targeted at the public sector, particularly municipalities, public works and utilities departments, transit organizations and disaster recovery and 
preparedness units. Resilience bonds, used as a project-based risk reduction mechanism, are envisioned as a way to "realize the potential insurance benefits from infrastructure improvements and monetize the physical and financial risk reductions associated with investments in resilient systems" (Re.Focus 2017). Through resilience bonds Re.Bound, along with the Rockefeller Foundation had finally found a way to monetize resilience. The proposal, however, hinges on selling public sector actors and private sector investors that this new technology could be simultaneously beneficial for cities, citizens, and stakeholders and, perhaps more importantly, profitable for everyone.

The problem articulated by Re.Bound is one that speaks directly to municipal concerns. The story Re.Bound tells of how public resilience has been done is compelling. Governments have typically been seen as 'insurers of last resort' when catastrophic losses caused by disasters occur. Governments or other public bodies have historically solely assumed the costs associated with recovery efforts, rebuilding, and future disaster proofing. This has gradually emptied coffers, often at the expense of other services. As the frequency and severity of natural disasters have grown, government bodies have assumed the role of 'insurer as first resort' when disasters occur. This situation is unviable economically, and unsustainable for already cash-strapped municipalities. Risk reduction efforts need to be able to leverage other sources of revenue-so the thinking goes. Enter 'Resilience Bonds' as a silver bullet. Resilience bonds are presented as a viable solution to "align public-sector disaster risk reduction measures with private insurance" (Re.Bound 2017, 2). The form that this approach takes is a derivative of catastrophe bonds - commonly referred to as 'cat bonds' — which already benefit from a robust track record of generating profits. Catastrophe bonds work by calculating the 
probability of loss and risk that result from a natural disaster. Everything from daily meteorological trends to exceptional 100 -year storm data is accumulated and deployed using advanced algorithms to arrive at a probability of an event. Catastrophe bonds have attracted the attention of insurers as they can diminish catastrophic losses. According to Re.Bound, these new resilience bonds work in a similar fashion, by "link[ing] insurance and resilience projects to monetize avoided losses - such as a reduction of hurricane insurance costs and claims - through a rebate structure. The resulting 'resilience rebate' can serve as a source of predictable funding which sponsors (insurance policyholders) can proactively invest in projects that strategically reduce risk" (Re.Bound 2017, 3). The language used to describe these insurantial technologies is an indication of its heightened financialized form. For example, Re.Bound draws two analogies: "if catastrophe bonds are similar to life insurance policies that only pay out when the worst disasters strike, then resilience bonds are more like progressive health insurance programs that provide incentives to make healthy choices - quitting smoking or exercising regularly - that reduce long-term risks and the cost of care" (Re.Bound 2017, 3). According to Re.Bound, resilience bonds offer, "public officials who have visibility and control over resilience projects a new way to leverage private capital to speed along the design, funding, and implementation of high-priority projects (Re.Bound 2017, 8). Resilience bonds are intricately tied into private capital streams, much like catastrophe bonds. Resilience bonds, however, differ in one significant way: private capital not only has a vested interest in the bond itself, but also in the potentially massive market of resilience projects that are tied to the bond obligations. Using ANT language, we may say that the technology of resilience bonds functions to interest investors; that is to say that investors 
become interested in the bond market because of the work that a resilience bond can do. The horizon of opportunity created by resilience bonds hinges on a singular perception: predictability.

According to Re.Bound, public sector projects that seek to build resilience, while being well intentioned and having a clear set of benefactors, are regularly underfunded and "remain in the design phase" (Re.Bound 2017, 3). According to this reading, private capital is being held up on the drawing board and projects never come to fruition. Resilience bonds offer a way to ensure that streams of capital triggered by investment projects continue to flow in a more or less predictable way. Predictable how? Resilience bonds build on the technical methods that catastrophe bonds use to calculate the probability of a catastrophic event; catastrophe bonds rely on a robust calculation of probability. This probability is then used to determine how much of a risk a particular bond carries and to subsequently develop a parametric trigger. For example, the parametric trigger for a catastrophe bond may be defined in terms of a flood surge height 5.5 feet above a 50 -year historic flood level. If during the bond's term a storm hits, and floodwaters rise above this level, the bond can be cashed in by the policyholder. If the parametric trigger is not set off, meaning a storm of that particular proportion does not hit, investors benefit from a coupon return. These returns on investment are usually within the $4-7 \%$ range. In this scenario, the policyholder pays premiums on insurance coverage they already needed: in the event no disaster occurs, investors claim a return; if a flood does happen, the policyholder has access to a sum of money for rebuilding efforts. A resilience bond introduces another layer to this arrangement. 
Upon issuing the resilience bond policy, a clear set of publicly funded projects that will be undertaken to mitigate certain risks is drawn up. Returning to the example above, these projects may reinforce drainage capacity ensuring that a rise in flood surge of 10 feet can occur without loss. The parametric triggers associated with the bond would then change to reflect a 10 -foot or more flood, which would be at 100 -year flood levels, for example. This results in less risk of loss. The policyholder benefits from discounted premiums, while coupon returns are lowered to reflect a lowered investment risk. It's very much like betting on the weather. In the resilience bond arrangement, public entities are financially enticed to fully execute resilience-building projects—-getting them up off the drawing board. As such, private investors and insurers wishing to reap returns are offered a higher level of predictability: not only are there reduced levels of disaster risk, but projects are actually carried from the planning stage to the execution stage. Finance and investment logics collide with resilience. 


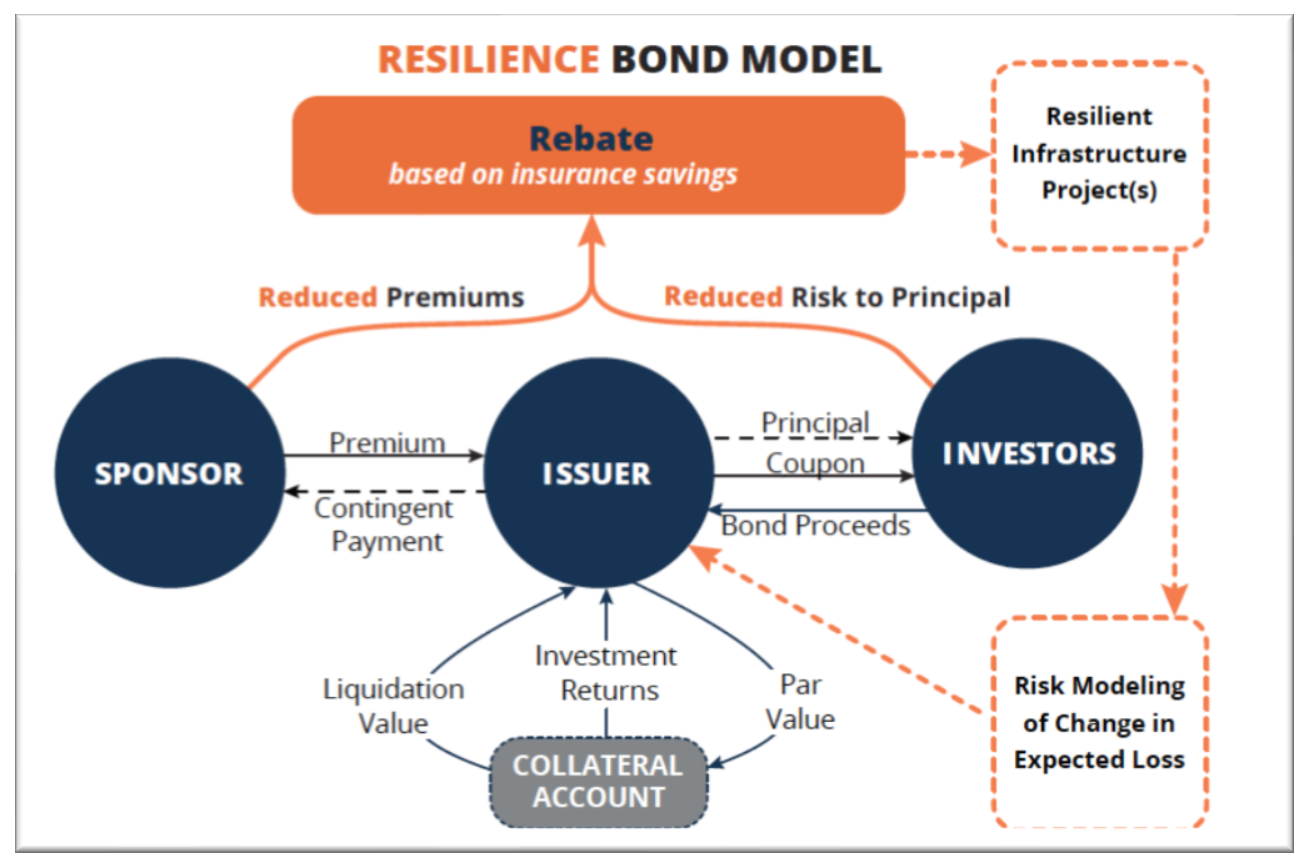

Illustration 10 Re.Bound Resilience Bond Model

Image source: Re.Bound 2017, 6

In September 2019, the European Bank for Reconstruction and Development (EBRD) launched the first dedicated climate resilience bond. Acting as joint bookrunners (underwriters), BNP Paribas, Goldman Sachs, and Skandinaviska Enskilda Banken AB raised US\$700M for the bond. Over 40 investors from 15 different countries purchased the bond. Central banks and private banks secured 59\% of the bond, $32 \%$ was secured by asset managers and around $9 \%$ of the bond was bought by insurance industry actors and pension fund managers (EBRD 2019). This form of bond does not work in the same way as a parametric-style resilience bond. Investors in this scheme are expected to benefit from a $1.625 \%$ return on investment. Money raised by the bond sale is earmarked by EBRD to support a series of "climate resilient investments" including "climate resilient infrastructure (water, energy, transport, urban communications); climate resilient 
business and commercial operations; and climate resilient agriculture and ecological systems" (EBRD 2019). What is also novel about the 5-year bond is that it is based on a set of 'Climate Resilience Principles' promoted by The Climate Bonds Initiative.

The Climate Bonds Initiative is a not-for-profit that offers policy and market research and develops standards and certificates for climate bonds. The organization markets itself as "an international organisation working solely to mobilize the largest capital market of all, the $\$ 100$ trillion bond market, for climate change solutions" (CBI 2020). In an effort to develop a series of guiding principles for certifying climate resilience bonds, the Climate Bonds Initiative created the Adaptation and Resilience Expert Group. Membership includes major actors in the financial world-KPMG, Goldman Sachs, S\&P Global, Moody's Investment. The group also benefited from involvement from some important actors from within the resilience network: World Bank; United Nations Development Program; United Nations Office for Disaster Risk Reduction; Stockholm Environment Institute; Four Twenty-Seven; and, Global Resilience Partnership. The latter organization is the brainchild of the Rockefeller Foundation. The link between philanthropy and climate bonds does not stop there, however. In addition to having input into the design and operation of resilience financing from the Rockefeller Foundation, the Climate Bonds Initiative receives funding from other large philanthropic entities, including the Gordon and Betty Moore Foundation; the Oak Foundation, the Frederick Mulder Foundation (formally Prairie Trust); the KR Foundation; Bloomberg Philanthropies; and, of course, the Rockefeller Foundation.

Recall how the Rockefeller Foundation relied on Arup's City Resilience Index and the 100RC's community consultations to build municipal resilience strategies. In much a 
similar way, the Climate Bonds Initiative developed the Climate Resilience Principles by starting with an abstract definition of resilience then expanding that conceptual basis into a particular practical application. The two processes are analogous. In this case, a "framework for Climate Resilience Criteria to be applied to all assets and activities included in a bond seeking certification under the Climate Bonds Standard" (CBI 2019, 31). The framework accomplishes a similar goal of translation as the City Resilience Index. Furthermore, the Climate Bonds Initiative started with definitions of adaptation and resilience found in a 2014 International Panel on Climate Change report. The definition they turned to considers resilience to be:

The capacity of social, economic, and environmental systems to cope with a hazardous event or trend or disturbance, responding or reorganizing in ways that maintain their essential function, identity, and structure, while also maintaining the capacity for adaptation, learning, and transformation (IPCC 2014, 5).

This systems-level understanding of resilience is broad and not limited to a specific context. The desired end state for Climate Bonds Initiative, however, is climate resilience as an investment technology. As such, when applied to portfolio finance, Climate Bonds Initiative's practical definition of resilience needed to place emphasis on a different set of variables. In order to "inspire investors and issuer engagement," Climate Bonds Initiative says that:

Climate resilience investments improve the ability of assets and systems to persist, adapt and/or transform in a timely, efficient, and fair manner that reduces risk, avoids maladaptation, unlocks development and creates benefits, including for the public good, against the increasing prevalence and severity of climate-related stresses and shocks (CBI 2019, 18).

With a focus on assets, risk avoidance, and benefits, this context-specific definition of resilience investments underpins the framework of the Climate Resilience Principles. The principles are broken-down into three pillars: framing, design and management. 


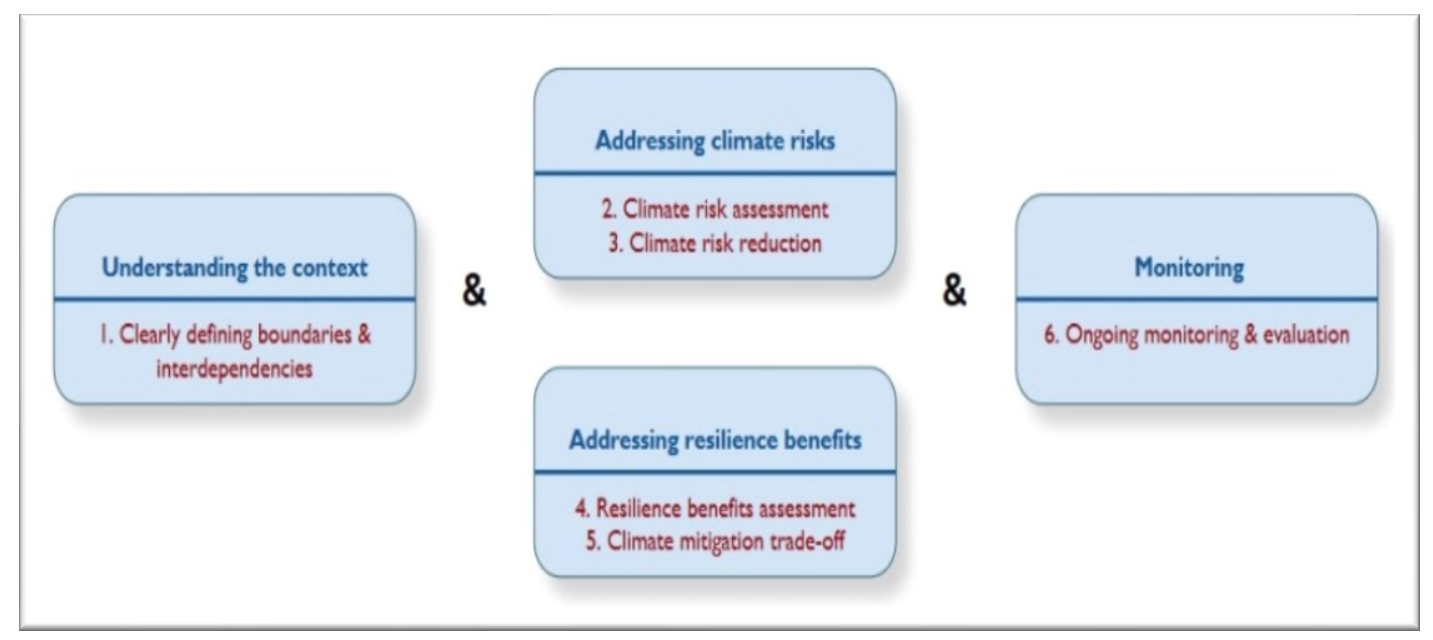

\section{Illustration 11 Climate Resilience Principles}

Image source: CBI 2019, 31.

The Climate Resilience Principles developed by Climate Bonds Initiative are intended

to:

require issuers to understand the climate risks faced by the asset and/or activity and system which is the focus of the bond's use of proceeds, or impacted by it, and to address those risks through flexible risk-reduction measures which take account of inherent uncertainties around climate change, and ensure the asset, activity and/or system is 'fit-for-purpose' in the face of that uncertainty (CBI 2019, 31).

Taming uncertainty through a series of risk modelling activities is also required in order to monitor the "performance of assets and activities" to "ensure adjustments to risk reduction measures are made over time" (CBI 2019, 31). The invitation to invest in climate resilience through this scheme is marketed as a way bond investors can capitalize on an emerging opportunity to both earn profits and "enhance the resilience of a system or community" (CBI 2019,9). According to the Climate Bonds Initiative, the intended benefits to the private sector are numerous and include "indirect financial benefits, such as enhanced liability management, increased reputation among local communities, trust among suppliers and customers, and employee protection" (CBI 2019, 9). A few of the 
examples of how bond proceeds could be used under this model include upgrading and modifying existing infrastructure to be climate resilient; relocation of at-risk infrastructure; use of climate resilient crops; the use of novel fodder species and enriched feed for livestock at the farm level; and, multi-asset, multi-action adaptation projects, that may include a series of timed or triggered upgrades (CBI 2019, 10). Once the world is seen as being composed of assets and liabilities, investors can choose to enhance the resilience of worthy causes while collecting a return.

At the start of this chapter, I showed a gradual evolution in organizational resilience thinking, springing between calls to find ways to adapt rapidly to changing environments while fostering desired human traits to overcome vulnerability and uncertainty. The technology of resilience bonds is yet another evolution in resilience engineering. The resilience bond acts as a buffer between unpredictable organizations and unpredictable environments. Municipalities are too capricious, unstable, and sometimes erratic; the environment too unruly, fickle, and sometimes volatile. Catastrophe and resilience bonds, with their associated juridico-legal backing in the form of contracts and speculative financial controls, are much more predictable. Losses can be measured against potential gains and elusive human resilience traits are almost entirely sequestered. It is a way of governing resilient subjects and objects. The private capital that assembles in the form of investments in the bond market is also the same private capital that designs, oversees, and builds infrastructure projects - the benevolent destinations of bond proceeds. The analogy, then, is closer to that of placing a bet on heads and tails simultaneously. While potentially benefiting from the occurrence of a climate disaster and climate disaster 
avoidance measures, private capital is free to flow in both directions within the resilience marketplace.

The conditions of possibility for the emergence of financialized resilience can be located within a historically contingent set of relations. They start with the view that cities are "overexposed and underinsured" to extreme weather events, earthquakes, floods, and wildfires (Re.Bound 2017, 3). Next, financialized resilience is made possible by changes in weather patterns, to be sure, but also by city density and growing metropolitan populations that share geographical proximity and a certain social distance/dissidence. Then, when an event like a hurricane or a flood occurs in a populous city, many feel the impact. Networks of urban relationships are fragile and, as such, a disruption to these networks is readily experienced. Relatedly, "aging and failing infrastructure systems...increase the potential for cascading failures and devastating losses" (Re.Bound 2017, 3). Often municipalities own these infrastructural arrangements and the repairs needed following a calamity are paid for using declining pools of tax dollars. Discontent, disquiet, distress, and dread. Disasters are not easy to deal with either; the complexities of preventing disturbances are dizzying. The material conditions of metropolitan cities have themselves led to a heightened exposure to unpredictable risks. Financialized resilience pivots on these material and social conditions to position insurance schemes, investment funds, and speculative finance as viable routes to securing and safeguarding municipal and public infrastructure and, by consequence, urban ways of life. What is considered to be a public good teeters on the edges of the hegemony of financialized capitalism. 


\subsection{Conclusion: Capitalizing on Disaster}

In what has become a yearly occurrence, spring floodwaters creep out onto roads and into basements across the Ottawa Valley and Outaouais region. I am wary. Much talk of disaster recovery and resilience has occurred since the long winter's snow began to melt. The immediacy of a flood provides a vivid and opportune moment for policy makers and politicians to push new ways of inhabiting flood-prone areas. All proposals are welcomed. Needed, even. The problem of financing pinches sensitive nerves. Consideration. Clean up. Debate. Engrained patterns resurface. Some small changes occur: more rapid communication between departments, more streamlined emergency processes-machines are purchased to more quickly fill sandbags. Waters recede. Summer fades memory. Snow falls. Spring will eventually turn up too. Cyclical. But it is not this relapsing struggle with unruly rivers and frail dams that I am most leery of. The water will do what the water will do.

The proliferation of clean-up services and post-disaster profiteering has been well documented (Gotham 2012; Klein 2007; Mutter 2015). I have not explored this side of the financialized resilience form, but these privatized elements are present. What I have explored in this chapter includes proposals and so-called imaginative responses that have been bent on securing cash to retrofit or upgrade infrastructure or on offering incentives to property holders to relocate to higher ground. The focus of these interventions, for the most part, has been the financial side of disaster resilience with calculated summoning of individuals' engrained resilient traits. As demand for financialized resilience blooms (BIS 2009), so too does the supply. As I have shown, the financialized form of resilience is underscored by private capital and an expectation of a return on investment. Catastrophe 
and resilience bonds offer an alluring profit generating mechanism for savvy investors willing to place bets on climate change's devastating effects. The seemingly now antiquated model of tax-supported municipal infrastructure investment has been, essentially, outsourced to shareholder-led conglomerates that claim to be working on behalf of the public good. Dilemmas over accountability, transparency, and governance have consequently surfaced. The potential of financialized resilience to overtake publicled projects is imminent.

If we were still wondering if the concept of a resilience dividend would stick, the 2019 iteration of the Global Platform for Disaster Risk Reduction convened by the UNDRR, can quiet our reservation. The three-day event brings together some 4,000 participants including climatologists, meteorologists, government officials, and representatives of signatory countries of the Paris Climate Agreement and the Sendai Framework: the kind of folks who take disaster risk reduction seriously and have the means to enact disaster risk reduction strategies and policy. The overall theme of the conference: 'Resilience Dividend: Towards Sustainable and Inclusive Societies'. It is one indication of the direction that the UNDRR wishes to steer discussions surrounding sustainable development goals and disaster risk in general. One of the working sessions of the gathering is aptly titled 'Unlocking the Resilience Dividend'. The use of the concept is meant to signal, "How managing disaster risk and risk-informed development investments pay dividends in multiple sectors and geographies, across all scales, and encompass more than just economic profit, also strengthening outcomes across the social, economic, financial and environmental sectors in the long term" (UNDRR 2019, 8). In 
the imaginative, resilience dividends trickle down. In the actual, resilience dividends accumulate in the form of profits from bonds.

Resilience has come a long way from being associated with echoes. The language and metaphors of resilience have indeed become interlaced with those of finance. This chapter began with a selective review of administrative and organizational studies literature dealing with resilience. Through this overview, I showed where the desire to measure resilience arose. Next, I showed how the RAND Corporation managed to extract value from resilience interventions by creating the RDVM. RAND has taken steps to paint the RDVM model as neither a 'black box', nor a 'plug-and-play' tool. The model is presented as a "flexible approach that helps users think about interventions in a structured, systems-focused way," as it "guides users in how to use data to provide evidence" of a resilience dividend (Bond et al. 2017a, 2). The resilience dividend is the pivot between philanthropic resilience and financialized resilience. The RDVM is seen as being of equal benefit to decision makers and practitioners with a full range of data-or even when only partial data is available for analysis. As such, it is the dividend that is important, not the craft of quantifying it. I showed the effects of calculating a resilience dividend by exploring the emergent field of resilience bonds. I argued that the financialized form of resilience is born by a financial desire to extract surpluses from resilience interventions through the resilience bond market. 


\section{Chapter 7: Conclusion: Bouncing Back, Bouncing Forward}

The water is rising all around them. Waves are topping seawalls. Saltwater is bubbling up through storm drains and canals. And it is seeping through the porous limestone bedrock South Florida sits on, contaminating aquifers that supply the region's drinking water. Wide swaths of Miami-Dade County could be underwater by the end of the century, scientists warn. The sheer existence of the greater Miami area-home to 2.7 million people-is threatened by flooding and sea levels rising faster than experts predicted...it is one of the most hurricane-prone regions on earth, and this August, will commemorate the 25th anniversary of Hurricane Andrew, a destructive Category 5 storm. The Zika pandemic arrived last year. The area's infrastructure is aging. Its mass transportation system is overtaxed. And poverty and a lack of affordable housing remain chronic problems.

Roberts 2017b, 68

A story, a good story, as Walter Benjamin tells us (2007, 83-109), is marked by the defiance of expectations. Surprises. The storyteller, from a lineage of farmers and trading seamen, master craftsmen and travelling journeymen, relied on experience to form the substance of stories that could be recorded, retold, and passed down. These new storytellers could transform the tale, adapt it to their own experience, and defy expectations anew. Experience and imagination combined in ways to produce surprise. It was also more than simple surprise. The author of stories, good stories, also offered counsel. "Counsel," for Benjamin, "is less an answer to a question than a proposal concerning the continuation of a story which is just unfolding" (86). Combined with practical — but not necessarily pragmatic or programmatic — ends and "woven into the fabric of life," counsel coalesces into wisdom (86-87). Information, the relevance of which is found in the now and is made old in the very moment that it is produced, has come to replace the story, which is timeless and "does not expend itself" (90).

The storyteller is gone too, Benjamin tells us. Whereas an audience, building on a narrative and discursive devices used by the storyteller, was able to incorporate a story 
into its own experience, consumers of information gratify immediate needs. Furthermore, information demands "prompt verifiability" (89) and, due to the lack of connectivity between consumers and producers of information, is unable to confer wisdom. Information thus serves to satisfy a will to know and a lust for knowledge. Surprise, not surprisingly, is not a characteristic of information.

In recent times, Benjamin's storyteller form has undergone yet another transformation. From recounting stories of experience outwardly—-for an audience, for counsel, for surprise — his exercise has been recast inwardly. An author simultaneously also plays the part of the audience during a rendition of a tale. The 'front stage' has become welded to the 'back stage' (Goffman 1959); the story narrated to oneself is to be devoid of surprise, constructed so as not to challenge expectations or disrupt flows. Several illustrations of this will steer us, and $m y$ story of resilience, toward clarity—and to a close. Counselling, marketing, disasters.

A counselling clinic located in Ajax, Ontario describes its clients' psychological processes prior to commencing what is called 'narrative therapy' as follows:

Stories in a 'narrative therapy' context are made up of events, linked by a theme, occurring over time and according to a plot. A story emerges as certain events are privileged and selected out over other events as more important or true. As the story takes shape, it invites the teller to further select only certain information while other events become neglected and thus the same story is continually told. These stories both describe and shape people's perspectives on their lives, histories and futures (NTC 2019, n.p.).

Problems occur, the clinic claims, when this pattern produces continual negative thoughts. Intervention is required to change the story, to focus on different information within one's narrative. Individuals interested and in need of such services are invited to "collaborate with people in 're-authoring' the stories of their lives" (NTC 2019). The 
story that defies expectations is lacking, replaced by 'co-authorship' of a radically different form than Benjamin's storyteller. A second example comes to us from the American Marketing Association (AMA).

The AMA, established in 1937, produces tools and resources to support marketing practice. As a professional organization, it serves a knowledge transfer function by financing and disseminating marketing research. One of its members, BizBuilder magazine, produced a report detailing that consumers are eager to purchase products that are associated with brands that tell stories. The AMA extended this assumption to aspiring employees, urging for the creation of personal branding. "When writing your story for your own personal brand," the AMA says, "it is you who is the living story. The beginning stages of developing your story should start with introspection" (Huhman 2012, n.p.). Accordingly, we are offered prompts for this introspective journey: "Describe the path you took to get to the place you are today. How is your product or service different than others? How can you set yourself apart and succeed in your industry?" (Huhman 2012, n.p.).

The branded labourer, of course, comes armed with a curriculum vitae and a list of references. Information to be verified. The narrative story produced by 'personal branding' serves to construct a linear model - 'describe the path' - in an approach that omits the possibility for a disrupting reflexive moment. Furthermore, the branding carries the effect of rendering the reflexive individual a commodity. The task of objectifying a potential employee reaches completion when they are made into an object of labour. Much like seeking narrative advice from counselors, the social type of the job seeker relies on an entire mode of production for their existence. As such, institutional and 
systemic aspects of social forms are important to keep in mind. They also require materials for their operation, such as clinical guides, that seem to vanish from accounts of their effects. The branded labourer is thus a part of resilience governance structures that promote a positive 'freedom to' act (O'Malley 2013). The above two examples, I think, point to attempts to limit surprise and highlight aspects of the philanthropic and financialized resilience forms that this dissertation has shed light on. The actors are different; the processes, however, are not so dissimilar. It's about structuring the unruly: taming chance (Hacking 1990) to overcome surprise.

C. Wright Mills proclaimed that, "ours is a time of uneasiness and indifference" (2000, 11). This mixture of emotional responses, for Mills, is spurred by both awareness and ignorance of threats. Brad Evans and Julian Reid's contemporary formulation"Ours is an age of catastrophe" (2014)—is pointedly analogous. From terrorist plots to environmental calamities, and from plunging stock rates to pandemics, exceptional failure has morphed into quasi-habitual breakdown: daily conditions of living. While an awareness of disaster may serve to configure how we act and react to events, ignorance and secrecy serves just as an important role in forming thoughts and actions (Simmel, 1906). Surprise, when the previously hidden and unknown emerges, has been seen as part and parcel of life. Ralph Waldo Emerson, who Nietzsche frequently quoted, tells us that, "life is a series of surprises and would not be worth taking or keeping if it were not" $(1903,67)$. Yet, it seems ours is an age of non-surprise.

In 2005, when Hurricane Katrina hit the town of New Orleans, it "should have come as no surprise" that the city's levee system failed (NPR News 2005). On July 6, 2013, when 74 train cars loaded with crude oil derailed and exploded on the tracks that run 
through the town of Lac-Mégantic, Quebec, killing at least 42 people and levelling more than 30 buildings, it was seen as having been just a matter of time before such an incident would occur. While high-risk technologies carry catastrophic potential (Perrow 1999), John C. Burnham (2009) argues that most, if not all, contemporary disasters do not carry the weight of being called accidents. Accidents necessitate that the cause of calamities remains unknown or somehow unpredictable. The language of injury and disability, Burnham tell us, has come to prominence precisely because of an expansion in catastrophic knowledge and related preventive measures. Accidents are surprises only inasmuch as they are not anticipated. The calamities that lie ahead, however, have been anticipated.

In trying to understand the networks that emerge around philanthropic and financialized forms of resilience, the notion of predictable surprises is useful (Bazerman $\&$ Watkins 2004). Predictable surprises catch agents and organizations off guard, much like a surprise, but are characterized by the knowledge of the possibility of an event-and prior awareness of the information needed to anticipate the event and its consequences. It's an appropriate concept for the post-narrative solutionist (Morozov 2013) stream of resilience-building this dissertation has been focused on. Disasters linked to climate change are the classic contemporary example of predictable surprises (Bazerman 2006). Predictable surprises rely simultaneously on a close proximity of agents to information, and the creators or holders of that information, and on a distancing of mental acceptance of particular bits of information (rising sea levels, for example). These categories are premised on the existence of a rationally calculating, entrepreneurially inclined, riskadverse actor (Lentzos \& Rose 2009; Neocleous 2012) that is simultaneously "self- 
sustaining, empowered, [and] collectivized (Larner \& Moreton 2016)-the resilient subject.

In this dissertation, I have not presented a definitive definition of the concept of resilience. Instead, I have shown how a variety of actors mobilize the concept and put resilience to work in their own ways. My focus in Chapter 4 was to document a series of ways that resilience has been envisioned in order to show how many resiliences can coexist - resilience multiple. I offered a select reading of some of the ways that the concept of resilience has been deployed. I showed how resilience has had a trajectory—a career. The range of definitions of the concept that I presented is indicative of not only a sustained interest in the term over time, but also indicates a series of truth claims concerning what the concept can and cannot (or should not) address. I pointed to the development of both resilience centres of synthesis and resilience centres of calculation. I argued that both types of institutional assemblages create and expand the resilience network. At each subsequent alteration of the concept, humans have been distanced from what makes resilience actually work. Paying attention to things-nonhumans-through an ANT lens, allowed me to retain a focus on what was being targeted for resilience interventions as well as resilience network-building efforts.

In Chapter 5, I introduced the concept of philanthropic resilience as a way to make sense of the Rockefeller Foundation's 100 Resilient Cities (100RC) initiative. I showed how the 100RC plan involved enrolling corporate partners who developed resilience models and tools, and subsequently selecting cities across the globe to participate in the experiment. I argued that the target of the 100RC's work was to integrate their definitions of resilience into municipal programs and policies. I also showed how the Rockefeller 
Foundation strived to limit cities' decision-making abilities concerning resilience interventions through contractual agreements and the adherence to Arup's City Resilience Index. Combined, these two components worked to frame the deployment of resilience. Models, guidelines, and templates structured how municipalities engaged in resiliencebuilding efforts. I showed how the 100RC initiative also gave birth to a new category of municipal actor-the Chief Resilience Officer. I traced the work that Chief Resilience Officers do, as well as how these actors fit into a larger resilience network. Chief Resilience Officers operate as conduits, combining the theoretical with the practical. I argued that philanthropic resilience starts with the philanthropic sector's involvement in, and desire to influence, municipal programs and projects. One of the form's key characteristics is its drive to link private capital with public institutions/goods. I also argued that a second key characteristic of philanthropic resilience resides in its ultimate goals: business continuity, return on investment, and standardization. In order to sustain this argument, I followed the actors that constitute the resilience network into the field of finance.

In Chapter 6, I critically examined the ways in which the discourses and practices of resilience have been informed by financial logics. I traced the rise of business and organizational resilience discourses, arguing that the desire to measure resilience was born from within the organizational sphere. I then argued that the financialization of resilience is rendered most evident by RAND Corporation's development of the Resilience Dividend Valuation Model (RDVM). The financialized form of resilience also places humans at arm's length. Through technical appraisal models, such as the RDVM, project managers are able to quantify the potential financial returns of resilience-building 
efforts. These metrics serve to inform a growing industry of specialized insurance products aimed at the resilience market. I traced the main theoretical and applied aspects of the RDVM to show how the model served a fundamental role in quantifying the 'resilience dividend'.

I have argued that resilience dividends connect philanthropic resilience to its financialized form. Once resilience can be valued, and a quantifiable dividend can be extracted from resilience interventions, resilience itself is free to circulate much like capital. The financialized form of resilience prioritizes quantifiable data points over qualitative assessments. This form of resilience promotes accurate measures of weather patterns and robust risk projections as more meaningful than how people cope in their day-to-day lives. The real-life struggles of rebuilding a community following a disaster are reduced to a single metric: a dividend. I showed how resilience dividends could be traded and used within speculative financial arrangements through the development of a resilience bond framework proposed by Re.Bound (2017). Resilience bonds, a derivative of catastrophe bonds, have been sold in an effort to bolster capital stocks for infrastructure development as well as divide risk among more actors. With the advent of resilience bonds, a project must show profitability as well as the capacity to spread risk in the event of catastrophe. Relying on an expanding set of data, resilience bonds epitomize how resilience has come to be understood and practised: technical, data driven, without risk or surprise, and exportable. What worked in one city's downtown core could, should, and will work in another's. Relatedly, I shed light on the theoretical and practical ways that climate resilience bonds have been structured to support certain kinds of interventions for particular private interests. I showed how financialized resilience has 
roots in the Rockefeller Foundation and seeks to incentivize municipal authorities through capital investments in resilience projects. I have also argued that financialized resilience has been bolstered by philanthropic resilience: the two go hand in hand. This configuration is how resilience meets the demands of calculability, profitability, predictability, and surplus extraction: the business of resilience.

\subsection{What's Next?}

What causes a disruption to become a disaster? We do. Disasters are almost always human made or, at least, intensified by how well people have prepared for, responded to, and recovered from a crisis. Disasters are the result of disruptions coinciding with vulnerabilities, our lack of awareness of the threats we face, our lack of diversity of options and choices to prevent disruptions or manage them when they occur, and our instability and poor adaptiveness to new circumstances as they emerge.

Rodin 2014, 92

No other cars. The lights are out. Doesn't look good. The sign reads Fermé: déménagé. Our local restaurant has shuttered its doors and moved on. Merde. We pick up grocery store pizza. A desperate move. Weeknight dinners are unremarkable. The goal is to eat, at least something, then head to bed. Early mornings and commuting into the city on our minds. Maybe we'll watch a few minutes of a movie or a Netflix show, read a few pages of a book. It wasn't the best food anyway. Overly salty egg rolls and mostly broccoli stems. Noodles were passable. Restaurants and rural towns don't easily go well together. At least not in our rural town. A restaurant opening is a big deal; but, one closing usually reaffirms what is taken for granted - city folks have it all.

For those who can afford it, the metropolis offers a tyranny of choice. Availability is not a problem. The factories that were once at the centre of the urban experience have, for the most part, been replaced by other economic activities. "The city, of course, is not just 
a built environment consisting of buildings and streets and subways and parks and waste systems and communications cables," Hardt and Negri remind us, "but also a living dynamic of cultural practices, intellectual circuits, affective networks, and social institutions" $(2009,154)$. Capitalism, the story goes, has eroded the fabric (hopefully not the foundation) of social and political life. Market rationalism and a quest for profits have all but destroyed the idea of urban commons. Capitalism, in its biopolitically driven neoliberal version, has churned the metropolis into the centre of profit extraction at the expense of the social condition. The imagined good and sacred of it, at least. Cities pull in people and resources, and the machine pumps out capital, presumably, for a select few. Our forced hand towards cardboard pizza can be explained in much this way-maybe. We decided to live a rural life because the city was too dizzying. Too much noise and too many distractions. We wanted a simpler way. It isn't always simple, nor is it always distraction free. The idyllic versions of both the metropolis and the rural are complex, not easily captured or conveyed. Messy. So, too, is resilience.

Practitioners and concerned community members, on the whole, do not care much about the subtleties of the historical trajectory of resilience discourses. In times of uncertainty, people tend to want strategies to move forward and ways to help each other. When a flood hits, or a hurricane strikes, I highly doubt it is the historically specific aspects of aid work that homeowners are paying attention to while deploying sandbags or boarding up windows. Questions of when people can go back to their homes will win that intellectual battle. If turning to resilience can help, who am I, as an outsider, to contest that decision? From this perspective, resilience is simply another way forward, a way of thinking and defining actions that can have real applications and on-the-ground 
implications. When the dust settles or the floodwaters retreat, however, we are often left with a series of questions: What could have prevented the crisis? Could more be done in the future to ward off calamity? Why did this happen? Throughout this dissertation my intention has been to raise questions - to question deeply. In doing so, to make resilience matter. To the list of questions that we inevitably ask each other and ourselves after a disaster, my intention has been to add: who gains, and who loses?

As I indicated in Chapter 5, the 100RC initiative came to a close in April 2019. That ending coincided with my own sort of culmination with resilience, with this particular project about resilience anyway. That coincidence was rendered more fitting by another ending: the last volume of the journal Resilience. Edited by David Chandler, the journal began in 2013 - October, actually — exactly when I began (officially) my own resiliencefilled transience. In the official journal closure announcement, Chandler cites a lack of institutional subscriptions and the resulting financial unviability for the journal's publisher (Taylor \& Francis) as the main reason that the seventh volume was the last. Although a steady stream of intellectual supply existed and demand (article downloads and citations) was high, it came down to money. It is curious, then, that in Chandler's concluding article in the journal, he advances an argument that resilience "appears to be increasingly exhausted as a governmental or analytical framing" $(2019,1)$. After seven years of research showing how engrained the concept of resilience is (was?), there now is no future in the idea. As in Stephen King's The Dark Tower series, the world has moved on, according to Chandler. Onto what, then? What's next?

Perhaps Chandler is correct in predicting that resilience and other forms of policy arrangements promoting adaptation will dwindle. Perhaps the termination of the 100RC 
initiative was part of this retreat of resilience. It would be tempting, likewise, to point to populist politicians' stance on climate change and environmental protections as also being part of the retrenchment of resilience and adaptation. Perhaps, much like Chandler's journal, it is not a question of supply or demand, but a question of money. The form of resilience that I have shown to be circulating looks different than what was in circulation in 2013. From the philanthropic form to the financialized form, who/what is envisioned to be resilient and how that resilience is to be attained shifts. Maybe Chandler wanted to frame the journal's closure in terms that shifted the onus outward (resilience will not be around much longer anyway). I suspect that he is not so naïve, though. What does a journal look like when its focal point has morphed into a profit-generating mechanism? What are the long-term effects of the resilience turn? Is it possible to appeal to resilience without its accompanying philanthropic mechanisms? Can resilience be mobilized in non-financialized forms? Is it imaginable that psychology and narrative therapy's focus on resilience could be applied to organizations like municipalities? Are cities in need of re-articulating their narrative? What would re-branding ourselves as resilient based on a scorecard look like? These are the types of questions that require additional attention. I have offered only a partial glimpse at resilience. Philanthropic and financialized resilience will evolve as new actors enter the network. The rules of the game will shift and mutate accordingly. There will be unavoidable quarrels over definitions and objectives. The business of resilience will carry on. 


\subsection{The 'Art' of Resilience}

Resilience forces us to think more strategically about how we plan, build and run our cities - and ensure that our systems are working for all citizens. If we are spending fortunes of money rebuilding and repairing after emergencies, we'll never make a dent in any of our other goals — whether it's fighting disease outbreaks, social inequities, or rising unemployment. It is critical that we not just see resilience as something that we call on after a shock, but something we actively pursue - governments, private enterprise, and citizens - together in those moments in between...not just for the benefit of our city, but for all cities... and because our future is an urban future - for the betterment of the world

Judith Rodin, 2015, n.p.

Artists trying to find work and make music in the busy streets of Vancouver, British Columbia, are faced with financial, personal, and socio-economic circumstances that have put pressure on their art-making abilities. Perhaps from a desire to find more accommodating surroundings, or maybe from a need for change, artists have left Vancouver to find refuge in more sustainable cities across the world. There are, however, a growing number of artistic hubs, designed to capitalize on local talent and, more importantly, keep artistic flight in check. "As the map of Vancouver continues to be divvied up among real estate developers and powerful entrepreneurs," Mark Streeter tells us, "powerful voices from the city's resilient cultural communities remind us of what the map doesn't show" (2018). Vancouver's 'resilient' artistic scenes are among the most recent additions to an ever-expanding list of people and things that are praised for the ability to bounce back, face adversity, and 'keep on keeping on'. What is different is that these artists eagerly embrace the label of resilience. I wish to pause momentarily on the coupling of art, resilience, and empowerment found within this example, for it is indicative of what Larner and Moreton (2016) signal as ways in which "communities and individuals are envisioning and experimenting with alternative environmental, economic, 
political, and social futures" as well as an example of how "heterogeneous aspects of political life are being taken up and reconfigured in governmental formations that attempt to move beyond neoliberalism (51).

In the previous pages, I have stressed that resilience has emerged as a conceptual framework that promises to tame uncertainty and prepare for calamity. While doing so, the deployment of resilience is creating avenues for new forms of sociability. As I have shown, municipal governments have embraced resilience planning. These plans include a reimagining of how the urban is to be negotiated, with potentially significant implications for the spatial disposition and configuration of people and things within the urban. If we are to continue to take seriously the implications of the business of resilience, future research in the field will need to shed light on which changes to the urban environment carry influence over the long term and which fail with a return to entrenched ways due precisely to what they are advocating: bouncing back. While we must keep an eye on moments when resilience is deployed as a form of 'actionable knowledge' (Henderson \& Denny 2015) within individualizing governance regimes, we also must attend to the progressive potentialities that resilience carries—especially for historically marginalized and silenced communities. 


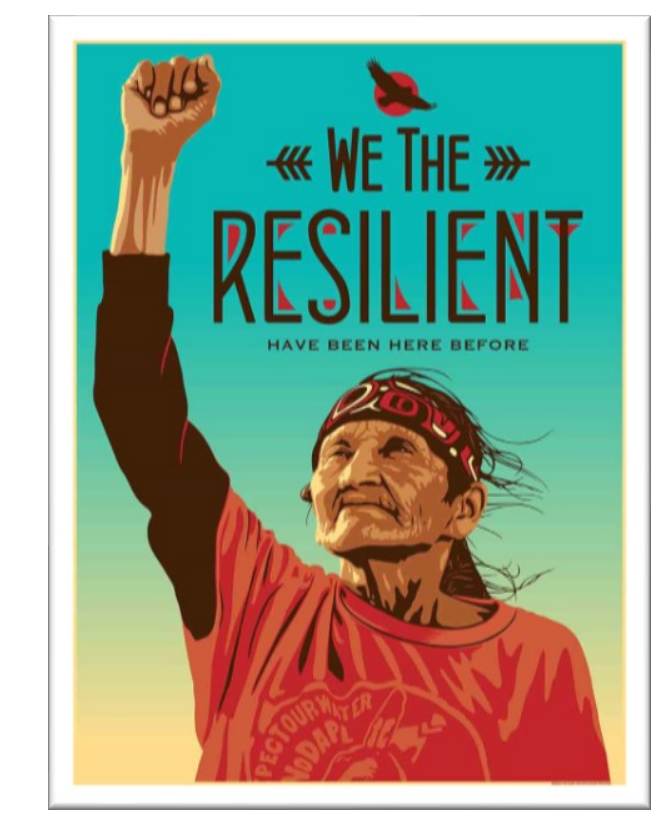

\section{Illustration 12 We The Resilient}

Image source: http://activistnyc.tumblr.com/post/

165031042893/defenddaca- donald-trump-announced-that-he-is

Under certain resilience frameworks, strategies and tactics are aimed at overcoming crisis, returning to prior states following a traumatic experience, and building capacity to overcome potential future disruptive events. Resilience can come to exist as a form precisely because it allows for additional social forms to emerge. Will we start to categorize people and things as more or less resilient? Will we be measured against a resilience barometer? There are signs that this work is already underway. For example, the Global Resilience Partnership, convened by the Rockefeller Foundation and USAID (with financial commitments worth over USD150M), created a typology of resilient cities. Montreal topped the list in 2014, supposedly because of aging but well maintained infrastructure and low levels of unemployment. Grosvernor, an international property investment firm, has a similar ranking of cities. Toronto, Vancouver and Calgary were positioned as being most resilient compared to other Canadian cities. Toronto scored 100 
'Adaptive Capacity' points—-for what it's worth. Sorting, classifying, and ranking cities is just one of the ways that resilience can be made into an assessment category. Classifications lead to decisions that have powerful social effects-where to relocate one's family, how many resources are offered by schools, how at-risk youth are supported in the community, how affordable public transit is, where new roads get built. But it doesn't have to be this way. The art of resilience, both in terms of thinking of resilience work as craft as well as the aesthetics of resilience itself, can help us uncover another side to the resilience story.

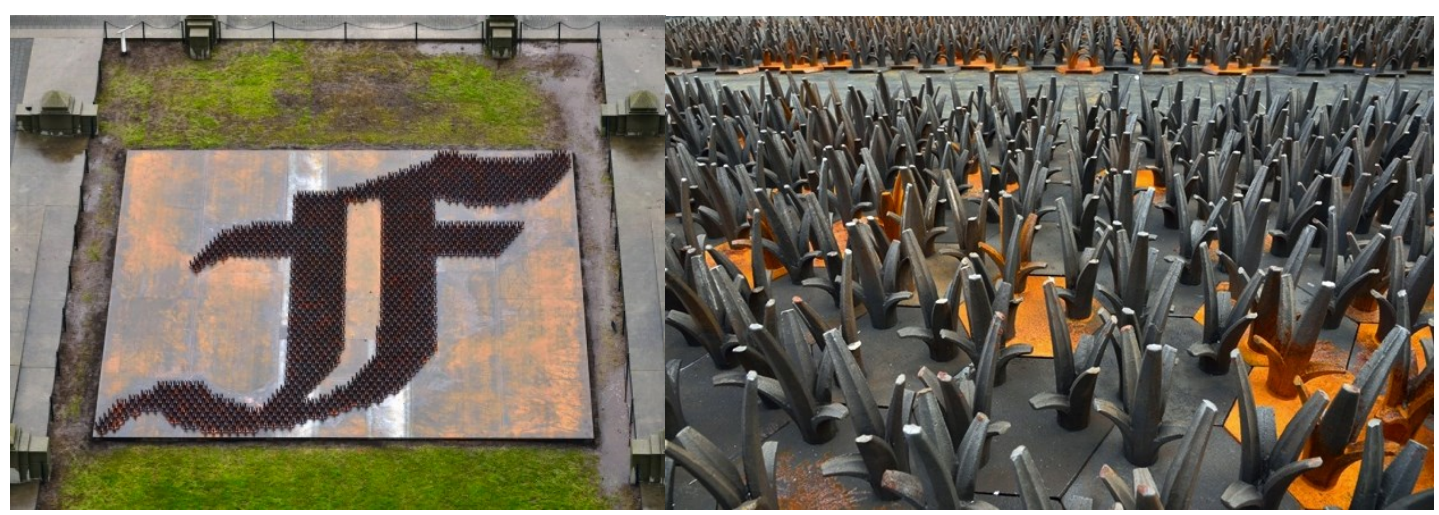

Illustration $13 F$ Grass installation in Vancouver, B.C

Image source: http://www.straight.com/arts/793716/ai-weiwei-plants-f-grass-part-vancouver-biennale

In Harbour Green Park, a 182 square metre art installation attempts to convey the essence of resilience. Designed by Ai Weiwei for the Vancouver Biennale, the installation is portrayed to represent "the relationship between the individual and the collective and the resilience of the human spirit ${ }^{32}$ ", (Vancouver 2014). Entitled 'F Grass', the display offers an illusion of a field sculpted to form a calligraphic letter $f$. Laurence tells us ' $\mathrm{F}$ as in freedom, $\mathrm{F}$ as in fortitude, $\mathrm{F}$ as in 'Fuck you!' to surveillance, censorship,

\footnotetext{
32 The installation is intended as a critique of what Ai Weiwei, and others, perceive as draconian Chinese state censorship, control, and secrecy (Luk 2014).
} 
and oppression" $(2014)^{33}$. The marketing director for the Biennale, Miriam Blume, says that, "grass is ubiquitous - we barely even notice it in the landscape but yet it's quite resilient" (Luk, 2014). Grass represents a "beautiful and powerful metaphor for the human spirit," Blume continues, "you try to stomp it and you try to weed it out, grass keeps coming back" - a testament to the fact that even if it looks fragile and alone, grass, and by extension the human spirit, can bounce back. The ecology of grass and the condition of the human spirit are simultaneously captured within the installation. The art can be looked at "both in terms of individual pieces showing a kind of resiliency in ordinary lives with ordinary people," and, as Blume matter-of-factly states, "in terms of the collective." This triad is artistically fashioned by 1,328 tufts of twisted iron: ornaments, individually and collectively representing resilience. The seeming disparity that iron is much less elastic than it is rigid is symbolic to the installation's demonstration that resilient bodies are hardened bodies. That human spirits can be both fragile and sturdy. Resilient.

The resilient form, however, is not concerned with disciplining bodies in the traditional sense. Resilience does not inherently make individuals more pliable. And, contrary to what popular 'how-to guides' would like us to believe, resilience cannot be accomplished in solitude. Resilience requires relations. It is relational. The network that I have been mapping up to this point attests to this dimension of resilience. At the same time, there is no monopoly on who can summon resilience as a label or identity. Even though the Rockefeller Foundation has done extensive work to create and sustain a resilience network, the way resilience is done philanthropically and financially can be

\footnotetext{
33 Incidentally, the letter $\mathrm{F}$ is also as in 'Facebook', that multi-billion dollar company.
} 
challenged and resisted. Who wins and who loses depends on the networks that are formed around particular deployments of resilience. The concept of resilience contains an open invitation for it to be mobilized and put into practice in novel ways. Not a requisite. It is, fundamentally, a choice.

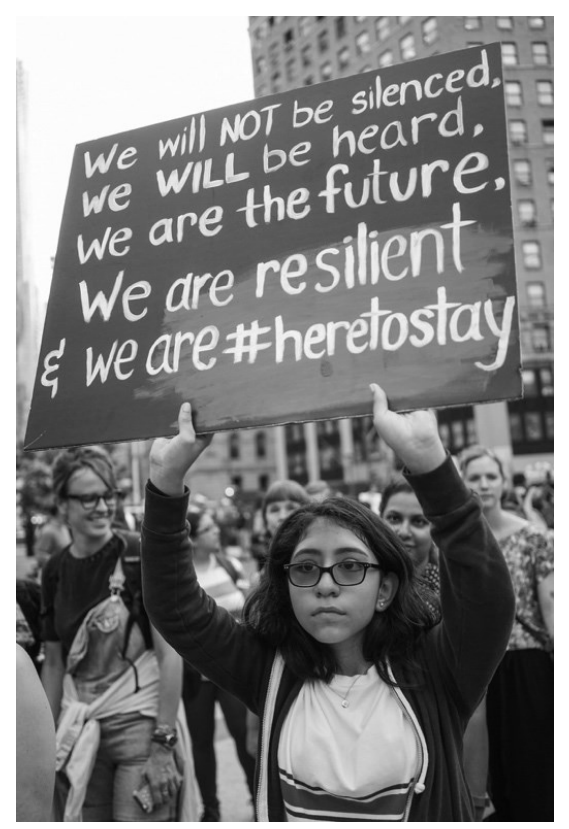

\section{Illustration 14 We Are Resilient}

Image source: https://amplifier.org/downloads/people-shepard-fairey-defenddignity/ 
Appendices 


\section{Appendix A Key Resilience Discourses found in Social Science Publications}

\begin{tabular}{|c|c|c|c|}
\hline $\begin{array}{l}\text { Reference } \\
\text { (First author, year) }\end{array}$ & Discipline & Level of Analysis & Definition \\
\hline Bodin, 2004 & Physical Sciences & Physical Systems & $\begin{array}{l}\text { The speed with which a system returns to equilibrium after } \\
\text { displacement, irrespective of how many oscillations are } \\
\text { required. }\end{array}$ \\
\hline Gordon, 1978 & Physics & Physical Systems & $\begin{array}{l}\text { The ability to store (strain) energy and deflect elasticity under a } \\
\text { load without breaking or being deformed. }\end{array}$ \\
\hline Holling, 1973 & Ecology & $\begin{array}{l}\text { Ecological Systems - } \\
\text { Original }\end{array}$ & $\begin{array}{l}\text { Measure of the persistence of systems and of their ability to } \\
\text { absorb change and disturbance and still maintain the same } \\
\text { relationships between populations or state variables }\end{array}$ \\
\hline Waller, 2001 & Ecology & Ecological Systems & $\begin{array}{l}\text { Positive adaptation in response to adversity; it is not the } \\
\text { absence of vulnerability, not an inherent characteristic, and not } \\
\text { static. }\end{array}$ \\
\hline Klein, 2003 & Ecology & Ecological Systems & $\begin{array}{l}\text { The ability of a system that has undergone stress to recover and } \\
\text { return to its original state; more precisely (i) the amount of } \\
\text { disturbance a system can absorb and still remain within the } \\
\text { same state or domain of attraction and (ii) the degree to which } \\
\text { the system is capable of self-organizing. }\end{array}$ \\
\hline Longstaff, 2005 & Ecology & Ecological Systems & $\begin{array}{l}\text { The ability by an individual, group, or organization to continue } \\
\text { its existence (or remain more or less stable) in the face of some } \\
\text { sort of surprise. Resilience is found in systems that are highly } \\
\text { adaptable (not locked into specific strategies) and have diverse } \\
\text { resources. }\end{array}$ \\
\hline Carpenter, 2001 & Ecology & Ecological Systems - & Resilience of what to what? \\
\hline
\end{tabular}




\begin{tabular}{|c|c|c|c|}
\hline & & Operational & \\
\hline Holling, 2001 & Ecology & $\begin{array}{l}\text { Ecological Systems - } \\
\text { Heuristic }\end{array}$ & $\begin{array}{l}\text { Quantitative property that changes throughout ecosystem } \\
\text { dynamics and occurs on each level of an ecosystem's } \\
\text { hierarchy. }\end{array}$ \\
\hline Cumming, 2005 & Ecology & $\begin{array}{l}\text { Ecological Systems - } \\
\text { Operational }\end{array}$ & $\begin{array}{l}\text { The ability of the system to maintain its identity in the face of } \\
\text { internal change and external shocks and disturbances. }\end{array}$ \\
\hline Gunderson, 2002 & Ecology & $\begin{array}{l}\text { Extended Systems- } \\
\text { Principally Ecological }\end{array}$ & $\begin{array}{l}\text { The magnitude of disturbance that can be absorbed before } \\
\text { the system changes its structure by changing the variables } \\
\text { and processes that control behaviour. }\end{array}$ \\
\hline Walker, 2006 & Ecology & $\begin{array}{l}\text { Extended Systems- } \\
\text { Principally Ecological }\end{array}$ & $\begin{array}{l}\text { The capacity of a system to experience shocks while } \\
\text { retaining essentially the same function, structure, } \\
\text { feedbacks, and therefore identity. }\end{array}$ \\
\hline Walker, 2002 & Ecology & $\begin{array}{l}\text { Extended Systems - } \\
\text { Principally Ecological - } \\
\text { Characteristics }\end{array}$ & $\begin{array}{l}\text { Capacities of systems (i) to absorb disturbances (ii) for } \\
\text { self-organization, and (iii) for learning and adapting. }\end{array}$ \\
\hline Folke, 2004 & Ecology & $\begin{array}{l}\text { Extended Systems- } \\
\text { Principally Ecological - } \\
\text { Aspects }\end{array}$ & $\begin{array}{l}\text { (i) Latitude (width of the domain) } \\
\text { (ii) Resistance (height of the domain) } \\
\text { (iii) Precariousness } \\
\text { (iv) Cross-scale relations }\end{array}$ \\
\hline $\begin{array}{l}\text { Resilience Alliance, } \\
\text { 2006; 2012; } 2015\end{array}$ & $\begin{array}{l}\text { Ecology/Systems } \\
\text { Theory }\end{array}$ & $\begin{array}{l}\text { Ecological Systems - } \\
\text { Social \& Ecological }\end{array}$ & $\begin{array}{l}\text { (i-2006) The capacity of a system to absorb disturbance } \\
\text { and reorganize while undergoing change so as to still } \\
\text { retain essentially the same function, structure and } \\
\text { feedbacks - and therefore the same identity. } \\
\text { (ii-updated 2012.) The capacity to tolerate disturbance } \\
\text { without collapsing into a qualitatively different state } \\
\text { (iii-updated 2015) Resilience is the capacity of a social- }\end{array}$ \\
\hline
\end{tabular}




\begin{tabular}{|c|c|c|c|}
\hline & & & $\begin{array}{l}\text { ecological system to absorb or withstand perturbations } \\
\text { and other stressors such that the system remains within } \\
\text { the same regime, essentially maintaining its structure and } \\
\text { functions. It describes the degree to which the system is } \\
\text { capable of self-organization, learning and adaptation. }\end{array}$ \\
\hline Egeland, 1993 & Psychology & Individual & $\begin{array}{l}\text { The capacity for successful adaptation, positive } \\
\text { functioning, or competence despite high-risk status, } \\
\text { chronic stress, or following prolonged or severe trauma. }\end{array}$ \\
\hline Butler, 2007 & Psychology & Individual & $\begin{array}{l}\text { Good adaptation under extenuating circumstances; a } \\
\text { recovery trajectory that returns to the baseline functioning } \\
\text { following a challenge. }\end{array}$ \\
\hline Bonanno, 2006 & Psychology & Individual & $\begin{array}{l}\text { Adult capacity to maintain healthy, symptom-free } \\
\text { functioning following potentially traumatic events. }\end{array}$ \\
\hline Cederblad, 1994 & Psychology & Individual & Capacity for successful coping. \\
\hline Connor, 2003 & Psychology & Individual & $\begin{array}{l}\text { Possession of selective strengths or assets to help an } \\
\text { individual survive adversity. (Connor \& Davidson, } 2003 \\
\text { " "biology of resilience") }\end{array}$ \\
\hline Friborg, 2003 & Psychology & Individual & $\begin{array}{l}\text { Ability to sustain normal development despite long-term } \\
\text { stress, adversity, or maltreatment. }\end{array}$ \\
\hline Wagnild, 1993 & Psychology & Individual & $\begin{array}{l}\text { Emotional stamina, a characteristic of people who display } \\
\text { courage and adaptability in the wake of life's } \\
\text { misfortunes. }\end{array}$ \\
\hline Masten, 1990 & Psychology & Individual & $\begin{array}{l}\text { The process of, capacity for, or outcome of successful } \\
\text { adaptation despite challenging or threatening } \\
\text { circumstances. }\end{array}$ \\
\hline Adger, 2000 & Geography & Social and Ecological & The ability of communities to withstand external shocks \\
\hline
\end{tabular}




\begin{tabular}{|c|c|c|c|}
\hline & & Systems & $\begin{array}{l}\text { to their social infrastructure as a result of social, political, } \\
\text { and environmental change. }\end{array}$ \\
\hline Bruneau, 2003 & $\begin{array}{l}\text { Disaster } \\
\text { Studies }\end{array}$ & Social Systems & $\begin{array}{l}\text { The ability of social units to mitigate hazards, contain the } \\
\text { effects of disasters when they occur, and carry out } \\
\text { recovery activities in ways that minimize social } \\
\text { disruption and mitigate the effects of future disturbances } \\
\text { (earthquakes particularly in this case). }\end{array}$ \\
\hline Godschalk, 2003 & $\begin{array}{l}\text { Disaster } \\
\text { Studies }\end{array}$ & Social Systems - The city & $\begin{array}{l}\text { A sustainable network of physical systems and human } \\
\text { communities, capable of managing extreme events; } \\
\text { during disaster, both must be able to survive and function } \\
\text { under extreme stress. }\end{array}$ \\
\hline Brown, 1996 & $\begin{array}{l}\text { Health } \\
\text { Sciences }\end{array}$ & Community & $\begin{array}{l}\text { The ability to recover from or adjust easily to misfortune } \\
\text { or sustained life stress. }\end{array}$ \\
\hline Sonn, 1998 & Psychology & Community & $\begin{array}{l}\text { The process through which mediating structures (schools, } \\
\text { peer groups, family) and activity settings moderate the } \\
\text { impact of oppressive systems. }\end{array}$ \\
\hline Paton, 2001 & $\begin{array}{l}\text { Disaster } \\
\text { Studies }\end{array}$ & Community & $\begin{array}{l}\text { The capability to bounce back and to use physical and } \\
\text { economic resources effectively to aid recovery following } \\
\text { exposure to hazards. }\end{array}$ \\
\hline Ganor, 2003 & & Community & $\begin{array}{l}\text { The ability of individuals and communities to deal with a } \\
\text { state of continuous, long-term stress; the ability to find } \\
\text { unknown inner strengths and resources in order to cope } \\
\text { effectively; the measure of adaptation and flexibility. }\end{array}$ \\
\hline Ahmed, 2004 & & Community & $\begin{array}{l}\text { The development of material, physical, socio-political, } \\
\text { socio-cultural, and psychological resources that promote } \\
\text { safety of residents and buffer adversity. }\end{array}$ \\
\hline
\end{tabular}




\begin{tabular}{|c|c|c|c|}
\hline Kimhi, 2004 & & Community & $\begin{array}{l}\text { Individuals' sense of the ability of their own community } \\
\text { to deal with ongoing disturbances (political violence } \\
\text { particularly in this case). }\end{array}$ \\
\hline Coles, 2004 & & Community & $\begin{array}{l}\text { A community's capacities, skills, and knowledge that } \\
\text { allow it to participate fully in recovery from disasters. }\end{array}$ \\
\hline Pfefferbaum, 2005 & & Community & $\begin{array}{l}\text { The ability of community members to take meaningful, } \\
\text { deliberate, collective action to remedy the impact of a } \\
\text { problem, including the ability to interpret the } \\
\text { environment, intervene, and move on. }\end{array}$ \\
\hline Norris, 2008 & Psychology & Community & $\begin{array}{l}\text { A process linking a set of adaptive capacities to a positive } \\
\text { trajectory and adaptation after a disturbance. }\end{array}$ \\
\hline Katz, 2004 & Geography & Community & $\begin{array}{l}\text { Ways in which people adapt to changing circumstances to } \\
\text { get by and 'make do' through the exercising of } \\
\text { autonomous initiative. }\end{array}$ \\
\hline Hill, 2008 & $\begin{array}{l}\text { Urban and } \\
\text { Regional } \\
\text { Development }\end{array}$ & Region & $\begin{array}{l}\text { The ability of a region to recover successfully from } \\
\text { shocks to its economy. }\end{array}$ \\
\hline Brock, 2002 & $\begin{array}{l}\text { Ecology \& } \\
\text { Economics }\end{array}$ & System & $\begin{array}{l}\text { Transition probability between states as a function of the } \\
\text { consumption and production activities of decision } \\
\text { makers. }\end{array}$ \\
\hline Perrings, 2006 & $\begin{array}{l}\text { Ecology \& } \\
\text { Economics }\end{array}$ & System & $\begin{array}{l}\text { The ability of the system to withstand either market or } \\
\text { environmental shocks without losing the capacity to } \\
\text { allocate resources efficiently. }\end{array}$ \\
\hline
\end{tabular}




\section{Appendix B Selection of Academic Journals Having Published Resilience Related Articles in the Past 20 Years}

- American Economic Journal, Macroeconomics

- American Ethnologist

- American Journal of Political Science

- American Journal of Sociology

- American Naturalist

- American Political Science Review

- American Sociological Review

- Annual Review of Anthropology

- Annual Review of Political Science

- Annual Review of Sociology

- Antipode

- Annual Review of Ecology, Evolution \& Systematics

- Annual Review of Environment and Resources

- BEHEMOTH: A Journal on Civilization

- British Journal of Political Science

- British Review of Sociology

- Brookings Papers on Economic Activity

- Canadian Public Policy

- Canadian Review of Sociology

- Comparative Political Studies

- Cultural Anthropology

- Current Anthropology

- Dialogues in Human Geography

- Disaster Resilience Journal
- Ecological Economics

- Ecological Monographs

- Ecology

- Ecology and Society

- Ecology Letters

- Econometrica

- Economic Geography

- Economy and Society

- Energy Journal

- Environment and Planning D: Society \& Space

- Evolutionary Anthropology

- Frontiers in ecology and the environment

- Foreign Affairs

- Geoforum

- Global Change Biology

- Global Ecology and Biogeography

- Global Environmental Change

- Global Environmental Change

- Global Environmental Politics

- Global networks

- Global networks: A Journal of Transnational Affairs

- Human Nature - an interdisciplinary biosocial perspective 
- Int'1 Journal of Adaptive, Resilient and Autonomic Systems

- International Journal of Child and Adolescent Resilience

- Int'l Journal of Disaster Resilience in the Built Environment

- International Journal of Supply Chain and Operations Resilience

- International Studies in the Philosophy of Science

- ISME Journal

- Journal of Conflict Resolution

- Journal of Economic Geography

- Journal of Economic Literature

- Journal of Economic Perspectives

- Journal of Environmental Economics and Management

- Journal of Finance

- Journal of Human Evolution

- Journal of Human Security \& Resilience

- Journal of Peasant Studies

- Journal of Political Economy

- Journal of Politics

- Nature Climate Change

- Political Analysis

- Political Geography

- Politics and Society
- Progress in Human Geography

- Public Opinion Quarterly

- Quarterly Journal of Economics

- Quarterly Journal of Political Science

- Review of Environmental Economics and Policy

- Resilience: A Journal of the Environmental Humanities

- Resilience: Int'l Perspectives on Science and Humanitarianism

- Resilience: International Policies, Practices and Discourses

- Review of Economic Studies

- Review of Financial Studies

- Security Dialogue

- Social Forces

- Social Networks

- Sociological methodology

- Sociological Methods and Research

- Sociological Theory

- Sociology of Education

- The Lancet

- Transactions of the Institute of British Geographers

- Trends in Ecology and Evolution

- Wiley Interdisciplinary Review, Climate Change 


\section{Appendix C Extract From 100 Resilient Cities Member Guide: Understanding Of Mutual Commitment}

\section{SECTION 2. AGREE}

Upon resding the following Undarstanding of Mutusl Commitment, the City Lasder (Mayor or

Chlaf Executive) and the person assigned as the Initial, primary point of contact between your

city and IOORC should Indicate agrooment by signing and raturning this document to

challenge0100resillentcities. org by June 15, 2016. If obtaining the City Leader's signature will

cause sigrificant dalays due to approval processes, etc., please contact us to devise an

alternative plan. Plesse note that the terms batwoen the city and loORC will be finalized in a

formsl grant agreament batwoen the two parties.

\section{UNDERSTANDING OF MUTUAL COMMITMENT}

We at 100 Resilient Cities belave strongly that our collective success is rooted in sharad commitments with each member clty. We designed this program and its offerings to support your city's resillence goals and vision. To that end, we are dedicated to delivering some of the world's best resources to equip your clty for success in this partnership.

Your application to the 100 Raslliant Citles Challenge Indicated strong dedication to collsboration and public engagement, exacutive support and access for the Chief Rasilience Officar, craation of an integrated Resllence Strategy, and active participation in a peer network. We selected your city in part because of these cornmon values. We have summarizad below the principal commitments between 100RC and asch mamber city that are essential for our joint success.

The City is eligible to recelve the following from 10ORC:

1. Funding to the City to retain a Chief Resilience Officer (CRO) for no less than two yosrs.

2. Technical and capacity-buliding services and support for the development and axecution of a Resilience Strategy for the City in cooperation with the community. various stakehoiders, and municipal officials.

3. A dedicated Associate Director of City Relationships who will work closaly with the $\mathrm{CRO}$ and other designated personnel to support the city's resilience-bullding goals, assist with timaly axecution of milestones, and help raduce barriers wherevar poss ble.

4. Inclusion in a 10ORC paer-to-pear and laarning network among member citles, creating opportunities for professional devalopment, shared axperiances and best practices, and axchange of innovative Resilience Strateglas among CROs and other city officials. 
5. Access to the 100RC Platform of Partners, providing resources to enable Implementation of Reslilence Strategles and raslience-ralated initiatives, Including finance, technology. Infrastructure and land use, buliding and design, communications, community angagernent, and many more.

The City will:

1. Participate in the full $100 \mathrm{RC}$ program, including committing to inclusive and broadbased engagement that seaks input and participation from diverse stakehoiders both Inside and outside of government.

2. Ensura substantial Involvement from the City Lesder, munldipal governmant, and senlor officials in key mlestones throughout the Rasillance Strategy process.

3. Commit to hiring a CRO at a senior leval within municlpal govarnmant, and collaborate with 1OORC around the selection of a candidate, placement within the government, and raporting structures.

4. Engage in and contribute to the 100RC Network, focused on buliding a professional field of resilence practitionars, sharing lassons and practices, and wheraver possible acting as an advocate and lialson to non-100RC members in your reglon and around the globe who are Interasted in learning how to create Resillence Strategles.

5. Leverage applicable tools, services, and partnars from the 10ORC Platform as your city davelops and Implaments Its Rasilence Strategy-

6. Encourage cooparation across municipal functions and authoritias for the purpose of developing a comprehensive resilience strategy.

7. Provide timaly raports, avaluations, and grant monitoring to $100 \mathrm{RC}$.

B. Engage in a transparent and collaborative partnership with 1OORC based on principlas of buliding holistic city resilience and work with 100RC to understand and navigate changing local clrcumstances as they arise.

We, the undersigned, understand that the above cornmitments are central to the success of asch mamber city of the network, and confirm that we will put forth evary affort to fulfill each of them.

(City Leader's SIgnature)

(Title, City)
(Point Of Contact's SIgnature)

(Point of Contact's Title) 


\section{References}

100 Resilient Cities (2016). Resilience in Action: Early Insights Into How Cities Are Institutionalizing Resilience. October. Accessed from:

https://www.100resilientcities.org/wp-

content/uploads/2016/10/Resilience20in20Action20100RC20Report20October20 2016.pdf

100 Resilient Cities (2017). About Us-FAQ: What is the goal of the 100RC Resilience Strategy Process? Accessed from: https://100resilientcities.org/faq/

Adger, W. (2000). Social and Ecological Resilience: Are They Related? Progress in Human Geography, 24(3), 347-364.

Alameda (2019). Climate Action and Resiliency Plan (CARP), September 2019. Accessed from: https://www.alamedaca.gov/files/sharedassets/public/publicworks/climate-action-page/alameda_carp_final_091119.pdf

Alexander, D.E. (2013). Resilience and Disaster Risk Reduction: An Etymological Journey. Natural Hazards and Earth System Sciences, 13, 2707-2716.

Almedom, A.M. \& Glandon, D. (2007). Resilience is not the Absence of PTSD Any More Than Health is the Absence of Disease. Journal of Loss and Trauma, 12, 127-143.

Anderies J.M. et al. (2006). Loss of Resilience, Crisis, and Institutional Change: Lessons from an Intensive Agricultural System in Southeastern Australia. Ecosystems. 9(6), 865-878.

Andes, L. \& Round, J. (2015). The Role of 'Persistent Resilience' Within Everyday Life and Polity: Households Coping With Marginality Within the 'Big Society'. Environment and Planning A, 47, 676-690.

Aranda, K., Zeeman, L., Scholes, J., \& Morales, A.S-M. (2012). The Resilient Subject: Exploring Subjectivity, Identity, and the Body in Narratives of Resilience. Health, 16(5), 548-563.

Arrow, K., Dasgupta, P., Goulder, L., Daily, G., Ehrlich, P. et al. (2004). Are We Consuming Too Much? Journal of Economic Perspectives, 18(3), 147-172.

Arup (2015). City Resilience Index. December. Accessed from: https://www.rockefellerfoundation.org/wp-content/uploads/City-ResilienceFramework-2015.pdf

Asdal, K. (2008). On Politics and the Little Tools of Democracy: A Down-to-Earth Approach. Distinktion: Scandinavian Journal of Social Theory, 9(1), 11-26.

Atlantic Council (2019). Adrienne Arsht Center for Resilience: Our Approach. Accessed from: https://www.atlanticcouncil.org/programs/adrienne-arsht-center-forresilience 
Bacon, F. (1670). Sylva Sylvarum, Or Of Natural History In Ten Centuries. London: S. G. \& B. G. for William Lee.

Ball, M. (2011). Self-Government and the Fashioning of Resilient Personae: Legal Education, Criminal Justice, and the Government of Mental Health. Current Issues in Criminal Justice, 23(1), 97-111.

Barker, E. (2014). How to be Resilient: 8 Steps to Success When Life Gets Hard. Time. Accessed from: https://time.com/3002833/how-to-be-resilient-8-steps-to-successwhen-life-gets-hard/

Bazerman, M.H. (2006). Climate Change as a Predictable Surprise. Climate Change, 77, 179-193.

Bazerman, M.H. \& Watkins, M.D. (2004). Predictable Surprises: The Disasters you Should Have Seen Coming and How to Prevent Them. Boston: Harvard Business School Publishing.

Beck, S. \& Knecht, M. (2016). 'Crisis' in Social Anthropology: Rethinking a Missing Concept. In A. Schwarz, M.W. Seeger \& C. Auer (Eds.). The handbook of international crisis communication research. New York: Wiley. pp. 104-116.

Béné C. et al. (2014). Resilience, poverty and development. Journal of International Development. 26(5), 598-623.

Benjamin, W. (2007[1936]). The Storyteller: Reflections on the Works of Nikolai Leskov In Zohn, H. (trans.) Illuminations: Essays and Reflections. New York: Schocken. pp.83-109.

Bergson, H. (1911). Creative Evolution. London: Macmillan.

Bergström, J., van Winsen, R. \& Henriqson, E. (2015). On the Rationale of Resilience in the Domain of Safety: A Literature Review. Reliability Engineering and System Safety, 141, 131-141.

Berkes, F. \& Ross, H. (2013). Community Resilience: Toward an Integrated Approach. Society and Natural Resources, 26(1), 5-20.

Berkowitz, M (2019, April 1). An Update from 100 Resilient Cities. 100 Resilient Cities Blog. Accssed from: http://100resilientcities.org/update-from-100rc/

Berkowitz, M. (2014, August 6). What Makes a Good 100RC Application? 100 Resilient Cities Blog. Accessed from: https://www.100resilientcities.org/what-makes-agood-100rc-application/

Bijker, W. (2008). Vulnerability of Technological Cultures. In M. Leach (ed), ReFraming Resilience: A Symposium Report, STEPS Working Paper 13. Brighton: STEPS Centre.

Birch, K. (2016). Rethinking Value in the Bio-Economy: Finance, Assetization, and the Management of Value. Science, Technology, \& Human Value, 42(3), 460-490.

Birn, A.E. (2014). Philanthrocapitalism, Past And Present: The Rockefeller Foundation, The Gates Foundation, and The Setting(s) of The International/ Global Health Agenda. Hypothesis, 12(1), 1-27. 
BIS (2009). Basel Committee on Banking Supervision, Consultative Document, Strengthening the Resilience of the Banking Sector. Basel, Switzerland. Accessed from: http://www.bis.org/publ/bcbs164.pdf

Bishop, M. \& Green, M. (2008). Philanthrocapitalism: How The Rich Can Save The World. London: Bloomsbury Press.

Bliss, L. (2019, April 11). '100 Resilient Cities' Is No More. Now What? Citylab. Accessed from: https://www.citylab.com/environment/2019/04/rockefeller-100resilient-cities-climate-philanthropy-end/586522/

Blok, A. \& Torben E. J. (2011). Bruno Latour: Hybrid Thoughts in a Hybrid World. London: Routledge.

Blount, T. (1656) Glossographia; or, a dictionary interpreting the hard words of whatsoever language, now used in our refined English tongue. London: Thomas Newcomb for George Sawbridge.

Boin, A., Comfor, L.K. \& Demchak, C.C. (2010). The Rise of Resilience. In L.K. Comfort, A. Boin \& C.C. Demchak (Eds) Designing Resilience: Preparing for Extreme Events. Pittsburg: University of Pittsburg Press. pp. 1-12.

Bonanno, G., Galea, S., Buciarelli, A. \& Vlahov, D. (2007). Psychological Resilience After Disaster. Psychological Science, 17(3), 181-186.

Bond, C.A., Strong, A., Burger, N. \& Weilant, S. (2017b). Guide to the Resilience Dividend Valuation Model. Santa Monica, CA: RAND Corporation. Accessed from: https://www.rand.org/pubs/research_reports/RR2130.html.

Bond, C.A., Strong, A., Burger, N., Weilant, S., Saya, U. \& Chandra, A. (2017a). Resilience Dividend Valuation Model: Framework Development and Initial Case Studies. Santa Monica, CA: RAND Corporation. Accessed from: https://www.rand.org/pubs/research_reports/RR2129.html.

Bourdieu, P. \& Chartier, R. (2015). The Sociologist \& The Historian. Cambridge: Polity Press.

Brand, F.S., Jax, K. (2007). Focusing the Meaning(s) of Resilience: Resilience as a Descriptive Concept and a Boundary Object. Ecology and Society, 12(1), 23-38.

Brassett, J., Croft, S. \& Vaughan-Williams, N. (2013). Introduction: An Agenda For Resilience Research In Politics And International Relations. Politics, 33(4), 221228.

Brooks, R. \& Goldstein, S. (2004). The Power of Resilience: Achieving Balance, Confidence, and Personal Strength in Your Life. New York: McGraw Hill.

Bulley, D. (2013). Producing and Governing Community (through) Resilience. Politics, 33(4), 265-275.

Burnham, J.C. (2009). Accident Prone: A History of Technology, Psychology, and Misfits of the Machine Age. Chicago: University of Chicago Press. 
Burt C.H. et al. (2012). Racial Discrimination, Ethnic-Racial Socialization, and Crime: A Micro-sociological Model of Risk and Resilience. American Sociological Review. 77(4), 648-677.

Butler L., Morland, L. \& Leskin, G. (2007). Psychological resilience in the face of terrorism. In B. Bongar, L. Brown, L. Beutler, J. Breckenridge \& P. Zimbardo (Eds.), Psychology of terrorism. New York: Oxford University Press. pp. 400417.

Callon, M. (1984). Some Elements of the Sociology of Translation: Domestication of the Scallops and the Fishermen of St.Brieuc Bay. The Sociological Review, 32(1), 196-233.

Callon, M. (1986). The Sociology of an Actor-Network: the Case of the Electric Vehicle. In M. Callon, J. Law and A. Rip (Eds.) Mapping the Dynamics of Science and Technology: Sociology of Science in the Real World. London: Macmillan. pp. 1934.

Callon, M. (1995). Four Models for the Dynamics of Science. In S. Jasanoff, G.E. Markle, J.C. Peterson \& T. Pinch (eds) Handbook of Science and Technology Studies. London: Sage. pp. 29-63.

Callon, M. \& Latour, B. (1992). Don't Throw the Baby Out with the Bath School! A Reply to Collins and Yearley. In A. Pickering (Ed.) Science as Practice and Culture. Chicago: Chicago University Press. pp. 343-368.

Callon, M. \& Law, J. (1997). After the Individual in Society: Lessons in Collectivity from Science, Technology and Society. Canadian Journal of Sociology, 22(2), $165-182$.

Callon, M., Law, J. \& Rip, A. (1986). Mapping the Dynamics of Science and Technology: Sociology of Science in the Real World. London: MacMillan Press.

Carpenter, S., Walker, B., Anderies, J.M.,\& Abel, N. (2001). From Metaphor to Measurement: Resilience of What to What? Ecosystems, 4, 765-781.

Carson, J. (1820). On the Elasticity of the Lungs. Philosophical Transactions of the Royal Society of London. Part I, 29-44.

CBI [Climate Bonds Initiative] (2019). Climate Resilience Principles: A Framework for Accessing Climate Resilience Investments. Accessed from: https://www.climatebonds.net/files/page/files/climate-resilience-principlesclimate-bonds-initiative-20190917-.pdf

Cederblad, M., Dahlin, L., Hagnell, O. \& Hansson, K. (1994). Salutogenic Childhood Factors Reported by Middle-Aged Individuals. European Archives of Psychiatry and Clinical Neuroscience, 244, 1-111.

Chadburn, M. (2015). Resilience is Futile. Economic Hardship Reporting Project. Accessed from: http://economichardship.org/archive//resilience-is-futile-howwell-meaning-nonprofits-perpetuate-poverty 
Chandler, D. (2012). Resilience and Human Security: The Post-Interventionist Paradigm. Security Dialogue, 43(3), 213-229.

Chandler, D. (2013a). International Statebuilding and the Ideology of Resilience. Politics, 33(4), 276-286.

Chandler, D. (2013b). Resilience and the Autotelic Subject: Toward a Critique of the Societalization of Security. International Political Economy, 7, 210-226.

Chandler, D. (2019). Resilience and the End(s) of the Politics of Adaptation. Resilience, 7(3), 304-313.

Chason, R. (2017, July 27). D.C. Adds Officers Dedicated to Improving City's Resilience. The Washington Post. Accessed from:

https://www.washingtonpost.com/local/dc-politics/dc-adds-office-dedicating-toimproving-citys-resilience/2017/07/27/133c72f0-7233-11e7-8f39-

eeb7d3a2d304_story.html?utm_term $=.8 \mathrm{a} 8908853 \mathrm{bfl}$

Chavel, B. \& Yadlosky, J. (2011). Framework for Improving Resilience of Bridge Design. Report No.: FHWA-IF-11-016. Federal Highway Administration. Washington, DC.

Clarke C. (2015). Learning to fail: resilience and the empty promise of financial literacy Education. Consumption Markets \& Culture, 18(3). 257-276.

Coaffee J. (2013). Rescaling and Responsibilising the Politics of Urban Resilience: From National Security to Local Place-Making. Politics, 33(4), 240-252.

Coaffee, J., Wood, D.M. \& Rogers, P. (2009). The Everyday Resilience of the City: How Cities Respond to Terrorism and Disaster. Palgrave Macmillan: London.

Cohen, R. (2014, April 4). Alameda Loses the Rockfeller Foundation Grant It Only Just Received. Nonprofit Quarterly. Accessed from:

https://nonprofitquarterly.org/alameda-loses-the-rockefeller-foundation-grant-itonly-just-received/

Collins, H. M. \& Yearley, S. (1992). Epistemological Chicken. In A. Pickering (Ed.) Science as Practice and Culture. Chicago: Chicago University Press. pp. 301326.

Colussi, M. (2000). The Community Resilience Manual: A Resource for Rural Recovery. Canadian Centre for Community Renewal. Accessed from: https://communityrenewal.ca/sites/all/files/resource/P200_0.pdf

Connor, K.M., Davidson, J. \& Lee, L.C. (2003). Spirituality, Resilience, and Anger in Survivors of Violent Trauma: A Community Survey. Journal of Traumatic Stress, $16,487-494$.

Cote, M. \& Nightingale, A. J. (2011). Resilience Thinking Meets Social Theory:

Situating Change in Socio-ecological Systems (SES) Research. Progress in Human Geography, 36(4), 475-489. Current Issues in Criminal Justice, 23(1), 615.

Coutu, D.L. (2002). How Resilience Works. Harvard Business Review, 80(5), 46-55. 
Cressman, D. (2009). A brief Overview of Actor-Network Theory: Punctualization, Heterogeneous Engineering and Translation. ACT Lab/Centre for Policy Research on Science and Technology (CPROST), School of Communication, Simon Fraser University, Burnaby, British Columbia, Canada. Accessed from: http://blogs.sfu.ca/departments/cprost/wp-content/uploads/2012/08/0901.pdf.

Cretney, R. (2014). Resilience For Whom? Emerging Critical Geographies Of SocioEcological Resilience. Geography Compass, 8(9), 627-640.

Curtis, B. (2014). Data Provenance, Metadata, and Reflexivity: Comments on Method. Encounters on Education, 15, 43-61.

Curtis, D.R. (2014). Coping With Crisis: The Resilience and Vulnerability of PreIndustrial Settlements. Farnham: Ashgate.

Daubach, T. (2018, September 11). With more data, Asia Pacific can build more resilient cities. Eco-Business. Accessed from: https://www.eco-business.com/news/withmore-data-asia-pacific-can-build-more-resilient-cities/

Davidson, D. (2010). The Applicability of the Concept of Resilience to Social Systems: Some Sources of Optimism and Nagging Doubts. Society and Natural Resources, 23(12), 1135-1149.

Davidson, D.J. (2013). We Still Have a Long Way to Go, and a Short Time to Get There: A Response to Fikret Berkes and Helen Ross. Society and Natural Resources, 26(1), 21-24.

Davies, W. (2015). The Happiness Industry: How the Government and Big Business Sold Us Well-Being. London: Verso.

Davoudi, S. (2012). Applying the Resilience Perspective to Planning: Critical Thoughts from Theory and Practice. Planning Theory \& Practice, 13(2), 299-333.

Dill, K. (2016, November 3). 'Don't Screw It Up': Judith Rodin Reflects on the Challenges of Going First. Forbes. Accessed from: https://www.forbes.com/sites/kathryndill/2016/11/03/dont-screw-it-up-judithrodin-reflects-on-the-challenges-of-going-first/\#47ff33de2225

Diprose, K. (2014). Resilience is Futile: The Cultivation of Resilience is not an Answer to Austerity and Poverty. Soundings: A Journal of Politics and Culture, 58, 4456.

Disaster Resilience Leadership Program (DRLA) (nd). “Leadership Matters”. Accessed from:

https://www.preparecenter.org/sites/default/files/disaster_resilience_leadership_pr ogram_tulanedrg.pdf

Downes, B. J., Miller, F., Barnett, J. Glaister, J. \& Ellemor, H. (2013). How Do We Know About Resilience? An Analysis of Empirical Research on Resilience, and Implications for Interdisciplinary Praxis. Environmental Research Letters, 8, 1-8.

Dreistadt, R. (1968) An Analysis of the use of Analogies and Metaphors in Science, Journal of Psychology, 68(1), 97-116. 
Durkheim, E. (1938). The Rules of Sociological Method ( $8^{\text {th }}$ ed.). Chicago: University of Chicago Press.

Dutton M.A. \& Greene R. (2010). Resilience and crime victimization. Journal of Traumatic Stress, 23(2), 215-222.

Dwiartanta, A., \& Rosin, C. (2014). Exploring Agency Beyond Humans: The Compatibility of Actor-Network Theory (ANT) and Resilience Thinking. Ecology and Society, 19(3), 28-37.

EBRD [European Bank for Reconstruction \& Development] (2019, September 27). Press Release: 1.625\% US\$700 Million 5-year Climate Resilience Bond due 27 September 2024. Accessed from: https://www.ebrd.com/documents/treasury/1625-us700-million-5year-climateresilience-bond-due-27-september-2024.pdf

Egeland, B., Carlson, E.A. \& Sroufe, L.A. (1993). Resilience as Process. Development and Psycopathology, 5(4), 517-528

Ellson, M. (2014, April 3). City Loses Disaster Preparedness Grant. The Alamedan. Accessed from: http://thealamedan.org/news/city-loses-disaster-preparednessgrant

Ellson, M. (2014, May 12). Special Report: How The Grant Was Lost. The Alamedan. Accessed from: http://thealamedan.org/news/special-report-how-grant-was-lost

Elmqvist T. et al. (2003). Response diversity, ecosystem change, and resilience. Frontiers in Ecology and the Environment, 1, 488-494.

Emerson, R.W. (1903). The Complete Works of Ralf Waldo Emerson. Cambridge: Riverside Press.

Endress, M. (2015). The Social Constructedness of Resilience. Social Sciences, 4, 533545.

Engelbrecht, H.J. (2016). Comprehensive Versus Inclusive Wealth Accounting and the Assessment of Sustainable Development: An Empirical Comparison. Ecological Economics, 129(c), 12-20.

Epstein, E. J. (1983). Ruling the World of Money. Harper's Magazine, November, 4348.

Evans, B. \& Reid, J. (2013). Dangerously Exposed: The Life and Death of the Resilient Subject. Resilience: International Policies, Practices and Discourses. 1(2), 8398.

Evans, B. \& Reid, J. (2014). The Promise of Violence in the Age of Catastrophe. Truthout. Accessed from: http://truth-out.org/opinion/item/20977-the-promise-ofviolence-in-the-age-of-catastrophe.

Ewald, F. (1986). L'État Providence. Paris: Grasset.

Flyvbjerg, B. (2001). Making Social Science Matter: Why Social Inquiry Fails and How it Can Succeed Again. Cambridge University Press: Cambridge. 
Folk, C. (2006). Resilience: The Emergence of a Perspective for Social-Ecological Systems Analysis. Global Environmental Change, 16, 253-267.

Foucault, M. (1988a). The History of Sexuality, Vol. 3: The Care of the Self. New York: Vantage.

Foucault, M. (1988b). Technologies of the Self. In Technologies of the Self: A Seminar with Michel Foucault, edited by Luther H. Martin and et al. Amherst: University of Massachusetts Press. pp. 16-49.

Foucault, M. (1995[1977]). Discipline \& Punish: The Birth of the Prison. New York: Vintage Books.

Foucault, M. (2011). The Government of Self and Others: Lectures at the Collège de France, 1982-1983. New York: Palgrave.

Foucault, M. (2012). The Courage of Truth (The Government of Self and Others II): Lectures at the Collège de France, 1983-1984. New York: Palgrave.

Friborg, O., Hjemdal, O., Rosenvinge, J.H. \& Martinussen, M. (2003). A New Rating Scale for Adult Resilience: What are the Central Protective Resources Behind Healthy Adjustment? International Journal of Methods in Psychiatric Research, 12(2), 65-76.

Fuller, D. \& Sedo, D.R. (2013). Reading Beyond the Book: The Social Practices of Contemporary Literary Culture. New York: Routledge.

Furlong, K. (2016). Leaky Governance: Alternative Service Delivery and the Myth of Water Utility Independence. Vancouver and Toronto: UBC Press.

Gaillard J.C. (2010). Vulnerability, capacity and resilience: Perspectives for climate and development policy. Journal of International Development, 22(2), 218-232.

Gallopín G.C. (2006). Linkages between vulnerability, resilience, and adaptive capacity. Global Environmental Change, 16(3), 293-303.

Garrett, P.M. (2016). Questioning Tales of 'Ordinary Magic': 'Resilience' and NeoLiberal Reasoning. The British Journal of Social Work, 46(7), 1909-1925.

Gingras, Y. \& Guay, A. (2011) The Uses of Analogies in Seventeenth Century and Eighteenth Century Science, Perspectives on Science, 19(2), 154-191.

Goffman, E. (1959) The Presentation of Self in Everyday Life. New York: Doubleday. Gotham, K. F. (2012). Disaster, Inc.: Privatization and Post-Katrina Rebuilding in New Orleans. Perspectives on Politics, 10(3), 633-646.

Graham, L. (2013). Bouncing Back: Rewiring Your Brain for Maximum Resilience And Well-Being. Novato, CA.: New World Library.

Graham, L. (2018). Resilience: Powerful Practices For Bouncing Back From Disappointment, Difficulty, And Even Disaster. Novato, CA.: New World Library.

Grimm, V. \& Wissel, C. (1997). Babel, or the ecological stability discussions: an inventory and analysis of terminology and a guide for avoiding confusion. Oecologia, 109, 323-334. 
Gunderson, L.H. (2000). Ecological Resilience - In Theory and Application. Annual Review of Ecology and Systematics, 31, 425-439.

Gunderson, L.H. \& Holling, C.S. (eds) (2002). Panarchy: Understanding Transformations in Human and Natural Systems. Island Press: Washington, D.C.

Gunderson, L.H. \& Pritchard, L. (eds) (2002). Resilience and the Behavior of Large-scale Systems. Washington, DC: Island Press.

Hackett E.J. \& Parker, J.N. (2016). From Salomon's House To Synthesis Centers. In T. Heinze \& R. Muench (eds). Innovation in Science and Organizational Renewal: Historical and Sociological Perspectives. New York: Palgrave Macmillan. pp. 53-88.

Hacking, I. (1988). The Sociology of Knowledge About Child Abuse. Noûs, 22(1), 5363.

Hacking, I. (1990). The Taming of Chance. Cambridge: Cambridge University Press. Hall, M. (1856). Periscope. The Medical Chronicle: Communications, 4(4), 151-155. Hamel, G. \& Välikangas, L. (2003). The Quest for Resilience. Harvard Business Review, $81(9), 52-63$.

Hamilton, K. \& Hartwick, J. (2014). Wealth and Sustainability. Oxford Review of Economic Policy, 30(1), 170-187.

Hardt, M. \& Negri, A. (2009). Commonwealth. Cambridge: Belknap.

Hardy K. (2014). Resilience in UK counter-terrorism. Theoretical Criminology, 19(1), $77-94$.

Harman, G. (2009). Prince of Networks: Bruno Latour and Metaphysics. Melbourne: re.press.

Harrison E. (2013). Bouncing back? Recession, resilience and everyday lives. Critical Social Policy, 33(1), 97-113.

Hart, A., Blincow, D. \& Thomas, H. (2007). Resilient Therapy: Working with Children and Families. London: Routledge.

Hempel, L. \& Lorenz, D.F. (2016). Resilience as an Element of a Sociology of Expression. BEHEMOTH: A Journal on Civilisation, 7(2), 26-71.

Henry, A. (2017). A Generation of Scrappers. Montreal Review, January. Accessed from: http://www.themontrealreview.com/2009/A-Generation-of-Scrappers.php

Herrman, H., Steward, D., Diaz-Granados, N., Berger, E., Jackson, B., \& Yuen, T. (2011). What is Resilience? Canadian Journal of Psychiatry/La Review canadienne de Psychiatrie, 56(5), 258-265.

Hill, L. \& Larner, W. (2017). The Resilient Subject. In Higgesn, V. \& Larner, W. (eds) Assembling Neoliberalism: Expertise, Practices, Subject. Palgrave: Macmilan: New York. pp. 263-281.

Hoffman, R.E. (1948). A Generalized Concept of Resilience. Textile Research Journal, 18(3), 141-148. 
Holling, C.S. (1973). Resilience and Stability of Ecological Systems. Annual Review of Ecology and Systematics, 4, 1-23.

Holling, C.S. (1986). Resilience of Ecosystems: Local Surprise and Global Change. In W.C. Clark \& R.E. Munn (eds) Sustainable Development of the Biosphere. Cambridge: Cambridge University Press. pp. 292-317.

Holling, C.S. (1996). Engineering Resilience versus Ecological Resilience. In National Academy of Engineering Engineering Within Ecological Constraints. Washington, DC: The National Academies Press. pp. 31-44.

Holling, C.S. (2001). Understanding the Complexity of Economic, Ecological, and Social Systems. Ecosystems, 4(5), 390-405.

Holling, C.S. (2017). Bubbles and Spirals: The Memoirs of C. S. Buzz Holling (second edition). Accessed from: http://www.stockholmresilience.org/holling-memoirs

Holling, C.S. \& Gunderson, L.H. (2002). Resilience and Adaptive Cycles. In L.H. Gunderson \& C.S. Holling (eds). Panarchy: Understanding Transformations In Human And Natural Systems. Island Press, Washington, D.C. pp. 25-62.

Holling, C.S., Gunderson, L.H. \& Ludwig, D. (2002). In Quest of a Theory of Adaptive Change. In L.H. Gunderson \& C.S. Holling (eds) Panarchy: Understanding Transformations in Human and Natural Systems. Washington, D.C.: Island Press. pp. 3-24.

Horne, J.F. (1997). The Coming Age of Organizational Resilience. Business Forum, 22, 24-28.

Horne, J.F. \& Orr, J.E. (1998). Assessing Behaviors That Create Resilient Organizations. Employment Relations, 24(4), 29-39.

Huhman, H.R. (2012, August 4). How To Create The Story of Your Personal Brand. Accessed from:

https://archive.ama.org/archive/Careers/Pages/HowtoCreatetheStoryofYourOwnP ersonalBrand.aspx

Igoe, M. (2019, April 4). Global Development Briefing. DevEx. Accessed from: https://www.devex.com/news/trump-s-central-america-shutdown-rockefellerends-100rc-and-the-food-conflict-connection-this-week-in-development-94634

IMDB (2014b) Resilience. Accessed from: $\mathrm{http}: / / \mathrm{www} . \mathrm{imdb} . \mathrm{com} / \mathrm{title} / \mathrm{tt} 1516120 /$ ref_efn_al_tt_4

IPCC [Intergovernmental Panel on Climate Change] (2014). Climate Change 2014: Impacts, Adaptation, and Vulnerability. Working Group II Contribution to the Fifth Assessment Report of the Intergovernmental Panel on Climate Change. Accessed from: https://www.ipcc.ch/site/assets/uploads/2018/02/ar5_wgII_spm_en.pdf

Ives, A.R. (1995). Measuring Resilience in Stochastic-Systems. Ecological Monograph, $65,217-233$. 
Jacobsen, M.H., \& Marshman, S. (2008) Bauman's Metaphors: The Poetic Imagination in Sociology, Current Sociology, 56(5), 798-818.

Jones, L. (2019). Resilience Isn't the Same for all: Comparing Subjective and Objective Approaches to Resilience Measurement. WIREs Climate Change, 10(1), 1-19.

Joseph, J. (2013). Resilience as Embedded Neoliberalism: A Governmentality Approach. Resilience: International Policies, Practices and Discourses, 1(1), 38-52.

Keck, M. \& Sakdapolrak, P. (2013). What is Social Resilience? Lessons Learned and Ways Forward, Erdkunde, 67(1), 5-19.

Keessen A.M. et al. (2013). The Concept of Resilience from a Normative Perspective: Examples from Dutch Adaptation Strategies. Ecology and Society. 18(2), 45-57.

Kivinen, O. \& Piiroinen, T. (2006). Toward Pragmatist Methodological Relationalism. Philosophy of the Social Sciences, 36(3), 303-329.

Klein, N. (2007). The Shock Doctrine: The Rise of Disaster Capitalism. Toronto: Alfred A. Knopf Canada.

Klein, R., Nicholls, R.J. \& Thomalla, F. (2003). Resilience to Natural Hazards: How Useful is this Concept? Environmental Hazards, 5(1-2), 35-45.

Konnikova, M. (2016). How People Learn to Become Resilient. The New Yorker. Accessed from: https:/www.newyorker.com/science/maria-konnikova/the-secretformula-for-resilience

Kopans, D. (2016). How to Evaluate, Manage, and Strengthen Your Resilience. Harvard Business Review, June 14. Accessed from: https://hbr.org/2016/06/how-toevaluate-manage-and-strengthen-your-resilience

Lakoff, G., \& Johnson, M. (1980). Metaphors we live by. Chicago: University of Chicago Press.

Lal, S., Suto, M., \& Ungar, M. (2012). Examining the Potential of Combining the Methods of Grounded Theory and Narrative Inquiry: A Comparative Analysis. The Qualitative Report, 17(41), 1-22.

Lang, T, (2010). Urban Resilience and New Institutional Theory: A Happy Couple for Urban and Regional Studies. In B. Müller (ed) German Annual of Spatial Research and Policy 2010. Berlin: Springer. pp. 15-24.

Larner, W. (2000). Neoliberalism: Policy, Ideology, Governmentality. Studies in Political Economy, 63, 5-25.

Larner, W. \& Moreton, S. (2016). Creating Resilient Subjects: The Coexist Project. In R.K. Lippert, M. Brady (eds) Governing Practices: Neoliberalism, Governmentality, and the Ethnographic Imaginary. Toronto; Buffalo; London: University of Toronto Press. pp. 50-71.

Lash, S. (2005). Lebenssoziologie: Georg Simmel in the Information Age. Theory, Culture \& Society, 22(3), 1-23.

Lash, S. (2010). Intensive Culture: Social Theory, Religion and Contemporary Capitalism. London: Sage. 
Latour, B. (1983). Give Me a Laboratory and I will Raise the World. In K. D. KnorrCetina and M. J. Mulkay (Eds.) Science Observed. Beverly Hills: Sage.

Latour, B. (1986). The Powers of Association. In J. Law (ed) Power, Action and Belief: A New Sociology of Knowledge. London: Routeledge. pp. 264-280.

Latour, B. (1986b). Visualization and Cognition: Thinking With Eyes and Hands. Knowledge and Society: Studies in the Sociology of Culture Past and Present, 6, $1-40$.

Latour, B. (1987). Science in Action: How to Follow Scientists and Engineers Through Society. Philadelphia: Open University Press.

Latour, B. (1988a). Mixing humans and nonhumans together: The sociology of a doorcloser. Social Problems, 35(3), 298-310.

Latour, B. (1988b). Part II: Irreductions. In B. Latour, The Pasteurization of France. Cambridge, Mass.: Harvard University Press.

Latour, B. (1992). Where are the Missing Masses? Sociology of a Few Mundane Artefacts. In W. Bijker and J. Law (Eds.) Shaping Technology, Building Society: Studies in Socio-technical Change. Cambridge, Mass: MIT Press. pp. 225-258.

Latour, B. (1993). We Have Never Been Modern. Cambridge, MA: Harvard University Press.

Latour, B. (1996). On Actor-Network Theory: A Few Clarifications Plus More Than a Few Complications. Soziale Welt, 47, 1-14.

Latour, B. (1999). On Recalling ANT. In J. Law and J. Hassard (Eds.) Actor Network and After. Oxford: Blackwell (also in the Sociological Review (1999) 47(S1), 15-25).

Latour, B. (2003). What if we Talked Politics a Little? Contemporary Political Theory, (2), 143-164.

Latour, B. (2004). Nonhumans. In S. Harrison, S. Pile and N. Thrift (eds) Patterned Ground: Entanglements of Nature and Culture. London: Reaktion Books.

Latour, B. (2005). Reassembling the Social: An Introduction to Actor-Network-Theory. Oxford: Oxford University Press.

Latour, B. and S. Woolgar (1979). Laboratory Life: the Social Construction of Scientific Facts. London: Sage.

Laurence, R. (2014, December 23). Ai Weiwei Plants F Grass as Part of the Vancouver Biennale. Straight.com: Vancouver's Online Source. Accessed from: http:/www.straight.com/arts/793716/ai-weiwei-plants-f-grass-part-vancouverbiennale

Law, J. (1984). On the Methods of Long Distance Control: Vessels, Navigation and the Portuguese Route to India. Sociological Review, 32(1), 234-263.

Law, J. (1986). On Power and Its Tactics: a View from the Sociology of Science. The Sociological Review, 34(1), 1-38. 
Law, J. (1991). Power, Discretion and Strategy. In J. Law (Ed.) A Sociology of Monsters? Essays on Power, Technology and Domination. London, Routledge. 38. pp. 165191.

Law, J. (1992). Notes on the Theory of the Actor-Network: Ordering, Strategy and Heterogeneity. Systems Practice, 5, 379-393.

Law, J. (1997). 'Traduction/Trahison: Notes on ANT', published by the Centre for Science Studies, Lancaster University, Lancaster. Accessed from:

http://www.comp.lancs.ac.uk/sociology/papers/Law-Traduction-Trahison.pdf

Law, J. (2004). After Method: Mess in Social Science Research. New York: Routledge.

Law, J. \& Singleton, V. (2000). Performing Technology's Stories: On Social

Constructivism, Performance, and Performativity. Technology and Culture, 41 (4), 765-775.

Law, J. \& Singleton, V. (2014). ANT, Multiplicity and Policy. Critical Policy Studies, $8(4), 379-396$.

Lazzarato, M. (1996). Immaterial Labour. In P. Virno \& M. Hardt (eds) Radical Thought in Italy. Minneapolis: University of Minnesota Press.

Lentzos, F. \& Rose, N. (2009). Governing Insecurity: Contingency Planning, Protection, Resilience. Economy and Society, 38(2), 230-254.

Lévis-Strauss, C. (1974). The Savage Mind. London: Weidenfeld.

Liebenberg, L. (2009). The Visual Image as Discussion Point: Increasing Validity in Boundary Crossing Research. Qualitative Research, 9(4), 441-467.

Liebenberg, L. Ungar, M., \& Theron, L. (2014). Using Video Observation and Photo Elicitation Interviews to Understand Obscured Processes in the Lives of Resilient Youth. Childhood, 21(4), 532-547.

Liebenberg, L., Didkowsky, N. \& Ungar, M. (2012). Analysing Visual Data Using Grounded Theory: An Exemplar of the Negotiating Resilience Project. Visual Studies, 1(27), 59-74.

Liebenberg, L., Ungar, M., \& LeBlanc, J. C. (2013). The CYRM-12: A Brief Measure of Resilience. Canadian Journal of Public Health, 104(2), 131-135.

Lindquist, E.A. (2000). Government Restructuring and Career Public Service in Canada: Introduction and Overview. In E.A. Lindquist (Ed) Government Restructuring and Career Public Service in Canada. Toronto: The Institute of Public Administration of Canada. pp. 1-26.

Linnenluecke, M.K. (2015). Resilience in Business and Management Research: A Review of Influential Publications and Research Agenda. International Journal of Management Review, 19(1), 4-30.

Luk, V. (2014). Ai Wei Wei Vancouver Sculpture Symbolizes Resilience and Defiance. CBC News, December 17, 2014. Accessed from: http://www.cbc.ca/news/canada/british-columbia/ai-wei-wei-vancouver-sculpturesymbolizes-resilience-and-defiance-1.2875667 
Luthar, S.S., Cicchetti, D. \& Becker, B. (2000). The Construct of Resilience: A Critical Evaluation and Guidelines for Future Work. Child Development, 71(3), 543-562.

MacKinnon, D. \& Derickson, K.D. (2012). From Resilience to Resourcefulness: A Critique of Resilience Policy and Activism. Progress in Human Geography, 37(2), 253-270.

Mallak, L. (1998). Putting Organisational Resilience to Work. Industrial Management, 40(6), 8-13.

Martin et al. (2018) Institutionalizing Urban Resilience: A Midterm Monitoring Evaluation Report of 100 Resilient Cities. Urban Institute. Accessed from: http://www.100resilientcities.org/wp-content/uploads/2019/03/100RC-2018Urban-Institute-Midterm-Report.pdf

Martin, P. (2015). Commercialising Neurofutures: Promissory Economics, Value Creation and the Making of a New Industry. BioSocieties, 10(4), 422-43.

Masten, A., Best, K. \& Garmezy, N. (1990). Resilience and Development: Contributions from the Study of Children who Overcome Adversity. Development and Psychopathology, 2, 425-444.

Meier, J.D. (2016). How to Develop a Psychology of Resilience. Time. Accessed from: https://time.com/4256436/resilience/

Merriman, M. (1907). Strength of Materials: A Text-Book for Manual Training Schools. New York: John Wiley \& Sons.

Michelsen, N. (2017). On the Genealogy of Strategies: Resilience in the Revolution. Resilience: International Policies, Practices, and Discourses, 5(1), pp. 61-77.

Miller et al. (2010). Resilience and Vulnerability: Complementary or Conflicting Concepts? Ecology and Society, 15(3), 11-35.

Mills, C.W. (2000[1959]). The Sociological Imagination. New York: Oxford University Press.

Mittelbach, G., Turner, A., Hall, D. \& Rettig, J. (1995). Perturbation and Resilience: A Long-Term, Whole-Lake Study of Predator Extinction and Reintroduction. Ecology, 76, 2347-2360.

Mock, B. (2018). Resilience Tutherism Explained. CitiLab, March 19. Accessed from: https://www.citylab.com/environment/2018/03/resilience-trutherism-and-climatemanipulation-explained/555944/

Mol, A. (1998). Ontological Politics: A Word and Some Questions. The Sociological Review, (46), 74-89.

Mol, A. (2002). The Body Multiple: Ontology in Medical Practice. Durham and London: Duke University Press.

Mol, A. (2010). Actor-Network Theory: Sensitive Terms and Enduring Tensions. Kölner Zeitschrift für Soziologie und Sozialpsychologie, 50, 253-269. 
Montminy, Z. (2015). 21 Days to Resilience: How to Transcend the Daily Grind, Deal with the Tough Stuff, and Discover Your Strongest Self. New York: Harper Collins.

Morozov, E. (2013). Click Here to Save Everything: The Folly of Technological Solutionism. New York: Public Affairs.

Muir-Wood, R. (2016). The Cure for Catastrophe: How We Can Stop Manufacturing Natural Disasters. Basic Books: New York.

Mullarkey, J. (2007). Life, Movement and the Fabulation of the Event. Theory, Culture \& Society, 63(6), 642-650.

Murray, J. (1821). Account of a Portable Apparatus for Restoring the Action of the Lungs. The Philosophical Magazine and Journal: Comprehending The Various Branches of Science, The Liberal and Fine Arts, Geology, Agriculture, Manufacture and Commerce, 58, 276-279.

Mutter, J. C. (2015). Disaster Profiteers: How Natural Disasters Make The Rich Richer And The Poor Even Poorer. New York: Palgrave Macmillan.

National Institute of Standards and Technology (NIST) (2014). Community Resilience Center of Excellence. Accessed from: https://www.nist.gov/coe/communityresilience-center-excellence

Neocleous, M. (2012). "Don't be Scared, Be Prepared": Trauma-Anxiety-Resilience. Alternatives: Global, Local, Political. 31(3), 188-198.

NewYork City Department of Transportation (NY-DoT) (2009). Street Design Manual. Accessed from: www.nyc.gov/streetdesignmanual.

Nimmo, R. (2011). Actor-Network Theory and Methodology: Social Research in a MoreThan-Human World. Methodological Innovations Online, 6(3), 108-119.

Norris, F. N., Stevens, S. P., Pfefferbaum, B., Wyche, K. F. \& Pfefferbaum, R. L. (2008). Community Resilience as a Metaphor, Theory, Set of Capacities, and Strategy for Disaster Readiness. American Journal of Community Psychology, 41(1-2), $127-$ 150.

NPR News (2005, September 2). Why Wasn't New Orleans Better Prepared? Accessed from: http://www.npr.org/templates/story/story.php?storyId=4829443

NTC (2019). About Narrative Therapy. Accessed from: https://narrativetherapycentre.com/about/

O’Malley, P. (2004). Risk, Uncertainty, and Government. London: Glasshouse.

O’Malley, P. (2011). Security after Risk: Security Strategies for Governing Extreme Uncertainty.

O'Malley, P. (2013). Uncertain Governance and Resilient Subjects in the Risk Society. Oñati Socio-Legal Series, 3(2), 180-195.

Oberholzer, B., Knep, A. \&Vögeli, M. (2017). Valuing the Resilience Dividend. Basel, Switzerland: Global Infrastructure Basel. Accessed from: https://gibfoundation.org/wp- 
content/uploads/2020/01/RF_GIB_Resilience_Dividend_Final_research_report.p $\mathrm{df}$

Obrist B., Pfeiffer, C. \& Henley, R. (2010). Multi-Layered Social Resilience: A New Approach in Mitigation Research. Progress in Development Studies, 10(4), 283293.

Olsson, L., Jerneck, A., Thorén, H., Persson, J. \& O’Byrne, D. (2015). Why Resilience is Unappealing to Social Science: Theoretical and Empirical Investigations of the Scientific use of Resilience. Science Advances, 1(4), 1-11.

Orr, D.W. (2013). Reflections on Resilience in a "Black Swan" World. Resilience: A Journal of the Environmental Humanities, 1(1) (January).

Owens, C. (2014). The Future of Resilience. Next City. November 10. Accessed from: https://nextcity.org/daily/entry/chief-resilience-officer-job-cities-challengesclimate-change.

Passoth, J.H., and Nicholas J.R. (2010). Actor-network State: Integrating Actor-Network Theory and State Theory. International Sociology, 25(6), 818-841.

Paton, D. \& Johnston, D. (2006). Disaster Resilience: An Integrated Approach. Springfield, Il.: Charles C. Thomas.

Perrings, C. (1998). Resilience in the Dynamics of Economy-environment Systems. Environmental and Resource Economics, 11, 503-520.

Perrow, C. (1999). Normal Accidents: Living with High-Risk Technologies. Priceton, NJ: Princeton University Press.

Pickett, S.T.A., Cadenasso, M.L. \& Grove, J.M. (2004). Resilient Cities: Meaning, Models, and Metaphor for Integrating the Ecological, Socio-Economic, and Planning Realms. Landscape and Urban Planning, 69, 369-384.

Pimm, S.L. (1991). The Balance of Nature? Chicago: University of Chicago Press.

Polasky, S., Bryant, B., Hawthorne, P., Johnson, J., Keeler, B. \& Pennington, D. (2015). Inclusive Wealth as a Metric of Sustainable Development. Annual Review of Environment and Resources, 40, 445-466.

Ponomarov, S. Y., \& Holcomb, M. C. (2009). Understanding the concept of supply chain resilience. The International Journal of Logistics Management, 20(1), 124-143.

Public Safety Canada (2013). Building Resilience Against Terrorism: Canada's CounterTerrorism Strategy. Accessed from:

http://www.publicsafety.gc.ca/cnt/rsrcs/pblctns/rslnc-gnst-trrrsm/rslnc-gnsttrrrsm-eng.pdf

Pyyhtinen, O. (2010). Simmel and 'The Social'. New York: Palgrave Macmillan.

Re.Bound (2017). A Guide For Public-Sector Resilience Bond Sponsorship. Program report, September 2017. Accessed from: http://www.refocuspartners.com/wpcontent/uploads/pdf/RE.bound-Program-Report-September-2017.pdf

Re.Focus (2017). Re.Bound Program: Partners. Available from: http://www.refocuspartners.com/rebound/ 
Reid, J. (2012). The Disastrous and Politically Debased Subject of Resilience.

Development Dialogue - The End of the Development-Security Nexus? 58, 67-80.

Reivich, K. \&Shatté, A. (2002). The Resilience Factor: 7 Essential Skills for Overcoming Life's Inevitable Obstacles. New York: Broadway Books.

Rittel, H. W., \& Webber, M. M. (1973). Dilemmas in a General Theory of Planning. Policy sciences, 4(2), 155-16.

Roberts, J. (2017a). The Front Lines of Resilience. Best's Review, 118(2), 58-63.

Roberts, J. (2017b). Rising Tide. Best's Review, 118(2), 68-71.

Roberts, J. (2017c). Facing Long Odds. Best's Review, 118(2), 65-67.

Roberts, J. (2017d). Fires, Floods \& Beetles: Boulder CRO Knows Climate Change Is Far From Merely A Coastal Threat. Best's Review, 118(2), 72-74.

Rockefeller Foundation (2019 April, 1). The Rockefeller Foundation Announces $\$ 30$ Million Grant to the Adrienne Arsht Center for Resilience at the Atlantic Council. Press release. Accessed from: https://www.rockefellerfoundation.org/news/rockefeller-foundation-announces30-million-grant-adrienne-arsht-center-resilience-atlantic-council/

Rodin, J. (2013a, June 24). The Resilient City. The Resilient City. 100 Resilient Cities Blog. Accessed from: https://www.rockefellerfoundation.org/blog/the-cityresilient/

Rodin, J. (2013b, September 2). What Is The Business Case For Improving The Resilience Of Cities? The Guardian. Accessed from: https://www.theguardian.com/sustainable-business/business-case-improvingresilience-cities

Rodin, J. (2014). The Resilient Dividend: Being Strong in a World Where Things go Wrong. NewYork: Public Affairs

Rodin, J. (2015, October 25). Revisiting 'The City Resilient'. The Resilient City. 100 Resilient Cities Blog. Accessed from: https://www.100resilientcities.org/revisiting-the-city-resilient/

Rogers, P. (2012). Resilience \& The City: Change, (Dis)Order and Disaster. Routledge: London \& New York.

Rogers, R.T. (1948). The Vanderbilt Rubber Handbook $9^{\text {th }}$ edition. New York: Vanderbilt Co.

Ross, H. \& Berkes, F. (2013). Community Resilience: A Rejoinder to Debra J. Davidson. Society and Natural Resources, 26(1), 25-29.

Rutter, M. (1985). Resilience in the Face of Adversity: Protective Factors and Resistance to Psychiatric Disorder. British Journal of Psychiatry, 147(6), 598-611.

Rutter, M. (1987). Psychosocial Resilience and Protective Mechanisms. American Journal of Orthopsychiatry, 57, 316-331.

Ryan, C. (2015). Everyday Resilience as Resistance: Palestinian Women Practising Sumud. International Political Sociology, 9, 299-315. 
Saja, A.M.A., Goonetilleke, A., Teo, M. \& Ziyath, A.M. (2019). A Critical Review of Social Resilience Assessment Frameworks in Disaster Management. International Journal of Disaster Risk Reduction, 35, 1-14.

Schwab, K. (2017, March 23). How 5 Chief Resilience Officers Are Preparing For The Next 50 Years. Fast Company. Accessed from: https://www.fastcompany.com/3069136/how-5-cities-are-preparing-for-the-next50 -years

Scott-Smith, T. (2016). Paradoxes of Resilience: A Review of the World Disasters Report 2016. Development and Culture, 49(2), 662-677.

Scottish Government (2015). Safer Scotland, Ready Scotland. Preparing for and Dealing with Emergencies, Resilience Division. Accessed from: https://www.readyscotland.org/ready-government/resilience-division/

Seligman, M. (2011). Building Resilience. Harvard Business Review. Accessed from: https://hbr.org/2011/04/building-resilience

Serres, M. (2007). The Parasite. Minneapolis: University of Minnesota Press.

Shaikh, A. \& Kauppi, C. (2010). Deconstructing Resilience: Myriad Conceptualizations and Interpretations. International Journal of Arts and Sciences, 3(15), 155-176.

Sharifi, A. (2016). A Critical Review of Selected Tools for Assessing Community Resilience. Ecological Indicators, 69, 629-647.

Shaw, N. \& Austin, E. (1919). Manual of Meteorology, Volume III: The Physical Processes of Weather. Cambridge: Cambridge University Press.

Shrader-Frechette, K.S. \& McCoy, E.D. (1993). Method in Ecology: Strategies for Conservation. Cambridge: Cambridge University Press.

Simmel, G. (1906). The Sociology of Secrecy and of Secret Societies. American Journal of Sociology, 11, 441-498.

Simmel, G. (1971[1903]). The Metropolis and Mental Life. In D. Levine (ed) Georg Simmel: On Individuality and Social Forms. Chicago: University of Chicago Press. pp. 324-339.

Simmel, G. (1971[1908]). How is Society Possible? In D. Levine (ed) Georg Simmel: On Individuality and Social Forms. Chicago: University of Chicago Press. pp. 6-22.

Simmel, G. (1971e[1908]). The Stranger. In D. Levine (ed) Georg Simmel: On Individuality and Social Forms. Chicago: University of Chicago Press. pp. 143149.

Simon, S. \& Randalls, S. (2016). Geography, Ontological Politics and the Resilient Future. Dialogues in Human Geography, 6(1), 3-18.

Star, S.L. \& Griesemer, J.R. (1989). Institutional Ecology, 'Translations and Boundary

Objects" Amateurs and Professionals in Berkeley's Museum of Vertebrate Zoology, 1907-39. Social Studies of Science, 19)3), 387-420.

Stengers, I. (2004). Cosmopolitics I. Minneapolis: University of Minnesota Press. 
Stone-Jovicish, S. (2015). Probing the Interfaces Between the Social Sciences and SocialEcological Resilience: Insights from Integrative and Hybrid Perspectives in the Social Sciences. Ecology and Society, 20(2), 25-47.

Streeter, M. (2018). Step Inside The Spaces Belonging To Vancouver's Resilient Music Scenes. Redbull. Accessed from: https://www.redbull.com/ca-en/vancouverspaces

Strunz, S. (2012). Is Conceptual Vagueness an Asset? Arguments from Philosophy of Science Applied to the Concept of Resilience. Ecological Economics, 76, 112118.

Styhre, A. (2015). Financing Life Science Innovation. Basingstoke, UK: Palgrave Macmillan.

Swedberg, R. \& Reich, W. (2010). Georg Simmel's Aphorisms, Theory, Culture, Society, 27(1), 24-51.

Tasan-Kok, T., Stead, D. \& Lu, P. (2013). Conceptual Overview of Resilience: History and Context. In A. Araydin \& T. Tasan-Kok (eds) Resilience Thinking in Urban Planning. New York: Springer.

Thompson, K. (2011). Resiliency and Freedom: Response to Pat O'Malley's "From Risk to Resilience". Carceral Notebooks, 7, 69-75.

Thorén, H. (2014). Resilience as a Unifying Concept. International Studies in the Philosophy of Science, 28(3), 303-324.

Thorén, H. \& Persson, J. (2015). Resilience: Some Philosophical Remarks on Ostensive and Stipulatively Defined Concepts. Sustainability: Science, Practice \& Policy, 11(1), 64-74.

Time Magazine (2013). President Obama's Remarks on the Boston Marathon Tragedy (Transcript and Video). Accessed from:

http://swampland.time.com/2013/04/15/president-obama-remarks-on-the-bostonmarathon-tragedy-transcript/

Toronto (2013). The Resilient City. Accessed from: http://www.toronto.ca/planning/chiefplannerroundtable/resilientcity.htm

Toronto (2017, June 15). City of Toronto in partnership with 100 Resilient Cities appoints Elliott Cappell as Toronto's first Chief Resilience Officer. Press Release. Accessed from:

http://wx.toronto.ca/inter/it/newsrel.nsf/7017df2f20edbe2885256619004e428e/d6 5f6e0c8fe4160185258140004d0fe9?OpenDocument

Toronto (2017, November 29). 'Chief Resilience Officer'. Staff Directory, Divisions \& Customer Care. Accessed from: https://www.toronto.ca/citygovernment/accountability-operations-customer-service/city-administration/staffdirectory-divisions-and-customer-service/chief-resilience-office/ 
Toronto (2019). Toronto's First Resilience Strategy. Accessed from:

https://www.toronto.ca/ext/digital_comm/pdfs/resilience-office/toronto-resiliencestrategy.pdf

Tredgold, T. (1818). On The Transverse Strength and Resilience of Timber. The Philosophical Magazine and Journal: Comprehending The Various Branches of Science, The Liberal and Fine Arts, Geology, Agriculture, Manufacture and Commerce, London.

Tutton, R. (2011). Promising Pessimism: Reading the Futures to Be Avoided in Biotech. Social Studies of Science, 41(3), 411-29.

Twain, M. (2010). Autobiography of Mark Twain, Volume 1. Berkeley and Los Angeles, CA: University of California Press.

UNDRR (United Nations Office for Disaster Risk Reduction) (2018). Words into Action Guidelines: Implementation guide for local disaster risk reduction and resilience strategies. Accessed from:

https://www.preventionweb.net/files/57399_drrresiliencepublicreview.pdf

UNDRR (United Nations Office for Disaster Risk Reduction) (2019). Global Platform for Disaster Risk Reduction, Sixth session Programme 13-17 May. Geneva, Switzerland. Accessed from:

https://www.preventionweb.net/files/58809_programmedefopeningtimeupdated[1 ].pdf

Ungar, M. (2003). Qualitative Contributions to Resilience Research. Qualitative Social Work, 2(1), 85-102.

Ungar, M. (2004). A Constructionist Discourse on Resilience: Multiple Contexts, Multiple Realities Among At-Risk Children and Youth. Youth Society, 35(3), 341-365.

Ungar, M. (2005). Pathways to Resilience Among Children in Child Welfare, Corrections, Mental Health and Educational Settings: Navigation and Negotiation. Child and Youth Care Forum, 34(6), 423-444.

Ungar, M. (2007). Playing at Being Bad: The Hidden Resilience of Troubled Teens. Toronto: McClelland \& Stewart.

Ungar, M. (2011). The Social Worker: A Novel: The Advantages of Fictional RePresentations of Life Narratives. Cultural Studies Critical Methoodologies, 11(3), 290-302.

Ungar, M. (2012). Social Ecologies and Their Contribution to Resilience. In M. Ungar (ed) The Social Ecology of Resilience: A Handbook of Theory and Practice. New York: Springer. pp. 13-32.

Union des municipalités du Québec (2019, March 21). Les gouvernements de proximité mobilisés pour mieux affronter les changements climatiques. Accessed from: https://umq.qc.ca/publication/les-gouvernements-de-proximite-mobilises-pourmieux-affronter-les-changements-climatiques/ 
UNU-IHDP, UNEP, 2012. Inclusive Wealth Report 2012: Measuring Progress toward Sustainability. Cambridge, UK: Cambridge University Press.

UNU-IHDP, UNEP, 2014. Inclusive Wealth Report 2014: Measuring Progress toward Sustainability. Cambridge, UK: Cambridge University Press.

UNU-IHDP, UNEP, 2018. Inclusive Wealth Report 2018: Measuring Progress toward Sustainability. Cambridge, UK: Cambridge University Press.

van der Meer-Kooistra, J. \& Scapens, R.W. (2008). The Governance of Lateral Relations Between and Within Organisations. Management Accounting Research, 19(4), 365-384.

van der Spek, R., Kruizinga, E. \& Kleijsen, A. (2009). Strengthening Lateral Relations in Organisations Through Knowledge Management. Journal of Knowledge Management, 13(3), 3-12.

Vancouver (2014). F Grass. Vancouver Biennale: Public Art, Film, Learning. Accessed from: http://www.vancouverbiennale.com/artworks/f-grass/

Wagnild, G.M. \& Young, H.M. (1993). Development and Psychometric Evaluation of the Resilience Scale. Journal of Nursing Measurement, 1(2), 165-178.

Walker B. \& Salt, D. (2006). Resilience Thinking: Sustaining Ecosystems and People in a Changing World. Washington: Island Press.

Walker B.H., Carpenter, S.R., Rockstrom, J., Crépin, A.-S. \& Peterson, G.D. (2012). Drivers, "Slow" Variables, "Fast" Variables, Shocks, and Resilience. Ecology and Society, 17(3), 30-34.

Walker, B.H. (1981). Is Succession a Viable Concept in African Savanna Ecosystems? In D.C. West, H.H. Shugart \& D.B. Botkin (eds) Forest Succession: Concepts and Application. New York: Springer-Verlag. pp. 431-447.

Walker, J. \& Cooper, M. (2011). Genealogies of Resilience: From Systems Ecology to the Political Economy of Crisis Adaptation. Security Dialogue, 42(2), 143-160.

Walklate S. (2011). Reframing criminal victimization: Finding a place for vulnerability and resilience. Theoretical Criminology, 15(2), 179-194.

Walklate, S., Mythen, G., \& McGarry, R. (2012). States of Resilience and the Resilient State. Current Issues in Criminal Justice, 24(2), 185-204.

Ward, S. (1996). Filling the World with Self-Esteem: A Social History of Truth-Making. Canadian Journal of Sociology, 21(1), 1-23.

Welsh, M. (2014). Resilience and Responsibility: Governing Uncertainty in a complex World. The Geographical Journal, 180(1), 15-26.

Werner, E. \& Smith, R. (1982). Vulnerable but Invincible: A Longitudinal Study of Resilient Children and Youth. New York: Adams, Bannister and Cox.

Westley, F., Carpenter, S.R., Brock, W.A., Holling, C.S. \& Gunderson, L.H. (2001). Why systems of people and nature are not just social and ecological systems, in: L.H. Gunderson \& C.S. Holling (eds) Panarchy: Understanding Transformations in Human and Natural Systems. Washington: Island Press. pp. 103-119. 
Wheatley, M. J. (1994). Leadership and the New Science. San Francisco, CA: BerrettKoehler Publishers.

White, I. \& O'Hare, P. (2014). From Rhetoric to Reality: Which Resilience, Why Resilience, and Whose Resilience in Spatial Planning. Environment and Planning C: Politics and Space, 32(5), 934-950.

Wolf, E.R. (2002). Facing power: Old insights, new questions. In J. Vincent (ed.), The anthropology of politics. A reader in ethnography, theory, and critique. Oxford: Blackwell. pp. 222-233.

World Bank (2006). Where is the Wealth of Nations? Washington DC: World Bank.

World Bank (2011). The Changing Wealth of Nations: Measuring Sustainable Development in the New Millennium. Washington DC: World Bank.

World Bank (2013). Building Urban Resilience: Principles, Tools, and Practice. Accessed from: http://www.gfdrr.org/sites/gfdrr/files/publication/Building_Urban_Resilience.pdf Zebrowski, C. (2012). The Biopolitics of Resilience. (Unpublished doctoral dissertation). Keele University, Keele, United Kingdom.

Zebrowski, C. (2016). The Value of Resilience: Securing Life in the Twenty-First Century. New York: Routledge.

Zolli, A. (2013). Resilience: Why Things Bounce Back. New York: Simon \& Schuster. 